The social license to operate of oil and gas development in Greenland 


\section{Thesis committee}

\section{Promotor}

Prof. Dr J.P.M. van Tatenhove

Professor Marine Governance and MSP

Aalborg University, Denmark

\section{Co-promotor}

Dr J. van Leeuwen

Assistant professor, Environmental Policy Group

Wageningen University \& Research

\section{Other members}

Prof. Dr B. Arts, Wageningen University \& Research

Prof. Dr A.M. Hansen, Ilisimatusarfik, Greenland and Aalborg University, Denmark

Prof. Dr F.M.D. Vanclay, University of Groningen

Dr A.J.M. Scheepstra, University of Groningen

This research was conducted under the auspices of the Wageningen School of Social sciences (WASS). 


\title{
The social license to operate of oil and gas development in Greenland
}

\author{
Coco C.A. Smits
}

\section{Thesis}

submitted in fulfilment of the requirements for the degree of doctor at Wageningen University

by the authority of the Rector Magnificus

Prof. Dr A.P.J. Mol,

in the presence of the

Thesis Committee appointed by the Academic Board

to be defended in public

on Friday 20 September 2019

at 1:30 p.m. in the Aula. 
Coco C.A. Smits

The social license to operate of oil and gas development in Greenland, 222 pages.

PhD thesis, Wageningen University, Wageningen, the Netherlands (2019)

With references, with summary in English

ISBN 978-94-6395-045-9

DOI https://doi.org/10.18174/496700 


\section{TABLE OF CONTENT}

List of figures $\quad 11$

List of abbreviations $\quad 12$

Chapter 1: Introducing the social license to operate of oil and gas development in Greenland

$\begin{array}{lll}1.1 & 14\end{array}$

$1.2 \quad$ The Arctic 15

1.2.1 Arctic oil and gas resources 16

1.2.2 The Arctic in the world's political theatre 19

1.2.3 Arctic oil and gas resources in a worldwide societal debate 21

$1.3 \quad$ Greenland 22

1.3.1 Oil and gas exploration in Greenland 23

1.3.2 The Greenlandic regulatory framework for oil and gas development 23

1.3.3 Greenlandic societal debate on oil and gas development 25

$1.4 \quad$ The social license to operate in a multilevel context 25

1.4.1 A multilevel understanding of the social license to operate 27

$1.5 \quad$ Research objective and questions 30

$1.6 \quad$ Research approach 31

1.6.1 Case selection 32

1.6.2 Data collection and analysis 32

$1.7 \quad$ Outline of this thesis 35

Chapter 2: Authority in Arctic governance: Changing spheres of authority in Greenlandic offshore oil and gas developments

$2.1 \quad$ Introduction 41

2.2 Nested governance arrangements and authority in Arctic 43 governance

2.3 History of oil and gas in the Arctic and Greenland 45

2.4 Nested governance arrangements in Greenland's offshore oil and 48 gas development

2.4.1 The Arctic Council 48

2.4.2 Other Arctic governance arrangements 50

2.4.3 The national Greenlandic governance arrangement on oil and gas 51

2.4.4 The Greenland-Denmark governance arrangement 55

2.5 Changing authority of the Greenlandic government in governing 56

$\begin{array}{lll}2.6 & \text { Conclusion } & 60\end{array}$ 
Chapter 3: The challenges \& opportunities for Arctic microstates in developing an energy sector: The role of human capital development and knowledge institutes

$\begin{array}{lll}3.1 & 65\end{array}$

$3.2 \quad$ Iceland 66

3.2.1 The history of Icelandic development 67

3.2.2 The role of brain circulation in the development of Icelandic hydro- and 69

3.2.3 Challenges in present-day Iceland 71

3.3 Evolution of human capital and knowledge institutions in the 71

3.3.1 The historical evolution of Faroese academic institutions 72

3.3.2 The university in the knowledge economy 73

3.3.3 The university and the public sector 74

$\begin{array}{ll}\text { 3.3.4 Current challenges } & 75\end{array}$

$3.4 \quad$ Greenland 76

3.4.1 The development of Greenlandic knowledge institutes and education 76

3.4.2 Creating human capital and a knowledge-based economy 77

$\begin{array}{ll}\text { 3.4.3 Future challenges and opportunities } & 78\end{array}$

$\begin{array}{lll}3.5 & \text { Conclusion } & 79\end{array}$

Chapter 4: Human capital development and a social license to operate: Examples from Arctic energy development in the Faroe Islands, Iceland and Greenland

4.1 Introduction $\quad 85$

4.2 A social license to operate 87

4.2.1 The emergence of the concept of a social license to operate 87

4.2.2 How to obtain and maintain a social license to operate? 88

$\begin{array}{lll}4.3 & 90\end{array}$

4.3.1 Icelandic hydropower development 91

4.3.2 Icelandic geothermal energy development 93

4.3.3 The historical success factors in creating societal acceptance and 94

4.3.4 The recent development of a new energy sector: offshore oil and gas 95

4.4 The Faroe Islands 96

4.4.1 Stimulating socio-economic development from the start 97

4.4.2 Local benefits after 15 years of exploration 98

4.4.3 Trust building between stakeholders in the hydrocarbon cluster 100

4.5 Greenland 101

4.5.1 Human capital development and the economic legitimacy of oil and 102

4.5.2 Human capital development and trust building between stakeholders 104

$\begin{array}{lll}4.6 & 105\end{array}$

$\begin{array}{lll}4.7 & \text { Conclusion } & 107\end{array}$ 


\section{Chapter 5: Oil and gas development in Greenland: A social license to operate,} trust and legitimacy in environmental governance

development in Greenland
5.4.2 The legal license: a strong legal framework, but weak from a social perspective

5.4.3 The social license: increased awareness and empowerment

5.5 Trust and legitimacy as key elements in the interaction between the political, legal and social licenses in Greenland

5.6 Conclusion

\section{Chapter 6: Multi-level dynamics in a social license to operate: What can we} learn from Arctic oil and gas development? Introduction separate licenses on the national and international level Conditions for and consequences of overlapping or separate political licenses

6.4.2 Conditions for and consequences of overlapping or separate legal licenses

6.4.3 Conditions for and consequences of overlapping or separate social licenses

6.5 Exploring the multilevel interaction between licenses and the influence on the local implementation of an activity

6.5.1 Hybrid type a) One social license, but separate legal and political licenses

6.5.2 Hybrid type b) One legal license and one political license, but separate social licenses

6.5.3 Hybrid type c) All licenses partly overlap with their nationall international counterpart

6.6 Oil and gas development in Greenland as an example of a multilevel social license to operate

6.6.1 Oil and gas development in Greenland: national and international dynamics 
6.6.2 The political license at the national and international level 149

6.6.3 The legal license at the national and international level 149

6.6.4 The social license at the national and international level 151

6.6.5 Separate but interacting national and international political, legal and 152

6.7

153

\section{Chapter 7: Conclusion}

7.1

7.2

7.2.1

7.2.2 The social license to operate and the need to study it in relation to the political and legal licenses of Greenlandic oil and gas activities

7.2.3 The role of trust and legitimacy in the legal, political and social licenses of oil and gas development in Greenland

7.2.4 The challenges and opportunities in maximising the local benefits of oil and gas development

7.2.5 The contribution of human capital development to a social license to operate in small Arctic societies

7.2.6 The international level social license to operate of Arctic oil and gas activities and its influence on Greenland

7.3 The social license to operate: The case study of Greenland and a multilevel approach

7.3.7 The national level social license to operate needs to be studied in relation to the legal and political licenses using a broader definition of trust and legitimacy

7.3.8 The social license to operate concept needs a multilevel approach

7.3.9 The importance of human capital development in a multilevel social license to operate of oil and gas development in Greenland

7.3.10

7.4

7.5

7.6

7.6 .1

7.6 .2 concluding remarks

Theoretical reflections

Methodological reflections

Recommendations

Recommendations for further research

Recommendations for daily practices
159

160

160

161

162

163

163

164

166

166

167

169

170

171

174

176

176

178

182

\section{References}

$\begin{array}{lll}\text { Appendix 1: } & \text { List of interviews 2015/2016 } & 200 \\ \text { Appendix 2: } & \text { List of interviews 2012 } & 201\end{array}$

Appendix 3: List of interviews 2011202

Appendix 4: Interview questionnaire 2015/2016 203 
About the author

List of publications

215

Acknowledgements / Dankwoord 


\section{LIST OF FIGURES}

Figure 1: West Texas Intermediate crude oil prices per barrel 14

Figure 2: AMAP definition of the Arctic 16

Figure 3: Estimates of Arctic oil and gas resources probability 18

Figure 4: Outline of this thesis 36

Figure 5: AMAP definition of the Arctic 46

Figure 6: One social license, separate legal and political licenses 144

Figure 7: One legal and one political license, separate social licenses 146

Figure 8: All licenses partly overlap with their national/international 147

counterpart 


\section{LIST OF ABBREVIATIONS}

\begin{tabular}{|c|c|}
\hline $\mathrm{ACIA}$ & Arctic Climate Impact Assessment \\
\hline AMAP & Arctic Monitoring and Assessment Programme \\
\hline BMP & Bureau of Minerals and Petroleum \\
\hline $\mathrm{BOE}$ & Barrels of Oil Equivalent \\
\hline CLCS & Commission on the Limits of the Continental Shelf \\
\hline CSR & Corporate Social Responsibility \\
\hline DCE & Danish Centre for Environment and Energy \\
\hline EAMRA & $\begin{array}{l}\text { Environmental Agency for the Mineral Resources Area (or Miljøstyrelsen } \\
\text { for Råstofområdet) }\end{array}$ \\
\hline EEZ & Extended Economic Zone \\
\hline EIA & Environmental Impact Assessment \\
\hline EU & European Union \\
\hline GEUS & Geological Survey of Denmark and Greenland \\
\hline GINR & Greenland Institute for Natural Resources \\
\hline GOIA & Greenlandic Oil Industry Association \\
\hline IA & Inuit Ataqatigiit \\
\hline IBA & Impact Benefit Agreement \\
\hline IOCs & International Oil Companies \\
\hline IOGP & International Association of Oil and Gas Producers \\
\hline KANUKOKA & Municipalities Association of Greenland \\
\hline MIMR & Ministry of Industry and Mineral Resources \\
\hline MLG & Multi-Level Governance \\
\hline MLSA & Mineral License and Safety Authority (or Råstofstyrelsen) \\
\hline MRA & Mineral Resources Act (or Råstofloven) \\
\hline NGO & Non-Governmental Organisation \\
\hline OSPAR & $\begin{array}{l}\text { Convention for the Protection of the Marine Environment of the } \\
\text { Northeast Atlantic }\end{array}$ \\
\hline SAR & Search and Rescue \\
\hline SLO & Social License to Operate \\
\hline SSIA & Social Sustainability Impact Assessment \\
\hline UNCLOS & United Nations Convention on the Law of the Sea \\
\hline UNU GTP & United Nations Geothermal Training Programme \\
\hline UK & United Kingdom \\
\hline USA & United States of America \\
\hline USGS & United States Geological Survey \\
\hline WWF & World Wildlife Fund \\
\hline
\end{tabular}




\section{CHAPTER}
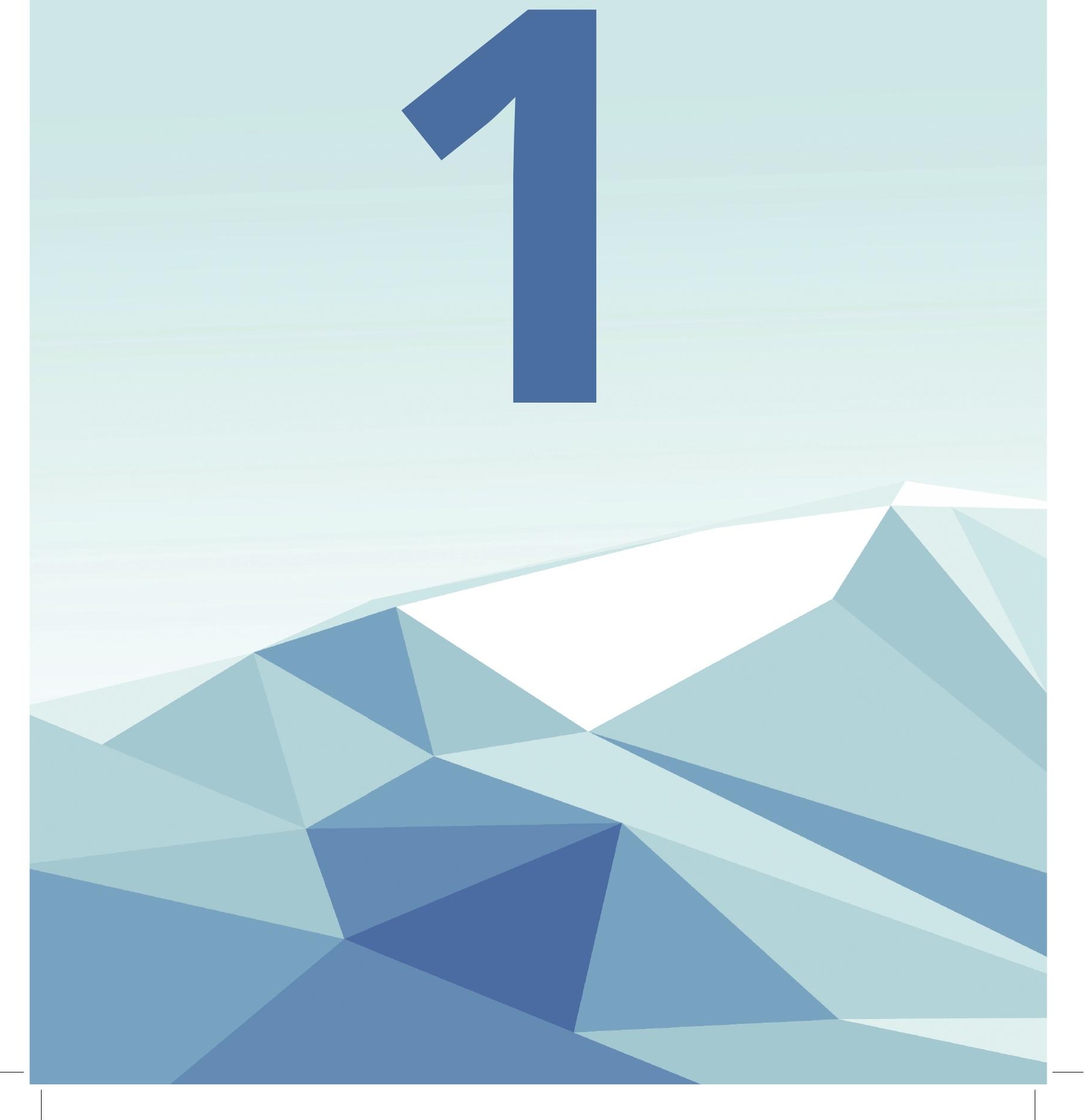


\section{Introducing the social license to operate of oil and gas development in Greenland}




\subsection{INTRODUCTION}

The Arctic is changing. The environmental and socio-economic ties with the rest of the world are becoming increasingly apparent through the changes that are taking place in this region. As 'canary in the coalmine' it shows the world the effects of climate change (NASA 2013; The Economist 2004). The greenhouse gases emitted elsewhere in the world impact the Arctic. Sea ice extend is decreasing and temperatures are rising faster than anywhere else (ACIA 2004). Changes in the Arctic will in turn impact southern regions. The melting Greenlandic ice sheet is expected to contribute 6 meter to global sea level rise and threatens densely populated coastal communities around the world (NSIDC 2017a).

At the same time, the decreasing sea ice extent and snow cover also creates new opportunities. The region is opening up to activities such as fisheries, shipping, tourism, mining and oil and gas. Over the past decade the region experienced an increase of these economic activities and it is estimated that the Arctic can potentially attract over $\$ 100$ billion of investments (Lloyds 2012). Shipping, mining and oil and gas activities were regarded as the largest drivers of this economic development.

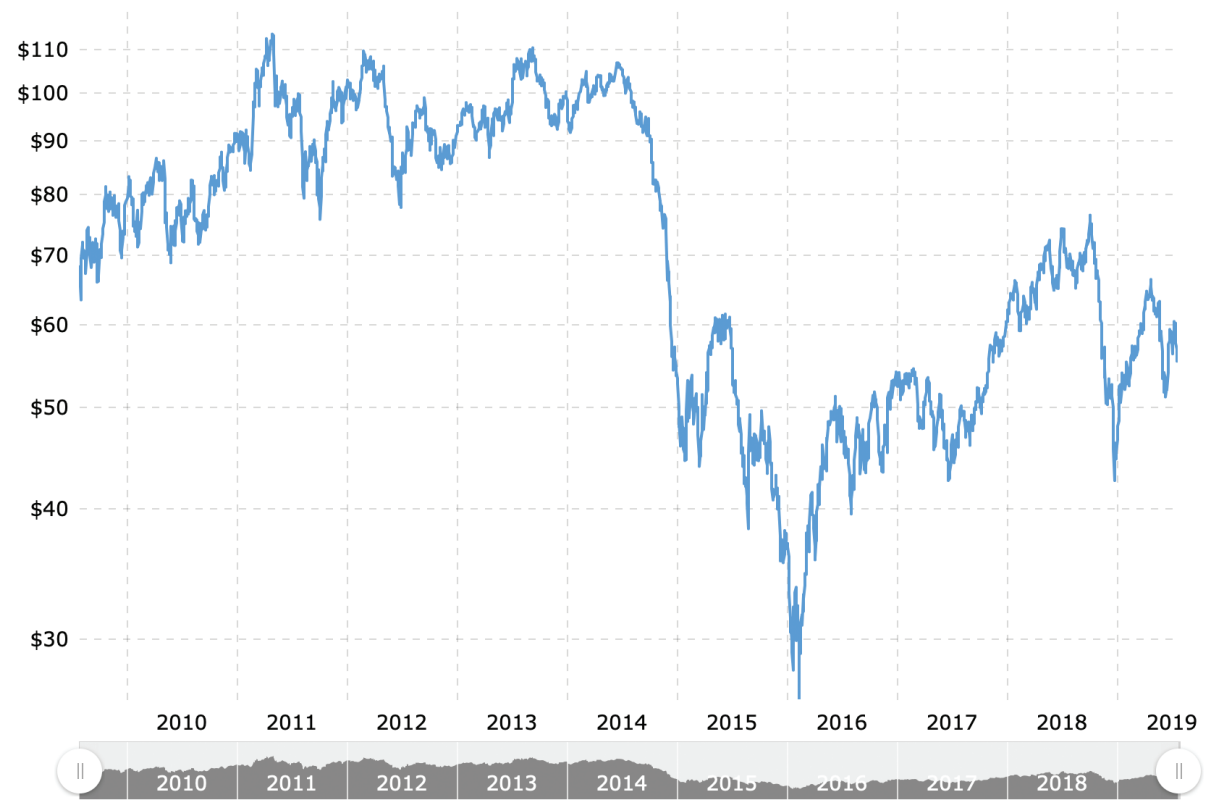

Figure 1: West Texas Intermediate crude oil prices per barrel (source: www.macrotrends.net) 
However, in 2014 the global oil prices have collapsed and global prices for minerals decreased as well (see Figure 1; World Bank 2016). It can thus be questioned whether the estimated investments can still be attracted by the region, as the collapsed commodity prices have impacted the main drivers of the estimated economic development.

Even though the development of offshore Arctic oil and gas activities has largely come to a halt now, it has sparked a lot of debate and controversy over the past years. This thesis studies the debate and controversy of oil and gas development in the Arctic, with a particular focus on Greenland. As a starting point it uses the social license to operate concept, which is often used to study (controversial) resource extraction, including energy projects, from a social science perspective. Whether the traditional focus of this concept on the local context of a project allows for a thorough understanding of the social license to operate is however questioned. The case of oil and gas development in Greenland shows that multiple geographical layers connected with each other and that the development of oil and gas is not solely a national affair. It has therefore proved to be an interesting case to study, both from a local perspective related to balancing the environmental and social risks and opportunities of these oil and gas developments, as well as from a global perspective in relation to climate change and the transition to renewable energy resources.

This chapter comprises an introduction to the Arctic oil and gas context and takes a closer look at the developments in Greenland. It also elaborates upon the key concepts, the research objective, questions and methods that guided this case study.

\subsection{The Arctic}

The Arctic is home to approximately four million people living across eight countries, namely the Russian Federation, the United States of America (Alaska), Canada, the Kingdom of Denmark (Greenland and the Faroe Islands), Iceland, Norway, Sweden and Finland (Arctic Council 2015). Different actors use different definitions of the Arctic. Definitions are for example based on the tree line, the Arctic Circle (at 66 34' North) or the 10 degrees Celsius isotherm (NSIDC 2017b). For this research the definition proposed and used by the Arctic Monitoring and Assessment Programme of the Arctic Council has been used (AMAP 1998), which defines the Arctic as:

"[...] the terrestrial and marine areas north of the Arctic Circle (66 $320 \mathrm{~N})$, and north of $62^{\circ} \mathrm{N}$ in Asia and $60^{\circ} \mathrm{N}$ in North America, modified to include the marine areas north of the Aleutian chain, Hudson Bay, and parts of the North Atlantic Ocean including the Labrador Sea." 
This definition is used for this research because it includes all relevant areas for studying oil and gas developments within the Arctic Circle and adjacent regions in North America and Siberia as well as parts of the Atlantic Ocean and the Bering Strait (Figure 2).
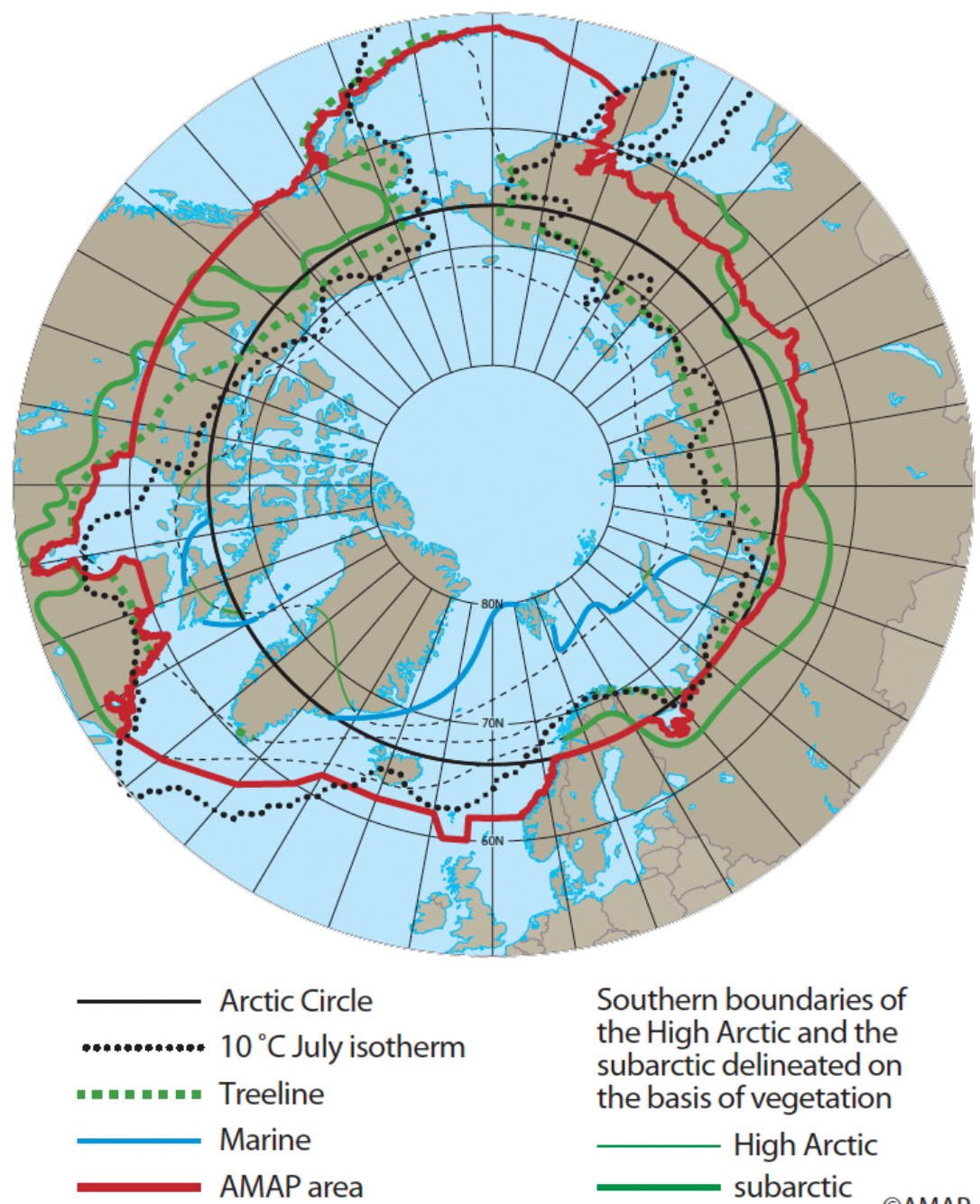

Southern boundaries of the High Arctic and the subarctic delineated on the basis of vegetation

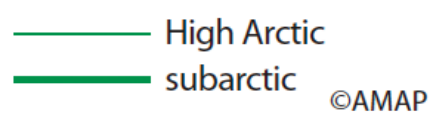

Figure 2: AMAP definition of the Arctic (source: AMAP 2014)

\subsubsection{Arctic oil and gas resources}

The Arctic has been home to oil and gas activities for almost a century. The Mackenzie Valley, the Alaskan North Slope and Yamalo-Nenets Autonomous Okrug in Russia were 
the first areas where small scale onshore oil and gas activities were taking place prior to World War II (AMAP 2007). Large scale onshore oil and gas activities took off in the same areas during the 1960s and 1970s. In the 1970s also nearshore locations were explored and exploited in Alaska. And during the 1970s and 1980s exploration for offshore oil and gas started to take place in the Norwegian Sea, the (Russian part of the) Barents Sea, in other Russian waters and offshore the coast of Greenland (AMAP 2007). Nowadays four out of the five Arctic coastal states are producing oil and/or gas (Rekacewicz and Ahlenius 2006).

Next to the already known resources, the Arctic Ocean is expected to hold a vast amount of undiscovered oil and gas reserves. In 2008 the Unites States Geological Survey (USGS) published its findings on Arctic oil and gas resources. It is estimated that these resources could amount up to 90 billion Barrels of Oil Equivalent (BOE) and 1.670 trillion cubic feet of natural gas, which are technically recoverable (USGS 2008). This equals approximately $22 \%$ of the world's undiscovered technically recoverable oil and gas resources (Figure 3). Most of these resources are expected to be found offshore, whereby most of the oil is expected to be found in Arctic Alaska, the Amerasia Basin, the East Greenland Rift Basin, the East Barents Basins and between West Greenland - East Canada. Most of the gas is expected to be found in the West Siberian Basin, the East Barents Basins and in Arctic Alaska.

Since the start of this century the attention for oil and gas in the Arctic has surged. The high oil prices (\$147 in July 2008), combined with the favourable geological projections of the USGS, advancing technologies and a politically stable climate (Brookings 2014) have raised the attention to unprecedented highs. The boom in offshore exploration activities is illustrated by activities of Cairn Energy in Greenland (2010/2011), Shell in Alaska (2012 and 2015) and Statoil in the Barents Sea (2011 onwards). Stimulating new activities to be developed, also the license rounds organised by Arctic states have followed each other at a fast pace, including Greenland in 2010, 2012/2013, 2014, 2016, 2017 and 2018 (BMP 2011a; Naalakkersuisut 2014b), Norway in 2012, 2014 and 2017 (NPD 2012; NPD 2014) and Alaska in 2011, 2012, 2013 and 2014 (Deloitte 2014). 


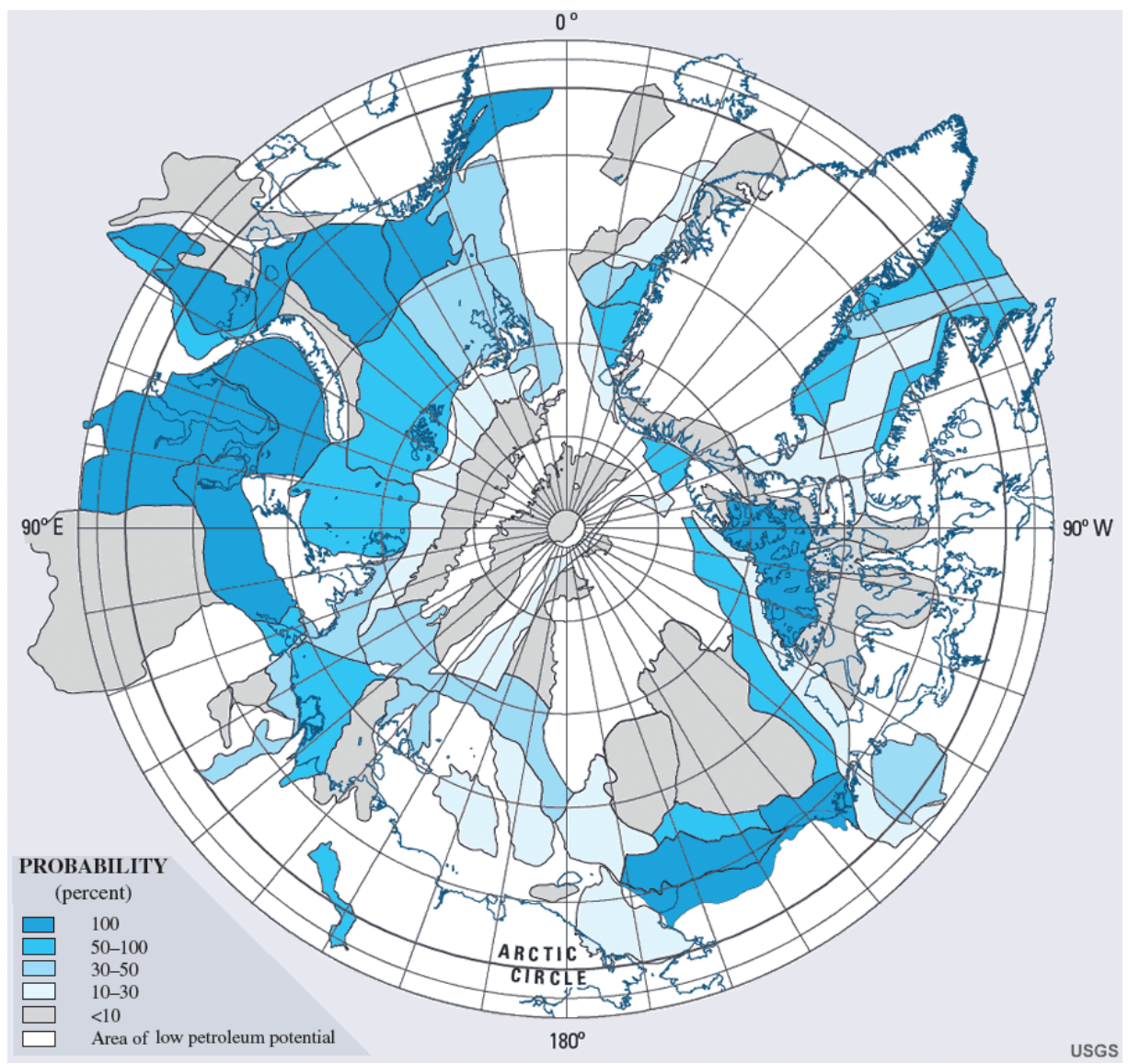

These license rounds are in many cases subject to stringent requirements, aiming to select only the large, (financially) robust and experienced oil companies that can bear the high costs of these Arctic operations, also in the case of a potential oil spill in ice-infested waters. Oil companies that owned licenses throughout the Arctic include Shell, Total, ConocoPhillips, ENI, Statoil, Chevron and BP. Costs of Arctic operations differ throughout the region depending amongst others on remoteness, presence of sea ice and technical difficulties. Statoil for example has divided the Arctic into three categories (Hansen 2015):

- Workable: Including areas like the Southern Barents Sea and the east coast of Canada. Although conditions are cold and harsh, there is little or no ice in these areas. On the short to medium term it is possible to develop technological solutions that make it possible to operate here. 
- Stretched: Including areas like the north-east Barents Sea. These are areas where there is seasonal ice, and to operate here on the medium to long term major innovations are needed.

- Extreme: Including areas like north-east Greenland. Year-round heavy ice conditions are present in these areas, and there is a short open season. Technology is not yet known and investment in research \& development with a long term focus is needed to develop these areas.

Depending on the location it would take approximately 15 to 30 years before Arctic discoveries reach production. It is estimated that oil and gas operations in the Barents Sea, a relatively easy destination, need an oil price between $\$ 80$ and $\$ 110$ per barrel depending on the size of the field to break even (Rystad Energy in Reuters 2014). Since the drop in oil prices in 2014 and given the current price volatility, the business cases of many Arctic projects have gone negative. Even though Arctic exploration efforts were never aiming at the short term and the demand for energy is likely to rise over the coming decades, many oil companies such as Shell, Statoil and Chevron have given back licenses they owned in Greenland and other parts of the Arctic (Financial Times 2015).

\subsubsection{The Arctic in the world's political theatre}

The increasingly apparent climate change effects and new economic opportunities also brought the Arctic region to the centre of global political attention. Illustrative of the increasing international political attention for the Arctic are the many applications of non-Arctic states as observer at the Arctic Council. In 2013 six new countries, including China, India, Italy, Japan, Republic of Korea, and Singapore were granted observer status. This doubled the total number of observer countries at once.

The Arctic Council is considered as the main governance arrangement for this region. Established in 1996 by the Ottowa Declaration, the Arctic Council is a high level intergovernmental forum for cooperation, coordination and interaction among the Arctic States, with Arctic indigenous communities as permanent participants (www. arctic-council.org). The chairmanship is rotating every two years, with Iceland being the chair from 2019 to 2021, after taking over from Finland in spring 2019. Even in the current international political turmoil the Arctic Council is still a platform for cooperation on particular issues of sustainable development and the environment, also with the Russian Federation. All parties stressed the fact that the Arctic should remain a place where a dialogue with Russia is continued (Washington Post 2015). 
The Arctic Council has a number of Working Groups and Task Forces where member states, permanent participants and observers work together on various topics, including emergency preparedness and response, sustainable development, flora and fauna and contaminants. The Arctic Council produces valuable reports and guidelines based on scientific research, indigenous knowledge and industry experience. It has produced the following guidelines and reports in the field of oil and gas:

- $\operatorname{AMAP}(2007)$ Arctic Oil \& Gas Assessment;

- PAME (2009) Arctic Offshore Oil \& Gas Guidelines. Previous versions stem from 2002 and 1997; and

- PAME (2014) Arctic Offshore Oil \& Gas Guidelines: Systems Safety Management and Safety Culture. Avoiding Major Disasters in Arctic Offshore Oil and Gas Operations.

The Arctic Council itself does not produce legally binding agreements. The Arctic states have however signed legally binding agreements with each other, based on negotiations held in the context of the Arctic Council. In 2011 the first binding agreement, on Arctic Search and Rescue, was signed followed by an agreement on the Cooperation on Marine Oil Pollution Preparedness and Response in 2013 (www.arctic-council.org).

With the increased international attention, Arctic coastal states have made it very clear that Arctic matters are an affair of the Arctic States and not of anyone else (Ilulissat Declaration 2008). Major parts of the Arctic Ocean fall under their jurisdiction and almost all coastal states have submitted their claim for an extension of their Extended Economic Zone (EEZ) under the United Nations Convention on the Law of the Sea (UNCLOS), leaving little left as high seas (Berkman \& Young 2009). The oil and gas activities that are taking place at the moment or were expected to take place in the short- to mid-term are located within the EEZ of the coastal states and therefore fall under their jurisdiction. Since there is no binding legal framework that covers all oil and gas activities in the Arctic, the regulatory regime differs per country. The requirements that guide the oil and gas developments may thus be more or less stringent depending on the country where these developments take place. Some of the environmental impacts however will not stop at a country's borders. And if an oil spill would occur in the country with the least stringent regulations, this is likely to affect the activities in all other countries. So while the sector and the environmental impacts of its activities transcend boundaries, the regulation and implementation of the activity is very much organised at state level. 


\subsubsection{Arctic oil and gas resources in a worldwide societal debate}

What is also not confined to state boundaries is public protest against Arctic oil and gas activities. The increasing attention for climate change and oil and gas resources in the Arctic at the start of this century did not only comprise non-Arctic nation states and companies, but also included a societal debate held at a global level. International environmental NGOs that are concerned about climate change identified the increasing interest in oil and gas development as a risk for the vulnerable Arctic environment. Both Greenpeace and WWF started an Arctic campaign against these activities and put effort in mobilising the largest possible group of concerned global citizens. WWF focussed on educating citizens and politicians about the risks of these activities and issuing research and tools that supported this message, while Greenpeace took a more activist approach and attracted attention for their message by scaling drilling rigs and starting an online petition directed towards the Arctic activities of one company, namely Shell.

Via internet and social media, people from all over the world got involved in the debate on Arctic oil and gas development. The link with global climate change and a global transition towards renewable energy made it a relevant topic to millions worldwide. The debate was not only held in the digital world on the internet, but also in real life via panel discussions, (parliamentary) debate (i.e. in the UK with the House of Lords Committee on the Arctic, in the European parliament, in the Netherlands in relation to a new Arctic policy), conferences (i.e. Arctic Frontiers, Arctic Circle, Arctic Oil and Gas conferences) and protest actions (such as scaling drilling rigs and buildings of oil companies, petitions and demonstrations, and from example the kayaktivists from Seattle). The urgent environmental risk of an oil spill against the backdrop of decreasing sea ice and a melting Greenlandic ice sheet stimulated taking action now. The relation between international environmental NGOs and local indigenous communities in the Arctic was and is however troubled. The anti-whaling and -sealing campaigns during the previous century and the existing European ban on sealskin products have caused a lot of damage that is not forgotten (personal communication - interview Greenpeace 2016; Quartz 2015). Also the tendency of the NGOs to regard the Arctic environment as an untouched sanctuary where no economic activities are allowed, is against the views of indigenous communities who have lived in the Arctic for centuries and have hunted its living resources for subsistence. With regards to the development of Arctic oil and gas resources different opinions exist within the indigenous communities. These opinions and discussions within the communities have not necessarily been part of the global discussion. 
In Greenland everything comes together: The melting ice sheet is illustrating global climate change and at the same time the government expressed the ambition to develop oil and gas as a means to diversify the economy and gain additional income to become (financially) independent from Denmark. Opening up to oil and gas development attracted the attention from some of the largest international oil companies, the world's largest states, as well as critique from individual citizens and NGOs in Greenland and far beyond. It is therefore an interesting case to study both national and international dynamics, involving many different stakes and stakeholders, on a relevant topic namely oil and gas development in relation to the future of the world's energy outlook. The next section takes a closer look at Greenland and its ambition to develop oil and gas activities.

\subsection{Greenland}

Greenland is the world's largest island, yet it only has a population of approximately 56.000 people. Its population lives in cities and villages scattered around the entire coastline as the inland is covered by the second largest ice sheet of the world (Nielsen 2001). Approximately 89\% of the Greenlandic population is Inuit, sharing their roots with Inuit in Canada, Alaska and Chukotka, Russia (inuit.org). The largest city and capital of Greenland is Nuuk, which is situated slightly below the Arctic Circle on the west coast and counts approximately 17.000 people (Statistics Greenland 2018). Nuuk is also home to the Greenlandic government (Naalakkersuisut) and Parliament (Inatsisartut). In 2009 Greenland obtained Self-Rule within the Kingdom of Denmark (Hansen 2014). The authority over the underground including oil, gas and minerals was transferred from the Danish state to the Greenlandic government. Only foreign affairs, security and defence remained shared policy domains (Queen of Denmark 2009).

Financially, Greenland still depends on Denmark via a fixed block grant ${ }^{1}$ that it receives on an annual basis. The level of this grant was frozen in 2009, making it decreasing in relative terms over time. Achieving financial independence is a long-term goal that is regularly expressed by the Greenlandic government (Pfeifer and Thompson 2011). At the moment, the Greenlandic economy is mainly based on fisheries, tourism and the public sector. The government is therefore looking at ways to diversify the economy. The development of oil, gas and mineral resources could potentially generate the additional income needed to replace the annual block grant (Naalakkersuisut 2014b).

1 Definition of a 'block grant': a grant from a central government that a local authority can allocate to a wide range of services. 


\subsubsection{Oil and gas exploration in Greenland}

The 2008 USGS study estimated that 31 billion Barrels of Oil Equivalent (BOE) could be found in the north-eastern waters and 17 billion BOE in the north-western part of the seas around Greenland (USGS 2008a; USGS 2008b). Up until now 14 explorations wells have been drilled in Greenlandic waters: five in the 1970s, one in 2000 and eight in 2010/2011 (govmin.gl). This thesis focuses on the most recent exploration activities, comprising the exploration drills that were conducted by a Scottisch oil company Cairn Energy in 2010 and 2011. Other companies such as Shell have performed seismic surveys and (strategic) environmental and social studies (Naalakkersuisut 2015). These companies were granted a license in one of the licensing rounds that took place since 2002. The licenses have granted them the right to explore and exploit oil and/or gas (BMP 2009a). The national oil company of Greenland, NunaOil, is represented in all of the oil and gas exploration licenses that have been granted in Greenland. It has a 12,5\% share in each license and should build capacity and gain experience by cooperating with international oil companies (BMP 2009a).

Capacity building by means of human capital development has been and still is a top priority for the Greenlandic government (Naalakkersuisut 2012). The average education level is low and school drop-out rates are high. To participate in the offshore industry, oil companies require a number of formally acquired skills and competencies. Even though offshore oil rigs offer a number of job opportunities for an unskilled or semiskilled workforce, these functions require high school education at minimum (Houston Chronicle 2012). This is a challenge in Greenland. In 2006 only one third of the potential workforce (age 15 - 62) had acquired an educational level that would qualify them for jobs above unskilled level (European Commission 2007). However, the total number of graduates from post-primary education in Greenland has increased by $64 \%$ during the first phase (2006 - 2012) of the "Greenland Education Program" (www.nanoq.gl) and is promising.

\subsubsection{The Greenlandic regulatory framework for oil and gas development}

The focus on human capital development is also apparent in the Mineral Resources Act (MRA or Råstofloven), which governs the oil and gas activities in Greenland. The law came into force in 2010 and replaced the former Danish Act on Mineral Resources in Greenland from 1998. The aim of the MRA is to ensure that the oil and gas exploration and anticipated production activities are securely conducted in terms of safety, health, environment, social responsibility and according to international best practice (Mineral Resources Act, Part 1, 1). It has been inspired by Norwegian, Canadian and other international oil and gas legislation (BMP 2011b). The regulatory framework obliges 
oil companies to conduct an Environmental Impact Assessment (EIA) and a Social Sustainability Impact Assessment (SSIA) for their activities in Greenland. Based on the Social Sustainability Impact Assessment, an Impact Benefit Agreement is negotiated between the company and the national and local government authorities of Greenland (Smits et al. 2017).

Since 2010 the MRA has been amended twice. After amendments in 2012, the division of tasks to govern the development of oil and gas activities was restructured and spread across multiple government authorities in 2013. Prior to this amendment all tasks related to the governance of oil, gas and mineral activities were the responsibility of one authority: the Bureau of Minerals and Petroleum (BMP). The advantages of clustering all knowledge and competencies related to oil, gas and minerals into one government authority include efficiency and bundling human resources that are already scarce within such a small bureaucracy. However, the BMP was criticised for a lack of transparency and mistrusted by a suggestion of wearing multiple hats at the same time (Aaen 2012). The Greenlandic government has therefore decided to divide the tasks over the following government authorities (govmin.gl: MLSA Newsletter 8-01-2014):

- Mineral License and Safety Authority (MLSA or Råstofstyrelsen): Falls under the Ministry of Mineral Resources and functions as the administrative authority and is responsible for license and safety matters.

- Ministry of Mineral Resources: Is responsible for legal, geological and marketing issues.

- Ministry of Industry, Labour and Trade: Is responsible for socio-economic issues, including the Social Sustainability Impact Assessment and Impact Benefit Agreement.

- Environmental Agency: Falls under the Ministry of Nature, Environment and Energy and is responsible for environmental issues, including the Environmental Impact Assessment.

Due to a lack of trust by citizens and civil society organisations, the capacity of the authorities to govern the development of oil and gas activities in Greenland remains subject of debate at the national level. The next section elaborates upon the societal debate of the oil and gas development including the capacity of the government in Greenland. 


\subsubsection{Greenlandic societal debate on oil and gas development}

The potential for oil and gas development has never led to large scale overt protest actions and demonstrations in Greenland. It did however trigger a debate in Greenlandic society about the risks and benefits that these activities would bring to Greenland. The (economic) benefits were clearly linked to the long term wish of Greenland to become independent from Denmark. The main risks included an oil spill, pollution and a potential influx of foreign workers. Over time, the critique on these activities has increased and divided society as some were in favour and others were against them. Next to Greenlandic citizens and organisations, also the international environmental NGOs were amongst the actors that asked critical questions about the activities in Greenland. Most of the critique was directed to the government and its authorities for not being transparent and a lack of trust in their competencies to ensure the interest of Greenlandic society. The government has acted on these points of critique by amending the legal framework and formally adjusting their organisation. Although the amendments to the legal framework made by the government were seen as an improvement, critique on the government and its authorities still existed.

\subsection{The social license to operate in a multilevel context}

Criticism on and protest against the decisions of governments and the way they enforce the regulatory framework is a worldwide phenomenon that manifests itself especially in the case of large industrial projects with an environmental and social impact. In the past, the development of these large industrial activities, such as oil and gas development, was predominantly the domain of state authorities and companies. The state authorities represented their country's citizens and would take care of their interests. However, protest actions, critique and societal debate show that citizens and civil society organisations are increasingly dissatisfied with the implementation of industrial activities by private sector companies and the (lack of) enforcement by state authorities (Boutilier 2014). Next to the continued role of state authorities, citizens and civil society demand a larger say in the decision making processes leading to the development of large industrial activities. Illustrative of the growing level of conflict is that the time for oil and gas projects to reach production has almost doubled over the past decade. Nontechnical risks and in particular relationships with social actors, accounted for nearly half of the risks resulting in this delay (Franks et al. 2014).

To study the societal debate and unrest related to the oil and gas activities in the Arctic and in Greenland, this thesis uses the social license to operate concept. The concept of a social license to operate relates to the social risks of an activity and it is usually defined in scholarly literature as the (ongoing) acceptance/approval of an activity or 
decision by local communities and other stakeholders (World Bank 2003b; Thomson \& Boutilier 2011; Moffat \& Zhang 2014; Hall et al. 2015). The concept originated in the mining industry during the late 1990s and has since then been applied in various other sectors as well. Typically the literature has focused on questions such as "What is a social license to operate?", "What elements contribute to a successful social license to operate?" and "How can companies obtain and maintain a social license to operate?". The interaction between local communities and private sector companies is usually the primary concern of this body of research (Hall et al. 2015; Moffat and Zhang 2014; Parsons et al. 2014; Prno, 2013; Boutilier et al. 2012; Prno \& Slocombe 2012).

The case of Greenland shows that the development of oil and gas activities is not solely an affair of state authorities and companies, nor is it solely a national affair: National level stakeholders want to become more involved in the decision making process and at the same time the oil and gas activities are closely linked to the globally debated theme of climate change and the transition towards renewable energy. The rather instrumental focus of the social license to operate on the local project context and the relation between a company and its local stakeholders therefore misses essential elements of today's increasingly interconnected and complex society. What is the role of governments in this context? As the energy domain concerns an issue of strategic national importance, governments are still one of the main actors involved in the decision making process related to these large industrial activities. How does the social license to operate relate to / interacts with the regulatory framework that applies to a specific activity and has been formulated by governments? The regulatory framework sets the legal requirements companies need to comply with, but does not necessarily satisfy the expectations of citizens and civil society organisations (Morrison 2014; Franks et al. 2014). And how does societal debate on other geographical levels influence / interacts with local level societal concerns? Do these debates complement or contradict each other and in what way(s) could they influence the successful implementation of an activity locally? The current understanding of the social license to operate does not answer these questions. The case of oil and gas development in Greenland however shows that these questions are relevant in order to analyse and understand what is happening with the support of society for these large energy projects. It can thus be questioned whether applying the understanding of the social license to operate concept generates the necessary insights to adequately address societal concerns and contribute to the successful implementation of an internationally debated activity. 


\subsubsection{A multilevel understanding of the social license to operate}

A contextually informed, multilevel understanding of the social license to operate does not yet exist. However, there are a few publications that go beyond the traditional local level and instrumental focus that dominates social license to operate literature. These are used as a starting point to expand the social license to operate concept. Moreover, other fields of social science research, such as governance and post international theory, offer valuable insights and concepts that could form a starting point for the development of a multilevel understanding of the social license to operate concept. This section elaborates upon the theoretical concepts that are used to create a contextually informed and multilevel understanding of the social license to operate.

To widen the scope of the social license to operate concept and include the interaction with the political domain and the legal framework, this thesis builds on the idea that successful implementation of an activity is determined by its social, political and legal licenses together (Morrison 2014). The political license is defined as 'the authority that the government gives to any other organisation to undertake a particular activity' (Morrison 2014). A country's regulatory framework is setting the requirements for a legal license, which is granted by an assigned government authority after following a set of legal procedures. The social license to operate can be said to have emerged as a third type of license, next to the other two licenses. The social license is not a 'tick-the-box' license, but rather an ongoing process that runs throughout the entire lifecycle of a project.

In social license to operate literature it is generally acknowledged that trust and legitimacy play an important role in obtaining and maintaining a social license to operate (Thomson \& Boutilier 2011; Morrison 2014). Generating trust and legitimacy relates to the way you engage with stakeholders, do projects and take decisions. It is not something that can be designed from behind a desk. Trust and legitimacy are not only important in the relation between society and companies, which is the current focus of social license to operate literature, but also play an important role in the political and legal licenses and the changing relationship between governments and society (Rosenau 1997, 2003, 2006). Next to distinguishing two forms of trust (i.e. interactional and institutional), the focus of the main body of social license to operate literature is predominantly output oriented as it often discusses the legitimacy of an activity in terms of its economic and/or socio-political contribution to society. However, literature from other scientific fields such as governance theory, political and public administration sciences shows that multiple forms of legitimacy exist (van Tatenhove 2011). How do these other forms of legitimacy relate to the social license to operate context? And what is the role of all these forms of trust and legitimacy in the interaction 
between the political, legal and social licenses of an activity? This thesis takes a closer look at these questions and studies the role of trust and legitimacy in the interaction between the three licenses using the case of oil and gas development in Greenland.

As was highlighted in section 2 of this chapter, human capital development is of great importance in the Greenlandic context. This is not only a practical matter of enabling as many people as possible to be able to seize the employment opportunities that arise from these new oil and gas activities. It is also relevant to study the relation between human capital development and different forms of trust and legitimacy. In what ways could human capital development contribute to building a basis of trust and legitimacy? And could it be more than an economic benefit to the local workforce? In order to answer these questions, this thesis does not only draw on the case of oil and gas development in Greenland, which is still in its infancy, but also takes a closer look at experiences with human capital development related to more mature developments of energy activities in other small Arctic societies.

Next to widening the scope of the social license to operate concept at a national level, the case of oil and gas development in Greenland shows it is also relevant to enrich the concept with a multilevel focus. These oil and gas activities have been subject to international public debate and scrutiny, even though they are implemented within a local context, falling under the national jurisdiction of a democratically elected state. How do these two levels interact? And are they complementing or contradicting each other? The link between multiple geographical levels is considered especially relevant to activities that are regarded to be controversial from an environmental and/or social perspective, since environmental and social impacts often do not confine themselves to nation state boundaries (Harvey \& Bice 2014). In this respect oil and gas activities are considered to be controversial as they have environmental and social impacts that transcend boundaries, are subject to global commodity prices and are often implemented by international companies (ibid.). The link between Arctic oil and gas activities and the global level is even stronger because of the Arctic oil and gas paradox: Throughout the region, snow and ice have melted due to global warming. The worldwide combustion of fossil fuels plays an important role in the emission of greenhouse gases that link to climate change. The region where the effects of climate change are most profound was at the same time seen as an area with a high potential for the development of new oil and gas activities at the start of this century. The development of a multilevel social license to operate concept is therefore essential in order to analyse and understand the social license to operate of these Arctic oil and gas activities. 
In order to develop a social license to operate concept that includes a multilevel focus, this thesis draws on insights and concepts from governance and post international theory. Given the case of oil and gas development in Greenland, which includes a national level context in which the oil and gas activities are implemented and an international level context in which the climate debate is held, the multilevel focus is developed based on two geographical levels: The national level and the international level. Since the very origin of the social license to operate concept is explained by the failure of the political and legal systems of a nation state and the shortcomings of private sector companies in the local implementation of an activity, the social license to operate concept in its current form is not ready to be applied on an international level and address multilevel challenges. In developing a new, multilevel approach to the social license to operate this thesis builds amongst others on the research of Rosenau $(1997,2003,2006)$ in which he studies the role of nation states at both the national and international level. Over the last decades, the role of nation states has changed from a state-centric world to a bifurcated system where states compete, cooperate, interact and/or coexist with other state and non-state actors that have gained power and authority. States therefore engage in different types of governance arrangements at the same time. On the one hand this empowers states to pursue national interests in an international arena (Compagnon et al. 2012), on the other hand it limits their authority as it becomes dispersed over various arrangements and actors.

Non-state actors with which nation states compete, cooperate, interact and/or coexist in the international arena, consist of amongst other international environmental NGOs and multinational private sector companies. These companies play an increasingly large role in the international arena due to liberalisation of domestic markets and trade agreements (Ruggie 2004). The international environmental NGOs address global issues whereby the state is not necessarily their main point of focus, nor are government related tools and procedures necessarily used to reach their goals. These NGOs also address the social responsibility of multinational private sector companies. Worldwide protest actions against Arctic oil and gas, but also against climate change and rainforest destruction, illustrate the increasingly international character of civil society activity. Even though the protest actions themselves are executed on a local level, they are organised and debated on a global level in a digital world facilitated by the internet and social media (Cullen-Knox et al. 2017; Yates \& Horvath 2013). As the same activities are thus debated at two different levels at the same time, this sparks the question if, how and when they interact? And what is the role of international environmental NGOs, who are organising the protest actions worldwide and often have local branches, as well as the role of multinational companies, who develop activities worldwide and implement 
them locally, in relation to a social license to operate? As Rosenau illustrates, nation states now share their authority with these actors at an international level, but what is the influence of these international non-state actors on the authority of a state within the national level context and related to the three national licenses applicable to an activity?

Social media and smartphones could play an important role in the connection and interaction between social licenses at multiple levels: They enable people and organisations to instantly share their point of view and connect to others elsewhere in the world. It is both a tool to mobilise a public movement as well as a means for debate and dialogue (Castells 2008). The media have become a space of politics and the internet provides a public space, which is not geographically anchored (Castells 2000, 2005). In this digital public space powerful images and simple messages can drive social change. This raises the question what role social media and the internet have played in the context of Arctic oil and gas development? Did it facilitate interaction between the national level Greenlandic debate and the international level debate on Arctic oil and gas development? And how did it or did it not contribute to a social license to operate? At the international level, international environmental NGOs such as WWF and Greenpeace have started social media campaigns against oil and gas activities throughout the Arctic region. They mainly used social media to convey their message to millions worldwide, supported by strong images of dark drilling rigs in a white Arctic environment.

This thesis builds upon the aforementioned elements including the three different licenses, various additional forms of trust and legitimacy, combined with Rosenau's concept of a bifurcated governance system, the shared authority between nation states and non-state actors and the role of social media, for the development of a multilevel social license to operate concept.

\subsection{Research objective and questions}

As the previous sections have illustrated, debates about the social license to operate are emerging in relation to industrial projects with an environmental and social impact. This is particularly the case for controversial activities such as oil and gas development in the Arctic. Often a narrow definition and isolated approach towards the social license to operate is used. In scholarly literature and in oil and gas projects the main focus is on local stakeholders and their interaction with a private sector company as project proponent. Trust and legitimacy are key components, but also difficult to measure and therefore less examined. The role of human capital development is hardly studied, 
although human capital development is one of the main social challenges in small Arctic societies. Influences from political and legal arenas or other operational levels that could influence the implementation of an activity are not necessarily integrated in the current social license to operate approaches. The objective of this research is therefore as follows:

To increase the understanding of the development of a social license to operate of controversial energy projects by analysing the role of trust, legitimacy and human capital development in an Arctic context and by developing a multilevel approach of a social license to operate that includes legal and political licenses.

To reach this objective this thesis investigates the case of Arctic oil and gas development, with a particular focus on Greenland, as it is one of the most controversial activities from a global energy perspective of the last decade. The following research question and sub-questions are posed:

How is the social license to operate of Greenlandic oil and gas activities influenced by legal and political licenses in a multilevel context, what is the role of trust, legitimacy and human capital development and how does this contribute to a multilevel approach of a social license to operate?

1. What is the multilevel governance setting in which Arctic oil and gas activities take place and what is the authority of a state such as Greenland?

2. What is a social license to operate and how does it relate to the legal and political licenses of oil and gas activities in the Greenland?

3. In what way do trust and legitimacy play a role in the different licenses to operate for oil and gas activities in Greenland?

4. What are the challenges and opportunities for Greenland to maximise local benefits in the development of an oil and gas sector?

5. In what way does human capital development contribute to a social license to operate for oil and gas development in Greenland and other small Arctic states?

6. How has the social license to operate of Arctic oil and gas activities developed at the international level and how does it interact with the local level?

\subsection{Research approach}

To answer the research questions outlined in the previous section, a case-study approach was selected. A case study is "an empirical inquiry that investigates a contemporary phenomenon in depth and within its real-life context, especially when the boundaries between 
phenomenon and context are not clearly evident" (Yin 2009). This approach is particularly suitable to study a case in great detail and from various angles, to understand how and why certain processes take place in the real world. The goal is to contribute to theory building by analytic generalisation (Yin 2009). In qualitative research this is an iterative process based on an ongoing interaction between theory, data gathering and analysis. The case-study approach is the best suitable method to study the social license to operate of Arctic oil and gas development, due to its contemporary and complex nature and the little control the researcher has over the phenomenon.

\subsubsection{Case selection}

A general selection criterion was that the energy projects are considered controversial and evoke debate in society both locally and internationally. Furthermore, information about the decision making process regarding these projects and legal and policy documents should be relatively easy to access in the public domain and in a language that is mastered sufficiently. The case of oil and gas development in Greenland matched all these requirements. Greenland, whose ice sheet is studied from a climate change perspective and its melt can increase global sea levels, expressed a clear ambition to develop oil and gas resources. The largest international oil companies took part in the various licensing rounds that were organised by the government. The renewed attention for oil and gas resulted in a doubling of the total exploration drills in 2010/2011. The most recent exploration drills were not only subject to a national debate, but were also part of an international debate on climate change and the transition towards renewable energy.

Greenland also qualified as case study because it is a small state within the context of a highly securitised energy domain and an increasingly politicised Arctic. It was only in 2009 that they just obtained Self-Rule, including the rights to the underground. With its approximately 56.000 inhabitants Greenland is a (very) small state, which found itself in the centre of attention of not only the largest oil companies in the world, but also some of the world's largest countries such as China. This context does not only make it interesting to study the interaction between large international companies and local indigenous communities, as is normally done in social license to operate research, but also to study the international influences on Greenlandic society and the role of the government in this setting.

\subsubsection{Data collection and analysis}

This research is based on data collected via interviews, observations and document and literature analysis. The empirical data has been gathered between 2011 and 2016. 
By collecting data in three different ways, data triangulation ensures that the data and findings are confirmed or disconfirmed in multiple ways (Yin, 2009; Vennix, 2006). In 2011 I started with investigating numerous documents. Those gave rise to a number of questions that were addressed in the first set of interviews that were conducted by the end of 2011. In turn the interviews and later observations also initiated interests and topics for further investigation, which led me to study new documents and later conduct a second set of interviews. It was thus an iterative process between theory, data gathering and data analysis.

A variety of documents has been studied within the context of this case study. These do not only include scientific literature, but also (research) reports, project documents such as environmental and social impact assessments, governmental documents and videos, factsheets, newspaper articles and minutes of public consultations. Many of these documents were freely accessible on the internet, either in Dutch, English or Danish. I used the analysis of these documents to get a first understanding of the context, identify the relevant actors for this case study and identify the key issues in the societal debate on Arctic oil and gas development.

The social license to operate of Arctic oil and gas development does not necessarily manifest itself in a physical location, but is also shaped digitally. Observations did not take place in one location, but took place on a number of different occasions. Since the Greenlandic context of oil and gas development is an important part of my case study, I visited Greenland in December 2011 and February 2016. In 2011 I spent two weeks in the capital Nuuk. In 2016 I visited both Nuuk and Sisimiut. Someone from a country as densely populated as the Netherlands can try to imagine what it is like to live in a capital counting 16.000 inhabitants and not having road connections to other cities, but experiencing and observing this reality creates a greater understanding of the challenges Greenland is facing. Furthermore, participative observations took place in the Dutch Arctic Circle. This is a platform where the Dutch government, companies, nature organisations and knowledge institutes that work on Arctic issues meet each other and share their knowledge, expertise and experience.

The interview data for this research consists of two sets of formal semi-structured interviews and a number of informal, open interviews. The first set of semi-structured interviews was conducted in 2011 and the second in 2016. Some interviewees that were interviewed in 2011 were again interviewed in 2016. Prior to each interview an interview guide including open-ended questions was prepared based on the preceding document analysis and observations. The interviews took one hour on average and 
have been documented in a transcript. Respondents were asked if they wanted to review the transcript, but they did not deem this necessary. The interviewed authorities, companies and organisations have been selected based on their involvement in the development of oil and gas activities in Greenland and the wider Arctic. A balanced representation of sectors (government, private and civil society) and of geographical origin (local, national or international) was ensured in the selection process (see Appendices). The socio-political focus of this research determined which departments or representatives were approached, e.g. (representatives and experts of) social/ economic/political departments within governments, companies and organisations rather than (representatives and experts of) the technical departments. A list of interviewees can be found in Appendices.

It should be noted that some local and national organisations are so small, that the entire organisation consists of one to five employees. The representatives of the organisations that have been interviewed were all high level policy or executive officers that spoke on behalf of the organisation they represented. Some of them have been born and raised in Greenland, while others are Danes that now work and live in Greenland or representatives that work and live in other European countries. All interviews were conducted in English as I do not master the Danish and Greenlandic languages sufficiently to conduct semi-structured interviews. This only affected the selection process concerning the local civil society organisations: Some local civil society organisation were happy to conduct the interview in English and could therefore be included in this research. However, the researcher also approached the Greenlandic workers and fishermen and hunters organisations but due to the language barrier no interviews could be conducted with these two organisations. By interviewing the President of the Inuit Circumpolar Council, the stakes of Greenlandic workers, fishermen and hunters were included in this research. The Inuit Circumpolar Council maintains close ties with these two as well as other Greenlandic NGOs. This is amongst others illustrated by the fact that the Greenlandic workers and fishermen and hunters organisation are officially part of the ICC Greenland Delegation (inuit.org).

Furthermore, a number of informal, open interviews were held during my first visit to Greenland in 2011 and various conference visits, including the European Arctic Oil \& Gas seminar (2012), the Arctic Frontiers Conference (2013, 2014 and 2015) and Arctic Technology Conference (2015). The informal, open interviews were conducted with representatives of national and international private sector companies, the public sector (Arctic and non-Arctic) and international civil society. Some of these conversations were extensive, while others were rather short, but all were informative and helped contributed to my understanding of oil and gas development in the Arctic and in Greenland. 
The data was analysed using different conceptual frameworks that were each formulated to suit the needs of the specific research question at hand. The operationalisation outlined in the various conceptual frameworks was used to construct a coding scheme in qualitative data analysis software (QDA Data Miner). The interview transcripts were then labelled according to the coding scheme, which made it possible to link the interview data to the specific research questions. These conceptual frameworks include concepts such as governance arrangements (Chapter 2), human capital development (Chapter 3), trust (Chapter 4 and 5), legitimacy (Chapter 4 and 5), and multilevel social license to operate (Chapter 6). It has structured the analysis of the data concerning actors, rules and regulations, resources, various forms and ways trust and legitimacy are being formed and the dynamics of a multilevel social license to operate on Arctic oil and gas activities.

\subsection{Outline of this thesis}

The six sub-questions of this research are answered in five scientific papers, which are presented as the five following chapters in this thesis. An overview of the five papers that answer the various sub-questions of this research is presented in Figure 4.

Chapter 2 explores the multilevel governance setting of Arctic oil and gas activities and studies the changing spheres of authority in Greenland (sub-question 1). One of the biggest risks for Greenland is not being able to maximise the benefits from the offshore oil and gas developments. Chapter 3 therefore takes a closer look at the challenges and opportunities of maximising the local benefits of energy development for small Arctic states including Iceland, the Faroe Islands and Greenland (subquestion 4). It appears that creating a critical mass of local human capital is essential in maximising local benefits. Chapter 4 therefore examines the role of human capital development in relation to obtaining and maintaining a local social license to operate for the development of energy activities in these three Arctic states (sub-question 5). Chapter 5 presents a broader perspective on the social license to operate concept and studies the role of various forms of trust and legitimacy in the social license and its interaction with the legal and political licenses (sub-question 2 and 3). Chapter 6 builds on the more inclusive approach towards the social license to operate as developed in Chapter 5 and in turn develops a set of hypotheses and a typology for the interaction of the social license at multiple levels.

Based on the research findings presented in Chapter 2 to 6, Chapter 7 answers the main research question and outlines recommendations for future research. 

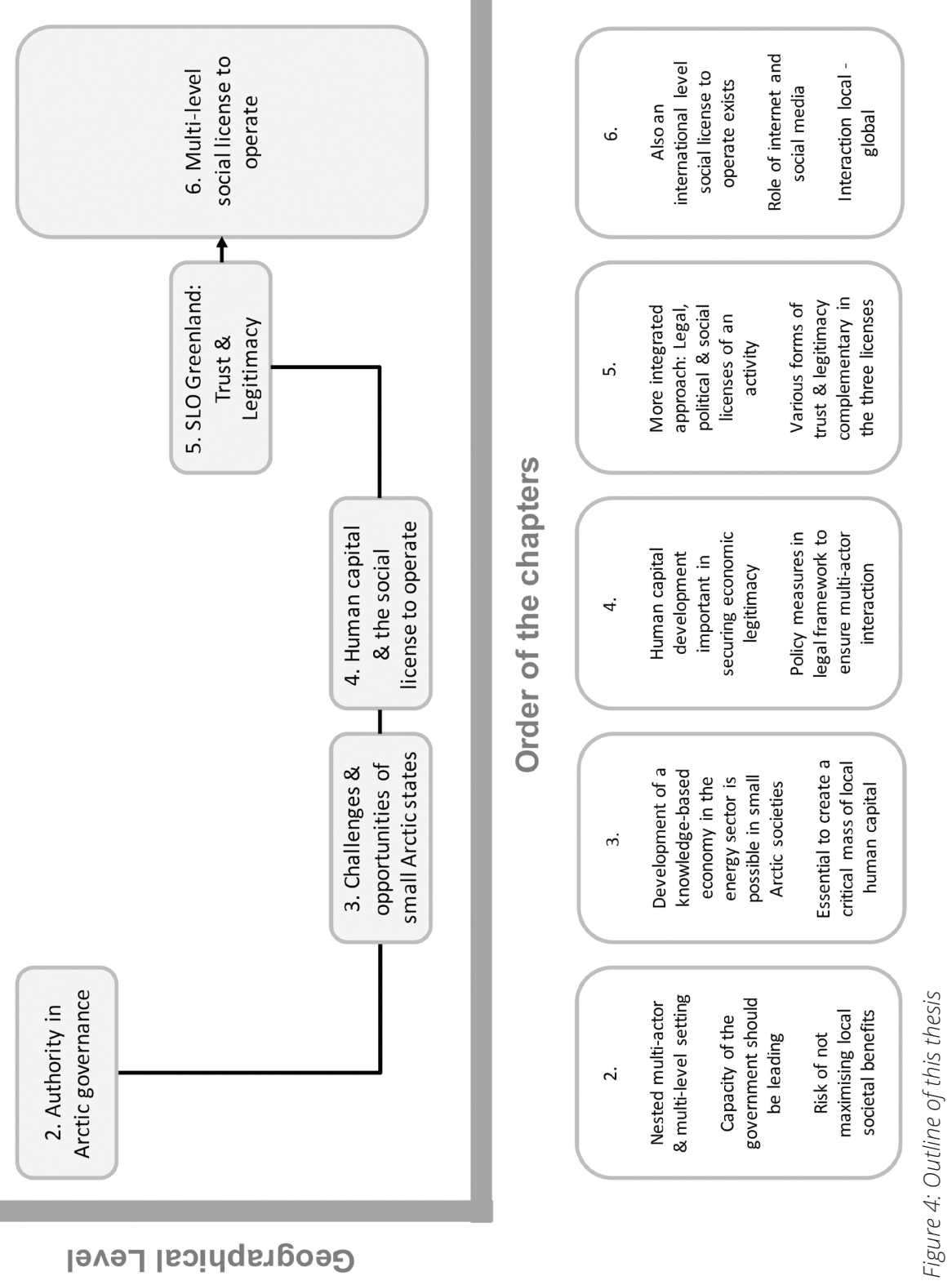


\section{CHAPTER}

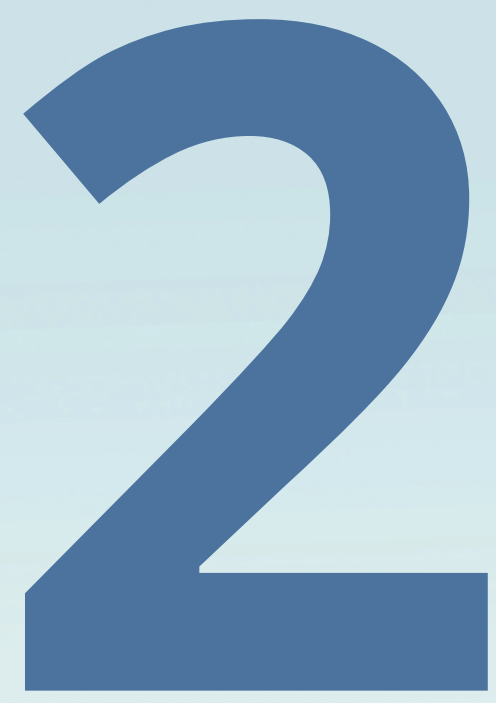




\section{Authority in Arctic governance: Changing spheres of authority in Greenlandic offshore oil and gas developments}

C.C.A. Smits

J.P.M. van Tatenhove

J. van Leeuwen

International Environmental Agreements: Politics, Law and Economics, 2014, 14, 4, 329-348 


\section{ABSTRACT}

The Arctic has rapidly transformed from a "frozen desert" into a theatre for high-level politics. Climate change and socioeconomic interdependencies bring the World more and more to the Arctic and vice versa. Increased geological knowledge, new technologies, and high-energy prices make it possible to develop oil and gas resources in the Arctic; however, the effectiveness of oil spill response techniques remains a key concern. To understand oil and gas exploration in the Arctic governance setting, and especially the authority of Greenland, we combine a multi-level governance framework with the concept sphere of authority from post-international theory. The Arctic sphere of authority on oil and gas consists of many different governance arrangements, of which the most well-known governance arrangement is the Arctic Council. This chapter focuses on the authority of Greenland in the changing oil and gas governance arrangements in the Arctic. Crucial is the changing Danish-Greenlandic relationship, in which the development of a Greenlandic oil and gas sector is seen as a tool to become financially independent. It can be concluded that the capacity of the Greenlandic government and civil society actors should be the primary guideline for the pace in which oil and gas activities are being developed. Taking this approach will ensure that the Greenland is retaining its central position and high degree of influence on the governance of oil and gas development in its country. Otherwise, it will lose influence and benefits will flow elsewhere. 


\subsection{INTRODUCTION}

The Arctic has rapidly transformed from a "frozen desert" into a theatre for highlevel politics and geopolitical struggles. Climate change and socioeconomic interdependencies bring the world more and more to the Arctic and vice versa. Due to climate change, the sea ice and snow cover is decreasing, making the Arctic region increasingly accessible for all kinds of activities, such as shipping, oil and gas exploitation, fisheries, and tourism. Combined with increased geological knowledge, new technologies, and high-energy prices, it is considered possible to exploit oil and gas resources in the Arctic (IFPA 2012). The major concern related to the exploration and exploitation of oil and gas is the effectiveness of oil spill response techniques in Arctic waters. An oil spill would have an adverse impact on the sensitive marine environment, and there is no prove yet that the technology currently used can clean up oil in or under ice effectively (PEW 2013).

Today's world is highly dependent on fossil fuels for its energy provision. Together with a growing population and increasing welfare, this causes a rise in the demand for fossil fuels, which is likely to continue in the (near) future. The conventional and easy-to-reach resources have largely been discovered and exploited. These resources thus come to an end, and oil companies are searching for less conventional places and reserves to fulfil the world's demand. Although the costs to explore and exploit these resources are higher than elsewhere in the world, the operations become more and more feasible. This is especially the case for oil projects (Short and Murray 2011), as the prices for oil are higher than the prices for gas. Due to among others the recent shale gas developments in the USA the price of gas has been decreasing, resulting in a changing business case for Arctic gas projects such as Shtokman in Russia. That also Arctic oil projects can face difficulties is shown by the John Castberg project in Norway, which has been delayed due to uncertainties in the resource estimates, investment, and changes in the Norwegian tax system (Statoil 2013). On the short term, it could be the case that some already discovered Arctic resources will not immediately be exploited, but since exploration activities in the Arctic fall within a longer-term strategy, they are likely to continue in the coming years.

As a result of these biophysical changes and technological, economic and environmental developments, the interest of the rest of the world in the Arctic is rising (Arctic Governance Project 2010). Not only the attention of Arctic states is triggered by these developments, but also other public and private actors enter the geopolitical stage, such as non-Arctic states, the European Union (EU), China, oil and gas companies, 
mining companies, shipping companies, the tourist sector, fisheries, (environmental) NGOs, banks, and insurance companies. This will change the balances of power in the Arctic region. Looking at the exploitation of oil and gas resources, the Arctic can be seen as the last frontier for the oil industry.

Governing Arctic oil and gas is a dynamic, fragmented, and complex issue, giving rise to a debate on both the nature of fragmentation in Arctic governance as well as avenues for future development of Arctic governance (see Humrich 2013 for a review of this debate). This chapter studies the current governance of oil and gas development in the Arctic and in Greenland in particular. To diversify its economy and secure an additional source of income, the Greenlandic government wants to further develop oil and gas activities. Since 2009, Greenland has Self-Government, meaning that they now have authority over their underground and thus over the resources in it (BMP 2009a). The development of their oil and gas resources is watched by the rest of the world, particularly by other Arctic states and environmental NGOs. Finding a balance between economy, ecology, and society is of utmost importance if Greenland wants to make its oil and gas development into a success.

The challenge for Greenland will be to deal with the tensions between the nationally desired development of oil and gas developments and the exact authority that it has in shaping this development in a sustainable way, given the increasing nesting of governance arrangements in Arctic governance. The Arctic governance setting is fragmented and highly politicized, consisting of states, market parties, and several formal and informal institutions, such as the legal framework of UNCLOS and the intergovernmental Arctic Council. The increasing dependencies between the Arctic and the rest of the world will produce a denser web of governance arrangements for the Arctic and will affect the authority of individual Arctic states. The main objective of this chapter is to analyse the increased nesting of governance arrangements in the Arctic sphere of authority relevant for oil and gas developments in Greenland and the resulting changes in the authority of Greenland in shaping these developments. We will analyse the role of Greenland and how its position and authority is shaped by the Denmark-Greenland arrangement of Self-Government and its participation in the Arctic Council. Based on this analysis, we will discuss the main factors that will change the authority of Greenland over its gas and oil activities in the near future.

In analysing the authority of the Greenlandic government in Arctic governance, especially in the exploration of oil and gas, we will use the concepts of marine governance arrangements and sphere of authority, combining a multi-level governance perspective 
with a post-international perspective. In Section 2.2, we introduce our theoretical framework after which an introduction to the history of oil and gas exploration in the Arctic and in Greenland is given in Section 2.3. The relevant government arrangements in Greenland's offshore oil and gas development are discussed in the following section, and Section 2.5 discusses the changes in authority of the Greenlandic government in particular. Conclusions on the nested government arrangements and changing authority related to the development of offshore oil and gas in Greenland can be found in Section 2.6.

\subsection{Nested governance arrangements and authority in Arctic governance}

To understand oil and gas exploration in the Arctic governance setting, and especially the authority of Greenland, we combine a multi-level governance framework with the concept sphere of authority from post-international theory (PI). While multilevel governance (MLG) understands the multi-actor and multi-level dynamics of policymaking and politics (Bache and Flinders 2004; Hooghe and Marks 2003), postinternational theory challenges the notion that the world is divided by territorial boundaries into sovereign, legally dependent states. PI departs from the observation that numerous actors of different types, both state and non-state, which together determine the process and outcome of global politics (Ferguson and Mansbach 2007) crowd contemporary politics. The role of states and non-state actors is changing due to the processes of political modernization. Political modernisation refers to "the shifting relationships between the state, the market, and civil society in political domains of societies - within countries and beyond-as a manifestation of the 'second stage of modernity' implying new conceptions and structures of governance" (Arts and Van Tatenhove 2006: 29). Structural processes of transformation, such as globalization and individualization, affect the political and economic domains of societies and are causing a skills revolution empowering individual citizens and non-state actors as well as forces that de-territorialise politics (Rosenau 1997, 2003, 2006). In general, globalisation is the widening, deepening, and speeding up of worldwide interconnectedness in all aspects of contemporary social life (Held et al. 2000). Scholars, such as Giddens, Castell, Held, Sassen, and Rosenau, see globalization as a central driving force behind the economic, social, and political changes, reshaping modern society, states, and the world order. As a result, politics becomes bifurcated, as it nowadays is a mixture between conventional inter-state politics and a new world of politics consisting of un-institutionalised interactions between a plethora of actors across the international-domestic divide (Rosenau 1997, 2006; Beck 2005). 
The increasing power of non-state actors and the forces of cross-border social, political, and economic processes have an effect on the authority of national governments. As global politics is undergoing processes of restructuring, so are states (Beck 2005; Spaargaren and Mol 2008). Several scholars discuss the relationship between territory, authority, and sovereignty. According to Held et al. (2000), "a new 'sovereignty regime' is displacing traditional conceptions of statehood as an absolute, indivisible, territorially exclusive, and zero-sum form of public power." According to Sassen (2006), globalisation has destabilised the marriage of territory, authority, and rights within the nation-state and is characterized by the emergence of different assemblages of territory, authority, and rights (Sassen 2006). In this setting of complex transnational networks (Keohane 1995) and an emerging network society (Castells 2009), individual states and their governments are also faced with emancipated citizens and civil society groups as well as with complex problems that go beyond their territorial-based control. States become increasingly dependent on other actors because they lack the resources or legitimacy to deliver public services, or face an environment that is increasingly ungovernable (Pierre and Peters 2000). States therefore engage in different types of governance arrangements at the same time - through international agreements with other states and partnership constructs with non-state actors-creating an ever-denser web of actors, institutions, and policies. This web of governance arrangements on the one hand empowers the state as it offers possibilities to further national interests with regard to certain areas, issues, and activities (Compagnon et al. 2012). On the other hand, it limits authority as it becomes dispersed over various arrangements and actors.

The concept sphere of authority refers to this web of arrangements in terms of "collectivities that have the authority to evoke compliance from those who are ruled" (Rosenau 2002, 2003, 2006). Collectivities are governance arrangements in which actors embedded in a shared institutional setting engage in politics and policymaking. An arrangement is a temporary stabilisation of the organisation and substance of a policy domain (Arts et al. 2000) aiming to develop effective and legitimate steering mechanisms (Van Leeuwen 2010). The organisation of a sphere of authority is characterised by the actors (on different levels) involved, the power resources that these actors have, and the rules of the game or institutions that allow these actors to interact (Arts et al. 2000). The substance of a policy domain is defined by the discourses that different actors hold over the problem definition and possible solutions (Arts et al. 2000). Steering mechanisms refer to the types of law and (formal and informal) regulation used to shape activities of actors (Van Leeuwen 2010). The web of governance arrangements shapes the authority of actors within the sphere of authority. Authority is defined as having the right to govern and the ability to generate compliance of those persons to 
which authority is issued (Rosenau 2002, 2003; Van Leeuwen 2010). Key in asserting authority is therefore the ability to influence and adopt steering mechanisms as well as ensuring that they are implemented and enforced effectively. Arrangements within a sphere of authority overlap, layer, and nest because they share the same political space in a certain policy domain (Van Leeuwen and Kern 2013; Van Tatenhove 2013; Ferguson and Mansbach 2007). For example, in the development of Arctic offshore oil and gas developments, several arrangements come together under one sphere of authority. The way in which arrangements for Arctic offshore oil and gas developments become nested differs per Arctic country, because each country also has its national arrangement to regulate offshore oil and gas developments. Together, these (nested) multi-level and multi-actor arrangements define the authority exercised within a sphere of authority.

\subsection{History of oil and gas in the Arctic and Greenland}

To define the extent of the Arctic sphere of authority, it is of importance to establish a clear understanding of the definition of "the Arctic." Defining "the Arctic" is not as simple as it might appear at first sight. Many different definitions exist, which are used by different actors. For this research, the definition proposed and used by the AMAP (AMAP 1998, p. 2-10) of the Arctic Council has been used:

[...] the terrestrial and marine areas north of the Arctic Circle $\left(66^{\circ} 32^{\prime} \mathrm{N}\right)$, and north of $62^{\circ} \mathrm{N}$ in Asia and $60^{\circ} \mathrm{N}$ in North America, modified to include the marine areas north of the Aleutian chain, Hudson Bay, and parts of the North Atlantic Ocean including the Labrador Sea.

This definition includes all areas within the Arctic Circle and adjacent regions in North America and Siberia as well as parts of the Atlantic Ocean and the Bering Strait (Figure 5). For almost a century, oil and gas activities have been conducted in the Arctic. Oil exploration began on a small scale before World War II in the Mackenzie Valley in Canada, the Alaskan North Slope, and in the Yamalo-Nenets Autonomous Okrug area in Russia (AMAP 2007 pp. 2-16). However, it would last until after World War II before large-scale onshore exploration activities took off in Alaska, Canada, and Russia. In the 1960s and 1970s, large reserves were found. In case of Alaska, the oil and gas exploration activities also went offshore by that time. The first activities took place in the Beaufort Sea, but later also the Bering and Chukchi Seas were included (AMAP 2007, pp. 2-16). In the 1970s and 1980s, offshore oil and gas exploration was also conducted in the Norwegian Sea, the (Russian part of the) Barents Sea, in other Russian waters, and offshore the coast of Greenland. In the case of Norway and Russia, major petroleum reserves were discovered and exploitation wells were drilled. In Greenland, 14 exploration wells have been drilled up until 2012 (BMP n.d.) of which five have been 
drilled in the 1970s, one in 2000, and another eight in 2010 and 2011. Nowadays, four out of five countries bordering the Arctic Ocean are producing oil and/or gas onshore, near shore, and/or offshore (Rekacewicz and Ahlenius 2006).

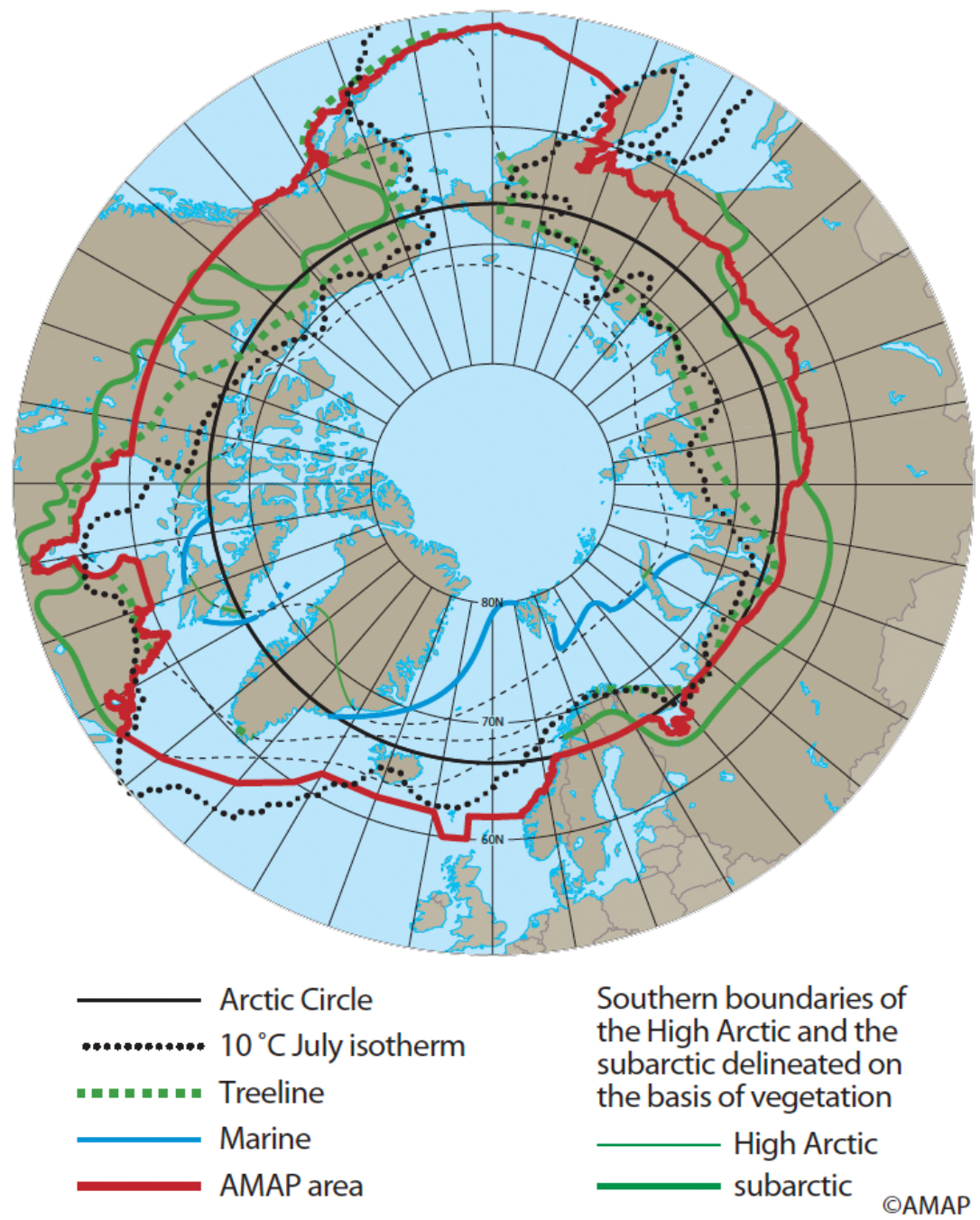

Figure 5: AMAP definition of the Arctic (source: AMAP 2014)

When the industry started to fully develop oil and gas in the Arctic region, the first protests appeared as well. In the beginning, the protests mainly came from indigenous people that had lived on the land for centuries, but now started to feel the impact of the development of onshore and offshore oil and gas on their daily practices (AMAP 
2007, pp. 3-09; Coates 2007). However, the indigenous people often did not possess official land ownership rights, making their claim difficult to pursue. Besides the direct effects on their livelihoods resulting from changing land use, due to the construction of pipelines and onshore oil fields, indirect effects impacting the (marine) mammals and fish on which they depend were felt as well. These protests started in the 1960s and continued throughout the 1970s in Canada and Alaska (Coates 2007). The objections of indigenous people toward the development of oil and gas were picked up by the environmental movement that was emerging at that time (Coates 2007). Protest groups like the Sierra Club, Friends of the Earth, and Greenpeace brought the development of Arctic oil and gas into international debates and under the attention of many people in the world. In the case of the Trans- Alaskan Pipeline, environmental groups made objections that brought the case into court (Alaska History and Cultural Studies n.d.). The amount of environmental legislation that was formulated at that time is reflecting the attention paid to environmental issues.

After this phase of environmental and indigenous protest, a relatively silent period started which lasted until the 2000s. Only when climate change reached the international agenda in the early 2000s, attention shifted again to the Arctic (Young 2009). Climate change and its impacts were becoming particularly visible in the Arctic and have resulted in people's association of climate change with melting glaciers and a lonely polar bear clinging on to a small chunk of sea ice in the middle of a big blue ocean. At the same time, the need for fossil fuels is still apparent and keeps growing. The potential of the Arctic region was recognized by oil companies. Worldwide attention was drawn to the Arctic's potential by the release of USGS study in 2008 (USGS 2008a). Compared to previous decades, the technology to develop, explore, and exploit the Arctic has developed (Lloyds 2012; AMAP 2007, pp. 2-250), and backed by the trend of rising oil prices, expectations about projects in this region becoming economically feasible are rising. The attitude of indigenous people varies across the Arctic and even within regions and communities (Harris 2012; Reeves 2011). Environmental organizations such as Greenpeace have reinforced their campaign against Arctic oil and gas development and reached international media by entering drilling rigs such as Cairn Energy's rig in 2011 (Vidal 2011) and disturbing meetings regarding Arctic oil and gas development (Agence France-Presse 2011). The reasons for these differences in attitudes mainly relate to the risks and challenges that come with Arctic oil and gas development, and in particularly the concerns related to oil spill response techniques and their effectiveness. 


\subsection{Nested governance arrangements in Greenland's offshore oil and gas development}

Studying the sphere of authority governing Greenland's oil and gas development begins with a deeper understanding of the individual governance arrangements that are nested within this sphere of authority. Currently, there are many different actors involved shaping Greenland's development of offshore oil and gas production, ranging from states to market parties and civil society organizations. All actors have their agendas, power resources, and interests that they want to pursue in the sphere of authority governing Greenland's oil and gas activities. These actors have entered into various different partnerships and are part of multiple governance arrangements at the same time. In this complex, governance setting actors are interdependent of each other, as authority is being spread over different arrangements and actors.

\subsubsection{The Arctic Council}

The most important state actors within the Arctic sphere of authority on offshore oil and gas development are the five states surrounding the Arctic Ocean, namely Russia, Norway, Denmark (Greenland), Canada, and the USA (Alaska). These actors are involved in several governance arrangements that deal with different issues in the Arctic. The most well-known Arctic governance arrangement is the Arctic Council, which is a "high-level intergovernmental forum" that was formally established by the Ottowa Declaration of 1996 (www.arctic-council.org). The Council has been established to deal with environmental protection and sustainable development of the Arctic, and to provide a forum to stimulate cooperation, coordination, and interaction between the Arctic states, the indigenous people, and other inhabitants of the Arctic (Ottowa Declaration 1996). It is unique in the world, because it gives the indigenous people a formal place in the decision making procedure alongside nation states. Other, nonArctic states and actors can apply to become an observer, so that they are allowed to attend all meetings of the Council. Several nation states, such as the Netherlands, and NGOs, such as WWF, have obtained this status (Arctic Council 2011). Others, such as the European Union, are eager to obtain it, but the 8 Arctic member states are well aware of their powerful position and have until now refused to grant the European Union (EU) an observer status. During the latest meeting of the Arctic Council, China, India, Italy, Japan, Republic of Korea, and Singapore were granted the observer status². This illustrates that the role of the Arctic Council is changing, a process that is still ongoing. The Arctic Council is now in the centre of attention when it comes to Arctic developments. The Arctic Council has become a high level political organization where non-Arctic states

2 Kiruna Declaration, Arctic Council Ministerial Meeting, Kiruna Sweden, May 15, 2013. 
and world powers want to be part of. The main issue will be to include these states in a way that does justice to their driving (industrial) influence on Arctic resources demand (Koivurova 2013). Besides non-Arctic states getting a more official position in the most important Arctic governance arrangement, also non-state actors are showing more and more interest in becoming part of this arrangement. Recently, the oil industry began showing interest in becoming part of the Arctic Council coalition, as the International Association of Oil and Gas Producers (IOGP) applied for an observer status in 2009 (www.ogp.org.uk). With the Arctic now becoming a theatre of high-level politics, the Arctic Council is seen by multiple different actors as the most legitimate governance arrangement to deal with Arctic issues (personal communication- interview Shell, WWF, Greenland; Rottem 2013).

The changes in the role of the Arctic Council fit into a wider trend of rising interest in the Arctic. Since the early 2000s, climate change impacts have gained more attention on the international agenda (Young 2009). The Arctic Climate Impact Assessment (ACIA), published in 2004, changed the discourse from the Arctic as a "frozen desert" to the Arctic as "a dynamic region in transformation" and as the canary in the coalmine when it comes to climate change (Koivurova 2010; ACIA 2004). Nowadays, this is the dominant discourse within the Arctic Council and has led to policies being reformulated by Arctic actors since the emergence of this discourse. Also, the oil industry sees the Arctic as a region in change, bringing about many opportunities, but this based on a different discourse. They identify the development of exploration/exploitation technology, rising oil prices, and a better understanding of the region's geological characteristics as the underlying factors for their interest in the Arctic (personal communication-interview Shell; Dahl-Stamnes 2012).

Moreover, there is not one comprehensive set of steering mechanisms that form a framework to structure the new interests in the region and the offshore oil and gas development activities across the Arctic. It is more like a patchwork of policies that each covers a specific subject, at least if one looks at the formal, legally binding steering mechanisms (Berkman and Young 2009). The Arctic Council has always been strong on creating a shared knowledge base through initiating, organizing, and publishing a series of assessment reports (Underdal 2013). Based on this knowledge base, a more or less comprehensive set of Arctic standards related to offshore oil and gas development has been formulated by updating the Arctic Offshore Oil and Gas Guidelines (PAME 2009). This steering mechanism is not legally binding, and it is left to the individual countries to decide which parts they implement. The non-binding nature of Arctic decisions limits creating a level playing field for oil and gas activities across the Arctic. However, 
in recent years, changes can be observed in the role of the Arctic Council: It now fulfils a decision-shaping function for legally binding decisions as well (Molenaar 2012). Examples of binding agreements that are a result of the decision-shaping function of the Arctic Council are the Search and Rescue (SAR) agreement of 2011 (Arctic Council 2014) and the agreement on Cooperation on Marine Oil Pollution, Preparedness, and Response in the Arctic of 2013 (Boyd 2013). By functioning as a preparatory platform for binding agreements, the Council further secures its future. If more binding agreements find their origin in the Arctic Council, it will become even a more central governance arrangement in Arctic matters. The fear expressed by Koivurova (2010) that the Arctic Council could face difficulties when sector-specific arrangements would originate in the future seems not to have materialised until now. For example, the SAR agreement has not initiated the formation of new institutional arrangements, except for the meeting of parties (Rottem 2013).

\subsubsection{Other Arctic governance arrangements}

Besides the Arctic Council, there are various other governance arrangements relevant to offshore oil and gas development in the Arctic sphere of authority that have emerged over time and are based on intergovernmental cooperation. In 2008, a first meeting was held between the "Arctic 5," in which the five Arctic coastal states2 participated (Revkin 2008) and a second meeting was held in 2010. The Arctic 5 made it clear to the rest of the world that they are the (only) legitimate actors, based on their sovereignty, to deal with issues concerning the Arctic Ocean. This arrangement received criticism from various actors, as it bypassed the Arctic Council and was limited to state actors only (Iceland Ministry of Foreign Affairs 2010; Koivurova 2010; Sheridan 2010).

Next to the arrangements that cover the entire Arctic, there are several governance arrangements that deal with specific sub-regions. Examples are the Barents EuroArctic Council, forming an arrangement between European Arctic states, Russia and indigenous people, and the Nordic Council, including all Nordic countries3 (www.beac. st). To an increasing extent, these arrangements also take oil and gas developments into account. For the Nordic Council, this is illustrated by a proposal on environmental protection and oil and gas extraction in the Arctic that was issued in 2012 (Norden 2012).

Also important in connection to the development of offshore oil and gas in (parts of) the Arctic are the UNCLOS and the Convention for the Protection of the Marine Environment of the northeast Atlantic (OSPAR). UNCLOS came into force in 1994, has been ratified by all Arctic states except for the USA, and applies to the marine environment worldwide (Molenaar 2012). UNCLOS consists of legally binding regulations and procedures that 
define rights and responsibilities of states regarding the use and protection of the world's oceans. Under UNCLOS, the Commission on the Limits of the Continental Shelf (CLCS) provides for ways to structure claims for an extended continental shelf outside the EEZ of nation states. This is currently a highly relevant topic in the Arctic Ocean, as all Arctic coastal states (except the USA) have filed a claim for an extended continental shelf with the CLCS.

The OSPAR convention is a regional arrangement that is designed to regulate all human activities that might have an adverse effect on the ecosystems and biodiversity within its jurisdiction (i.e., the northeast Atlantic Ocean. Fisheries management and shipping are not covered by the OSPAR convention (Koivurova and Molenaar 2009). When there is no competent international body governing marine environmental protection issues, the OSPAR Commission can exercise a residual authority (Molenaar 2012).

Though the Nordic Council of Ministers and various departments of the United Nations are observers of the Arctic Council (Arctic Council 2014) and thus interact in a formal way with the Arctic Council as most central governance arrangement, other (regional) arrangements do not. In some cases, the same NGOs or state actors operate in more than one arrangement, stimulating the interaction and transfer of knowledge. However, this is not always the case, thereby hampering the coordination of activities and developments within Arctic governance.

\subsubsection{The national Greenlandic governance arrangement on oil and gas development}

One can distinguish a national Greenlandic governance arrangement concerning the oil and gas developments in Greenland. When gaining more authority in 2009, the Greenlandic government has chosen to adopt a one-stop-shop approach regarding the development of oil and gas resources (PAME n.d.). Following from this approach and the MRA (December 7, 2009) formulated at that time, the MLSA (or Råstofstyrelsen previously Bureau of Minerals and Petroleum (BMP)) is the central governmental actor in Greenland. The MRA is still the single set of rules of the game concerning oil and gas development in Greenland.

The BMP used to be an entity under the government of Greenland, more specifically under the Ministry for Industry and Mineral Resources (www.govmin.gl), and was a solitaire actor standing alone from other state actors and ministries. Due to its central position in the governance of oil and gas activities and the fact that all responsibilities relating to mineral resources (including oil and gas), mineral resource activities, use of the subsoil for storage or purposes relating to mineral resource activities, 
related energy activities, related pipeline activities (BMP 2012a) are concentrated in one organization, there was hardly any need for the BMP to cooperate with other state actors. This solitaire attitude was criticised by other state actors such as the Ministry of Environment and Nature (personal communication - interview Head of Section Environment Greenland 2011). The fact that this Ministry was only involved in the work of the BMP during the formal public hearing moments combined with the BMP as sole body responsible for everything, from royalty collection to enforcement of environmental standards, formed the main arguments of the Ministry. All other Arctic states have separated their environmental department from the rest of the responsibilities related to oil and gas development, even the USA after the Macondo disaster. The realisation of the MLSA can be seen as an attempt to address this criticism and reflects the separation of responsibilities (GEUS/MIMR 2013), by introducing an Environmental Agency for the Mineral Resources Area (EAMRA: Miljøstyrelsen for Råstofområdet). The EAMRA is the "administrative authority for environmental matters relating to mineral resources activities" and falls under the responsibility of the Ministry of Environment and Nature. Furthermore, the geological department has been placed directly in the Ministry of Industry and Mineral Resources (MIMR) itself. The MIMR, MLSA, and EAMRA are currently working together with several (Danish) research institutes, such as the Geological Survey of Denmark and Greenland (GEUS), Danish Centre for Environment and Energy (DCE), and Greenland Institute for Natural Resources (GINR) regarding environmental and geological matters (BMP 2012b, 2009b).

Greenland is still a young state in its current form, whereby Self-Government is accompanied by more authority and responsibilities. The civil society in Greenland is small and consists of only a few, mainly national actors. These civil society actors are active when it comes to addressing the concerns, risks, and challenges related to mineral resources development. Due to their limited capacity, choices have to be made regarding the focus of their attention: the oil and gas industry or the mining industry. Since in the last 2 years (2012 and 2013), the oil and gas activities were limited to a number of preparatory activities, while the mining activities included applications for construction permits, the main focus of the civil society actors has been on the mining sector. This has resulted in the formation of a number of coalitions, such as Friends of Nuuk's Fjord (Nuuk Fjords Venner) criticizing the London Mining iron ore project or the NGO coalition (including the Inuit Circumpolar Council Greenland (ICC Greenland), Friends of Nuuk's Fjord, Transparency International, WWF, and Avataq) related to the Tanbreez mining project (Sermitsiaq 2013). It is likely that when the oil and gas activities pick up again in the near future, these NGOs and coalitions will also become active in this sector. 
(International) Environmental NGOs like Greenpeace and WWF do not enjoy a great level of support among the Greenlandic population due to anti-whaling and antisealing campaigns in the past (personal communication-interview WWF Denmark Greenland, Greenpeace 2011). The limited capacity of the Greenlandic civil society also makes it difficult for them to comment in time on the extensive environmental and social documentation related with permit applications of oil companies (personal communication -interview WWF Denmark Greenland 2011; Macalister 2011). Moreover, the main criticism is that they are not consulted properly and that their comments and objections are not taken into account by the various industrial actors (WWF and ICC 2013; Duus 2012). This has led to protests in the past. That the Greenlandic civil society is able to mobilize society when it comes to sensitive issues related with mineral resources extraction is illustrated by a number of demonstrations regarding lifting the ban on uranium mining (Duus 2013; Rafaelsen 2013).

Within the Greenlandic parliament (Inatsisartut), the extractive industries are also subject to debate. Even though the two large political parties, Siumut and Inuit Ataqatigiit (IA), are in favour of developing oil and gas activities in Greenland, they have different opinions as to how these activities should be developed. Especially, the law on large-scale projects (storskalaloven), which applies to among others oil and gas projects, has attracted much attention. The law relaxes certain regulations for large-scale projects and would thereby enable cheap, foreign labour to come and work in Greenland, while the Greenlandic society faces unemployment issues itself (The Arctic Journal 2013). When IA was the governing party in 2012, Siumut refused to vote for this law. However, barely a year later, when Siumut became the governing party, it introduced some small changes and voted for the law (Mølgaard 2013). This law has caused much debate within Greenland, not only among political parties but also NGOs and the wider public. Moreover, it also tested the relation with Denmark as the authority to grant visa to foreign labour lies with the Danish authorities.

One of the primary reasons for discussion is a fundamental difference in discourse that exists between the oil industry on one side and most of the civil society actors on the other side. In general, the oil companies do not consider their Arctic activities as something new (Dahl-Stamnes 2012), as they argue they are already active in the Arctic and under extreme cold conditions since halfway the previous century. While the environmental NGOs do consider the activities to be new, as they argue the oil companies have never worked this far offshore and combined all other Arctic circumstances in one project. 
The oil companies active in Greenland belong to some of the major oil companies in the world, such as Shell, BP, and Exxon. They have formed the Greenlandic Oil Industry Association (GOIA 2011) to share knowledge and resources and to speak with one voice to the Greenlandic government on issues concerning the oil industry in Greenland in general. Greenland also has a national oil company, NunaOil, who has a share in all the licenses that have been granted up till now (BMP 2012b). Via NunaOil and its participation in the current developments, the government gains more insight into the functioning of the industry and builds up knowledge and expertise (BMP 2009a). By participating in the licenses, it allows the government also to gain from the development of future oil and gas resources, in other ways than only royalties and taxes.

Although the oil companies might have more (financial) resources than the Greenlandic government, this does not mean that the government has lost control. The Greenlandic government has used its regulatory power resources to put in place a framework of steering and compliance mechanisms to steer and guide the oil and gas development (BMP 2009a). The government decides, based on a Strategic Environmental Impact Assessment, which areas will be opened for licenses and leaves it up to the oil companies to apply. Important in this context is that no activity is allowed if there is no permit and the burden of proof lays with the oil companies (BMP 2009a). However, the Greenlandic government does dependent on knowledge and expertise from "outside" as the MLSA/EAMRA lack the capacity to provide for all the knowledge and capacity that is needed.

It can be concluded that the national Greenlandic government arrangement governing oil and gas activities is subject to change recently. The former Bureau of Minerals and Petroleum used to be a closed, solitaire institution with the mandate to deal with all matters regarding oil and gas developments in Greenland. After continuous criticism, mainly from the Ministry of Environment and Nature, various NGOs, and other civil society actors, changes have been implemented in the past year. Responsibilities have been separated, and environmental matters now fall under a new agency. Their mandate is determined by the rules of the game, in this case the MRA, which also relates to their power resources and the steering and compliance mechanisms that are in place.

The limited size and capacity of the MLSA, EAMRA, the government, and civil society in Greenland is well known, and capacity building is a focus point of these actors. Knowledge and expertise are regarded as important power resources, and currently, the public hearing processes are criticized by civil society actors for being too short to make a meaningful contribution. On the side of the government, the amount of 
people now concerned with oil and gas activities and related domains cannot possess all knowledge and expertise available to guide, steer, and enforce a developing oil industry. This makes the government of Greenland dependent on other actors for specific knowledge about the environment, pollution, and techniques used in the oil industry. Scientific institutes are a major deliverer of this kind of products, making them an interesting partner. Various capacity building and knowledge exchange programs have been initiated, and education remains high in the agenda (European Commission 2007). Oil companies also have a vast pool of knowledge and expertise, but are at the same time the actors a government has to control. The oil companies that operate in Greenland have established a platform for information exchange and cooperation. Moreover, the national Greenlandic oil company, which is a party to every license, is seen as a tool to gain knowledge from the side of the private sector.

\subsubsection{The Greenland - Denmark governance arrangement}

Since Greenlandic Self-Government was established in 2009, it is a fairly new phenomenon to the country. Political and financial ties to Denmark still exist as Greenland did not become fully independent yet. Several political domains, including defence, foreign policy, and security, remain shared between both countries (Queen of Denmark 2009). This means that most activities on an Arctic level should be executed in cooperation or via Denmark. In the Arctic Council, it is Denmark who officially has a seat at the table, but in practice it is Greenland who is most active in the Council. In issues specifically addressing the Greenlandic Arctic, Denmark is following Greenland's perspective and advice in its position taking (personal communication - interview Government of Greenland 2011).

Furthermore, there are some less official ties to Denmark that could influence Denmark's influence on Greenland. One of the partnerships in this arrangement is the close cooperation of the MLSA/EAMRA (previously BMP) with Danish research institutes on environmental and geological matters concerning the oil and gas developments in Greenland. Because only limited knowledge in these fields is currently present in Greenland, criticism has been voiced that these research institutes de facto take the decisions (personal communication - interview Head of Section Environment Greenland 2011). Furthermore, one can generally conclude that most of the civil servants are Danish, while the politicians tend to be Greenlandic (Binderkrantz 2011). Therefore, one could argue that Denmark remains influential in Greenlandic politics albeit behind the doors. Establishing a Greenlandic bureaucracy would limit this influence. 
Once oil and/or gas exploration activities will take place on a larger scale and eventually even develop into exploitation activities, the relationship between Greenland and Denmark will be shaped in more detail. Under the current agreements, certain authority that could influence the oil and/or gas developments remains in the hands of Denmark. An example is the visa for a foreign workforce related to the "storskalaloven," of which the authority lies in Danish hands. Denying access to Denmark/Greenland by denial of visa applications could hinder developments and investments in Greenland, especially if it concerns large-scale workforces. This is currently an issue related to the development of a Greenlandic mining sector in particular but is likely to apply to the oil and gas sector in the future.

\subsection{Changing authority of the Greenlandic government in governing oil and gas developments}

Arctic oil and gas governance is characterized by a set of nested governance arrangements that interact, each covering different subjects and/or geographical areas. The Greenlandic government participates actively in several of these arrangements, as has been described above. Since recent years, the Arctic is developing into a highlevel political arena, becoming more closely connected with the rest of the world and its dynamics. The governance arrangements within the Arctic sphere of authority on offshore oil and gas development are constantly subject to change. This changing political environment influences the current and future role and authority of the Greenlandic government. This section will discuss these changes, their driving forces, and the potential influence on the authority of Greenland.

The currently changing role of the Arctic Council is likely to influence Greenland's authority on an Arctic level. The wish of non-Arctic state actors to obtain observer status illustrates the fact that the Arctic has become a high-level political theatre of which the Arctic Council is regarded as the most important governance arrangement. With the acceptance of more non-Arctic states as an observer (Pettersen 2013), the Council is increasing its legitimacy and securing its role in future governance of the Arctic, but also acknowledges that matters in the Arctic region are global matters. In addition, the Arctic Council is more and more a decision-shaping platform where a solid basis for legally binding agreements is being made by its Member States. In the future, this type of steering mechanisms might be more frequently used by the Arctic Council, enlarging the potential influence on Greenland's offshore oil and gas developments since the outcomes are legally binding. The Greenlandic government has been participating actively within the Council, even though the official seat at the table belongs to Denmark. The changing status and legitimacy of the Council might influence 
the authority of the Greenlandic state, because other states are not always keen on Greenland's independent participation. It remains a question whether Greenland can keep its unique position and matching influence in the future if the Arctic gains even more attention of the rest of the world. It is in the government's own interest to ensure that this will be the case. The relation with Denmark is thus of utmost importance.

Greenland could benefit from the decision-shaping function of the Arctic Council, in case it is able to put its national agenda forward. This will always have to happen in close cooperation with Denmark, since the latter is still responsible for foreign policy. However, the other way around could also happen: namely that because legally binding agreements tend to be more frequently the outcome of Arctic Council's working group discussions, the other Arctic countries will get more involved as well leaving less room for Greenland to freely manoeuvre and position their agenda. Therefore, it could benefit Greenland's authority when it is able to push its national agenda within the Arctic Council, but could also limit it when it is pushed to agree with something which is not in its own interest.

Within the governance arrangement of Denmark and Greenland, the tendency is that the Greenlandic state gains more authority step by step. It is a long-term process that has started in the 1970s. The current division in authority between Greenland and Denmark seems straightforward on first sight, but when one has a look at the details, there is room for potential conflict when it comes to (future) oil and gas development. How fast the Greenlandic state will gain even more authority or becomes independent from Denmark remains to be seen. The development of oil and gas resources is expected to play an important role in this process toward (economic) independency. However, even when Greenland could financially become independent, it remains to be seen if Greenland will make the choice to become fully independent. Its small society and human resource base could use the benefits of being connected to a larger (political) entity. This could be Denmark, but other governance arrangements could form a good alternative. At the same time, Denmark might want to keep its link with Greenland as well, because of access to new oil and gas resources.

Another element of the Greenlandic - Danish relationship has to do with the domestic organization and capacity to develop an oil and gas sector in Greenland. While the Greenlandic government remains fairly dependent on Danish expertise and capacity at the moment, it is likely that this will change over time. Greenland is working to increase its capacity and knowledge in the fields of, for example, environment and geology related to oil and gas resources and activities. As this process had already started and 
is on the agenda since 2009, one can expect that the influence of Denmark will gradually decrease over time. With a stronger knowledge base, the Greenlandic government will be able to strengthen its position vis-a-vis other Arctic states, non-Arctic states, civil society, and market actors.

Within the relationship Greenland - Denmark, the Greenlandic state gains authority and is likely to continue to do so. The relation with Denmark will also influence the position of Greenland in the Arctic Council. More independency will provide a more legitimate ground on which Greenland can act on its own behalf in the Arctic governance arrangements. If it fails to secure, its current freedom Greenland will become more dependent on Denmark again, something they are trying to reduce. If this happens, it will decrease the influence of Greenland on Arctic governance arrangements and the opportunity to let its voice being heard. On the other hand, if Greenland is able to secure or even expand its position in Arctic governance arrangements, it will need to invest in capacity and human resources to be able to benefit from it.

Domestically, the extraction of non-living resources is subject to a lively debate in which many actors take part. The government plays a central role and recently initiated changes in its organizational structure after years of criticism by national and international civil society actors. It has separated responsibilities that formerly belonged to the closed and solitarily operating Bureau of Minerals and Petroleum. Now, the authority of environmental matters has been assigned to a new organization, under the responsibility of the Ministry of Environment and Nature. It remains to be seen what concrete effects this organisational change will have.

Although the civil society in Greenland is still relatively small, it is active and that is likely to increase in the near future. Everyone is convinced that it is crucial to include civil society organizations into the decision-making process to increase the legitimacy of developing a Greenlandic oil and gas sector; however, the implementation lacks effectiveness (WWF and ICC 2013). Various NGOs have now formed coalitions and action groups that heavily criticize the development of various mining projects, since these projects are more active at this moment in time. However, it is likely that similar situations will occur when the offshore oil and gas start to take off. The NGOs have proven to be able to mobilise the Greenlandic society in demonstrations against controversial decisions. Furthermore, international NGOs, who are also present in Greenland, can put pressure on the Greenlandic state by mobilizing public opinion in the rest of the world. To prevent this from happening, the Greenlandic government should reconsider the implementation of its current decision-making process. The 
interplay between domestic and internationally organized civil society shows how the boundaries between domestic and international politics and policymaking are blurring.

What is striking in the sphere of authority of Greenland's offshore oil and gas developments is that there seems to be a lot of institutionalized forms of interaction between state actors and civil society via the various governance arrangements discussed above, while there are hardly any of such interaction forms between private sector actors and both other parties. Oil companies are occasionally interacting with actors from the state or civil society on an Arctic level, but not (yet) in a structural, continuous way. The oil industry is attending Arctic Council meetings on an ad hoc basis since 2009; has applied for observer status; and is represented in some studies performed on Arctic ecosystems, governance, and oil spill response techniques. That the interaction between actors of the private sector and actors of state and civil society is not occurring on a regular basis, can be a cause as well as a result of different discourses prevalent in both groups. Although the Arctic is perceived by all as a region subject to large-scale transformations due to primarily climate change, this is by the oil industry not considered as a driving force underlying the increasing of oil and gas activities. Relating to this is the controversy around the discourse of the oil industry that Arctic activities are not new at all to them. The opposing discourse that is expressed by state actors and civil society does consider oil and gas activities as new to the oil industry, resulting in a fundamental difference between actors of the particular groups.

While there might be limited interaction between the state and market actors on the Arctic level, there is more interaction on the national level between the Greenlandic government and oil companies. The Greenlandic government has authority over these companies when regulating their oil and gas production. The limited capacity of the government in terms of manpower and knowledge generation is an important factor in how the authority of the Greenlandic government evolves in the future when more companies want to operate in Greenland's territory. The capacity building programs and focus on education that are already in place form a good start, but need to be continued and possibly intensified in the future. Moreover, the influence of the Arctic Council, international and domestically organized civil society, and other partnerships of Arctic states or non-state parties will increase in the near future. It is the increasing nesting of these governance arrangements that will shape the authority of the Greenlandic government over its oil and gas resources. The fact that it is a dynamic and complex network makes it hard to predict how the authority of the Greenlandic government will exactly develop in the future. Greenland needs to be constantly aware of opportunities 
and risks, some of them discussed in this section that can influence their position in the Arctic policy arena.

\subsection{Conclusion}

The Arctic is a dynamic region, which is becoming ever closer connected to the rest of the world by socioeconomic and environmental processes. The world's rising population and increasing level of welfare are some of the most important drivers for rising demands in fossil fuels and minerals. The world is entering a phase in which the easy-to-reach resources are coming to an end, demand continues to rise, and thus new regions like the Arctic or unconventional resources like shale gas become interesting. This chapter analysed the current development of oil and gas in the Arctic and in Greenland using a post-international perspective. This theoretical approach enabled a structured analysis of the complex and dynamic political setting of Arctic oil and gas governance and the factors influencing Greenland's authority in particular. Various governance arrangements within the sphere of authority governing the development of Arctic offshore oil and gas exist, interact, and influence each other.

The Arctic sphere of authority on oil and gas consists of many different governance arrangements. Concerning oil and gas activities, the Arctic Council is a central governance arrangement, bringing together state actors and civil society (indigenous people). Market parties were absent until recently, but industry is becoming more involved in the Arctic Council. Moreover, the Arctic's energy resources are being securitized by the Arctic states and the region is becoming a theatre of high-level politics.

Given the nested multi-actor and multi-level governance setting of the Arctic, the Arctic Council, as the most comprehensive governance arrangement on the Arctic level, could play a crucial role in developing sustainable solutions. In this chapter, we focused on the Arctic sphere of authority to understand the changing authority of Greenland in its emerging oil and gas developments. Crucial in this respect is the expanding role of the Arctic Council in developing binding regulation for offshore oil and gas activities as well as the increasing role of non-Arctic states in this governance arrangement. In addition, the changing Danish-Greenlandic relationship is important. The development of a Greenlandic oil and gas sector is seen as a tool to become financially independent from Denmark. It is expected that other Arctic states will try to influence the Greenlandic oil and gas arrangements when Greenland becomes more independent from Denmark. It can be concluded that the capacity of the government and civil society of Greenland should be the primary guideline for the pace in which oil and gas activities are being developed. Taking this approach will ensure that the Greenlandic government and 
society is retaining its central position and high degree of influence on the governance of oil and gas development in Greenland. If not, it would run the risk that they remain formally the most important player, but that de facto other actors, whether it is the industry, (Danish) research institutes, or states (through the Arctic Council), take over that position causing the risk that benefits will not maximally benefit Greenland as they might flow to other places. 


\section{CHAPTER}

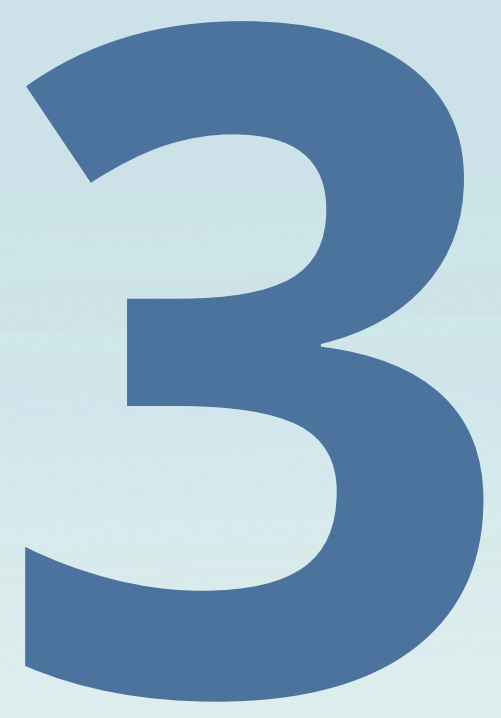


The challenges \& opportunities for Arctic microstates in developing an energy sector: The role of human capital development and knowledge institutes

\author{
C.C.A. Smits \\ R.G. Bertelsen \\ J.C.S. Justinussen
}




\section{ABSTRACT}

Like many Arctic states, Iceland and the Faroe Islands used to be the resource-based economies which Greenland is today. Remotely located in relation to the World economy, Iceland and the Faroe Islands have succeeded in developing a knowledgebased economy, also related to their energy sector. To create a knowledge-based economy a sufficient mass of human capital is of crucial importance. In forming this critical mass, higher education and knowledge institutes play a central role. The cases of the Faroe Islands and Iceland show that it is possible to create a critical mass of human capital by developing strong knowledge institutes and stimulating the exchange of knowledge. Iceland has successfully developed a knowledge-based energy sector based on hydropower over the last century. Icelanders bringing home knowledge gained via graduate education at top institutes abroad, appeared of major importance. More recently the Faroe Islands have developed human capital based on oil and gas exploration activities, while no economically viable resources have been found yet. Greenland on the other side has made some important steps in creating and strengthening strong knowledge institutes, but is still far from a full-fledged knowledge-based economy such as the one in Iceland. Are there lessons to be learned from Iceland and the Faroe Islands, and how much do historic path-dependencies matter in this context? These are questions that this chapter will explore. 


\subsection{INTRODUCTION}

Just like in many other Arctic states, natural resources form the basis of the Icelandic, Faroese and Greenlandic economies (Glomsrød \& Aslaksen 2009). Within this context energy plays and has played an important role in the development of these states. To benefit from the exploitation of natural resources, including energy resources, the authors believe that a knowledge-based economy and a strong educational sector are essential. However, the small size of these societies brings about specific challenges and opportunities. All three countries can be regarded as very small or microstates, due to the small size of their societies: populations of 315,281, 49,709 and 57,714 for Iceland, the Faroe Islands and Greenland respectively (www.cia.gov).

This chapter will analyse the challenges and opportunities in the creation of a knowledge-based economy around natural resources, with the development of an energy sector as an example. The focus of this analysis will be on the creation of human capital and the role of knowledge institutes, since education increases social capital which helps building human capital (World Bank 2009; World Bank 2003a). The question is whether historical path dependencies matter in developing a strong educational sector that is critical in the creation of human capital and a knowledge-based economy? To answer this question, the history and circumstances under which especially Iceland and the Faroe Islands have already developed their knowledge-based economy will be explored. Greenland finds itself much more at the beginning of developing a knowledgebased economy, and could benefit from the lessons learned of the other two countries.

The case of Iceland will be explored first, since it has successfully developed a knowledge-based energy sector based on hydropower (and geothermal power outside the scope of this chapter). Long established knowledge institutes like the University of Iceland (1911) have played a central role in the development of human capital and a knowledge-based economy in Iceland. Furthermore, "brain circulation" (see, for instance, Solimano 2008), defined as Icelanders going abroad to leading international universities and returning home with the gained knowledge, has been an important factor as well. Second, the much more recent case of the Faroe Islands will be discussed. Over the past 15 years the Faroe Islands have built up a knowledge-based economy on the back of oil and gas exploration activities, even though no economically viable reserves have yet been found. The Maritime College (1893) and the University of the Faroe Islands (1963), have played an important role in the transition from a resourcebased economy to a knowledge-based economy. 
Compared to Iceland and the Faroe Islands, Greenland stands at the early stages of developing a knowledge-based economy. As part of its strategy to diversify its economy, Greenland is currently looking to develop an energy sector. In order to maximise local benefits of these offshore activities, Greenland has implemented a number of tools in its regulation. Education is seen as a central element and much effort is made to prepare and qualify society for participation in these industrial activities.

\subsection{Iceland}

One of the teachers of Rasmus Gjedssø Bertelsen (co-author of this chapter) at the Austurbæjarskóli primary school in Reykjavik was the prominent Icelandic poet and translator Vilborg Dagbjartsdóttir. Vilborg was born in 1930 in the east coast settlement of Vestdalsheiði, near Seyðisfjörður, which is now abandoned. Vilborg told stories from her childhood of massive losses of life to tuberculosis and other infectious diseases and to the sea, and the self-sufficiency of households living off the land and the sea. When Vilborg was born in 1930, Iceland had just become a sovereign and independent state as the Kingdom of Iceland, having a common king with the Kingdom of Denmark since 1918. It would last another 14 years before Iceland would declare the republic it is today.

At the moment, we all know Iceland as an exceptionally highly developed independent very small state, with one of the highest levels of human development in the world (number 13; notwithstanding the 2008 financial crisis) (UNDP 2013). This development raises the question: what explains Iceland's remarkable political and socio-economic achievements over the 1900s? In this chapter it is argued that an important explanation of those achievements is the combination of a strong educational sector, strong human capital and abundant natural resources (Bertelsen \& Hansen 2015; Bertelsen, Justinussen \& Smits 2015).

Iceland is a natural resources-based economy as are all Arctic economies. In particular marine resources (which are outside the scope of this chapter) and renewable energy resources (the topic of this chapter) have played and continue to play a key role in the Icelandic economy and society. Icelandic exports have overwhelmingly been based on marine resources since the mechanisation of Icelandic fisheries (the industrialization of Iceland) in the early 1900s. Iceland, as a micro or very small island economy and peripheral to the world economy, has throughout its independent history struggled to develop and diversify its economy. This struggle to diversify and develop the Icelandic economy was closely connected with Iceland's other great natural resource: renewable hydro- and geothermal energy (Ármannsson 2005; Ísleifsson 2007; Jónsson 2005; 
Karlsdóttir 2010; Kristinsson 2005; Kristjánsson 1997; Pálsdóttir 2005; Ragnarsson 1975, 1976, 1977; Sigurðsson 2002; Pórðarson 2004).

The authors argue that Iceland has managed to create a domestically controlled, globally connected, knowledge-based energy sector (Bertelsen \& Hansen 2015; Bertelsen et al. 2015). This development has created work and intellectual opportunities for Icelanders at home and increasingly abroad. This development was driven by a fortuitous combination of a strong domestic tradition of primary, secondary, increasingly tertiary, and vocational education combined with a strong and successful tradition of "brain circulation": by going abroad for study or work experience and returning to Iceland with new knowledge and networks. This section of the chapter will discuss how this combination has laid the foundation of this domestically controlled, globally connected, knowledge-based energy sector. This chapter acknowledges the environmental tradeoffs in hydro- and geothermal energy projects, which has been the topic of intense debate in Icelandic society since the early 1900s. This topic is treated extensively in literature (see e.g. Hálfdanarson \& Karlsdóttir 2005; Karlsdóttir 2010 for historical overview), but is outside the scope of this chapter.

\subsubsection{The history of Icelandic development}

Iceland suggests a strong path dependency for the development of human capital, where building knowledge-based societies and economies has very deep historical roots in excellent domestic education in the native language combined with "brain circulation" with the outside world. This path dependency raises difficult questions for Greenland, while the Faroe Islands offer answers. Icelanders have travelled to Europe for knowledge since the settlement of Iceland in the Viking Age ( 800 to 1100), which is recorded in the Sagas. As a logical consequence of this close intellectual connection with Europe since its earliest settlement, the two late Viking age bishoprics of Iceland, first Skálholt in Southwest Iceland in the second half of the 1000s and subsequently Hólar in North Iceland in 1106, founded Latin Schools or grammar schools. The Skálholt school still exists today as the Reykjavik Grammar School (Menntaskólinn í Reykjavík, MR), which produced the first Kingdom of Denmark Nobel laureate, Niels Rybjerg Finsen (Medicine, 1903), and the literature Nobel laureate Halldór Laxness in 1955 (although he had left the school early). Since the Protestant reformation the school and church language of Iceland has been Icelandic.

The Skálholt and Hólar schools supplied lower ranking clergy and equipped Icelanders to travel (especially) to Denmark for higher education throughout the centuries. This shows that Iceland has had a long history of strong domestic primary and secondary 
educational tradition in the national language, equipping Icelanders for going abroad to enjoy higher education. This "brain circulation" supplied a steady stream of Icelandic pastors for church leadership and education, jurists for administration and physicians for the nascent health service. It also maintained a vibrant Icelandic intellectual life in Copenhagen among Icelandic students and scholars, which would have profound impact on Icelandic political, social and intellectual development. In 1828 and 1832 these Icelandic intellectual circles would voice the first calls for building tertiary educational capacity in Iceland, in order to supply for the necessary highly skilled and locally relevant human capital in theology, philosophy, medicine, natural history, economics and commerce for local socio-economic development. These early voices called for adding higher education offerings to the secondary school offerings of the old Skálholt school (Jónsson 1961; Háskóli Islands 2014). It was a debate predicting much later debates throughout the Arctic about building higher education capacity in northern communities.

The development of Icelandic higher education capacity is closely intertwined with state-building and independence politics. The Icelandic Althingi [Parliament] was reconstituted as a consultative assembly of the Danish King in 1845, and the School of Theology was created in Reykjavik in 1847 as a public administration capacity building initiative. In 1874, the Althingi gained legislative power over Icelandic affairs, and in 1876 the School of Medicine was created in Reykjavik to address recruitment problems and create locally relevant knowledge. In 1904, Iceland gained executive Home Rule, and in 1908 the School of Law was established in Reykjavik in light of the key role of building domestic law on the road to statehood. In 1911, the University of Iceland was founded, combining these schools and adding humanities with a clear purpose of supporting Icelandic state-building and independence aspirations. In 1918, Iceland gained sovereignty in a personal union with Denmark. In 1940, the University of Iceland inaugurated the main building of its future campus, which together with the neighbouring National Museum from 1950 (the National Museum was founded in 1863 as a nation-building institution) are key architectural manifestations of statehood and the republic declared in 1944. The University of Iceland has since grown by leaps and bounds to an about 14,000 students-strong research university, which is supplemented by the University of Akureyri (1987) with the satellite campus University Centre of the West Fjords in Ísafjörður (2005), the private Reykjavik University (1998), Bifröst University (1988), Hólar University College (2003) and the Agricultural University of Iceland (1889/1947). These institutions have deep roots in older schools. What should be noted about these universities, is that they are all founded and overwhelmingly staffed by Icelanders with graduate credentials from leading universities of North 
America, Europe and various other parts of the world (Jónsson 1961; Háskóli Islands 2014).

\subsubsection{The role of brain circulation in the development of Icelandic hydro- and geothermal power}

The renewable energy sector is the clearest example of how strong human capital has allowed Iceland to benefit from natural resources. Strong local human capital and the interaction with knowledge abroad, are leading throughout the history of Icelandic hydro and geothermal power. In the late 1800s, the world was gripped by the prospects of hydropower as an important resource fuelling the energy-intensive hightech industry of the day, namely nitrogen-based fertilizer. Iceland was keenly aware of these developments and a heated debate raged on the possibility of modernizing and diversifying the Icelandic economy, based on combining Icelandic hydropower resources, foreign capital and technology. Three key Icelanders serve to illustrate the importance of human capital and "brain circulation": Frímann B. Arngrímsson (1855-1936) was an Icelandic emigrant to North America, who had studied science at the University of Manitoba. He saw the potential of combining Icelandic energy resources and the technology of the day, and was its first advocate in Iceland, although in vain. Einar Benediktsson (1864-1940) was a prominent politician, poet and lawyer, trained at the University of Copenhagen. It should be noticed that he was a very active entrepreneur who founded hydropower investment companies with foreign capital. However, in 1904 it was master carpenter Jóhannes Reykdal (1874-1946) from Hafnarfjörður, who made the first small hydro electrical power plant in Iceland, after having spent time with his sister in Norway, a pioneering country in hydro electrical technology at that time (Ísleifsson 2007; Jónsson 2005; Karlsdóttir 2010; Kristjánsson 1997; Sigurðsson 2002; pórðarson 2004).

The early dreams of industrializing Iceland through hydropower, foreign capital and technology did not materialize for domestic, international political and financial reasons. Instead Iceland was electrified from the bottom-up with local installations. However, throughout this time, Icelandic engineering authorities did surveying work of the hydropower resources and from the late 1940s the National Director of Electricity guided large-scale geological and glaciological studies for hydropower development. Here it must be emphasized that this work was done by Icelanders, often as graduate students at or postgraduates from foreign universities working with foreign supervisors and colleagues, in collaboration with Harza Engineering International of the USA (Ísleifsson 2007; Jónsson 2005; Karlsdóttir 2010; Kristjánsson 1997; Sigurðsson 2002; pórðarson 2004). 
The Conservative-Social Democratic "Restoration" government of 1959-1971 (Viðreisnarstjórn) sought to internationalize and modernize the Icelandic economy. A key element was attracting the international energy-intensive industry, which was now the aluminium industry. In the 1960s, the Icelandic government secured funding from the World Bank and a power sales agreement with Alusuisse to build the Búrfell power station (the first large-scale hydro power station), powering the aluminium smelter at Straumsvík, which opened in 1969. What should be noticed here is that Harza Engineering International designed this first large-scale power plan, while Icelandic workers built it. Icelanders carried out much of the science, planning, law and financial negotiations. In the successive decades (1970s, 1980s and 1990s) a number of largescale hydro power plants were built in Iceland. These power plants were to an ever increasing and eventually full extent designed by Icelandic engineering companies, and built by Icelandic contractors. Finally, in the 2000s the enormous Fljótsdal/Kárahnjúkar power plant was designed again by Icelandic-international engineering companies, while the workers were now Portuguese and Chinese. So Iceland had come full circle from Icelandic workers building for American engineers to Chinese workers building for Icelandic engineers (Jónsson 2005; Karlsdóttir 2010; Pálsdóttir 2005; Sigurðsson 2002). This development could only be realized based on the strong Icelandic human capital basis, which seems to be built on a thousand-year-long tradition of a strong domestic primary, secondary and vocational (and recent tertiary) educational tradition coupled with successful "brain circulation".

Knowledge-based energy work has also become an important part of Iceland's international and transnational relations with the outside world. Exploring and surveying these resources has linked Icelandic and foreign universities and scientists since far back in the 1900s. Later, the Icelandic (engineering) companies, which have developed around hydro- and geothermal energy, have turned to market their knowledge and know-how internationally. This international work is often linked to Iceland's use of its hydro- and especially geothermal energy knowledge in its development work with developing countries that hold geothermal potential. Here the United Nations University Geothermal Training Programme (UNU GTP) must be emphasized. The UNU GTP is hosted by the National Energy Authority of Iceland. Since 1979 it has run a geothermal training program, which had trained 525 professionals from 53 countries in geothermal energy by 2012 (Friðleifsson, Svanbjörnsson \& Thorsteinsson 1984; personal communication). 


\subsubsection{Challenges in present-day Iceland}

Today, Iceland is in a way threatened by its own human capital success. Especially graduate study opportunities have expanded exponentially at the University of Iceland during the past 15 years. Earlier, young Icelanders could receive an excellent undergraduate degree in a wide range of topics from the University of Iceland, but where usually forced to go abroad for graduate studies. Faced with this choice, young Icelanders often chose international top-universities for their graduate study. This fed the highly fortuitous "brain circulation": supplying Icelandic academia, government and business with human capital with an excellent international background. However, going abroad for years of graduate studies comes with a steep economic and personal price. Today, young Icelanders often have the opportunity to stay at home for their graduate studies. If this leads to a slowdown of the "brain circulation" and internal recruiting practices related to especially academia, it will have very negative effects on Icelandic human capital. Iceland must ensure that domestic graduate studies are for those without the option of going abroad and foreign students, while the flow of Icelandic talent to and from the world's top universities does not slow down.

\subsection{Evolution of human capital and knowledge institutions in the Faroe Islands}

The modernisation of the Faroese society has largely depended on the expansion of commercial fishing in the North Atlantic region, helping it to transform from an agricultural peasant society to a market based economy successfully integrated into the world economy, creating an extreme dependency on domestic resources. The exploitation of marine resources has therefore played a dominant role in the social, political and economic life on the islands for over a century and still does (Justinussen 1999; Mørkøre 1991; OECD 2011). However, for almost 15 years, oil and gas exploration has taken place in the Faroese waters. So far, no economically viable reserves have been found, yet the Faroe Islands have still benefitted from these activities by creating a thriving knowledge-based economy related to the offshore energy sector. This offshore sector is now operating not just in the Faroes, but also worldwide. The important point is that this new energy sector is not competitive because of domestic natural resources, because none have been found yet. It is competitive because of the knowledge and expertise that has been developed since exploration began, thus breaking with the previous development path. In this section we shall look at the role of knowledge institutions in this development.

The Faroe Islands has a centuries-old tradition of regionally important knowledgebuilding institutions that contributed to the level of human capital apparent today. 
Faroese formal academic education dates back at least as far as to the priest college in Kirkjubø that educated King Sverri of Norway in the 1200s (Debes 2000; Young 1982). After the Reformation, this centre of learning was closed down, and a Latin school was established in Tórshavn. It was a tiny school, steeped in poverty, and almost eradicated by small pox in 1709, but a school with far reaching consequences for the development of the entire Faroese society, and beyond (Debes 2000). It is possible to divide the evolution of modern Faroese academic institutions into four distinct phases, beginning with the Latin school.

\subsubsection{The historical evolution of Faroese academic institutions}

The first phase emerges with the creation of the Latin school in the 1500s. The main purpose of this school was to recruit and train candidates for the clergy. Young boys were educated and prepared for later university studies in Copenhagen (Denmark) or Bergen (Norway), where they could become educated as priests. However, the school produced an excess of 'graduates', and only a small fraction of them left the country for further studies. The majority went back home to their villages, where they taught others to read and write. Many of these candidates became Sheriffs (Síðslumaður), Law Men (Løgmaður), Law-officers (Løgrættarmenn), administrators, and others engaged in trade. Thus the unintended consequence of the Latin school was a society wide education of the people and the creation of a Faroese elite (Debes 2000; Hentze 2000) with direct ties, through classmates, abroad, creating a domestic and international "brain circulation".

The second phase occurred during the social transformation from an agricultural to a fishery society in the second half of the 1800s. The Latin school had closed down and new educational demands had emerged as commercial fishery continued to develop. By the end of the 19th century, compulsory public education was introduced, and a teacher college was established (Holm 1970). Even the remotest villages were guaranteed education through a travelling teacher system (Petersen 1994). This was a huge step forward and created the basis for further education in the professional schools that followed.

The third phase begins with the establishment of a Faroese scientific society (Societas Scientarium Færoensis) in 1952. The society started a scientific journal in Faroese and organised a regular public lecture series (Gaini 2002). In 1965, the University of the Faroe Islands was established. A modern Faroese University was now a reality. A driving motivation behind this initiative was the idea that the university should contribute to cultural nation-building (Marnersdóttir 2003), especially in light of concerns that national 
identity was being eroded. A key element in this process was language. The main emphasis was therefore to develop a Faroese dictionary, and to collect and document Faroese language usage and traditions (Joensen 1988). The first academic employed was a professor in linguistics. In this period the university offered BA programmes in Faroese and history.

The fourth phase begins around the turn of the 21st century. The language battle was over and Faroese was established as a national language taught in all schools from primary to university level education. Today, the Faroese scientific journal, Fróðskaparrit, is over 50 years old, and Wikipedia has over 10,000 articles in Faroese (Jacobsen 2014). In this phase, the purpose of the University is not primarily cultural nation-building anymore, but also to be a major driver in the economic development of the society (Fróðskaparsetur Føroya 2014). Having good quality higher education available at a national level has been a major advantage for building up human capital and supports the development of a knowledge-based economy, which the Faroe Islands experiences today.

\subsubsection{The university in the knowledge economy}

Today it is recognized that research and development play a major role in the emerging Faroese knowledge economy (MTI 2005; Vinnumálaráðið 2013). Two major institutional and technological changes took place in this phase, which have made this transition possible.

First, the rapid innovation and spread of information technology and the Internet, which has revolutionised the world and given rise to completely new kinds of industries, and new ways to organise and conduct business. This technology has been particularly important for the Faroe Islands, since it has minimized the impact of distance and remoteness and not least, has provided access to information and research databases anywhere in the world. This technological innovation has made a new kind of "brain circulation" possible that is less tied to geography, and opens up completely new development paths for a remote microstate such as the Faroe Islands.

Second, since oil and gas exploration commenced in Faroese waters, licence holders have been obliged to pay a 'tax' to the Competence Development Fund. The purpose of the Fund is to promote education and research programmes that can increase the human capital in the country. The Fund has financed several large-scale research programmes conducted at the University of the Faroe Islands as well as several PhD projects.

Together these developments have fundamentally changed the playing field for knowledge institutions, giving rise to many new and exciting educational and research 
projects within the energy and other sectors. Over the last 15 years substantial expertise has built up in several fields, making it possible for the University to offer Bachelor degrees in the sciences, humanities, and social sciences, as well as Masters in Faroese Language and Law. Doctoral programmes are also offered on an individual basis. The most recent addition to the professorships at the University occurred in 2014, when Statoil, one of the major players in oil exploration in Faroese waters, funded a full professorship in energy engineering.

\subsubsection{The university and the public sector}

An important feature of the University lies in its close network and informal ties to researchers in other public institutions that conduct research related to their respective fields. For example, the Faroese Petroleum Administration (Jarðfeingi) has geologists, physicists, and PhD students engaged in research. These researchers frequently appear as guest lecturers at the University, helping to supplement the faculty's knowledge base. Similarly, the following public sector institutions all conduct research as a part of their duties and supply the University with guest lecturers on an informal basis:

- Føroya Landsbókasavn (Faroese National Library)

- Føroya Fornminnissavn (Faroese Archaeological Museum)

- Nátúrugripasavnið (Natural History Museum)

- Biofar (Kaldbak Marine Bio Lab)

- Heilsufrøðiliga Starvsstovan (Environmental Agency)

- Havstovan (Faroese Marine Research Institute)

- Landsskjalasavnið (National Archives)

- Jarðfeingi (Faroese Oil Administration)

- Fiskaaling (Aquaculture)

- Landssjúkrahúsið (National Hospital of the Faroe Islands)

- iNova (Research Park)

Since the inception of the University it has been recognized that, should the University have a chance to survive and flourish, it would need to draw on all available resources. On its own, the University does not have enough manpower and resources to cover all areas necessary for offering relevant research-based educational programmes. However, these partnerships have never been formalised in form of a contract between the University and the public sector, except for a recent agreement of understanding between the University and the Landsskjúkrahúsið (National Hospital of the Faroe Islands), and the recently created iNova (Research Park). Nevertheless, it has been a de facto practice over the years that employees in public institutions who are engaged 
in research are allowed to give lectures at the University during their usual working hours (Joensen 1988).

Though these kinds of networks are by no means exceptional, they are nevertheless exceptionally important for the University, since they provide vital input into the teaching and make it possible to offer a research-based education that extends far beyond the research conducted by the 73 academics currently employed at the University. The effect of this informal organisation is twofold. On the one hand these informal networks thus compensate for the limited scope for specialisation in a microstate, and make it possible to offer research-based teaching in a much wider range of areas than otherwise would have been possible. On the other hand they also integrate a much wider network of people in the process of research and teaching at university level and thus populate the critical mass necessary for an emerging knowledge economy.

\subsubsection{Current challenges}

One of the challenges in the development of human capital, which is so essential for knowledge based economy, is the integration of education and knowledge institutions in local society. Without a general society-wide integration of knowledge institutions, it is difficult to build up a critical mass for a knowledge-based economy. Education for a select few will not build a knowledge economy for the masses. In the Faroese case there has been a gradual long-term evolution of academic institutions and learning, which have embedded knowledge institutions into the wider society. However, the growth of education has outstripped the physical infrastructure and now knowledge institutes are widely dispersed. The University itself is scattered around the city in several different buildings. This sprawling decentralised development path is currently being counterbalanced by an attempt to centralise and integrate the many differentiated parts into larger units. The trend to formalise the 50-year-old tradition of informal cooperation between the University and other public institutions (Weihe et al. 2005), can be seen as a part of this process.

For years there have been talks about a new modern university campus in Tórshavn. However, these plans are still on the drawing board. The major challenge in the process will be to integrate the many different institutions into a cohesive unit, while at the same time living up to the nation's proud, historical educational roots, and ensuring societywide backing for a national centre of learning. A more pressing challenge is the exodus of young people travelling abroad for education and not coming back. Here the new campus might curb this emigration, however, the small population sets an inescapable limit on the range of educational opportunities - even in the best circumstances. 


\subsection{Greenland}

Like many other Arctic economies, Greenland's economy is mainly dependent on fisheries and the public sector. At the same time that Greenland is the largest island in the world, it has only 56,000 inhabitants, which live scattered along the cost. As part of the strategy to diversify its economy, Greenland is looking to develop an energy sector based on oil and gas exploitation (Naalakkersuisut 2014b). Until now, 14 exploration wells have been drilled (BMP n.d.), of which five have been drilled in the 1970s, one in 2000 and another eight in 2010 and 2011. In order to maximise the local benefits of these offshore activities, Greenland has implemented a number of tools in its regulatory framework. Education is seen as a central element and much effort is made to prepare and qualify society for participation in these industrial activities. Unlike the cases of Iceland and the Faroe Islands, Greenland has a much shorter history of higher education, building up human capital and a knowledge-based economy. Important steps towards a knowledge-based economy have been made over the past century, however education and building up human capital remains a focal point for the future.

The vast distances, the limited infrastructure and the small size of the population create challenges as well. Transforming the economy from one that is primarily focused on fisheries and the public sector, into a globally competitive knowledge-based economy with relevance for the private sector is not easy. In a country where costs are high and education levels are currently low (Naalakkersuisut 2014a), a lot needs to happen before a competitive knowledge-based economy will become reality. The School of Minerals and Petroleum (Råstofskolen) plays a central role in this context and is expanding its network (Christensen 2012; Troelsen 2012). The challenge for Greenland will be to establish a critical mass of skilled labour and to deal with the challenge of foreign labour influx if oil and gas activities really take off.

\subsubsection{The development of Greenlandic knowledge institutes and education}

Greenland is part of the Kingdom of Denmark, but has gained Home Rule since 1979 (Goldback \& Winther-Jensen 1988) and it was granted Self Rule in 2009 (Hansen 2014). Up until 1979 Denmark was initiating the policies and reformations of the educational system, but since 1979 this became a major responsibility of the Greenlandic government. Changing the primary language from Danish into Greenlandic was one of the most important decisions taken just after gaining Home Rule in 1979. Since then the teaching system has been more and more tailored towards the Greenlandic situation (Goldback \& Winther-Jensen 1988). 
In 1983 the Inuit Institute was founded in Nuuk as a study centre for Greenlandic literature, history and grammar (Olsen 2013). Later, in 1987, the Inuit Institute became the University of Greenland, Ilisimatusarfik (www.lisimatursarfik.gl). The University was established to provide higher education in Greenland itself, instead of in Denmark. Like its predecessor, the University of Greenland has remained focused on social sciences, culture and history until to date. It has contributed to nation-building and Greenland's cultural identity (European Commission 2013). Over time, the university has maintained and established cooperation with various foreign universities and is also part of the University of the Arctic (www.uni.gl).

Since 2004 the Greenlandic government has determined that education is a top priority (Naalakkersuisut 2012). This is reflected in the increased government budget and attention to education and training as of that year (European Commission 2007). In 2006 it became an aim of the Greenlandic government to increase the share of higher educated people in its workforce (European Commission 2007), supported by an overall education strategy up until 2020 in the "Greenland Education Program". The first phase (until 2013) of the Greenland Education Program aims at vocational training and making sure people acquire the right skills and qualifications for jobs above an unskilled level. The second phase (until 2020) focuses on the provision and increase of higher education to build up a critical mass of human capital locally. The European Union has identified education as a main domain for cooperation with Greenland.

\subsubsection{Creating human capital and a knowledge-based economy}

In a world economy that becomes increasingly globalised it is important to create sufficiently large human capital that is qualified, flexible and competitive in order for Greenland to make economic progress and establish a knowledge-based economy. Only by making economic progress can Greenland pursue its long term goal of becoming financially independent from Denmark. In order to become financially independent it does not only need to diversify its economy, but also localise the benefits of the (new) economic activities by participation of Greenlanders (Naalakkersuisut 2014a). Participation can only take place if people have the right skills and qualifications.

Creating a critical mass of human capital for a knowledge-based economy is challenging. In 2006 only one third of the potential workforce (15-62) had acquired an educational level that would qualify them for jobs above unskilled level (European Commission 2007). However, the total number of graduates from post-primary education in Greenland has increased by $64 \%$ during the first phase of the "Greenland Education Program" (www. nanoq.gl) and is promising. As dropout rates have remained roughly the same, it can be 
concluded that more people have obtained post-primary education. This forms a positive basis for phase two, to increase the amount of people that have received higher education and thereby can contribute to the development of a knowledge-based economy.

Most of the higher education institutes are located in Nuuk, of which the University of Greenland is currently the largest institute of higher education in Greenland. The enrolment of students to this university has risen steadily over time (European Commission 2013), however the curriculum of the university remains limited. It includes, amongst other, cultural \& social sciences, theology and language, but is missing (natural) science as a subject. The lack of (natural) science in the University's curriculum should not necessarily have to do with the country's small population size, since also the University of the Faroese Islands has a small population and has got science in its curriculum (European Commission 2013). Science is crucial in relation to economic progress and industrial activities, since it will educate highly-skilled (natural) scientist, which could well be needed by the currently developing natural resource activities. Developing this type of knowledge locally remains a challenge for Greenland, but partnerships like the ones existing in the Faroe Islands could be a solution.

Next to the University there are also a number of other institutes for higher education in Greenland, such as the Building School, Sanaartornermik llinniarfik, in Sisimiut. This institute includes a School of Minerals and Petroleum (Råstofskolen) and a Centre for Arctic Technology (ARTEK), which all have strong links with the Technical University of Denmark (DTU). It is the ambition of these institutes to become the technical powerhouse of Greenland. The School of Minerals and Petroleum in Sisimiut has been established in 2010 (www.sanilin.gl) and illustrates the need to build practical capacity and knowledge in the field of mineral resources by the Greenland society. The School provides training on a practical level and aims at providing Greenlanders with the right set of skills and qualifications to be able to apply for jobs in these industries. The School of Minerals and Petroleum cooperates closely with the Colorado School of Mines (United States), Ole Vig Upper Secondary School (Norway) and the Northern Centre for Advanced Technology in Sudbury (Canada) (Bell 2011). In this way "brain circulation" is being initiated and developed, supporting human capital building in Greenland.

\subsubsection{Future Challenges and Opportunities}

It is likely that the level of industrial activities related to natural resource and energy development is going to increase in the future (Naalakkersuisut 2014b). In recent years these activities have increased steadily, which are likely to continue now that a construction permit has been granted to the London Mining project on iron ore and 
the ban on uranium mining has been lifted, freeing the way for other large mining projects (RT 2013). In the meantime, the oil and gas industry is continuing its exploration activities and is likely to continue doing so in the future (Naalakkersuisut 2014b). However, when these activities will take place exactly is not certain, and currently the industry tends to take longer before large investments in the Arctic region are decided upon. Therefore one of the challenges for Greenland will be to educate its workforce at the right time with the right skills.

In general one can state that the expected increased industrial activities form an opportunity for Greenland to diversify its economy and maximise the local benefits. However, both the mining and the oil and gas industries require skilled labour with the right qualifications to work on their projects. In order for Greenland to maximise its local benefits of these industries, the main challenge will be to increase the level of (highly) skilled workforce that has acquired the right set of skills for these industries. A recent study however has indicated that the shortage of a highly educated workforce will continue to grow in the near future and last until at least 2025 (European Commission 2013). Various initiatives, mainly revolving around the Building School, School of Minerals and Petroleum and Centre for Arctic Technology in Sisimiut, have been taken to increase the level of skilled workers for these industries so that the Greenlandic society will be ready to take the employment opportunities when they arrive. Without having a critical mass of human capital in place, Greenland will not be able to maximise the local benefits and successfully create a knowledge-based economy. It will run the risk of foreign labour coming into the country to perform the jobs. The University of Greenland, which is currently focussed on social, historical and cultural sciences, can facilitate the creation of a highly skilled work force by including Science in its curriculum. It is expected that graduates from this subject will face no difficulties in finding a job (European Commission 2013). Lagging behind in capacity-building compared to the pace of industrial development could also prevent expertise and knowledge from becoming an export product in the future. This can become a serious strain on the process of becoming a self-sustaining economy.

\subsection{Conclusion}

The three cases that were studied more closely in this chapter illustrate the importance of local knowledge institutions and human capital building. The development of an internationally renowned knowledge-based energy sector based on hydro- and geothermal power in Iceland shows how local knowledge institutes, developed over centuries, were of crucial importance in creating human capital, which in turn enabled Iceland to maximise the local benefits. Century long "brain circulation", powered by 
Icelanders studying at top institutes abroad and returning home with the knowledge they gained, appears to be crucial. The development of this knowledge-based energy sector has been a lengthy process in which foreign (engineering) companies took the lead. Gradually Icelandic companies started to take over the design works, until in the 2000s the point was reached where the design was made by Icelandic companies and the actual building was performed by Chinese labour. This case suggests a strong historic path dependency, by centuries of human capital creation leading to a fullfledged knowledge-based economy based on natural resources in the 21st century. One of the main future challenges for Iceland will be to maintain a diversified portfolio of domestic educational and research programs, while at the same time maintaining a strong tradition of "brain circulation" with international top-universities.

The Faroe Islands illustrate that a knowledge-based energy sector can be created even though no economically viable oil and gas resources are found and with a less extensive history of human capital building and "brain circulation". Over the past 100 years the main steps have been taken to create the human capital base it has today. In recent years revenues from exploration activities have been used to support knowledge institutes and increase their capacity. In turn, these institutes supply the economic sectors with human capital that remains closely linked to these institutes via guest lectures and research opportunities. Technological innovations and the Internet have reduced the impact of remoteness and distance, particularly important for the Faroe Islands, and have thereby increased the opportunities for "brain circulation" with the rest of the world. The main challenge for the Faroe Islands in the future will therefore be to develop a new University campus in Tórshavn with the necessary facilities to attract more students and researchers to the country.

Greenland stands at the beginning of creating a knowledge-based economy. Human capital is an important factor, and the Icelandic and Faroese examples show that even a small state can create sufficient human capital to support a knowledge-based economy. This is particularly important if it wants to localise the benefits from a future energy sector as much as possible. The example of the Faroe Islands is most promising to Greenland, since it illustrates that it is not mandatory to have a century-long history in large scale human capital building and "brain circulation". Breaking with an economy based on primarily natural resources can be achieved, provided that emphasis is placed on building strong knowledge institutes and creating a critical mass of human capital locally. Education and the creation of human capital are defined as one of the top priorities and receive a lot of attention in Greenland. Institutes such as the School of Minerals and Petroleum have been created to support knowledge development related 
to the oil and gas sector. "Brain circulation" and exchange of experience takes mainly place with Denmark, Norway and North America (USA and Canada). The main challenge for Greenland will be to establish a critical mass of skilled labour and to deal with the risk of foreign labour influx if oil and gas activities really take off. 


\section{CHAPTER}

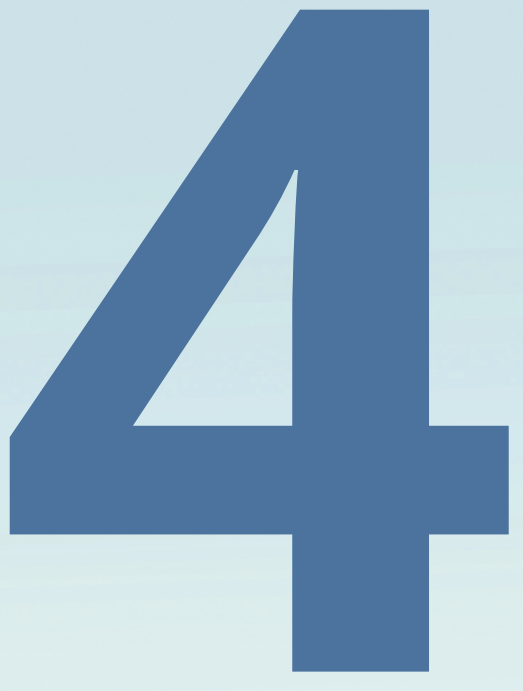




\title{
Human capital development and a social license to operate: Examples from Arctic energy development in the Faroe Islands, Iceland and Greenland
}

\author{
C.C.A. Smits \\ J.C.S. Justinussen \\ R.G. Bertelsen
}




\section{ABSTRACT}

The Arctic region is opening up due to climate change, causing sea ice extend and snow cover to decrease. Over the past decade economic activities, including fisheries, shipping, oil \& gas, mining and tourism have increased throughout the region. Especially the oil and gas activities are subject to public debate and attract a lot of (international) attention. Obtaining and maintaining the support of local stakeholders are thus of major importance if governments and companies want to see these activities continue and contribute meaningfully to the resilience of Arctic societies. The concept of a Social License to Operate addresses the acceptance of an activity by local communities and other stakeholders. This manuscript explores the role human capital development in obtaining and maintaining a Social License to Operate in Iceland, the Faroe Islands and Greenland. As trust and legitimacy are the two fundamental principles on which a Social License to Operate is based, these are being examined more closely. On the basis of three case studies, this chapter explores how human capital development can contribute to the legitimacy of Arctic energy development and trust building between various stakeholders. 


\subsection{INTRODUCTION}

The Arctic region is opening up due to climate change, causing sea ice extend and snow cover to decrease (ACIA 2004). The effects of cli-mate change are most profoundly felt in this part of the world, also called "the canary in the coal mine" (NASA 2013; The Economist 2004). Over the past decade economic activities, including fisheries, shipping, oil \& gas, mining and tourism have increased throughout the region. It is estimated that the resources to be found in this region could amount up to 90 billion BOE and 1.670 trillion cubic feet of natural gas, which are technically recoverable (USGS 2008a). This equals approximately 22\% of the world's undiscovered technically recoverable oil and gas resources. With oil and gas, mining and shipping as the largest drivers, the Arctic could potentially attract over $\$ 100$ billion of investments (Lloyds 2012). However, these economic estimates were made before the drop in oil- and other resource prices, making these them currently questionable on the near- to midterm.

The increase of Arctic oil and gas activities between 2008 and 2014 attracted a lot of attention and sparked public and political discussions on national, regional and international levels. The balance between economic development and environmental preservation is the main subject of these discussions. Already under pressure due to climate change, the oil and gas activities and the associated risks of an oil spill and pollution are seen as another threat to the sensitive Arctic ecosystem. At the same time, the (local) public debate is also focussed on the balance between local benefits and the risks associated with these activities. Since the region's own market for oil and gas is too small, the resources extracted in this region will be mainly transported to other parts of the world. How will the Arctic societies then benefit from these activities? And do these benefits compensate for the risks? As most of the resources are expected to be found in the EEZ of the Arctic countries, the decision to and the way in which these activities are developed lies primarily in their jurisdiction. Also, there are already a number of mechanisms to ensure the maximisation of local benefits that are incorporated in their regulatory frameworks. However, the mechanisms currently incorporated into the legislation do not necessarily meet the expectations of societies and other stakeholders. As a consequence public debate or opposition can arise against a company's planned activities, even though it fully complies with all the rules and regulations set in a specific country.

From a company's perspective, (negative) public debate and opposition is an undesired situation which can damage its reputation and become a costly affair. However, public debate and opposition is part of a democratic society and should therefore be 
respected. The trend is that the time for oil and gas projects to come online is increasing and has almost doubled in the past decade, making projects significantly more costly (Franks et al. 2014). Remoteness and scale play a role in this increasing trend, but part of it can also be explained by the increase of non-technical risks including public unrest. A concept that is increasingly used to address these non-technical risks is a social license to operate, which is aiming at obtaining and maintaining the acceptance and/ or approval of an activity by local and other stakeholders. Paying attention to these social aspects of an activity is extremely important, especially in the Arctic region where deadlines are tight and the window of opportunity in the ice-free summer is limited. Missing any deadline here, would imply major delays and additional costs. Having not only the support of a national government, but also of the society at large is therefore crucial for companies having the ambition to operate in the Arctic. Moreover, given the long term timeframe these resources generally take to be developed it is important to build a sustainable relationship based on trust and mutual understanding. Public acceptance cannot simply be bought, tricked or fooled.

This chapter will explore the concept of a social license to operate of energy development, including hydropower and geothermal energy and offshore oil and gas, in the Faroe Islands, Iceland and Greenland. Although the cases have considerable differences, there are also a number of similarities that make them interesting for comparison in this chapter: All three are located in the North-Atlantic part of the Arctic, were or are still part of the Kingdom of Denmark and have small societies ranging between 50,000 and 350,000 inhabitants. We chose three case studies because a comparison could generate lessons learned and conclusions applicable to a wider scale, compared to focussing on one case study only. To ensure the quality of the gathered data one has to use data triangulation. By choosing three different methods of data collection itis ensured that findings or data are confirmed or disconfirmed in multiple ways (Yin 2009; Vennix 2006]. This research is based on document analysis, participative observation and interviews. A total of eight interviews were conducted with representatives of the industry $(n=3)$ and governments $(n=5)$. The authors of this chapter have a background in science and the private sector.

The first section will elaborate on the concept of a social license to operate. Thereafter the case studies of a social license to operate for oil and gas development in Iceland, the Faroe Islands and Greenland will be presented. In these case studies we will look at how the development of human capital stimulates the institutional and business sector strength of that specific country. Both the short and long term opportunities related to human capital development in relation to a social license to operate will be 
discussed. Finally, the findings of these three case studies will be discussed together, after which this chapter will end with some concluding remarks.

\subsection{A social license to operate}

\subsubsection{The emergence of the concept of a social license to operate}

The concept of a social license to operate emerged in the late 1990s, when it was first used by the Canadian mining executive Jim Cooney in a meeting with World Bank officials (Boutilier 2014). Since then, the term is increasingly used by business people, academia, consultants and media, and is still on the rise. Most research has focused on the application of this concept in the extractive industries, but is also used to an increasing extend in other sectors such as forestry, agriculture, renewable energy generation and pulp \& paper manufacturing (Hall et al. 2015; Moffat \& Zhang 2014). Until now the social license to operate concept has been predominantly considered from an industry point of view, while its application also makes it an interesting concept to look at from a government and civil society perspective (Hall et al. 2015; Morrison 2014).

Cross-sector research has indicated that the concept is differently understood among various (energy) sectors, and that its application changes in every context (Hall et al. 2015). Elements that are commonly present in many of the definitions are (ongoing) acceptance, approval, local communities, stakeholders and industry's activities (Hall et al. 2015; Moffat \& Zhang 2014; Thomson \& Boutilier 2011; World Bank 2003b). Generally, in the literature a Social License is seen as an ongoing process that runs through the entire lifecycle of a project. It can be granted at one point in time but can be withdrawn again as well at another point in time. Often the withdrawal of a social license to operate for an activity happens much quicker than granting one. A withdrawal or lack of a social license to operate might not only affect the activity itself, but also has the potential to influence the reputation of a company and even an entire industry. The dynamic nature of a social license to operate requires companies to adapt and respond to changes if they want to secure and maintain the public acceptance of their activities (Prno 2013). Based on the aforementioned aspects, this chapter refers to a social license to operate as "the ongoing acceptance and approval of the activities of an industry by local communities and other stakeholders". This definition reflects the dynamic nature of a social license to operate and the fact that there are more than only local communities as stakeholders playing a role in this process.

One of the most challenging aspects of a social license to operate is the difficulty of measuring whether or not it has been granted. This also raises the question of who is 
granting the social license to operate. There will always be stakeholders opposing an activity, if only for fundamental beliefs or Not-In-My-Back-Yard (NIMBY) phenomena. The lack of a social license to operate is mostly measured based on the presence of protest and opposing voices in the public domain (Owen \& Kemp 2013; Prno \& Slocombe 2012). If there is protest against an activity, it is challenging to determine if this opposition represents the majority of stakeholders and the common interest, or not. One could argue that the loudest voice automatically 'wins', which goes against the democratic principles on which many societies are based. When an activity is in the interest of all other stakeholders, it does not necessarily mean that the one stakeholder opposing it holds a veto (Morrison 2014). Moreover activities may continue anyway when they are of regional or national importance (Yates \& Horvath 2013). On the other hand, measuring the existence of a social license to operate is difficult for a number of reasons too, as it is based on the assumption that a lack of objection means a social license to operate is present (Yates \& Horvath 2013). The lack of opposition or conflict in the public domain does not necessarily mean that stakeholders support or even accept the activity. The absence of publicly known objections and conflict may for example be caused by stakeholders disengaging from the project, cultural habits and customs or resistance voiced in less tangible/overt forms (Owen \& Kemp 2013). Thomson and Boutilier (2011) distinguish four levels of social license to operate: the lowest being the Social License withheld or withdrawn, then the mere acceptance of an activity, the level of approval when credibility is established and the level of psycho-logical identification when trust is established.

\subsubsection{How to obtain and maintain a social license to operate?}

The previous section illustrated that having a social license to operate is essential for companies wanting to successfully implement their activities against budget and time, but how does one obtain a social license to operate? And is there only one social license to operate? Thomson and Boutilier (2011) have developed a framework in which the social license to operate is seen to exist on a continuum: the lowest end on the continuum is if a social license to operate is withdrawn or withheld. Other stages at this continuum range from acceptance and approval to psychological identification with an activity. A company cannot influence a social license to operate directly, nor can it unilaterally declare to possess one (Morrison 2014). A social license to operate is heavily reliant on trust and legitimacy, two aspects that are hard to measure and influence directly. The immeasurability and thus the inability to directly manage the concept itself, makes it difficult for companies to use this concept in existing management systems. However, via the concepts of economic legitimacy, interactional trust, institutionalised 
trust and socio-political legitimacy companies and other organisations can work on obtaining and maintaining their social license to operate (Thomson \& Boutilier 2011).

One of the most fundamental parameters is the local benefits (IIED 2014; Prno 2013). An imbalance between local risks and benefits could impede local support. The level of local benefits influences the economic legitimacy of an activity, which can be said to be one of the four fundamental factors of a social license to operate (Thomson \& Boutilier 2011). The payment of royalties and taxes to a national government does no longer suffice in many cases. Therefore a project proponent needs to look at creating a local knowledge base and employment. However, hiring a certain percentage of local workforce and contracting local businesses are only sustainable when linked to the broader economy (Harvey \& Bice 2014). Only then it can create greater resilience among local communities.

A social license to operate is built on relationships in which meaningful participation and the quality, not quantity, of stake-holder contact play a key role (Moffat \& Zhang 2014; Prno 2013). By building up a relationship via high quality contact that is perceived as positive and pleasant, stakeholders are less likely to feel taken advantage of (Moffat \& Zhang 2014). "The perception that the company listens, responds, keeps promises, engages in mutual dialogue and exhibits reciprocity in its interactions" (Thomson \& Boutilier 2011) is the very definition of interactional trust. There are also different levels of trust: One can define trust in a person (i.e. personal trust), which strongly relates to the element of interactional trust as discussed in this section. Moreover, one can distinguish trust in an institution (i.e. institutionalised trust) which will be dis-cussed later in this section. Personal trust is based on reciprocity, and built on knowledge of the behaviour of one to another over time. Trust is a two-way process and involves multiple parties. Itis not something that can be declared to have obtained by a single actor. Trust can therefore be defined as a shared set of expectations between the actors involved (Zucker 1986). Essential in building trust between a company or industry and actors at a local level is the capacity of communities to meaningfully participate in the inter-action with a company. These relationship-building processes often take a lot of time to build and maintain (Prno 2013), potentially requiring too much capacity of small societies to be able to fully participate in it. Therefore investing in capacity building programmes for local societies does not only create a local workforce, but also enhances the capacity of a society to meaningfully engage with a company or industry. Local cluster development that includes businesses, knowledge institutes and government agencies offers the greatest opportunity for oil companies to build trust with local communities and other local stakeholders (Harvey \& Bice 2014). 
More difficult to reach is institutionalised trust, since this requires stakeholders to perceive that the relationships between their institutions and the company are based on mutual trust with respect for each other's interests (Thomson \& Boutilier 2011). Institutional trust resembles the trust of societies in systems and institutions (Giddens 1990; Zucker 1986; Luhmann 1979), which has led to our modern day society in which we trust the political and monetary systems. Important elements of institutional trust are openness, transparency, order and predictability (Giddens 1990). The interaction with representatives of a system can influence the people's perceptions on the reliability of a system (Giddens 1990). People are more likely to trust a representative or leader of an institution, than the institution itself (Morrison 2014). At the same time this makes an institution dependent on the reputation and behaviour of its representatives and leaders. If an institution wants to be judged more objectively, rather than on emotional and irrational aspects, it needs to invest in creating informed communities (Morrison 2014). When present, institutionalised trust often results in openly support for a specific activity or company. A social license to operate is also based on socio-political legitimacy, which relates to fairness, meeting expectations and contributing to the well-being of a region or country (Morrison 2014). Procedural fairness is also a strong predictor of trust, because if the procedures of a company are perceived to be fair, stakeholders will better accept or approve a project regardless of the outcome of the procedure (Moffat \& Zhang 2014).

Working on all of the four abovementioned aspects will enhance the levels of trust and legitimacy, which could result in sustainable relationships with (local) stakeholders and ultimately in ongoing approval for an activity. In the case studies that follow, the role of human capital development will be explored not merely from a company's perspective. Also governments want to explore for and potentially develop oil and gas resources. Therefore a wider perspective will be used to look at the institutional context, potential historical path dependencies and country-specific policy measures that are in place to stimulate human capital development related to offshore oil and gas development. The different development stages, in which the energy- and more specifically the oil and gas sector is currently in, make these three countries an interesting comparison.

\subsection{Iceland}

Around 1900 Iceland was an overseas autonomy of the Kingdom of Denmark and one of the poorest European societies. There was a strong political desire to expand political autonomy from Denmark and gain full independence, which was perceived as unrealistic by Danish political forces due to low socio-economic development in Iceland at that time. There was also a strong desire in Iceland to develop and diversify 
the economy away from its focus on agriculture and small-scale fishing (Nordal \& Kristinsson 1996). So it appears that there are parallels in the political and economic dreams of Iceland a century ago and later the Faroe Islands and today Greenland. Over time Iceland did achieve full independence and is today a highly developed country with a high level of human development (number 13 globally) (UNDP 2015). The interplay between human capital and natural resources has played an important part in enabling this development, and is very relevant for the Faroe Islands and Greenland in their aspirations for political independence and economic diversification (Bertelsen et al. 2015; Smits et al. 2015; Bertelsen \& Hansen 2015; Smits et al. 2014a).

Iceland thus offers a valuable case for discussing questions of legitimacy, local benefits and natural resources in very small North Atlantic Arctic societies, undergoing processes of political devolution. Iceland is a positive case that shows that a very small North Atlantic society through democratic governance and strong human capital can make legitimate decisions on natural resource use, and derive local benefits and sustainable development illustrated by the cases of geothermal and hydro power developments. The 19th century energy developments in Iceland have led to the development of large scale hydropower activities that could potentially influence the (local) environment and nearby societies. The successful implementation of hydropower and geothermal power generation has diversified the Icelandic economy and brought the society knowledge, welfare and eventually independence. By thoroughly analysing this case, a number of success factors relevant to other small scale societies, like the Faroe Islands and Greenland, can be distinguished. These success factors relate to local benefits, legitimacy and interaction between the various parties involved, making them interesting for contemporary discussion about the concept of a social license to operate. This section will end with a brief discussion of the recent oil and gas developments, the social license to operate discussion related to this and if the historical success factors could be of use in the $21^{\text {st }}$ Century.

\subsubsection{Icelandic hydropower development}

In the late 1800s there were many power intensive industries, such as for example nitrogen-based fertilizer plants. Hydropower could supply these industries with plenty of energy at low costs, and thus generated a lot of international attention at the time. Some Ice-landers, such as Frímann B. Árngrímsson (1855-1936), recognised the hydropower potential of Iceland and wanted to implement large scale hydropower activities backed by foreign investments. At the time it was the lawyer, politician and poet Einar Benediktsson (1864-1940) who raised international capital for these largescale projects in Iceland. However the timing of his efforts was unfortunate, as the 
early 1900s Icelandic political environment was one of an independence struggle from Denmark, which did not allow for foreign-owned utilisation of Icelandic hydropower resources. In 1907 his efforts were rejected by the Althingi in the Waterfall Law, which required Icelandic residence for owners of waterfall rights. Later, in 1973, then governor of the Icelandic Central Bank Dr Jóhannes Nordal would regret that Iceland had not used its hydropower potential in the early 1900s. This could have supplied Iceland with technological knowhow and infrastructure at an earlier stage (Nordal 1973).

Even though foreign-owned hydropower development did not generate the necessary social and political support at the start of the $19^{\text {th }}$ century, the hydropower potential was not left unused. Local Icelandic communities and individual farmers electrified towns, villages and farms on a smaller scale. Through ready-to-assemble kits and brochures from abroad, this foreign technology and knowledge was implemented by Icelanders at a local level. In the late 1950s the highly politicised economic system adverse to foreign investment, for example related to hydropower supporting aluminium-smelting projects, broke down and a Conservative-Social democratic Viðreisnarstjórn (Restoration Government) took office. This new government sought to diversify and internationalise the Icelandic economy, and large-scale hydropower development financed by foreign investors to support the aluminium-smelting industry was an important part of it. It secured World Bank funding for the development of the Búrfellsvirkjun hydropower station, which started operating in 1969 and would be repaid by selling power to the Straumsvík aluminium-smelter of Alusuisse of Switzerland. At the time the electricity sales agreement with Alusuisse was highly controversial concerning pricing of electricity to the foreign buyer compared to prices to Icelandic households, which has remained a contentious and complex question.

Where the Búrfellsvirkjun hydropower station was designed by Harza Engineering from Chicago, USA, and built by Icelandic workers, the situation changed and foreign technology and knowledge were transferred to Icelandic engineering companies from the 1970s through to the 2000s. Today, Iceland is renowned for its hydropower knowledge and technology, and exports it to the rest of the world. The strong (historic) connections of Iceland with foreign knowledge centres, the international exchange of knowledge, combined with strong primary, secondary, increasingly tertiary, and vocational education made the development of a locally controlled yet globally connected knowledge-based sector to a success. An important reason why this sector could be developed into a success and got a social license to operate of Icelandic society, even though it potentially has major environmental effects, was because of the high level of Icelandic involvement in the design, construction and operation of 
these plants and energy-consuming industries. The Icelandic political system has been able to adjudicate these trade-offs, which appear broadly legitimate within Icelandic society. However, this legitimacy has been questioned by foreign environmental NGOs during the development of the large hydropower station Kárahnjúkavirkjun, which was opened in 2009 .

\subsubsection{Icelandic geothermal energy development}

The development of geothermal energy in Iceland materialised earlier compared to the development of hydropower. It was ValtýrGuðmundsson (1860-1928), an Icelandic member of the Althingi at the time, who was interested in geothermal energy and wrote an influential article about geothermal heating in Idaho, USA (Guðmundsson 1910).From 1930 and onwards, Iceland developed an extensive geothermal infrastructure starting with the heating of the public primary school of Austurbæjarskólinn and the public swimming pool in Reykjavík. Today, all areas of Iceland where it is possible to obtain geothermal energy are heated by this hot water and steam technology. In regions where this is not possible, hydropower is used to generate electricity for heating. Geothermal energy was a signature Icelandic resource and technology, controlled and financed by Ice-landers who heated their homes and swimming pools that were the pride of the nation to foreign visitors. The geothermal revolution in Iceland was more indigenous than the hydropower and therefore much less controversial.

However, geothermal energy recently became more controversial with the increased size of the installations. The large installations also come with a greater environmental impact, including the increase of noise and smell. Future large scale geothermal installations will likely be used for electricity generation meant for the export, either by subsea power lines or power-intensive industries. It is thus no longer meant to heat the homes of Icelanders, making the benefits of geothermal energy generation less tangible for society while the local impacts increase. For this reason future geothermal energy could become as controversial as hydropower has long been. However, the likelihood of this controversy is mitigated by the strong Icelandic human capital involved in the development of geothermal energy. Icelandic companies, government and universities have built strong competences that are relevant on a global scale, especially now that the world is looking for options to generate renewable energy that substitutes fossil fuels and facilitates the energy transition to mitigate climate change (Jarðhitabók 2005; Friðleifsson et al. 1984) 


\subsubsection{The historical success factors in creating societal acceptance and legitimacy}

Iceland has managed to build a worldwide renowned hydropower and geothermal energy sector, which is controlled locally and based on the strong presence of Icelandic human capital. Especially related to the hydropower development the involvement of foreign investors was controversial for a long time. Iceland did not want to be controlled any longer by foreign decision makers, which resulted in the rejection of foreign investments during the first half of the 20th century. That is also the reason why the more Icelandic based geothermal energy development could take place on a larger scale at an earlier moment in time. Based on this case study one of the success factors for societal acceptance and legitimacy of implementing new energy activities is therefore the involvement of Icelanders in the design, construction and operation, thereby generating clear benefits at a local level.

However, to be able to participate and benefit from these new opportunities at a local level, people should have the right knowledge and skill set. Concerning geothermal energy a strong human capital base was already present in Iceland from the start, however related to large-scale hydropower this had to come from abroad. Only when opening up to foreign investments, and thereby creating the opportunity to transfer knowledge and skills to Iceland, a successful hydropower sector could be developed. Here Iceland benefitted from the existing quality of its local primary, secondary and vocational education, as well as its long tradition in undergraduate and more recently postgraduate education that is provided in Icelandic by Icelandic institutions (Bertelsen et al. 2015; Smits et al. 2015; Bertelsen \& Hansen 2015; Smits et al. 2014a). Local education and human capital development combined with a long tradition of Ice-landers going abroad to study or work at leading European and North-American knowledge institutes and companies, proved to be one of the key success factors in securing local benefits and thereby the acceptance of the development of new energy sectors. Within the development of a successful hydropower and geothermal energy sector an important role was reserved for the Icelandic government. Not only was the government responsible for blocking any foreign investments and therefore knowledge transfer in the first place, it also played an important role in securing that Iceland would sufficiently benefit from these new developments. At a very early stage, even before the hydropower and geothermal energy activities came to the fore, it invested in educational institutes so that a human capital base was created. Later, it took the lead in securing World Bank funding and made sales agreements with private sector companies. Furthermore it adjudicated controversies and environmental trade-offs. Taking the lead in these matters and acting as an interface between the private sector 
and Icelandic society, proved to be successful in addressing existing controversies and potential environmental impacts.

\subsubsection{The recent development of a new energy sector: offshore oil and gas}

Currently, Iceland is venturing into a new energy sector, namely offshore oil and gas in the Northeast corner of Iceland's Exclusive Economic Zone also known as the Dreki area. The reason for the recent interest is the settlement of border disputes around Jan Mayen Island with Norway, concluding that each state has a 25\%share in licenses on the other side of the border. At the moment two licenses to search of oil and gas in this area have been granted. One is owned by a consortium of the Chinese national oil company (CNOOC International), which has a 60\% share and is also the operator, the Icelandic Eykon Energy ehf (15\%) and Petoro Iceland AS (25\%). The second license is owned by a consortium consisting of Ithaca Petroleum ehf. (operator) with a $56.25 \%$ share, the Icelandic Kolvetni ehf. (18.75\%), and Petoro Iceland AS (25\%) (National Energy Authority Orkustofnun 2016).

Iceland has little experience and local knowledge about offshore oil and gas exploration and production. However, interviews with Icelandic authorities and companies reveal strong self-confidence based on a generally high-level of international science and engineering skills, knowledge and experience. Knowledge-transfer from Norway facilitated by Scandinavian educational and professional experience of Icelanders plays a significant role here. Icelandic authorities have prepared and Althingi passed new legislation to regulate the licensing of oil and gas activities (personal communication with four Icelandic Government Representatives). And Icelandic companies seem confident that they will be able to secure their share of this development by servicing the IOCs (personal communication with two Icelandic companies). There is no aversion to foreign investment related to this development, and both authorities and companies are confident they can secure ample of local benefits from this development.

The Icelandic public debate on offshore oil and gas production appears to focus on Iceland's global climate responsibilities and green image, rather than being exploited by large IOCs and foreign investment. The importance of economic legitimacy or local benefits from the offshore oil and gas activities seems not to be at the core of societal debate these days. Also, there seems to be a general level of trust in the international oil and gas companies that would execute these activities. The focus of Icelandic societal debate today, is on the socio-political legitimacy of these activities. Especially in the light of the recent Paris Global Climate Change Agreement, the legitimacy of starting new activities leading to fossil fuel extraction can be questioned. Also, it would concern 
resources that would be exported as Iceland does not need the additional resources to generate electricity or heat. At the same time gas is seen as a transition energy source on the path towards a renewable society, and could help other countries to speed up this transition moving away from the use of coal and oil.

According to Thomson and Boutilier (2011), if the socio-political legitimacy of an activity is lacking while maybe the economic legitimacy and interactional trust are still present, the social license to operate of an activity may at best be approved but could also be withdrawn. The largest amount of stakeholders is likely to grant an acceptance level of the social license to operate for these activities. At the same time the socio-political legitimacy, such as the role of certain activities or industry in the face of climate change is not something that individual companies can easily influence. It is therefore becoming much more of a global challenge, also involving a broader set of stakeholders. The socio-political legitimacy aspect of a social license to operate therefore closely relates to a company's or even industry's level of involvement in the challenge of developing a global social contract for global problems such as climate change (Thomson \& Boutilier 2011).

\subsection{The Faroe Islands}

In the Faroe Islands the development of an energy sector in the form of oil and gas started during the 1990s, after Denmark transferred the rights to underground resources to the Faroe Islands in 1992. Before that, the Faroe Islands were a dependent territory of the Kingdom of Denmark since the Treaty of Kiel in 1814. There was no incentive for the Faroese authorities to proceed with oil and gas exploration, as long as the rights to the underground were in the hands of Denmark. Under the Home Rule System, which came into force in 1948, all policy domains were placed on either 'List A' or 'List B'. The policy domains on List A could be taken over by the Faroese government at any time, while the domains on List B could only be taken over after negotiation and agreement with the Danish government. Since 1948 several attempts were made to gain authority over the rights to underground resources, which were on List B [18]. In 1992 the Danish government unexpectedly changed its mind. Without having to go through Parliament (Folketinget), the Danish government and Prime Minster at the time Poul Schluter, decided to transfer these rights to the Faroe Islands. On the 22nd December, 1992 the agreement between Denmark and the Faroe Islands was signed. The Faroe Islands had secured the rights to all mineral and hydrocarbon deposits in the Faroese underground (Harhoff 1993; Müller \& Djurhuus 2014). The transfer was transformative and kicked off a whole new phase of socio-economic development in the Faroe Islands (Bertelsen et al. 2015). 
With the rights to the underground secured, the Faroese government decided to start preparing for a future oil industry. It established the Hydrocarbon Planning Commission to investigate how future Faroese oil exploration and production legislation could be designed, and in such a way that it would mostly benefit the Faroese society. More specifically, the goal of the Commission was to advise the government on a future oil extraction policy and how labour, industry and social interest could be ensured in the best way possible if oil exploration and extraction should become reality (Oljurádleggingarnevndin 1997, p. 13). In terms of the social license to operate concept, the private sector was thus stimulated by policy measures in the regulatory framework to think and act on maximising the local benefits and working on the economic legitimacy of their activities. In this case study it is examined whether the measures set out in the regulatory framework were sufficient for the companies to ensure their economic legitimacy for the Faroese society. Furthermore, this section will examine whether there have been other success factors related to the social license to operate for the development of an oil and gas industry in the Faroe Islands.

\subsubsection{Stimulating socio-economic development from the start}

Based on the advice from the Hydrocarbon Planning Commission, the key component of the regulatory framework was based on three main principles (Oljuráðleggingarnevndin 1997):

1. All personnel and material to and from the oil platforms must pass through a Faroese harbour;

2. The Faroese workforce and industry should be given a fair and real chance to participate in the activities related to oil exploration and extraction; and

3. License holders had to financially commit to a Faroese Competence Development Fund that was to be used to finance education, research and other exploratory activities.

These three principles, stimulating foreign companies to engage and support the Faroese society, are now regarded as one of the success factors in the development of an oil and gas sector in the Faroe Islands. At that time, in the 1990s, the industry of the Faroe Islands had no experience in the oil and gas sector and very few, if any, personnel working for oil companies. If one were to take a snap-shot picture of the Faroese society anno 1998, there would not be any businesses that would have a chance to participate in the oil industry, and even fewer educated oil industry people. As a fishery nation however, many of the maritime skills could potentially be transferred to the offshore oil and gas industry. It was however clear from the beginning that if 
society was to benefit from the hydrocarbon activities, a deliberate effort should be made to develop the necessary skill sets and experiences, and a massive investment had to take place in entirely new sectors.

The three principles of the hydrocarbon legislation in the Faroe Islands were introduced to stimulate a broad socio-economic development. However, also from the side of the oil companies themselves there was an interest in promoting such development and fund research in the Faroe Islands. According to Anderson et al., who studied BP and its engagement prior to entering the Faroe Islands "Cultural research was also regarded as 'very necessary before entering the Faroe Islands. [in order to] get a good reputation before[it] even started drilling'. BP reported having substantial contact with Faroese representatives before maintaining a physical presence there. Furthermore, such 'pre-work' was deemed 'invaluable'." (Anderson \& Bieniaszewska 2005). This 'pre-work' is well documented in a recent publication by two Faroese journalists, Jan Muller and Tróndur Djurhuus, who closely followed the development of the oil industry in the Faroe Islands (Müller \& Djurhuus 2014).

In 1999 both journalists were part of a team of sixteen key 'influencers', including industry representatives, politicians, civil servants, academics, and journalists, from the Faroe Islands. The key influencers were invited on a trip to Alaska, which was paid for by BP, to study and see the oil fields and learn how the oil industry interacted with local communities over there. The two journalists were surprised by the opulence they were suddenly offered and commented: "Faroese news reporters and others don't have to live in double rooms, or student residencies, when they go abroad in 'off-shore errands'. Now there is space for them in four and five star hotels. The scoop and the 'sitting bathtub' is replaced by a huge bathroom of marble, and we dined well, without anybody having to think about to whom the bill will be sent to" (Müller \& Djurhuus 2014, p. 97). In Alaska, the team was met with one key message repeatedly: Oil exploration and oil extraction can be organized in a way that benefits both the oil industry and society as a whole. According Djurhuus, "Texaco does not hide that they hope that it [the trip to Alaska] also will benefit the oil companies, once the Faroese know how other societies cooperate with the companies. Over and over the slogan on the trip is win-win" (Müller \& Djurhuus, p. 123). Since the late 1990s, many influencers from the Faroe Islands have been invited to join similar trips, as this was a strategy pursued by the major oil companies at that time.

\subsubsection{Local benefits after 15 years of exploration}

In 2001 the first oil exploration well was drilled and the exploration for hydrocarbon resources in Faroese waters had officially begun. After 15 years of exploration, a lot of 
experience and knowledge has been gained in the Faroe Islands, but no oil has been found (yet) in commercially viable quantities. Nevertheless, the exploration activities are ongoing and have led to some major spin-off activities with significant socio-economic effects on a national level. An entirely new hydrocarbon cluster was created, consisting of new companies and offering new support to existing companies (Bertelsen et al. 2015; Müller \& Djurhuus 2014; Smits et al. 2014a). Parties that are participating in this hydrocarbon cluster include for example:

- Oil Companies (Atlantic Petroleum, Faroe Petroleum)

- Offshore supply companies (Skanksi, Thor, Jacobsen)

- Shipyard (MEST)

- Offshore Supply Services (Faroese Offshore Supply Services)

- IT (Simprentis, Føroya Tele)

- Harbor (Atlantic Supply Base)

- Petroleum Administration (Jarðfeingið)

- University of the Faroe Islands (Fróðskaparsetur Føroya)

- Maritime College (Vinnuháskúlin)

- NewsPortal (www.oljan.fo)

Important drivers in the creation of this cluster were the three principles on which the institutional set-up was based. For example, the legal requirement that all material destined for the oil platforms in the Faroe Islands must go through a Faroese harbour, has led to the creation of a new Atlantic supply base in the Faroese city of Runavik (Atlantic Supply Base 2011). The requirement that oil companies must give Faroese businesses and labour a real and fair chance to participate in activities of the industry, has led to the establishment of new offshore companies and the employment of Faroese personnel on platforms (Krúnborg Offshore 2012; Mest 2013; Skansi 2013; Thor 2011). The requirement to financially support the competence development fund has resulted in the investment of 180 million Danish Kroner on over 500 competence development projects (personal communication). Also, as a result of spin-offs from these pillars, a growing number of citizens from the Faroe Islands have found work in the oil sector abroad. Migration between the Faroe Islands and the plat-forms abroad is bringing in about 824 million Danish Kroner a year to the Faroese economy (Hagstova Føroya 2012). All in all, 942 people, representing 3.4\% of the total active labour force, were working within the hydrocarbon sector in 2013 (Hagstova Føroya 2015; Oljuvinnufelagið 2013).

This leads to an interesting observation: Until now, there is no commercially viable oil in the Faroe Islands, yet the nation has developed a substantial hydrocarbon cluster 
that competes at a global level. This implies that the competitiveness is not based on the presence of oil deposits in the Faroe Islands, because there are none found, but rather on the human capital that has evolved as a result of the particular development path that has been intentionally and strategically pursued since the late 1990s. As a whole, this has benefited Faroese society and has also given the hydrocarbon industry a high degree of economic and socio-economic legitimacy in terms of a social license to operate.

\subsubsection{Trust building between stakeholders in the hydrocarbon cluster}

The cluster development described above has also added a new dynamic to the Faroese society, as these players interact at local and international conferences, offshore business fairs, and in joint ventures. This dynamic creates an ongoing dialogue and competition of course - between these actors. Furthermore, the competence development fund has been managed in a way that can be described as a comanagement system, in which the oil industry (license holders) and the government administer the funds jointly. On the one hand, the companies were obliged to commit a certain amount of funds to the competence development fund. All applications to the fund had to go through the Petroleum Administration (Jarðfeingi), where jointly the formal eligibility is established and all applicants and grants are registered. However, the oil companies had, and still have, the final say on which project to fund. Thus the final decision on whether a PhD research project is granted or not, is taken by the oil company and the student receives a personal letter from the oil company, not from the Petroleum Administration (Jarðfeingi 2016; Oljumálaráðið 2003).This new cluster development and the co-management of the competence development fund, has led to an increasing and ongoing interaction between the Faroese oil administration, the oil industry, the Faroese business community and Faroese civil society. Over the past 15 years relations between these stakeholders have been built in multiple ways and in multiple platforms for cooperation. This has created a basis of interactional trust between the various stakeholders involved.

All in all, the clear local benefits and increased cooperation between stakeholders over the past two decades has resulted in a high score on the social license to operate continuum for the oil and gas activities in the Faroe Islands. How high the social license to operate is exactly, is difficult to pinpoint. However, it is a fact that there has not been a single protest or demonstration against the oil companies and their activities until now. Nor are there any social movements such as NGOs, political parties, or any other groups that are against oil exploration in the Faroe Islands. Instead, there is a high degree of positive expectation and support for the industry in the Faroese society. 
It is evident that the oil companies that were involved in the early development of the oil sector in the Faroe Islands, even before the actual exploration began, were concerned about the perceived legitimacy of their business in the local society, and there seems to have been a convergence of the political wishes for inclusive growth and the strategy pursued by the major oil companies. This is regarded as a success factor contributing to the effectiveness of the regulatory framework and ensures the hydrocarbon sector's social license to operate in the Faroe Islands.

\subsection{Greenland}

With a surface of more than 2 million square kilometres Greenland is the largest island of the world (www.cia.gov). Approximately $81 \%$ of the island is covered in ice, explaining why Greenland's society lives scattered along the $44.000 \mathrm{~km}$ long coast-line. At the same time, Greenland is considered to be a microstate based on the small size of its society which consists of approximately 56.000 people. Today, Greenland is still part of the Kingdom of Denmark but has Home Rule since 1979 and Self Rule since 2009 (Smits et al. 2014b). The Self Rule implies that only defence, foreign pol icy and security are shared responsibilities between Denmark and Greenland (Smits et al. 2014b). The underground and its resources belong to Greenland. Eventually it is the ambition of Greenland to become (financially) independent from Denmark, although the timeframe in which this goal should be realised is subject to debate. In order to become financially independent, the national economy that is now mainly dependent on fisheries, tourism and the public sector, needs to be diversified. The development of oil and gas but also mining activities is seen as an important element in this strategy (Naalakkersuisut 2014a). Based on the estimations of the USGS (USGS 2008a) it is expected that the Greenlandic waters contain large oil and/or gas undiscovered hydrocarbon resources. Over the last 40 years a limited number of exploration activities have been undertaken in Greenland's EEZ: In the 1970s a total number of 5 exploration wells were drilled followed by 1 in 2000 and another 8 in 2010/2011. Moreover, multiple sets of seismic data as preparation for (future) exploration drilling activities have been acquired over time.

The strategy of the Greenlandic government to develop oil and gas resources and the recent exploration drilling activities in 2010/2011 by Cairn Energy have attracted a lot of public attention, both on the national as well as the international level. On both levels there are stakeholders with different opinions on this matter, and stakeholder groups are divided on this topic. The risk of an oil spill and other potentially negative impacts on the fragile ecosystem is the main topic of the discussion, along with the importance of this ecosystem and its marine mammals for local societies (Pfeifer \& Thompson 2011). Because the past activities have sparked debates in society, one cannot assume to have 
a social license to operate at the start of (future) activities. Therefore the government as well as the companies that would like to start their activities in the Greenlandic waters need to take into account the potential non-technical risks. As legitimacy and trust are regarded as two of the main underlying principles in obtaining and maintaining a social license to operate (Thomson \& Boutilier 2011), focussing on these elements in a project's development strategy could contribute to obtaining and later sustainably maintaining a social license to operate. This section explores how human capital development could contribute to trust building and legitimacy of oil and gas activities in Greenland. It will primarily focus on the role of human capital in relation to the economic legitimacy of an activity, as this is the basis of a social license to operate. Moreover the role of human capital related to interactional trust will also be examined. Findings from the case studies of Iceland and the Faroe Islands will be used to determine a number of potential success factors in the Greenlandic context.

\subsubsection{Human capital development and the economic legitimacy of oil and gas activities in Greenland}

As is the case in the rest of the Arctic region, Greenland's economy is considered a small market (Ackrén et al. 2011) meaning that the majority of the resources would be shipped to global markets elsewhere. The most important challenge for Greenland's society and government is to maximise the local benefits from the (future) oil and gas activities (Naalakkersuisut 2014b; Smits et al. 2014a; Smits et al. 2014b). Local benefits are also an important basis for a social license to operate, as is illustrated by the 'economic legitimacy' principle of Thomson and Boutilier (2011). The regulatory framework in Greenland already includes a number of policy measures to stimulate the involvement of local stakeholders in the development of an activity. Working on these requirements to the best extend possible can contribute to a social license to operate. However, assuming that only compliance with these requirements will be sufficient is naive and should be examined on a continuous basis throughout the development process of an activity.

In order to maximise the (economic) benefits at a national level, the Oil \& Mineral Strategy 2014 - 2018 aims to sustainably develop oil and gas activities by prioritising the industry's interfaces with education, the labour market, existing infrastructure and social services (Naalakkersuisut 2014b). However, in order for society to maximally benefit, it needs to have the right education and qualifications to be able to participate in the industry (Bertelsen et al. 2016). These requirements do not only apply to individuals, but also to local businesses. Even though it can be questioned whether there will be any exploration drilling in the coming few years and thus why any knowledge in this 
field should be developed, the development of human capital and getting the right qualifications takes time. Increasing the level of education has already been a focus point for the government of Greenland over the past decade. Greenland does not have an extensive history of developing a knowledge-based economy via higher education and knowledge exchange, such as Iceland and the Faroe Islands (Smits et al. 2014a). Under the "Greenland Education Program" (www.nanoq.gl) the number of post-primary graduates has increased. However, creating a critical mass of (highly educated) human capital remains a challenge.

To ensure that the industry contributes to this challenge, the government has incorporated the IBA as a policy measure in the Mineral Resources Act, which is the central regulatory framework concerning the development of oil and gas resources. The aim of IBA is to "enhance and secure the involvement of relevant Greenlandic stakeholders" (Naalakkersuisut 2014c), and by doing so, increasing the positive impacts of the industrial development on the Greenlandic society. Since all oil companies that want to perform activities in Greenland need to agree on an IBA with the Greenlandic government and the affected municipalities, this forms a good starting point to work on the important social license to operate elements of trust and legitimacy. However, the outcomes of an IBA itself are focussing on the short- and mid-term when negotiated in relation to exploration activities. Of course the government can ensure that the agreement successfully contributes to the country's long term goals, by having their strategy in mind during the negotiations. If companies want to build a sustainable, long term relationship with local stakeholders, one should not only focus on the IBA alone.

Besides the formal requirements of an IBA, there are a number of ways in which companies could contribute to an increased human capital base in Greenland. Various initiatives in this field already exist and could form a starting point for engaging with local stakeholders and businesses. Preparing Greenlandic businesses for participation in the oil and gas industry is one of them. In 2012, the government started to sup-port local businesses in raising their profile and by granting support to diverse and selfsustaining initiatives in order to strengthen the development of the national economy. Another way to start engaging with local businesses is via existing partnerships, such as Suppliers Greenland (www.suppliers.gl), that aim at the oil and gas industry. These partnerships could serve as a link between the IOCs and local businesses. Knowledge exchange and capacity building are already on their agenda and could be further enhanced by the involvement of international knowledge and expertise from the IOCs. 
By contributing to human capital building international companies do not only comply with the regulatory framework and international best practice, but it could also be a basis for creating economic legitimacy of their activities and thus their social license to operate. Increasing and tailoring the skills and qualifications of people in order for them to be able to participate and contribute to the industry and its related activities, will enhance the (economic) benefits at a local level. However, only working on the economic legitimacy will only create an uncertain basis for a social license to operate, which is dependent on three more factors according to Thomson and Boutilier (2011). The following section will explore the role human capital development could play in relation to creating interactional trust.

\subsubsection{Human capital development and trust building between stakeholders}

As is concluded based on the Faroe Islands case study, human capital development could also serve as a platform to build trust between various stakeholders. This relates in the first place to what Thomson and Boutilier (2011) call 'interactional trust' and could ultimately lead to more 'institutionalised trust'. The legal frame-work already requires companies to engage stakeholders during the permitting process, for example via consultation rounds (BMP 2009c). The government facilitates this process and sometimes functions as an intermediate between large international companies and small Greenlandic societies (personal communication - interview Greenland Government 2016). By delivering what has is promised during the consultation process, a company has the opportunity to show their responsibility and build trust among local stakeholders. Even though the Greenland Government is in the process of revising the Social Impact Assessment procedures and requirements, these consultation processes are of a relatively short duration ( 6 weeks, with the possibility of extension) and limited to the permitting process prior to the activities itself.

Another opportunity to build trust between a private company and Greenlandic stakeholders is the IBA. The negotiation procedures involve not only the private company and the national government, but also the affected municipalities. Furthermore, the IBA is focussed on the use of Greenlandic labour and enterprises when performing activities in Greenland (BMP 2009c). This forms a basis to discuss the requirements and qualifications the industry needs from skilled labour and businesses, in order for them to participate in the industry. However, the formal stakeholders involved in the negotiation process are limited, as they do not include Greenlandic knowledge institutes and workers' associations (Ministry of Industry, Labour and Trade 2015; BMP 2009c). Moreover, the recent activities of the oil and gas sector were ad hoc and of a short 
duration (personal communication - interview Greenland Business 2016), making it difficult to establish a sustainable relationship build on trust.

Establishing a Greenlandic Industry Cluster, including the international company/ companies, government authorities, local businesses, NGOs/associations and knowledge institutes, according to Faroese example, is an opportunity to create trust when exploration activities would take place again in the future. Existing initiatives from the Greenlandic government or Greenlandic NGOs such as Corporate Social Responsibility (CSR) Greenland, could serve as a basis for cooperation in such a multistakeholder cluster on human capital development.

\subsection{Discussion}

Although the three case studies each have a different context and are at a different stage in the development of an energy sector, whether it is oil and gas, hydropower or geothermal energy, a critical comparison generates a number of valuable insights. The development of an energy sector and using this for export or to sup-port energy consuming export industries is or has been pursued by all three states to diversify their economy and boost socio-economic development. Having a social license to operate for these activities is of major importance in making this strategy a success. As appears from both the Icelandic and Faroese case study, it is crucial for an activity to have clear local benefits and thereby secure its economic legitimacy. More specifically, to generate this economic legitimacy and thereby create a social license to operate at acceptance level, these benefits should not only result from taxes and royalties but rather from participation of local communities in these new activities. Participation can be anything in the range from design, construction or operation. However especially in the case for large-scale developments, the local involvement should be substantial as was shown by the case of Iceland. Large scale foreign investments were rejected at first, because of little involvement of Icelanders in phases other than construction, and the fear of being dominated again by foreign powers. Later, when more experience was gained with small-scale hydropower Iceland felt more in control and foreign investments were seen as the key to socio-economic development. Only then the large scale hydropower installations were developed. Gradually, knowledge was transferred to Icelandic businesses, allowing for the development of hydropower to become fully Icelandic. And even though there are potentially large (environmental) impacts from large-scale hydropower development, the social license to operate is still present. Over time, Iceland has developed itself as a global player in the field of hydropower and Icelandic experts and businesses are now exporting their knowledge to other places in the world. 
Substantial involvement from the start and knowledge transfer during the development of a new industry seems to be a crucial element for the social license to operate. This is also underpinned by the case of the Faroe Islands, where involvement of the Faroese society and businesses was not only stimulated from the start by a number of policy measures, but was also explicitly present in the strategy of the IOCs. Since the exploration activities started, much attention has been paid to knowledge transfer and development. Within 15 years this has led to Faroese businesses being established, which do not only participate in the industry at a national level but also export their knowledge and experience to other places in the world. Compared to Iceland, the Faroe Islands have implemented more requirements in their regulatory framework to ensure society would benefit sufficiently from these new activities. A reason could be because there was no experience whatsoever with oil and gas in the Faroe Islands prior to the start of the exploration activities in 2001. Iceland however already had some experience with hydropower, albeit as small-scale hydropower, when it attracted foreign investments. From the Greenlandic case it appears that Greenland is following the same strategy as the Faroe Islands, and has implemented a number of policy measures such as the IBA to ensure involvement of Greenlandic society in new developments.

When requiring or desiring substantial involvement of a local society in new industrial activities, the right set of skills and knowledge should be available among the local workforce and businesses. This is thus not only in the interest of national governments, but also for international private sector companies. As the cases of Iceland and the Faroe Islands show, the high level of involvement from local people and businesses in new industrial activities generates clearer benefits for society and has the tendency to create a firm basis for a social license to operate. However, at the start of such new developments there is not necessarily a lot of knowledge and expertise in this field available among the workforce. The challenge is then to create the knowledge and expertise needed for these new activities, while ensuring that society is already involved from the start. For this reason the authors argue that human capital development plays a vital role in securing the local benefits and economic legitimacy of an activity, thereby contributing to obtaining and maintaining a social license to operate. Ideally the development of relevant knowledge and expertise should start prior to start of (large-scale) development of new activities. This facilitates the high-level involvement of society, as is shown by the Icelandic case. However if this is not possible, society could look at existing knowledge and try to apply that in the new industry, or base human capital development programmes on the already existing skills and expertise. This is how the Faroe Islands have transformed their offshore knowledge from fisheries into useful skills and expertise for the oil and gas industry. Establishing a fund to stimulate 
human capital development, which is co-managed by the industry and the government, is enhancing this process.

Next to the economic legitimacy, the focus on human capital development can also contribute to the creation of interactional trust. The hydrocarbon cluster that was formed in the Faroe Islands brought together various stakeholders ranging from government authorities, private sector international and national businesses to knowledge institutes. Stimulated by the regulatory framework, these stakeholders started coming together in this cluster and established a more institutionalised dialogue and cooperation. While working together on competence development projects and interacting over the past years, these stakeholders have been able to show each other that they deliver as promised. Relationships are built, adding to a better mutual understanding. As a wide variety of stakeholders is included in this cluster it covers different parts of society, leading to a broader acceptance. These are elements that all contribute to a more established social license to operate.

A discussion that particularly relates to the development of fossil fuels is whether it contributes to the future of a society in terms of sustainable development, energy transition and climate change. In Iceland this is the main subject of societal debate related to the oil and gas exploration in the Dreki area. Also in Greenland there are critical voices in society that focus on this element. Regarding a social license to operate for oil and gas activities, this relates to the socio-political legitimacy of an activity. This is an element that is difficult to influence by one company or stakeholder alone, and is something that requires the input of multiple stakeholders on a larger scale. However, this does not mean that a company or stakeholder should not look at what can be done at a smaller scale or within its own circle of influence. Focussing on gas as a transition fuel towards renewable energy is for example regarded as a more responsible attitude compared to focussing on the production oil. The socio-political legitimacy aspect of a social license to operate therefore closely relates to a company's or even industry's level of involvement in the challenge of developing a global social contract for worldwide problems such as climate change.

\subsection{Conclusion}

In this chapter the role of human capital development related to obtaining and maintaining a social license to operate for energy activities, including oil and gas, hydropower and geothermal energy, has been examined based on case studies from Iceland, the Faroe Islands and Greenland. Where Iceland and the Faroe Islands have already established an energy sector that allows them to export knowledge and 
expertise elsewhere, Greenland finds itself at the start of such development. Based on the Icelandic and Faroese cases, human capital development plays an important role in maximising local benefits and thereby securing the economic legitimacy of the new industrial activities. The economic legitimacy is the first element of a social license to operate and can generate an acceptance level for an activity among society. Important in this respect is to ensure substantial involvement from local people at the start of the new activities, and focus on knowledge transfer and development throughout the development process of an activity.

When there is no previous experience with the specific industry that wants to develop these new activities, this involvement and knowledge transfer can be stimulated by incorporating policy measures into a state's regulatory framework. This has proved to be a success in the Faroe Islands, and also Greenland is preparing itself for the development of a new energy sector in similar ways. For the local workforce to be able to participate in the new activities, their knowledge and skills should be applicable to this new industry. Focussing on human capital development is therefore essential. This is not only in the interest of a government, to ensure the benefits for its society are being maximised, but also for private sector companies in terms of their economic legitimacy and thus social license to operate. As human capital development requires the input of multiple stakeholders, the creation of a cluster as happened in the Faroe Islands can facilitate this process. Moreover, this cluster offers a platform for interaction between the different stakeholders over a longer period of time, thereby stimulating interaction and trust building between the parties involved.

Human capital development thus contributes in multiple ways to obtaining and maintaining a social license to operate for new energy activities in these three North Atlantic Arctic states. The main contribution is made related to the economic legitimacy of an activity via the maximisation of benefits at a local level. Maximising local benefits from these foreign investments was and is essential for all three societies. Especially in the light of a pathway towards independence, the economic diversification and benefits that come from the energy sector development are of major importance. In this context, the success factors for Iceland and the Faroe Islands that are identified in this chapter could be of interest to Greenland. 


\section{CHAPTER}

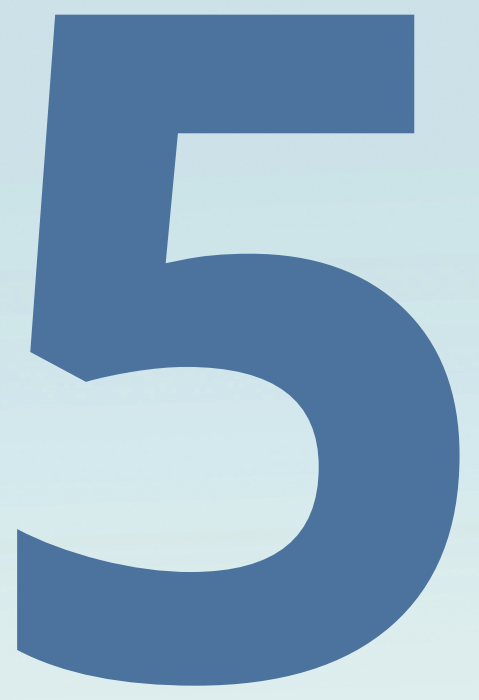




\title{
Oil and gas development in Greenland: A social license to operate, trust and legitimacy in environmental governance
}

\author{
C.C.A. Smits \\ J.P.M. van Tatenhove \\ J. van Leeuwen
}




\section{ABSTRACT}

Since the turn of the century, Greenland has been examining the possibilities to develop its potential oil and gas resources. The large scale oil and gas activities will impact the small Greenlandic society, both positively and negatively. In this chapter we employ the concept of a social license to operate to address the risks of an activity, represented by the acceptance or approval of an activity by societal actors. The focus of existing research is primarily on the interaction between local communities and companies. However, in an increasingly complex society, where the role of governments, companies and civil society is subject to constant change, social licenses to operate should be studied in an integrated way, to deal with all essential elements that influence the successful implementation of controversial activities.

This chapter builds on the idea that successful implementation of an activity is determined by social, political and legal licenses. Trust and legitimacy are regarded as the fundamental principles on which all three licenses are based. This chapter therefore adopts an integrated approach, in which the role of the political and legal licenses is taken into account as well as the social license. This approach provides for a more thorough analysis for different sources of personal and institutionalised trust as well as input, throughput and output legitimacy across the three licenses. The case study also illustrates the potential role of the government in co-shaping a social license to operate. 


\subsection{INTRODUCTION}

Oil and gas developments are subject to public debate. One source of controversy is that their large scale has the potential to transform communities, economies and environments (Harvey \& Bice 2014; Slack 2012; Omeje 2005). These changes can have both positive and negative impacts, and the distribution of those impacts can lead to controversy. Over the last decade, the time for oil and gas projects to reach production has nearly doubled (Franks et al. 2014). Almost half of the risks that companies face in the development of an oil and gas activity have a nontechnical nature, of which relationships with other stakeholders is the largest category (Franks et al. 2014).

Since Greenland gained Self Rule in 2009, the government is looking to develop oil and gas activities in order to diversify its economy and become financially independent from Denmark (Naalakkersuisut 2014b). Such large scale oil and gas activities will impact the small Greenlandic population, both positively and negatively. Oil and gas development could therefore spark societal debate, potentially leading to delays in implementation of the activities.

The concept of a social license to operate relates to nontechnical risks of an activity, based on focussing on the acceptance or approval of a certain activity by societal actors. The concept originates from the mining industry where it emerged during the 1990s (Gunningham et al. 2004). Since then it has been used in a wide variety of industrial sectors (Hall et al. 2015). Typically the literature has focused on questions such as "What is a social license to operate?", "What elements contribute to a successful social license to operate?" and "How can companies obtain a social license to operate?". The interaction between local communities and private sector companies is typically the primary concern of this body of research (Hall et al. 2015; Moffat \& Zhang 2014; Parsons et al. 2014; Prno 2013; Boutilier et al. 2012; Prno \& Slocombe 2012). This focus is valid and has contributed to establishing the concept of a social license to operate, not only from an academic point of view, but also in best practices of companies worldwide. However, current developments in society ask for a broader understanding of the social license to operate (Owen \& Kemp 2013; Harvey \& Bice 2014). In an increasingly complex society, where the role of governments, companies and civil society are subject to constant change, approaches that examine the social license to operate in isolation from other factors miss essential elements that influence the successful implementation of controversial activities (see also Prno \& Slocombe 2012). 
This chapter builds on the idea that successful implementation of an activity is determined by social, political and legal licenses (Morrison 2014). Empowered citizens and civil society organisations are not satisfied with how national governments and (multinational) private sector companies are implementing industrial activities such as oil and gas developments. As stakeholders have lost trust in the legal and the political systems to adequately deal with their concerns, the need for a social license to operate has emerged. Trust and legitimacy are regarded as the fundamental principles on which a social license to operate is based (Morrison 2014; Thomson \& Boutilier 2011), but also play an important role in the legal and political system. An integrated analysis of the acceptance of an activity thus requires studying the processes through which trust and legitimacy are established as part of all three licenses.

To understand the role of trust and legitimacy in the interactions between these three licenses, the authors studied the development of oil and gas activities in Greenland. The level of industrial activities in the Arctic region has increased over the last decade. Sparked by amongst others the increased accessibility due to receding ice and snow cover (ACIA 2004), technological advances, political stability and high commodity prices, the extractive industries have expanded their activities in this region (Brookings 2014; Smits et al. 2014b). It is estimated that the undiscovered hydrocarbon resources in this region could amount up to 90 billion barrels of oil equivalent and 1.670 trillion cubic feet of natural gas, which are technically recoverable (USGS 2008a). This equals approximately 13\% of the world's undiscovered oil resources. Since the 1970s, 14 exploration wells have been drilled in Greenland; eight of these were drilled in 2010 and 2011. No economically viable oil and/or gas resources have been found yet (www. govmin.gl). Now that the oil prices have dropped and are expected to remain volatile, the future of Greenlandic oil and gas activities is uncertain. This is a challenge for the Greenlandic government and society, since the development of oil in particular was seen as a driver for economic diversification and financial independence.

The following questions were examined in this case study: How are trust ensured between national government, local indigenous communities and oil companies? Who are legitimate decision makers on whether and under what conditions oil and gas may be developed in Greenland? What will be the consequences for granting a license to operate for future oil and gas activities? To answer these research questions, we will first elaborate on the case study and methods chosen for conducting the analysis (Section 5.2). Section 5.3 discusses in more detail how the legal, political and social licenses to operate interact, as well as how trust and legitimacy are operationalised. Section 5.4 analyses the three licenses in relation to the oil and gas development in Greenland, 
followed by a discussion about trust and legitimacy in the interaction between the political, legal and social licenses to operate in Greenland (Section 5.5). In Section 5.6 conclusions are drawn.

\subsection{Case study and methods}

The research for this chapter was conducted using a case study approach (Yin 2009), focused on the offshore oil and gas developments in Greenland. The methods that were used to gather the qualitative data for this case study consisted of semi-structured interviews, observation and literature and document analysis. The empirical data has been gathered between 2011 and 2016. By collecting data in three different ways, data triangulation ensures that the data and findings are confirmed or disconfirmed in multiple ways (Yin 2009; Vennix 2006). This chapter primarily draws upon the semistructured interviews conducted in 2016. The interviews were held with representatives of local $(n=1)$, national $(n=2)$ and international $(n=1)$ government authorities, local ( $n=$ 2 ) and international $(n=1)$ private sector companies, and local $(n=3)$ and international $(n=2)$ civil society organisations.

The interviewed authorities, companies and organisations have been selected based on their involvement in the development of oil and gas activities in Greenland. In the selection process the authors have ensured a balanced representation of sectors (government, private and civil society) and of geographical origin (local, national or international). The socio-political focus of this research determined which departments or representatives were approached, e.g. (representatives and experts of) social/ economic/political departments within governments, companies and organisations rather than (representatives and experts of) the technical departments. It should be noted that some local and national organisations are so small, that the entire organisation consists of one to five employees. The representatives of the organisations that have been interviewed were all high level policy or executive officers that spoke on behalf of the organisation they represented. Some of them have been born and raised in Greenland, while others are Danes that now work and live in Greenland or work and live in other European countries. All interviews were conducted in English as the authors do not master the Danish and Greenlandic languages sufficiently to conduct semi-structured interviews. This only affected the selection process concerning the local civil society organisations: Next to the three civil society organisations that have been interviewed, the authors also approached the Greenlandic workers and fishermen and hunters organisations, however due to the language barrier no interviews could be conducted with these two organisations. 
All interviews have been recorded, after which a transcript was made. The conceptualisation of the legal, political and social licenses and the elements of trust and legitimacy, as outlined in Section 5.3, was used to code each of the transcripts. The transcripts were then analysed with qualitative data analysis software. Furthermore, a number of informal interviews were held during various conference visits, including the Arctic Frontiers (2015) and Arctic Technology Conference (2015). The observations stem from two visits to Greenland: one in 2011 and one in 2016. Secondary material such as policy documents, scholarly literature and newspaper articles were used to complement the data generated from interviews and observations.

\subsection{Legitimacy and trust in the social, political and legal licenses}

To perform industrial activities, companies need permits and political support. These political and legal licenses of an activity are based on formal judicial and political procedures. The political license is 'the authority that the government gives to any other organisation to undertake a particular activity' (Morrison 2014), and is granted by politicians. The legal license applies to an activity outlined by the regulatory framework, and is granted for example as a permit by an assigned governmental authority, represented by its civil servants, based on well-defined legal procedures. Besides these political and legal licenses the past decennia gave rise to a new type of license: the social license to operate. A social license to operate is generally defined as 'the ongoing acceptance and approval from local communities and other stakeholders' (Parsons et al. 2014; Prno 2013; Thomson \& Boutilier 2011; Joyce and Thomson 2000). Different from the political and legal licenses to operate, the social license to operate is not granted by a public authority, but is rather a process that runs through the entire lifecycle of a project and seeks a 'license' from in particular local communities and other stakeholders (Hall et al. 2015; Prno 2013). This raises the question who grants a social license to operate? When is it obtained? And how is it obtained?

It is generally acknowledged among scientists and practitioners that trust and legitimacy play an important role in obtaining and maintaining a social license to operate (Morrison 2014; Thomson \& Boutilier 2011). By focussing on how, when and by whom a private sector company can obtain and maintain a social license to operate, the existing literature is predominantly output oriented and lacks in depth examination of the potential relationships with the legal and political licenses. The role of the government and its changing relationship with society is often overlooked. The close connection between society's increasing demand for influence on the development of industrial activities and its perception of the prevailing legal and political system and the failures there of, makes these political and legal systems important to study in relation to the 
social license to operate. To study the interactions between the three licenses, it is important to have a closer look at the role of trust and legitimacy in each of them. The remainder of this section will therefore explore the various forms of trust and legitimacy.

\subsubsection{Personal and institutionalised trust}

Previous scholarly work on the social license to operate literature has distinguished different levels of trust: trust in a person (i.e. personal or interactional trust) and trust in an institution (ie. institutionalised trust) (Thomson \& Boutilier 2011). In the present study the different levels of trust are applied to the relationship between society and a private sector actor, such as an oil company, as is usually understood in social license to operate literature (Thomson \& Boutilier 2011), as well as analysed in relation to the political and legal licenses. This section operationalises the concept of these different levels of trust, which can be applied in the analysis of all three licenses.

Personal or interactional trust is based on reciprocity, and builds on knowledge an actor has of the behaviour of other actors over time. It is a two-way process involving multiple parties that is not obtained by a single actor. Trust can thus be defined as a shared set of expectations between the actors involved (Zucker 1986). Managing the expectations from both parties is therefore a crucial element, often a central part of the stakeholder engagement process of a project.

Institutionalised trust resembles the trust of actors in systems and institutions (e.g. political and monetary) (Giddens 1990; Zucker 1986; Luhmann 1979). Important elements of institutional trust are openness, transparency, order and predictability (Giddens 1990). The way actors view an institution is based on the performance of this institution, and is influenced by irrational, emotional aspects and the opinion of experts (Morrison 2014). Personal trust, in the form of interaction with representatives of a system, can enhance institutionalised trust (Giddens 1990; Morrison 2014).

In order to conduct the Greenlandic oil and gas case study, the authors expand on the existing social license to operate literature by distinguishing between two forms of institutionalised trust: integrity-based and competence-based (institutionalised) trust. In case of integrity-based trust, actors from local communities know the values and principles on which an institution operates and perceive that the institution is adhering to these values and principles (Moffat \& Zhang 2014; De Vos 2011; Kim et al. 2004; Mayer et al. 1995). Competence-based trust relates to the perception of community actors that a government or company has the competencies and skills to manage the issues of interest to that community (Butler \& Cantrell 1984). 


\subsubsection{Input, throughput, and output and legitimacy}

Existing literature on the social license to operate discusses the legitimacy of an activity mainly in terms of its economic and/or socio-political outcomes (Thomson \& Boutilier 2011). By doing so, the focus is predominantly on the output legitimacy. While output legitimacy is an important form of legitimacy when it comes to the social license to operate concept, it is not the only form. In addition to existing literature, the present study therefore makes a distinction between input, throughput and output legitimacy (Van Tatenhove 2011).

Input legitimacy reflects whether stakeholders that are influenced by a decision actually have a say in the decision making process and whether their interests are taken into account. In decisions made by a government authority, democratic election should ensure the involvement of stakeholders and the accountability of the decision makers (Risse \& Kleine 2007). In decisions made by a non-state actor, for example a private sector company, other models such as an early stage and inclusive stakeholder engagement programme should be in place.

Throughput legitimacy relates to the decision making process itself and whether this is characterised by fairness, transparency, openness and efficiency (Van Tatenhove 2011; Risse \& Kleine 2007). These elements also contribute to trust building. Recent research has shown that procedural fairness is the strongest predictor of trust. If the procedures are perceived to be fair, stakeholders will better accept or approve an activity regardless of the outcome of the procedure (Moffat \& Zhang 2014).

Output legitimacy is derived when decisions or activities actively contribute to the welfare of a society and/or solve issues that cannot be solved by other actors alone. The present study uses the operationalisation that is widely used in social license to operate literature and distinguishes two types of output legitimacy, namely economic legitimacy and socio-political legitimacy. The economic (output) legitimacy refers to the local (economic) benefits that a specific activity brings to an area, as well as the balance between the risks and the benefits (Thomson \& Boutilier 2011). The socio-political (output) legitimacy relates to the contributions of an activity to the general wellbeing and livelihood of a region and whether it meets the expectations of society (Thomson \& Boutilier 2011). 


\subsubsection{The role of legitimacy and trust in the three licenses}

It is hypothesized that different forms of trust and legitimacy play a role in each of the three licenses. Ultimately, all forms of trust and legitimacy are important for the approval of an activity by society.

- The political license is typically granted by the government, which derives its authority mainly from its input legitimacy through political elections. While the input legitimacy is not under pressure in most contemporary societies, the output legitimacy of governments is. They are often criticized for not delivering what was promised or taking decisions that are not widely supported. Failing to meet expectations from society in delivering public goods and services has resulted in a decreasing level of institutional trust (Pierre et al. 2011; Pierre and Peters 2000). As a consequence, governments have turned to participatory processes in decision making to improve their levels of output legitimacy. However, whether participatory decision making indeed leads to improved output legitimacy and thus also into increased levels in institutionalised trust can be questioned (Boedeltje \& Cornips 2004).

- Similar to the political license, the legal license is dependent on input legitimacy. Granting and obtaining a legal license is a form of output legitimacy. The authorities are judged based on the implementation and enforcement of the legal requirements during the permitting process. Furthermore, the legal license determines which activities are legal and which are illegal within a certain context. Institutionalised trust in the legal system is thus important for a well-functioning permit system and ultimately to achieve output legitimacy. And because throughput legitimacy plays an increasingly large role as well, permit procedures now often incorporate requirements regarding stakeholder consultation and participation.

- Although a social license to operate has emerged because of decreasing institutionalised trust in and legitimacy of the political and legal licenses, the social license does not substitute for the other licenses (Morrison 2014; Owen \& Kemp 2013). The emphasis of a social license to operate is on benefits for society (economic output legitimacy) and on the openness and transparency of the decision making process leading up to a certain activity (throughput legitimacy). Input legitimacy plays a role as well, as it is important which stakeholders are taken into account during the decision making process. In contrast to the political and legal license, however, it is less clear who are the legitimate stakeholders and decision makers. 


\subsection{The political, legal and social licenses in the context of oil and gas development in Greenland}

To be able to analyse the interaction between the three types of licenses described in Section 5.5, this section first presents the context of the political, legal and social licenses to operate for oil and gas development in Greenland. Section 5.4.1 describes the context of the political license, followed by the legal and the social licenses in Sections 5.4 .2 and 5.4 .3 respectively.

\subsubsection{The political license in Greenland: centralised decision making, but a greater distance to society}

Greenland is a democratic society where elections determine the composition of the Parliament (Inatsisartut). The Parliament in turn appoints the Prime Minister, who then appoints its Ministers as members of the Cabinet (Naalakkersuisut). The Greenlandic political domain in its current form is relatively young: In 2009 Greenland obtained Self Rule within the Kingdom of Denmark, including the rights to the underground. Only a limited number of policy domains are still shared with Denmark, including Defence and Foreign Policy (Queen of Denmark 2009). In the longer term, the government of Greenland wants to become fully financially independent from Denmark. Today, Greenland's economy is mainly based on the public sector, which is largely financed by Denmark through an annual block grant. At the moment, the private sector economy is heavily reliant on the export of fish and to a lesser extent on tourism.

Currently the government's budget and spending are relatively balanced. However, spending is expected to increase while earnings will not automatically follow this trend (Committee for Greenlandic Mineral Resources to the Benefit of Society 2014). Based on the need for additional income to cover increasing government expenditures and the wish to become financially independent, the government has identified the development of oil, gas and minerals as key initiatives in their strategy to diversify the Greenlandic economy (Committee for Greenlandic Mineral Resources to the Benefit of Society 2014; Naalakkersuisut 2014b). Given the average unemployment rate of approximately 10\% (Statistics Greenland 2016) and relatively low education level among society, as about $70 \%$ of 15-64 year olds has only completed primary education (Committee for Greenlandic Mineral Resources to the Benefit of Society 2014), capacity building and creating new job opportunities are main priorities of the Greenlandic government (Smits et al. 2014b; Committee for Greenlandic Mineral Resources to the Benefit of Society 2014; Naalakkersuisut 2014b). Therefore also the government has an interest in developing these activities successfully. 
To govern the development of new oil and gas activities, the MLSA (or Råstofstyrelsen) has been established. This authority is part of the MIMR and functions as the administrative authority which governs license and safety matters. The Ministry itself is responsible for legal, geological and marketing related policy issues. The Ministry of Industry, Labour and Trade governs the socio-economic issues, including the SSIA and IBA. Environmental issues including the mandatory EIA are the responsibility of the Environmental Agency, which is part of the Ministry of Nature, Environment and Energy. The division of tasks across three Ministries was introduced in 2013, after amendments to the legal framework in 2012 (govmin.gl: MLSA Newsletter 8-01-2014).

The Greenlandic government is facing an increasingly critical society, which is losing both its personal and institutionalised trust in the country's politicians and governing authorities. There are a number of reasons for the decreasing level of trust in the government and its decisions. First of all, the distance between decision makers and local communities has steadily grown and still continues to do so. This is making personal trust, based on interaction, harder to achieve. As many decisions regarding oil and gas development are made at a national level by the government in Nuuk, the capital of Greenland, local communities are not directly involved in the decision making process anymore. This is especially the case when it comes to oil and gas development, because this policy domain is regarded to be a matter of national strategic importance and is therefore predominantly governed by national government authorities. Local government authorities, such as the municipalities who are the closest point of contact for many citizens, have a limited role in the national decision making process (personal communication - interview KANUKOKA Municipalities Association of Greenland 2016). Although the municipalities do have an official seat at the table during the negotiations of an IBA, it is the national government who ultimately decides upon the planning and the exact location of the activities (personal communication - interview KANUKOKA 2016). As trust building in Greenland is generally linked to individual persons (for example people might vote for a completely different political party if a specific person has switched from one to another) (personal communication - interview CSR Greenland 2016), the positive influence that interaction with a representative of the political system can have on the level of institutionalised trust, is therefore undermined (personal communication - interview KANUKOKA 2016).

Institutionalised trust (generated by the perception of having the right set of competencies and operating based on a shared set of values) is currently under pressure as well. Several civil society organisations and companies are questioning whether the government authorities possess a sufficient level of competencies and 
skills to secure favourable conditions and interests of Greenland in the negotiations with the IOCs (personal communication - interview Greenland School of Minerals \& Petroleum, CSR Greenland 2016; Aaen 2012; Transparency Greenland 2012). The government authorities recognise the decreasing level of competence-based trust, but are confident about their own capacity and that they are able to secure Greenlandic interests (personal communication - interview MLSA and Ministry of Industry, Labour and Trade 2016). However, society has not yet been convinced. The decreasing level of trust in the national government is fostered by the lack of openness and transparency and the feeling that concerns of people are not sufficiently taken into account by the government due to their eagerness to generate additional income.

The integrity of government authorities and politicians is also under pressure. The central authorities on oil and gas development, the MLSA and the MIMR, have been and to some extent are still perceived as closed institutes (personal communication interview WWF 2016; Aaen 2012; Transparency Greenland 2012). It can be questioned whether the general public is aware of the values and principles on which these government authorities operate. In the recent past, also the integrity-based trust in the political leadership has been jeopardised. This is illustrated by the resignation of the previous Prime Minister (Aleqa Hammond) after 1.5 years, based on the accusation of misusing public funds for flights and hotels (The Arctic Journal 2016).

Politicians and the political system in general are not only facing a decreasing level of trust, also their legitimacy is under pressure. The MLSA and MIMR are criticized for lacking transparency and openness in their decision making processes, as well as insufficient information sharing with the public (personal communication - interview WWF 2016; Aaen 2012; Transparency Greenland 2012). Combined with the often difficult technical language and the use of English in a number of documents, this has resulted in a critical attitude from civil society towards the government. The government's inability to make all documents available in a way that is understandable for Greenlandic people who do not or to a very limited extent speak English and/or Danish, is further undermining the throughput legitimacy and in turn decreasing the levels of institutionalised trust.

\subsubsection{The legal license: a strong legal framework, but weak from a social perspective}

In 2009 the Self Rule government created a new legal framework for oil and gas developments by means of the MRA. When formulating the legal framework, the laws and regulations of other (Arctic) countries such as Norway and the United States were taken as an example. The aim of the MRA is to ensure that the oil and gas exploration 
and anticipated production activities are securely conducted in terms of safety, health, environment, social responsibility and according to international best practice (Mineral Resources Act, Part 1, 1). The regulatory framework obliges oil companies to conduct an EIA and a SSIA for their activities in Greenland. Based on the SSIA, an IBA is negotiated between the company and the national and local government authorities of Greenland. Although the regulatory framework is considered strong on paper, the government's capacity to enforce it is being questioned (personal communication - interview CSR Greenland 2016; Transparency Greenland 2012). The level of trust in the legal system is thus very much linked to the level of competence-based trust in the government authorities that are tasked to execute what is in the legal framework.

Sparked by the decreasing levels of trust in the government and the lack of openness and transparency in the decision making process, a number of amendments have been introduced to the regulatory framework in 2012 and 2014. In 2014 new requirements concerning the public consultation process were introduced to ensure the involvement of stakeholders early on in the process. Prior to submission of the EIA and SSIA, the project proponent (i.e. the oil company) needs to submit a project description for a 35-day public pre-consultation (Mineral Resources Act, Part 18a, 87a). Afterwards the project proponent can continue drafting the EIA and SSIA, taking on the comments received during the pre-consultation. When the EIA and SSIA have been drafted and submitted, a public consultation period of 8 weeks is initiated with the possibility to extend. Furthermore, it is mandatory to hold public meetings in the villages or towns affected by the project.

Throughput legitimacy and the opportunities to interact and build a relationship based on personal trust have increased as a function of the new moments to consult the public earlier on in the decision making process. However, building personal trust cannot be guaranteed by a legal framework itself. It can only be stimulated by incorporating the requirements for multiple phases of stakeholder interaction (e,g, pre-consultation and consultation). The legal framework aims to increase the input legitimacy by stimulating companies to reach out to as many stakeholders as possible during the public consultation process, such as the prescribed public consultation meetings in the potentially affected villages and towns. To ensure the best possible results in practice, the Greenlandic government has published the 'Guidelines for Social Impact Assessments'. In these guidelines international companies can find more information about stakeholder identification in the Greenlandic context (Naalakkersuisut 2016). After the regulatory changes in 2014, this document has recently been revised and updated according to the new legal framework so as to include the new procedures that 
introduce more public consultation moments in the decision making process (interview - Greenland Representative in Copenhagen).

Ultimately, the outcome of the procedures set forth in the legal framework is a legal license (i.e. a permit). This permit allows the project proponent to legally conduct its activities in Greenland. The aim of the legal framework and the activities it approves is to contribute to the diversification of the Greenlandic economy and welfare of Greenlandic society. The legitimacy of the license and thus the activity in itself is very much outputoriented, focussing on its contribution to society in economic terms. However, the economic benefits and thus the output legitimacy can only be fully materialised if Greenlanders participate in the industry's activities. This is a challenge, due to the high level requirements regarding technical qualifications and language skills of the workforce as set by the oil and gas industry in combination with the relatively low education level of the Greenlandic society (Bertelsen et al. 2016; personal communication - Greenland School of Minerals \& Petroleum, Greenland Petroleum Services 2016). In this context, efforts related to human capital development are of great importance and contribute to the capacity of people to grasp the employment opportunities when they arise (Smits et al. 2016); such efforts have the potential to improve the output legitimacy of oil and gas developments in Greenland.

\subsubsection{The social license: increased awareness and empowerment}

The level and intensity of oil and gas activities in Greenland has been far from consistent. The most extensive activities in the recent past have been the eight exploration drills conducted by Cairn Energy in 2010 and 2011. At the start of this century, when the attention for Greenlandic hydrocarbon potential was on the rise, Greenlandic people and organisations had little experience and knowledge about the oil and gas sector. There were however high expectations about the benefits that the development of these activities would bring to Greenland. The exploration drilling activities gave rise to a public debate. The debate was initiated in relation to the public hearings concerning the exploration drilling activities. NGOs started to pose questions, handed in hearing comments during the public consultation moments and educated citizens on their rights in the decision making process (personal communication - interview Ministry of Industry, Labour and Trade, ICC Greenland 2016). The questions related to the risks and potential negative impacts of the activities added a critical voice to the decision making process and gave rise to even more questions from both citizens and politicians.

Greenlandic civil society consists of a number of organisations, many of which are driven by only a few people each. Examples of NGOs that are present in Greenland are CSR 
Greenland, Transparency International, ICC Greenland and WWF. Greenpeace is active in Greenland, albeit without representation on the ground. The presence of environmental NGOs is still a delicate issue due to the anti-whaling and-sealing campaigns in the 1980s. CSR Greenland and Transparency International, have been established specifically because of the anticipated oil and gas industry. These NGOs have helped educate local businesses and create general awareness on requirements related to health, safety and CSR (personal communication - interview CSR Greenland, Greenland Petroleum Services 2016). More recently these two NGOs have altered their agenda, since a basic level of awareness is present and the oil and gas activities have come to a halt. Other NGOs, such as the ICC Greenland, are informing local communities on their rights in the decision making process and the principle of free, prior and informed consent.

The IOCs are not originally Greenlandic and are not necessarily represented within local communities. The physical and language barriers hamper the communication between these companies and local stakeholders. To increase the level of personal trust, local community liaison officers hired by the international companies in every community could facilitate the interaction with local stakeholders, as they function as a channel for the company to inform people about their activities and for the community to voice their concerns about the company's activities (personal communication - interview Shell 2016). However, this approach involves a lot of training, time and upfront investment, which conflicts with the relatively short and ad hoc nature of the early stage exploratory activities related to oil and gas in Greenland.

The presence or absence of a social license to operate can be determined based on the level of protest that arises in society. However, large scale societal unrest in terms of demonstrations or protest marches did not occur in Greenland. Given the fact that no large scale oil and gas activities have taken place in Greenland since 2011, it remains difficult to assess whether a social license to operate for these activities would actually exist or not. However, in parallel to the oil and gas activities, mining activities are being conducted in Greenland. For the execution of their activities both industries demand an extensive geological knowledge base, the use of advanced technologies and heavy machinery.

Even though the oil and gas and mining industry are often mentioned in the same context, they also have particular differences. In Greenland the oil and gas activities mainly take place offshore whereas the mining activities take place onshore. At present, some of the mining activities are in or nearing construction and production. The oil and gas activities on the other hand have not yet exceeded the early stages of the exploration phase, with the exploration drilling of Cairn Energy in 2010/2011 being 
the most advanced (www.govmin.gl). While the some of the largest IOCs are involved in the exploration for offshore oil and gas resources, the mining exploration activities are mainly executed by small, junior companies (www.govmin.gl). Given the location and scale of the activities and the associated skill requirements, it is likely that the onshore mining activities generate more employment compared to the offshore oil and gas activities (personal communication - interview Greenland School of Minerals \& Petroleum, Greenland Petroleum Services 2016).

The protest movements that have been formed after the drilling activities of Cairn Energy finished in 2011 are illustrative of the increased level of awareness of extractive industries in Greenland (personal communication - interview KANUKOKA 2016). Examples are the Nuup Kangerluata Ikinngutai (Friends of Nuuk Fjord) protest movement against the iron ore mine near Nuuk, and the Urani Naamik! (No to uranium) movement against the rare earth / uranium mine in South Greenland. These protest movements were sparked by environmental concerns, the feeling that the government did not pay attention to the stakeholders' point of view and did not hear their critical voices during the hearing process (Nuttall 2015). As no large oil and gas activities have taken place after these protest movements towards the mining industry, it is unclear whether they will be formed against oil and gas activities in the future.

In general there existed and is still existing a willingness among Greenlandic people, organisations and companies to engage with the IOCs (personal communication interview CSR Greenland 2016). The positive attitude towards the oil companies is primarily driven by the awareness that the economy needs diversification to enhance job opportunities (personal communication - interview NunaOil, CSR Greenland, KANUKOKA 2016). Over time, also the awareness among Greenlandic people and civil society organisations about the risks of offshore oil and gas activities has risen. People are aware of the potential environmental impacts and what this could mean for traditional activities like fishing and hunting for seals or other marine mammals. However, the general perception of the interviewed Greenlandic stakeholders is that in the end people and politicians will favour the economic benefits (related to the perception of increased welfare and a potential future independence) over the environmental concerns (personal communication - interview CSR Greenland, KANUKOKA, WWF, Greenland Petroleum Services 2016).

The IBA is a legal requirement that is aiming to maximise the economic benefits for society in Greenland. The funds that are associated with an IBA are divided in a fund for educational purposes and a fund for cultural purposes. Both funds are governed by a 
committee, consisting of various Greenlandic stakeholders (personal communication - interview Greenland School of Minerals \& Petroleum 2016). In case multiple oil and gas companies have an IBA with the government at the same time, all contributions are deposited in the same fund. By having an impartial committee deciding on the allocation of the money that is deposited in the fund, the level of transparency is enhanced. By having an impartial committee, a company cannot be accused of 'buying' its social license to operate by funding specific projects or stakeholder groups directly. The education fund is aiming to raise the level of education and support the development of qualifications necessary to participate in the industrial activities. This is enhancing the chances for people to grasp the economic benefits in terms of employment, thereby providing a stronger basis for economic output legitimacy.

In order for a social license to operate to exist in Greenlandic society, the main elements are economic and educational benefits (personal communication - all interviews 2016), with an open and transparent decision making process in which the concerns of society are addressed. In terms of trust and legitimacy, the social license to operate is mainly based on economic output legitimacy and throughput legitimacy combined with building of personal trust.

\subsection{Trust and legitimacy as key elements in the interaction between the political, legal and social licenses in Greenland}

Given the context of the three licenses as elaborated upon in the previous section, this part of the chapter analyses the role of trust and legitimacy in the interaction between the political, legal and social license to operate. Although large scale societal unrest concerning offshore oil and gas development has not occurred in Greenland to date, one cannot conclude that there is a social license to operate. Interestingly, the critique of Greenlandic civil society and companies about the distribution of local benefits and a lack of information with regards to oil and gas exploration is not so much aiming at the oil and gas companies, but is rather aiming at the government.

As this case study shows, the expected economic benefits mainly generate the acceptance of oil and gas activities in Greenland. However, the capacity of the government to secure and maximise these economic benefits, while at the same time effectively dealing with the environmental and social risks, is questioned by Greenlandic society and NGOs. This is further enhanced by the feeling of citizens and NGOs that the government is not taking into account their concerns raised during the public consultations. Driven by a focus on additional income and economic diversification, the government would not be sufficiently critical towards the international companies 
that bring in the new activities. In addition, the integrity of the political system in general is being put under pressure as a result of recent scandals. The lack of openness and transparency of the main responsible government authorities in the decision making process related to oil and gas projects, has not helped to convince societal actors that the government is acting in their interest. It can thus be concluded that the level of competence based institutionalised trust is low, the integrity based institutionalised trust in the government is under pressure and also the throughput legitimacy is low. As a result, citizens and NGOs demand a larger formal role in the decision making process.

The Greenlandic government is trying to act on this critique by proactively amending the legal framework. Trying to accommodate the requirements of societal actors, the Greenlandic government has already amended the regulatory framework twice since 2009. The changes included amongst others more public consultation and a restructuring of government authorities to divide responsibilities. These measures were implemented to create more openness and transparency, to enhance the feeling that stakeholders can meaningfully participate in the decision-making process and to increase the opportunities for personal trust building through interaction. Due to the changes that have been introduced over the past years, a number of social license to operate elements related to openness and transparency, as well as personal trust are now formalised in the legal framework.

The proactive attitude of the government has both positive and negative consequences. The positive side is that citizens and NGOs have the feeling that something is being done and that the government is willing to improve. Furthermore, the wish of stakeholders to get a larger formal role in the national decision making process is being accommodated. However, having people meaningfully participate in the extended consultation process is a challenge in terms of both physical and intellectual accessibility to the consultation process. As the offshore oil and gas activities could potentially affect a large coastal area, it is a logistical challenge to give every local community a chance to be involved in the decision making process (personal communication - interview NunaOil 2016). Many cities and villages are isolated from each other and can only be reached by airplane/helicopter, if the weather is good, or by ship, if the waters are not frozen. Furthermore, the level of English and sometimes also Danish can be very low. Ensuring that everybody can meaningfully participate and contribute to the decision making process, requires that people understand the information documents and what is being said. Given that the amount of Greenlandic translators is limited and need to compete with other international industries, such as the mining activities, it is a challenge to make all information accessible in time. To assist the international companies in this challenge, 
the national oil company of Greenland, NunaOil, supports them in overcoming some of the logistical and language barriers by providing assistance in arranging a proper means of travel and translating services (personal communication - interview NunaOil 2016).

Moreover, changing the regulatory framework by adding requirements to the procedures for obtaining a legal license can negatively influence the decisions of international companies to invest in oil and gas activities in Greenland. Frequent changes can create an image that the rules of the game are fluid, making long term investment decision more risky. At the start of the investment no one knows what the future will bring and what the financial implications of the potential changes will be. Especially since Arctic operations are already more expensive than oil and gas activities elsewhere in the world, a stable political climate and clear rules of the game are even more important for investors.

The Greenlandic government, as an important actor in the political license, is not only proactively changing the regulatory framework to improve the level of trust in society and make its decisions more legitimate, but it is also playing a large role in facilitating the relationship between international companies and local stakeholders. The national government is taking the lead in the consultation process, initiates the town meetings and arranges a translator (Mineral Resources Act, part 18a, 87). By doing this, the government succeeds in creating an easy to work environment for the international companies, next to the logistical and technical challenges they face when developing activities in Greenland. On the one hand this is beneficial for the oil companies, who are still in the exploration phase and activities are performed while keeping expenses as low as possible and with an exit plan in mind (personal communication - interview Shell). However, as a consequence the government is taking on more responsibilities, while its capacities are already questioned.

Local people often address their complaints or concerns regarding a specific project or company to government authorities, rather than to a company itself (personal communication - interview Greenland Government 2016). Society predominantly considers the government to be mainly responsible for the oil and gas development. Due to the active role of the government in the entire decision making process, companies themselves are less visible. This creates a threshold for society to come into contact with them and making it easier to hold the government responsible. The large role of the government combined with the historically close connection between local communities and NGOs on the one hand and public sector decision makers on the other hand (personal communication - interview CSR Greenland 2016), is fostering this 
process. This is even further enhanced by the absence of a requirement for companies to have a grievance mechanism in place until recently (personal communication interview Greenland Government 2016).

On the one hand, the proactive attitude of the government and formalisation of society's requirements into the legal framework is positive for companies, because it facilitates stakeholder engagement and people voice their critique to the government in the first place. However, on the other hand there is also a risk for the companies in the increased responsibilities of the government: Due to the limited capacity of the government to execute the increased number of responsibilities, induced by the additional requirements in the legal framework, society is not necessarily satisfied. Combined with the low level of competence and integrity based institutional trust in the political system and the perceived lack of throughput legitimacy of the decision making process governed by the authorities, companies cannot assume a social license to operate already exists. The absence of a social license to operate voiced as critique towards the government might not directly harm companies or their reputation. It is nevertheless likely to affect the decision making process regarding their legal license to operate due to a lack of or decreasing level of political license.

\subsection{Conclusion}

The social license to operate concept has emerged to address a worldwide trend of increasingly empowered civil society actors combined with a decreasing level of trust in the political and legal system. Remarkably, existing scholarly literature does not discuss the interdependencies between the emerging social license to operate concept on the one hand and political and legal licenses to operate on the other.

This chapter used a more integrated approach by studying the role of trust and legitimacy related to the social, legal and political licenses: The political license is mostly dependent on institutionalised trust and input legitimacy, whereas the legal license is predominantly focussing on throughput and output legitimacy combined with institutionalised trust. The emphasis of the social license to operate is in contrast on personal trust, output and throughput legitimacy. It can thus be argued that the licenses are complementary to each other, as each have a different emphasis with regards to trust and legitimacy.

Based on a lack of throughput legitimacy, integrity- and competence-based trust, Greenlandic stakeholders have put pressure on the political system outside the regular election procedures. It illustrates how the level of the social license to operate 
is influencing the political license, which in turn influences the legal license: The legal framework now includes an increased number of mandatory interactions with stakeholders to enhance throughput legitimacy and personal trust building via faceto-face interaction. Furthermore, by redefining the responsibilities of government authorities, the legal framework is also used to increase the level of integrity-based institutional trust. Instead of substituting for any existing gaps, a social license to operate can thus enhance a legal license. The legal license can in turn contribute to establishing a social license to operate as well.

It can however be questioned whether the proactive role of the government will have the desired effect, namely broad societal support for the development of oil and gas activities. The relationship between the government, as the main actor involved in the legal and political licenses, and society is far from optimal. It is doubtful whether this will improve after the recent legal and political changes. Critique on the government still exists, but large scale public protests related to future oil and gas activities have not occurred in Greenland to date. However, the most recent exploration drilling activities took place in 2010 and 2011, while the amendments to the legal framework were made in 2012 and 2014. Since then most oil and gas activities have come to a halt, making it difficult to assess whether protest would arise if activities would be developed today. Given the status of the relationship between Greenlandic society and the government, it could be more beneficial for a social license to operate of oil and gas activities when the involved companies take on a more proactive role, in cooperation with the government.

The analysis in this chapter shows that an integrated approach towards a social license to operate, in which the role of the political and legal licenses is taken into account, helps to understand the way in which trust and legitimacy for a certain activity are shaped. A number of initial expectations have been put forward about the specific way in which the different licenses contribute to the acceptance of an activity by society at large. Further research will have to be conducted to find out which conditions influence the way in which the different types of trust and legitimacy are related to each of the three licenses identified. 


\section{CHAPTER}

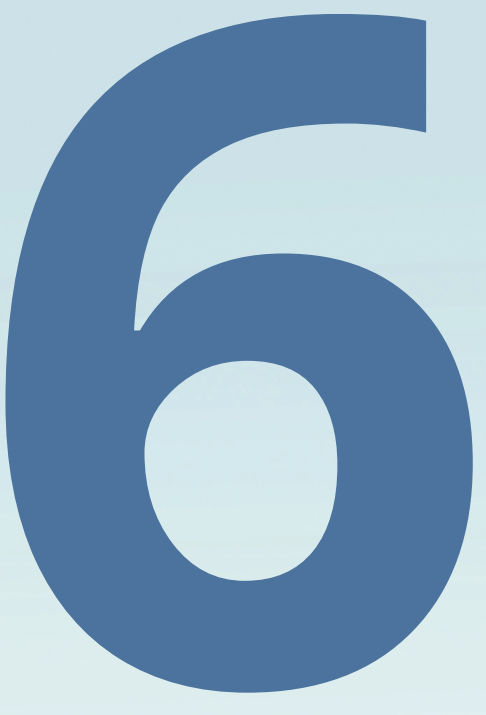




\title{
Multi-level dynamics in a social license to operate: What can we learn from Arctic oil and gas development?
}

\author{
C.C.A. Smits \\ J. van Leeuwen \\ T.F. Huber \\ J.P.M. van Tatenhove
}




\section{ABSTRACT}

The transition from fossil fuels to renewable energy has environmental, spatial as well as social and economic consequences, as new infrastructure for the production, transportation and storage of (renewable) energy will arise. Both (existing) fossil fuel and renewable energy activities face social resistance. The social license to operate concept is used in a growing body of literature to study social resistance against energy activities, but predominantly uses a local level perspective. However, the production, transportation and storage of energy is not solely a local or national affair. Noting this contradiction between a local empirical and conceptual focus of the social license to operate literature and the emergence of a strong international public debate regarding energy projects, we expect there is a need to reconceptualise the social license to operate concept to consider these international dynamics. This chapter therefore explores a multilevel approach towards the social license to operate, by developing a set of hypotheses and a typology for the interaction of the social license at multiple levels. We draw on various examples within the energy domain that are or have been subject to societal debate, including the development of oil and gas in the Arctic and renewable energy in Europe. 


\subsection{INTRODUCTION}

Reducing $\mathrm{CO}_{2}$ emissions to minimise the effects of global climate change is high on the agenda in many countries in the world. The objective set by the Paris Agreement (2015) to limit global warming to 1,5 degree Celsius requires a transformation of the energy sector. To reach these objectives the share of renewable energy should grow, while the use of fossil fuel has to decline (International Energy Agency 2017). The transition from fossil fuels to renewable energy has environmental, spatial as well as social and economic consequences, as new infrastructure for the production, transportation and storage of (renewable) energy will arise. With the heightened urge to switch to renewable energy, the exploitation of non-renewable energy resources, such as oil and gas, is becoming increasingly subject to societal debate. Both existing activities (such as gas extraction in Groningen (the Netherlands), and new exploration initiatives (such as oil and gas exploration in the Arctic) face social resistance.

There is an increasing body of literature that studies resistance against the implementation of mining and energy activities, by using the concept of 'Social License to Operate' (Hall et al. 2015; Yates and Horvath 2013). This body of literature predominantly focusses on local level resistance to such industrial developments, both conceptually as well as empirically. The social license to operate concept addresses the emergence of increasingly critical civil society organisations and citizens at a local level that seeks to have influence on the development of large industrial activities. The capacity of local communities and civil society to delay or postpone permit procedures indefinitely has made companies and governments recognise the importance of obtaining and maintaining the consent of these stakeholders (Franks et al. 2014; Harvey \& Bice 2014; International Council for Mines and Metals 2010).

However, debates on climate change, the energy transition and associated energy development projects are debated internationally and a strong civil society exists that fuels this debate. Some examples are the Urgenda lawsuit against the Dutch government to accelerate carbon emission cuts and the \#SavetheArctic campaign by Greenpeace. Also in other ways, the production, transportation and storage of energy is not solely a local affair, for example commodity prices for fossil fuels (i.e. oil and gas) are global and renewable energy asks for transnational cooperation due to fluctuations in production and (currently) limited opportunities for large scale storage. Noting this contradiction between a local empirical and conceptual focus of the social license to operate literature and the emergence of a strong international public debate regarding energy projects, we expect there is a need to reconceptualise the social license to 
operate concept to consider these international dynamics. This chapter therefore explores a multilevel approach towards the social license to operate.

Given that the social license literature does not incorporate these multi-level dynamics, this chapter will offer a conceptual exploration of how the social license to operate manifests itself in a multilevel setting. In doing so it will develop a set of hypotheses and a typology for the interaction of the social license at multiple levels. We will draw on various examples within the energy domain that are or have been subject to societal debate, including the development of oil and gas in the Arctic as one of the most controversial energy activities of the last decade and the development of renewable energy in Europe. This set of examples does not only explore the differences between more authoritarian and deliberative state organisations, but also takes a closer look at both fossil and renewable energy development.

The chapter thereby aims to contribute to the current social license to operate discussion and theory. The conceptual contribution to the social license to operate concept presented in this chapter are based on empirical research, which includes primary data that was mainly obtained in two rounds of semi-structured interviews (2011 and 2016) with national and international actors involved in the oil and gas development in Greenland. The concepts presented in this chapter build on empirical findings about authority of Greenland (Smits et al.2014b), the role of human capital development in the social license to operate of Arctic energy development (Smits et al. 2016), and trust and legitimacy in the social license to operate of oil and gas development in Greenland (Smits et al. 2017).

Section 6.2 provides a brief summary of the traditional focus of the social license to operate concept. Section 6.3 elaborates upon globalisation and social license to operate processes. Section 6.4 considers the conditions for overlap to occur (or not) between the same licenses on different levels (nationally and internationally). It also explores the consequences of the potential (lack of) overlap. In Section 6.5, this chapter puts forward a number of hypothetical situations in which the licenses are presented as fully separated, fully overlapping as well as a number of hybrid situations in which licenses partly overlap. In Section 6.6, it is examined how in the case of oil and gas development in Greenland, the political, legal and social licenses manifest itself in a multilevel context and what we can learn from this empirical example. Section 6.7 outlined the conclusions and suggestions for further research. 


\subsection{Current conceptualisation of the social license to operate}

The social license to operate concept, recognizing the increasing ability of communities and civil society to effectively express their concerns, studies how this growing unrest in society influences the development of large, industrial activities. Generally, the social license to operate concept is defined as the ongoing acceptance and approval of an activity by local communities and other stakeholders (Thomson \& Boutilier 2011; Parsons \& Moffat 2014; Prno 2013). The literature has studied the factors that lead to obtaining a social license and how the existence (and absence) of a social license can be measured (Moffat \& Zhang 2014; Parsons et al. 2014; Yates \& Horvath 2013; Prno 2013; Prno \& Slocombe 2012; Thomson \& Boutilier 2011). Different forms of trust (personal and institutional) and legitimacy (input, throughput and output) are key to obtaining and maintaining a social license to operate. (Thomson \& Boutilier 2011; Smits et al. 2017; Van Tatenhove 2011), ranging from complete rejection to full acceptance (or identification) (Thomson \& Boutilier 2011)

However, trust and legitimacy of an activity is not only determined by the SLO, but in the interaction between the social license with the legal and political licenses (Smits et al. 2017; Morrison 2014). The emphasis of the different forms of trust and legitimacy differs per license (Smits et al. 2017). For example, in general a political license emphasises institutionalised trust and input legitimacy, while throughput and output legitimacy combined with institutionalised trust are supported through the legal license. The social license itself mainly focusses on personal trust, (economic) output and throughput legitimacy. Due to their emphasis on different forms of trust and legitimacy, it can be argued that the three licenses are complementary to each other (Smits et al. 2017).

Since the rise of the social license to operate concept is driven by empowered citizens and civil society organisations, who are increasingly dissatisfied with the implementation of industrial activities by private sector companies and the (lack of) enforcement by state authorities (Boutilier 2014), the concept and its practical application in industrial projects are mainly studied from a company's perspective within a national level context. The focus is mainly on the relation between private sector companies and local communities. For example Prno (2013), has studied the social license to operate in a national context, focussing on community acceptance in four different case studies comprising mining activities in the USA, Canada, Peru and Papua New Guinea. Riabova and Didyk (2014) have studied the relationship of two mining and processing companies with local communities on the Kola Peninsula and the Murmansk region in Russia. Yates and Horvath (2013) illustrated the importance of a local community's approval or acceptance of an activity using three different case studies: A hydroelectric project and 
a LNG project in Australia, and a LNG project in Indonesia. And Hall et al. (2015) looked at energy industries as a whole, to see how the social license to operate concept had been translated into practice. These and other studies have provided valuable insights and brought social considerations within both projects and companies to the next level.

Since an activity does not only have a relationship with a local community, but has an array of relationships with multiple actors, including governments, some scholars have been rather critical to the narrow focus of the literature on communities and companies. Identifying those stakeholders that might influence a SLO is in fact one of the key challenges (Filer and Gabriel 2018; Wilburn and Wilburn 2011). Extending this critique, we argue that the array of stakeholders not only manifests itself on the local or national level, but also on the international and transnational level. The complex, transnational problems that society faces today go beyond the authority and span of control of individual nation states. Also (environmental) concerns and politics regarding large industrial activities, such as oil and gas development, do no longer confine themselves to the national level. The influence of globalisation and with that the increasing influence of transnational actors, politics and societal debates and their profound effect on the social license of industrial (energy) activities will only increase in the future.

\subsection{Globalisation and social license to operate processes}

The social license to operate literature has not yet acknowledged the potential influence of globalisation dynamics. While the very origin of the social license to operate concept is explained by the failure of the political and legal systems of a nation state and the shortcomings of private sector companies in the local implementation of an activity, the concept in its current form does not analyse the way in which globalised civil society and policy networks change national and local social license to operate processes. Worldwide protest actions against Arctic oil and gas, but also against climate change and rainforest destruction illustrate the increasingly international character of civil society activity. Protest actions are often executed locally, like scaling a drilling rig, but are supported, sparked, organised and debated in the (international) digital world on social media. Internet and social media enable citizens around the world to connect with each other faster and against lower cost than ever before. Citizens increasingly use (social) media and the internet to seek information and stress their point of view at any moment in time (Cullen-Knox et al. 2017; Yates \& Horvath 2013).

To incorporate a multilevel component in the social license to operate concept, we build upon the theory of Rosenau (2003). Rosenau focusses on the role of nation states 
at both the national and international level, thereby providing useful input for the operationalisation of multilevel political and legal licenses as part of the social license to operate concept. He states that over the last decades, the role of nation states has been transforming due to a number of social changes, including globalisation and the empowerment of citizens and civil society. These social changes do not only affect the political and economic domains within countries, they also drive a de-territorialisation of politics (Rosenau 1997, 2003, 2006). This de-territorialisation has led to the emergence of horizontal relations in networked governance arrangements and to a multi-centric world, where there is a whole plethora of sovereign-free actors that gain power and authority (Rosenau 2003). Rosenau stresses that a bifurcated system has emerged in which actors in the state-centric world compete, cooperate, interact or coexist with counterparts in a multicentre world comprised of an array of diverse actors and rule systems. This has implications for especially the political and legal licenses of energy projects as a multitude of political and legal forums, at different levels, can influence the political and legal licenses of local energy developments.

The skills revolution of citizens in turn provide for a stronger civil society. In the multilevel dynamics of civil society in this networked, multi-centric world, internet and social media play an important role. They enable networks to share information instantly, coordinate actions and manage complexity while retaining flexibility (Castells 2000). It also allows networks to grow and become truly global, as the high costs associated with geographical distances and thus the international information exchange via air travel, mail or telephone and the associated language barriers have vanished (Keck \& Sikkink 1999). Information is increasingly accessible, shared and contested via internet, which is in turn increasingly easy to access on tablets and smartphones for large groups in the world (Pew Research Center 2016). Castells' concept of the network society provides useful input on the operationalisation of an international level social license to operate. Individual citizens and/or NGOs are the most important actors driving societal debate. Internet and social media offer citizens and NGOs a means of what Castells (2007) calls 'mass self-communication' meaning "many-to-many in the sending and receiving of messages in a multimodal form of communication that bypasses mass media and often escapes government control". It can be used as space for dialogue and a tool to mobilise large groups of people instantly. Furthermore it works in a way that closely connects to the very nature of NGOs who, together with individual citizens, drive the international societal debate on energy issues in practice: they use simple messages supported by strong images to convey a message and influence social change (Castells 2008). Since internet and social media are local and global at the same time, they can be regarded as an important means of connecting different (social) licenses on the different levels. 
It is this mutual influence and potential tension of the interaction between licenses on multiple levels that is explored further in the remainder of this chapter.

\subsection{Exploring the conditions and consequences of overlapping and separate licenses on the national and international level}

In exploring a multilevel conceptualization of the social license to operate concept we first examine under what conditions and with which consequences the individual political, legal and social licenses overlap or exist separately on the national and international level. For the purpose of this hypothetical exercise only the two extremes are being considered: The national and international licenses are either fully overlapping and can therefore be regarded as one, or the licenses are not overlapping at all and can therefore be regarded to be separate.

When considering the connection between the same licenses on different levels, the authors note that the speed with which the licenses connect with each other on different levels may also vary. Internet and social media play a major role in the social license to operate and have the ability to connect large groups of people and organisations instantly. The connection between legal licenses on multiple levels is often much slower and of a more indirect nature: The effect of international binding agreements on national level legislation might take years. The connection between the national and international political license lies somewhere in between: Formal international political decisions can take years to trickle down in national realities, while national politicians nowadays also increasingly use internet and social media to convey their (international) point of view and thereby try to influence people's minds and social change directly.

\subsubsection{Conditions for and consequences of overlapping or separate political licenses}

In order to be able to speak about one political license, where the national and international levels fully overlap, hypothetically a strong international political forum or government should exist. This would mean that (a large part of) the political mandate of nation states has been transferred to the international level. In this situation, core decisions on global topics (in this case energy development) would be taken at the international level. The influence of the international level on national level politics would be large, as the main decisions would be taken internationally. Consequently, the distance between decision makers and local communities would grow.

Separate national and international political licenses would exist when the core decisions in e.g. the energy domain are taken at the national level. In this case, international political decisions are marginal and would not have a major influence 
on national level politics. As a consequence, international stakeholders that want to influence political decisions will have to aim at national level decision making processes. Achieving alignment between nation states on global issues such as energy (transition) would be time consuming, as global goals (less $\mathrm{CO}_{2}$ emissions from fossil fuels) do not necessarily match national interests (job creation and tax income from oil and gas activities).

\subsubsection{Conditions for and consequences of overlapping or separate legal licenses}

If an overarching, binding international legal framework for (Arctic) oil and gas activities would exist, one could imagine that the national and international legal licenses would fully overlap and therefore be one. This would mean that the same conditions for oil and gas activities would apply to all Arctic countries, thereby creating a level playing field for international oil companies and enabling knowledge transfer and capacity exchange between countries. The enforcement of the legal framework could for example be organised internationally with the help of national departments, so as to ensure to be close to the locations where the activities are actually being implemented. Having one international legal framework in place would leave nation states with fewer possibilities to amend the legal license and tailor it to local concerns.

Separate legal licenses would exist when there is hardly any/no interaction between the national and the international legal licenses. This could be the case when nation states decide not to be part of the few international binding agreements that exist in relation to oil and gas activities. When the majority of the (Arctic) states is not part of an international agreement or hardly any/no international agreements exist at all, it is likely to result in a fragmented Arctic governance setting for oil and gas activities: Each country has its own legal framework and conditions that companies need to comply with. The enforcement of the legal framework would in this case depend on national authorities and their individual capacities (or lack thereof).

\subsubsection{Conditions for and consequences of overlapping or separate social licenses}

One could envisage that when the goals, values and beliefs of the national and international social licenses are the same and when individuals and organisations of the national level are active on the international level (and vice versa), the social licenses of both levels fully overlap and can therefore be regarded as one. This means that citizens and/or national civil society organisations are immersed in and co-shaping the societal debate held on the international level, and the international debate is in turn shaping the national level societal debate. It is hypothesised that the licenses of both 
levels can only fully overlap when all actors have access to the debate and no barriers exist in terms of for example language proficiency and internet access.

Two separate licenses could be identified when there is hardly or no connection between the national and international level societal debates. This could be the case when there is limited access from the national level to the international level societal debate, for example because of limited internet access or language barriers. Divergent stakes and viewpoints regarding the same activity could also be a reason of a lack of connection between both levels, resulting in contradicting licenses. These contradictions could make it difficult to balance the stakes of both societal debates for the proponent of an activity, if the actor is active on both levels (such as an international oil company).

It should be noted that the social license to operate is always an ongoing process that runs throughout the entire lifetime of an activity. It can change over time, meaning that also the degree to which the social licenses of the national and international level overlap might change.

\subsection{Exploring the multilevel interaction between licenses and the influence on the local implementation of an activity}

Now that we have explored the conditions under which the national political, legal or social licenses can overlap with or be separate from its counterpart at the international level, we can start to conceptualise how the interaction between all licenses manifests itself. In order to do so, we develop a number of typologies in which the interaction between licenses is explored. We first identify three main categories of multilevel social license to operate processes, based on the level of overlap (fully overlapping, partly overlapping, not overlapping). In a second step we further operationalise the hybrid type of partly overlapping licenses as this category in itself can come in various forms. The full set of types are:

1. All licenses are separate: Each license occurs both at the national and the international level, but there is no multilevel interaction between the licenses.

2. All licenses are one: Each license fully overlaps with its national/international counterpart.

3. Licenses are partly overlapping. To further operationalise this, three hybrid types can be distinguished based on which licenses partly overlap:

a) There is one social license (national and international fully overlap), but there are separate political and legal licenses on both levels. 
b) There is one political license and one legal license (for these two licenses the national and international level fully overlap), but the social license is separate.

c) All licenses partly overlap with their national/international counterpart.

We do recognize however, that not all types mentioned above are likely to occur in practice. Type 1 and 2 are considered to represent the extremes (fully separated and fully overlapping) and are mentioned above to provide a complete overview. Type 1 , where there is no interaction between licenses at all, is in the current globalised world not likely to occur. This is even more the case with regards to energy developments, as there is always interaction between international and national level via political and policy processes as well as market prices and investment decisions. Type 2, where all licenses fully overlap with their national/international counterpart, is also not likely to occur as it would assume that national boundaries have completely evaporated. Since energy is still considered to be a matter of national security, this is not considered realistic even in the current globalised world.

The hybrid types are therefore regarded to provide the best reflection of the interactions that could take place between licenses on different levels. For hybrid type a) and b) to occur, it is hypothesised that one legal license for both the national and international level can only occur when there is also one political license for both levels. The reason is that for such a dominant (international) legal framework to be put in place, nation states would have already had to transfer most of their legislative authority to the international level. This implies that there is also a political consent and overlap between the national and the international level. Below, different cases are used to illustrate each of the aforementioned hybrid types: Oil and gas development in Russia is illustrative of hybrid type a), renewable energy development in Europe is used as an example of hybrid type b), and the case of oil and gas development in Greenland is used to illustrate hybrid type c).

\subsubsection{Hybrid type a) One social license, but separate legal and political licenses}

In this hybrid type there is one social license to operate, but separate legal and political licenses to operate for the national and international level (see Figure 6). This type is thought to occur when nation states, as leading actors in the political and legal licenses, do hardly/not participate in international governance arrangements and have their own regulatory framework. However, citizens and NGOs participate in an international societal debate, where shared goals and views are dominant. It could be argued that in this type the political and legal licenses on the national level are organised in a state- 
centric and traditional way in which hierarchical power dominates, while the social license has evolved to a transnational arrangement. For an (international) proponent of an activity this would mean that it is subject to two, potentially conflicting regulatory frameworks and political decisions at different levels. It could be hypothesised that when the national and international social licenses are one, the social license has a greater power to pressure nation states and/or the activity's proponent in order to achieve changes in for example the conditions of political and/or legal licenses and/or influence directly the way in which the proponent implements the activity.

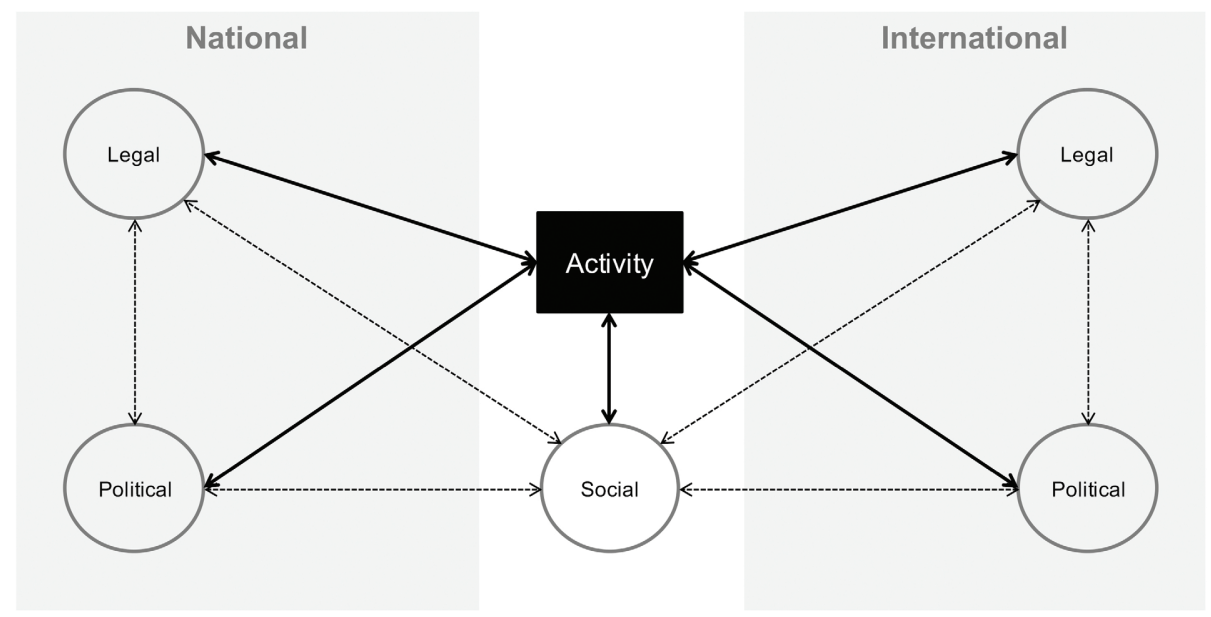

Figure 6: One social license, separate legal and political licenses

An example of this type is oil and gas development in Russia. Although Russia is part of several international binding (environmental) agreements, such as the Paris Agreement and the Kyoto Protocol, the translation into domestic policy is slow (Henry and Mc Intosh Sundstrom 2014, 2012) and participation in environmental agreements is mainly focussed on achieving other benefits, such as great power status and economic advantages (Newell and Henry 2016). During the summer of 2014, it was even considering to eliminate environmental impact assessments for projects, including offshore oil and gas drilling (ibid.). Illustrative for Russia's non-interference policy is its withdrawal from the Energy Charter Treaty. Russia signed the Energy Charter Treaty in the 1990s, but never ratified it because it would have too much influence on domestic policies and the management of Russian petroleum resources (Austvik and Lembo 2016). Eventually Russia withdrew from the Energy Charter Treaty in 2009 (Roche and Petit 2009). 
However, the international and national social licenses (consisting of environmental NGOs) are well connected. For various reasons it can even be regarded as one social license: The licenses share the same goals, values and beliefs, namely to protect the environment from the negative impacts of oil and gas activities and to prevent the degradation of the existing legal framework. The Russian government is trying to limit the (international) influence of this one social license and trying to move the two licenses apart, by imposing the Law on Foreign Agents in 2012. This law requires that "public organizations receiving foreign funding and engaging in "political activity" register as "foreign agents," pay significant fines, or cease operating" (Newell and Henry 2016). In 2015, a number of NGOs with an explicit environmental purpose were registered as foreign agents by the Ministry of Justice (ibid.).

In sum, in hypothesising on how the interaction between different licenses at multiple levels can look like, this type shows that while the political and legal licenses are different at the international and national level, the social license at the international and national level could still converge into one. In the case of Russia this has been a result of a conscious attempt of the government to keep full control over the political and legal decisions on energy developments.

\subsubsection{Hybrid type b) One legal license and one political license, but separate social licenses}

Another hybrid type that could occur is that there is one legal license and one political license, but that there are separate social licenses to operate for the national and international level (see Figure 7). In this type a nation government supports a strong political forum that shapes the political license not only internationally but also nationally. Moreover, there also exists an international legal framework that has been ratified and translated into the national one, creating overlapping legal licenses. However, this does not necessarily means that local/national societal stakes (i.e. job creation by developing oil and gas activities) do not differ from international societal stakes (i.e. combatting climate change by stopping oil and gas activities). 


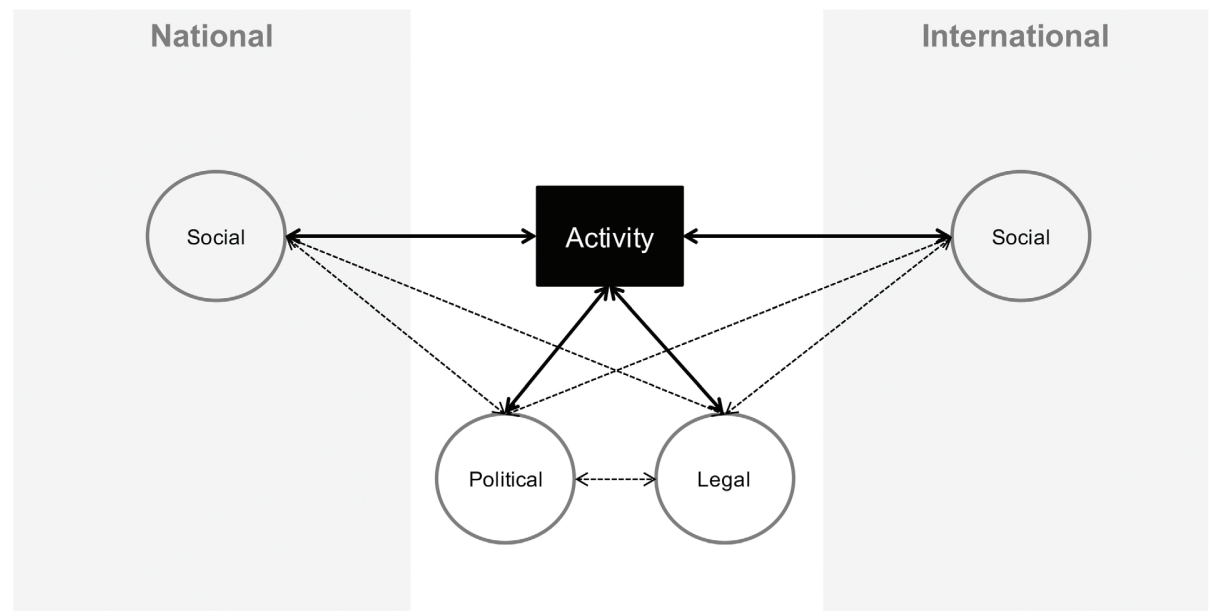

Figure 7: One legal and one political license, separate social licenses

It is likely that a continuous power play exists between civil society on both levels, who are trying to influence the implementation of the activity via the project proponent and/ or the state actors of the legal and political licenses. This could result in:

- Changes in the political and/or legal licenses; or

- Changes in the practical implementation of the activity (within the boundaries of the existing legal framework); or

- Cancellation of the entire activity, due to the impossibility to balance the different societal stakes and the risks this could impose on for example the proponent's reputation.

Hypothetically the political license could also get separated into a national and an international license (thereby also separating the legal licenses into a national and international license). In this case all licenses become separated, corresponding with type 1 mentioned at the start of this section.

An example of this type is the development of wind farms on land or near the coast in several European countries. The national and international political and legal license regarding the development of wind energy in European countries are often very closely connected, since the national level development of wind energy is driven by formal EU regulations (Directive 2009/28/EC) and international treaties (Paris Agreement). International environmental NGOs as part of the international civil society are advocating for a transition towards 100\% renewable energy generation and see wind energy as a solution that contributes to achieving this goal (Greenpeace 2015; Cambridge Econometrics for Greenpeace and WWF-UK 2012). However, nationally the development of wind farms on 
land and near the coast faces societal protest. In the Netherlands Dutch fishermen have sailed into Amsterdam as a protest against new offshore wind farms (The Guardian 2018) and citizens have organised petitions and other forms of protest against local wind farms on land (De Volkskrant 2017; AD 2017); in France fishermen, residents and dockers protested against the development of wind farms (The Local 2018). The international and national social licenses in these cases are clearly not aligned and can be defined as separate licenses.

In sum, this hybrid type draws attention to the fact that while both political and legal licenses might be strongly influence by international policy making, civil society does not necessarily have to be. There can still be differences in the kinds of stakeholders and concerns that influence the debate over the activity at the international or national level. Indeed renewable energy developments have - in general - strong civil society support at the international level, but face resistance at the local level.

\subsubsection{Hybrid type c) All licenses partly overlap with their national/international counterpart}

Another hybrid form that could also be hypothesised, is when none of the licenses are fully overlapping nor are they fully separated from their national/international counterparts (see Figure 8). An example of this type is the oil and gas development in Greenland. Since this is the most complex type with the highest number of licenses and interactions involved, a more extensive analysis of this type is presented in the following section by using the example of oil and gas development in Greenland.

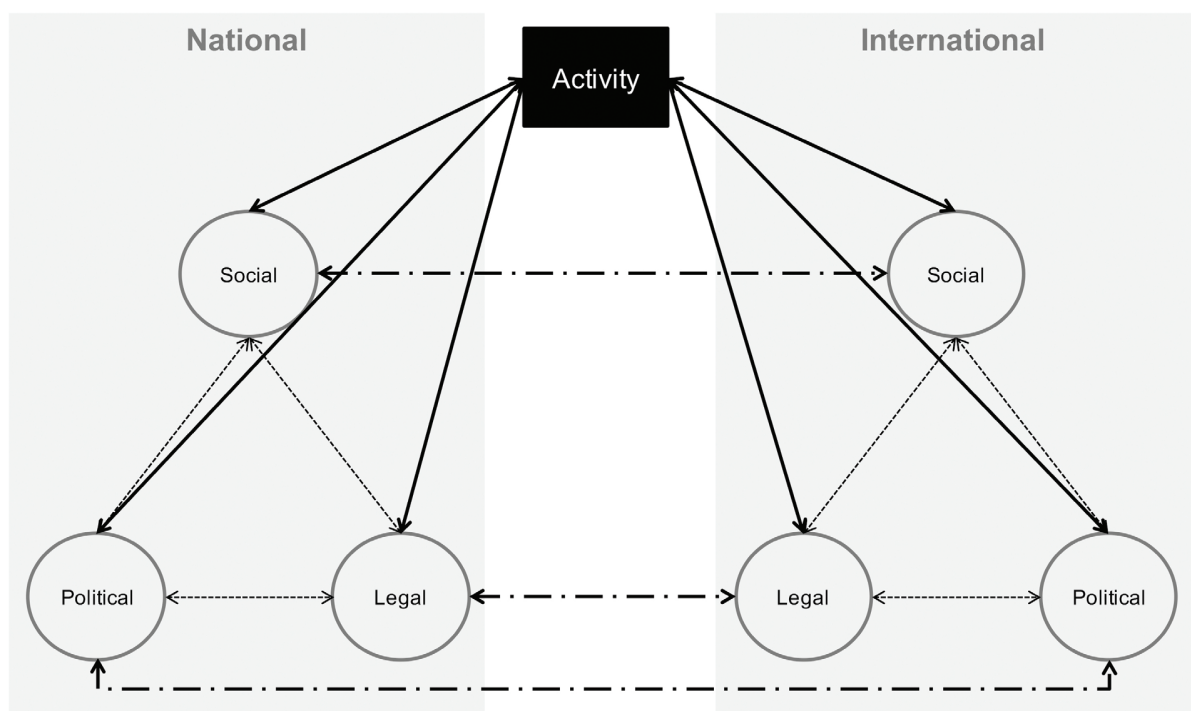

Figure 8: All licenses partly overlap with their national/international counterpart 


\subsection{Oil and gas development in Greenland as an example of a multilevel social license to operate}

The case of oil and gas development in Greenland illustrates that one activity's social license can be under pressure on both the national and the international levels at the same time. What is noteworthy is that the focus of the debates on these two levels is different and that both debates do not necessarily interact. They both however have the potential to influence the social license and therefore the implementation of the activity. Before the political, legal and social licenses are analysed in their multilevel context in more detail, the case of oil and gas development in Greenland is introduced.

\subsubsection{Oil and gas development in Greenland: national and international dynamics}

Energy development in the Arctic is highly politicised and predominantly a national affair. Because energy is a matter of national importance, the majority of the applicable rules and regulations are organised at the national level. Similar to other Arctic countries, also Greenland expressed its ambition to develop its potential oil and gas resources as a means to diversify its economy and become financially independent from Denmark (BMP 2009a; BMP 2009b). Some of the world's largest international oil companies obtained licenses to explore for oil and gas resources in Greenlandic waters (incl. Shell, BP, Chevron, ENI, Statoil and Conoco Phillips - govmin.gl). During the good weather seasons of 2010 and 2011 Cairn Energy drilled eight exploration wells in the waters of West Greenland (govmin.gl). These drills were not only subject to a national debate, but were at the same time also part of a bigger international debate on Arctic oil and gas activities.

The national debate mainly focussed on the balance between potential positive impacts, such as increased national income and job creation, versus potential negative impacts such as an oil spill. The international debate mainly focussed on whether the world should want to develop oil and gas in the Arctic given the impacts of climate change and the risk of an oil spill to the already sensitive environment (Smits et al. 2017). These two debates briefly coincided when Greenpeace scaled the rig that was performing the drills in both 2010 and 2011. The international debate was shaped by state actors in intergovernmental fora (United Nations), by scientists, by international Non-Governmental Organisations (NGOs), and by individual citizens in court cases and digital arenas. Individual companies and projects were subject to global scrutiny and international protest actions initiated by NGOs and often spread through (social) media and the internet. As simple messages are often the strongest messages, the most prominent companies and their most controversial projects were used to convey 
a point of view. An example is the \#SavetheArctic campaign by Greenpeace focussing on Shell's activities in Alaska.

\subsubsection{The political license at the national and international level}

Greenland has a democratically elected government that governs all aspects of oil and gas development. Also in other (Arctic) countries, energy development is a highly politicised and predominantly national affair: This is fostered by the point of view that energy is a matter of national importance and that the majority of the applicable rules and regulations are organised at the national level. For various reasons the governments of the Arctic states were looking to explore for new offshore oil and gas resources in their waters at the start of this century: The Greenlandic government wanted to develop oil and gas resources to diversify its economy and gain additional income to become financially independent from Denmark (BMP 2009). Alaska was looking to develop new oil and gas resources to replenish the decline of existing ones (www.eia.gov; Resource Development Council n.d.), while Russia as well as Norway were looking to expand their existing oil and gas exports as part of their export strategy (CIEP 2015; Vidal 2016).

Even though the development of oil and gas is mainly organised at the national level, within the larger domain of energy development it is also subject of global politics. As global politics is increasingly based on non-institutionalised inter-state cooperation combined with a range of interactions between state and non-state actors (Rosenau 1997, 2006; Beck 2005; Ferguson and Mansbach 2007) we need to look at a range of platforms and institutions to find sources of an international political license. At the international level, political processes are embedded in intergovernmental forums such as the United Nations, The World Trade Organisation etc. The organisation and mandate of such intergovernmental fora however differ and other inter-state and forms of cooperation have emerged as well (e.g. in Roundtables for Sustainable Development or the Forest Stewardship Council). Greenland is participating in a number of international platforms and institutions, including the Arctic Council and United Nations, mostly via Denmark as Foreign Affairs is a shared policy domain between the two (naalakkersuisut.gl).

\subsubsection{The legal license at the national and international level}

Typically, national laws and regulations determine where and how oil and gas resources may be explored and exploited. The national legal framework describes the steps and procedures that need to be followed in order to obtain a legal license. This involves procedures around environmental and social impact assessment, stakeholder consultation and impact benefit agreements. In the national context of Greenland, for example, licencing rounds are organised to open up certain areas for oil and gas 
exploration and exploitation. Companies that find it economically interesting and qualify to participate in these licensing rounds, put in a bid. The company with the winning bid is granted a license to explore or exploit for the resources in a specific area. Following the license, the oil company needs to submit a number of plans (e.g. an Environmental and Social Impact Assessment and a development plan) for formal approval by government authorities prior to any field work (govmin.gl). Which plans are needed, which government authorities are in charge of evaluating these plans and when and how these plans are made available to the public is set out in the Greenlandic Mineral Resources Act.

For the formulation of its Mineral Resources Act Greenland included elements of the existing laws in other (Arctic) countries, such as Norway, and international legal agreements, such as OSPAR (Vermont Law School 2011). Furthermore, Greenland is - via Denmark - part of a number of Arctic legally binding agreements including the Agreement on Cooperation on Marine Oil Pollution Preparedness and Response (2013) and the Agreement on Cooperation on Aeronautical and Maritime Search and Rescue (2011). The national Greenlandic legal framework applicable to oil and gas activities therefore overlaps with Arctic and international legally binding agreements. However, Greenland did not sign the Paris Climate Agreement (C.N.819.2016.TREATIESXXVII.7.d) and did not undertook any commitments under the Kyoto Protocol's second commitment period (2013 - 2020) (C.N.772.2017.TREATIES-XXVII.7.C).

Additionally, at the international level there is no common (Arctic) legal framework for oil and gas activities, it is rather a patchwork of different policies and agreements that partly cover the range of topics that need to be governed when developing oil and gas activities (Smits et al 2014b). As a result it differs per country what is expected to be studied from an environmental and social perspective, whether or not there should be an Impact Benefit Agreement (or something similar) in place, and whether or not an additional drilling rig should be located nearby to intervene when something goes wrong on the rig drilling the well (Dagg et al. 2011). Let alone that there is a governance arrangement or agreement that governs in which areas oil and gas resources will be developed and which areas will be closed for these developments. Also the Conference of Parties (COP) 21 under the United Nations Framework Convention on Climate Change (UNFCCC) that was held in Paris in 2015 did not include such a decision. The COP21 agreement set a goal to keep global temperature rise below two degrees Celsius, but left it to the individual countries themselves to decide whether this means that (some of) their oil and gas resources should be left in the ground. It can therefore be concluded 
that the legal licenses at the national and international level interact, but cannot be regarded as one nor are they completely separate.

\subsubsection{The social license at the national and international level}

At the time of the oil and gas exploration activities in Greenland a national societal debate arose on the trade-offs between positive impacts (i.e. increased national income and job creation) and negative impacts (i.e. in case of an oil spill). Furthermore, people and NGOs not necessarily criticised the company but the government about the way they were engaged in the (formal) decision making procedures: they demanded to have more opportunities to engage in the legal process and more time to make a meaningful contribution. As a consequence some nation states such as Greenland have amended their legal framework to varying degrees, to include moments and tools to engage with stakeholders during the decision making process (Smits et al. 2017). In this way civil society organisations and citizens have gained more opportunities to influence local and national level decisions related to oil and gas development.

The increasing oil and gas aspirations of the Arctic countries at the start of this century not only gave rise to national level societal debates, but also to an international protest movement, who was trying to limit and preferably stop new oil and gas developments in the region. Two international environmental NGOs (World Wildlife Fund (WWF) and Greenpeace) initiated the protest against Arctic oil and gas activities. They both launched Arctic campaigns that targeted the plans and activities of international oil companies and Arctic nation states to develop new offshore oil and gas resources. It is easier to prevent the development of new activities than to stop ongoing activities for which large corporate investments already have been made (personal communication - interview Greenpeace Denmark 2016). The actions and Arctic campaigns of these NGOs covered on social media, contributed to the mobilisation of public opinion around the world.

The relationship of both NGOs with indigenous communities in the Arctic is in many cases troubled due to the anti-whaling and anti-sealing campaigns of international environmental NGOs in the 1980s (personal communication - interview Greenpeace Denmark, WWF Greenland 2016). It was only in 2015 that WWF, as the first international environmental NGO, opened an office in Greenland (www.panda.org). Still there are conflicts of interest between the international environmental NGOs and the local indigenous communities. The NGOs see the Arctic as a pristine area and want to conserve what is there, including polar bears and marine mammals. For the communities the Arctic is their home and a place where they live and hunt the animals living there, including the polar bears and marine mammals (personal communication - interview 
Greenland Petroleum Services; WWF Greenland 2016). Also the focus of the societal debate is different on both levels: The national level focusses on a balance between risks and benefits, while the international level focusses on the contribution of oil and gas on climate change.

Even though there are a several reasons why separate social licenses to operate could be distinguished for both levels, there is also some (limited) interaction between the two: WWF has a local office in Greenland from where it contributes to the national level debate and tries to engage with Greenlandic organisations and people (personal communication - interview WWF Greenland 2016). And also Greenpeace contributes to the national level debate, albeit without a permanent physical representation within the country: They have amongst others used the formal public consultation procedures of the government to pose questions during public hearing sessions and make formal comments on the proposed plans regarding environmental issues, the lack of interaction and/or the lack of job generation (personal communication interview Greenpeace Denmark 2016). Also, when Greenpeace scaled the drilling rig of Cairn Energy in Greenlandic waters in 2010 and 2011, their action did not only spark international debate but was also part of the national debate. It can thus be concluded that even though both social licenses are separate and have their own specific focus, there are ways in which the international environmental NGOs interact with national level stakeholders and try to be part of the national level societal debate.

\subsubsection{Separate but interacting national and international political, legal and social licenses}

As the previous sections have illustrated, nation states have a central role in the political and legal licenses on the national level, but are one of many actors in different governance arrangements when it comes to the international political and legal licenses. The case of oil and gas in the Arctic shows that the national level social license debate in Greenland focussed on influencing the formal decision making of the national government, while the international level societal debate did not only focus on the national government(s) but also on general public opinion and private sector companies. The social licenses to operate debates on the two levels are too different to regard them as one. At the same time they are not completely separate either, as (limited) interaction was taking place between international and national level stakeholders.

The same accounts for the legal and political licenses: In the formulation of its legal framework, Greenland incorporated elements from existing laws and regulations of other (Arctic) countries. It also incorporated international legally binding agreements such as OSPAR of which it is, via Denmark, a part of. However, there are also some 
international legally binding agreements of which Greenland is not a part, such as the Paris Agreement, and at present an overarching international legal framework on (Arctic) oil and gas activities is non-existent. The legal licenses on the national and international level thus show some interaction, but cannot be regarded as one. The same accounts for the political licenses, because Greenland does participate in the international political arena via Denmark, but the core decisions on oil and gas development (including where to drill or not) are taken by national governments. The two levels thus interact, but cannot be regarded as one.

\subsection{Conclusion}

The cases of energy development in Russia, Europe and Greenland show that an activity can be debated at different levels at the same time. It also shows that the different levels interact and both have the potential to influence the implementation of the activity locally. Where the case of oil and gas development in Russia shows that the social license between both levels can be regarded as one, while separate legal and political licenses are distinguished for both levels. The case of wind energy development in Europe illustrates that the legal and political licenses on both levels are one, while separate social licenses exist on the national and international level. And last but not least, the case of oil and gas development in Greenland shows that each license exists on both the national and the international level, but interacts with its counterpart on the other level.

Hybrid situations such as in Greenland, where the licenses do not fully overlap and are not completely separate, are indeed becoming more likely in our globalising society. The nation states system still exist but is increasingly becoming networked through involvement in multiple governance arrangements across different scales. This bifurcated system, where the national state system evolves through its co-existence and interaction with the network (civil) society and global markets, influences the way in which the different licenses manifest themselves at different levels.

As licenses on both levels could influence the implementation of an activity locally, this chapter has studied the multilevel dimension of the social license to operate through a number of hybrid types where interaction and overlap occur (or not). This typology of hybrid SLO types helps to both conceptually and analytically identify how an energy development (or other large-scale industrial projects) can be influenced by different licenses, i.e. the political, legal and social licences, at multiple levels. Where this chapter has especially highlighted the national versus the international level, it is to be expected that the typology can also be applied on other levels, for example the local versus the national level. 
Incorporating a multilevel dimension in the social license to operate concept contributes to go beyond the narrow and local focus of the SLO concept and hence makes it more suitable to analyse the implementation of, among others, energy activities from a social perspective. Future research has to determine whether the typology developed in this chapter is complete or whether additional (hybrid) types can be defined. Moreover, a next step in furthering this conceptual framework would be to gain more insight in which conditions influence the overlap or separation between licenses on multiple levels. 


\section{CHAPTER}

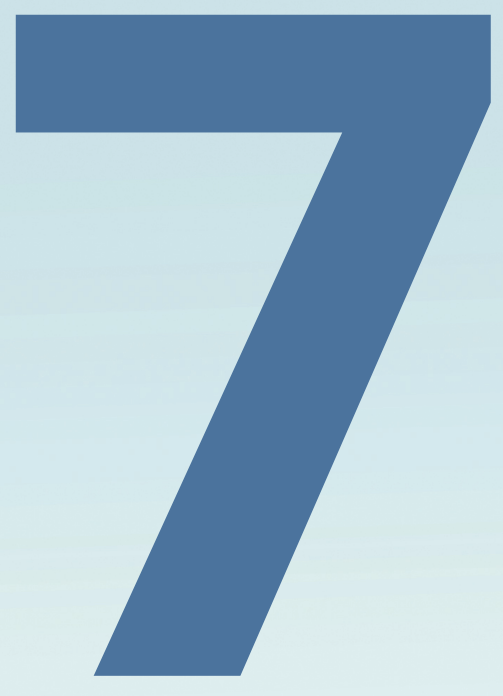


Conclusion 


\subsection{INTRODUCTION}

The development of offshore oil and gas activities in the Arctic has been one of the most controversial energy activities of the last decade and is subject to public scrutiny and protest. While it was once regarded as a frozen desert, the Arctic region has rapidly become the theatre of high level politics and global attention. Also Greenland, one of the smallest states yet biggest island in the world, expressed the ambition to develop offshore oil and gas activities. Opening up their waters for oil and gas exploration attracted the interest of some of the largest international oil companies as well as critique from individual citizens and other stakeholders within Greenland and far beyond.

The objective of this study was therefore to understand the development of a social license to operate of controversial energy projects by analysing the role of trust, legitimacy and human capital development in an Arctic context and by developing a multilevel approach of a social license to operate that includes legal and political licenses.

To reach this objective the following research question and sub-questions were posed:

How is the social license to operate of Greenlandic oil and gas activities influenced by legal and political licenses in a multilevel context, what is the role of trust, legitimacy and human capital development and how does this contribute to a multilevel approach of a social license to operate?

1. What is the multilevel governance setting in which Arctic oil and gas activities take place and what is the authority of a state such as Greenland?

2. What is a social license to operate and how does it relate to the legal and political licenses of oil and gas activities in the Greenland?

3. In what way do trust and legitimacy play a role in the different licenses to operate for oil and gas activities in Greenland?

4. What are the challenges and opportunities for Greenland to maximise local benefits in the development of an oil and gas sector?

5. In what way does human capital development contribute to a social license to operate for oil and gas development in Greenland and other small Arctic states?

6. How has the social license to operate of Arctic oil and gas activities developed at the international level and how does it interact with the local level?

In section 7.2 each of the research sub-questions is answered. Section 7.3 answers the main research question. Section 7.4 reflects on the contribution of this research to social 
license to operate and governance theory. Section 7.5 reflects on the methodology used during this study. In Section 7.6 the recommendations for future research and the daily practices of governments and companies are given.

\subsection{The social license to operate of Arctic oil and gas development}

This section answers the research sub-questions of this thesis. Based on the findings of this research, an analysis is made of how the social license to operate of Arctic oil and gas activities is influenced by the legal and political licenses in a multilevel context. This is done by looking at the role of trust, legitimacy and human capital development.

\subsubsection{The multilevel governance setting of Arctic oil and gas activities and the authority of Greenland}

The Arctic governance setting is fragmented and highly politicised, consisting of states, market parties, and several formal and informal institutions, such as the legal framework of UNCLOS and the intergovernmental Arctic Council. There was and is however no overarching legal framework, governing the development of new offshore oil and gas activities in this region. Within this fragmented, highly politicised and dynamic governance setting, Greenland gained extended autonomy under the rule of Denmark and expressed the ambition to develop offshore oil and gas activities. The oil and gas activities were expected to generate the necessary funds and employment opportunities to become financially independent from Denmark.

In order to maximally benefit from the oil and gas development it is necessary for the Greenlandic government to secure its central position and high degree of influence on the governance of oil and gas activities in Greenland. This accounts both to the regional level, when it comes to the influence of other states, as well as the national level, in relation to the influence of international oil companies. Regionally, other Arctic states will try to influence the Greenlandic oil and gas arrangements when Greenland becomes more independent from Denmark. Nationally, the limited capacity of the government in terms of manpower and knowledge generation is an important factor in the ability to enforce the Greenlandic legal framework on international oil companies. Furthermore, the influence of international and domestically organised civil society, and other partnerships with (Arctic) states or non-state parties is expected to increase. The increasing dependencies between the Arctic region and the rest of the world will produce a denser web of governance arrangements and will affect the authority of individual Arctic states. It is the increased nesting of these multi-level and multi-actor governance arrangements that shapes the authority of the Greenlandic government over its oil and gas resources. 
If the Greenlandic government wants to retain its central position and high degree of influence on the governance of oil and gas activities in Greenland, the capacity of its institutions should be the primary guideline for the pace of development. In this context capacity accounts to both a sufficient number as well as competent staff that have the right set of knowledge and skills to govern these new oil and gas activities. If the institutional capacity is not taken as a primary guideline, the Greenlandic government will formally remain the most important player while de facto other actors, whether it is the industry, (Danish) research institutes, or other states (through the Arctic Council) will take over their position and benefits flow to other places.

\subsubsection{The social license to operate and the need to study it in relation to the political and legal licenses of Greenlandic oil and gas activities}

Traditionally, the development of oil and gas activities was an affair of oil companies and nation states: Activities should have political support and comply with national laws and regulations. Processes of political modernisation are however changing the roles of state and non-state actors. Globalisation and individualisation empower individual citizens and non-state actors, who demand a larger say in decision making processes. Chapter 5 shows that this is also the case for Greenland, where citizens and civil society organisations became more and more critical towards their government about the way it developed the offshore oil and gas activities. The lack of openness and transparency in the decision making process, the few formal moments to provide input and have influence on the decision making process, and questions about the benefits for Greenland fuelled the debate among societal actors. The social license to operate concept addresses this phenomenon and emerged as a third type of 'license' next to the political and legal licenses, which were already applicable to oil and gas activities.

A social license to operate is generally defined as 'the ongoing acceptance and approval from local communities and other stakeholders'. It is not a tick-the-box license but rather an ongoing process that runs through the entire lifetime of an activity. Unlike the legal and political licenses, it is not granted by a public authority. The absence of a granting authority and lack of standard procedure makes it intangible and raises questions as to who grants it and how it can be obtained and maintained. These questions are predominantly studied from a private sector company's perspective, which is not a surprise as the other two licenses also need to be obtained by the company developing an activity. However, as Chapter 5 shows, it is also important to study the role of a national government in the social license to operate context: Society's increasing demand for influence on the development of oil and gas activities results from the perceived failure of the prevailing legal and political systems. It is therefore also 
important to understand the relations between the legal, political and social licenses to operate. As trust and legitimacy are the founding principles of a social license to operate and are also relevant to the legal and political licenses, the mutual relationships and interdependencies of the three licenses have been analysed by taking a closer look at the role of trust and legitimacy.

\subsubsection{The role of trust and legitimacy in the legal, political and social licenses of oil and gas development in Greenland}

In Greenland, the societal debate about oil and gas development was fuelled by a lack of throughput legitimacy regarding the decision making process, and a lack of integrity- and competence-based trust in government authorities. Stakeholders, such as critical citizens and environmental NGOs, put pressure on the political system outside of the regular election procedures, thereby influencing the political license. This has in turn influenced the legal license, illustrated by the amendments made to the regulatory framework twice since 2009. The case of oil and gas development in Greenland shows that different forms of trust and legitimacy are dominant in each of the licenses to operate. They complement each other, whereby the political license is mostly dependent on institutionalised trust and input legitimacy, the legal license is predominantly focussing on throughput and output legitimacy combined with institutionalised trust, and the emphasis of the social license to operate is on personal trust, throughput and output legitimacy.

The level of trust and legitimacy of one license influences the other licenses: The proactive role of the Greenlandic government, by taking into account the criticism from individual citizens and civil society organisations, has made the political license a linking pin between the social license and the legal license. It illustrates how a social license to operate contributes to enhancing the requirements set forth by the legal license. In turn, the legal license now comprises more elements, such as earlier and prolonged public consultation periods, that can contribute to the establishment of a social license. It should however be noted that the requirements of a legal license cannot be expected to automatically deliver a social license. The changes made to the legal license are still a reaction on the debate in relation to the social license. The expectations of society are subject to continuous change and might have altered compared to what is now required by the legal license. Even though the government of Greenland has met some of society's wishes, critique still exists and its relationship with society is still far from optimal. Large scale public protests against oil and gas activities have however not occurred until today. This is not necessarily the result of actively incorporating societal 
critique into the legislation, but could also stem from the fact that most oil and gas activities have come to a halt since 2014.

\subsubsection{The challenges and opportunities in maximising the local benefits of oil and gas development}

Maximisation of the benefits from the development of oil and gas activities was one of the main focus points in the Greenlandic societal debate, especially since these benefits could contribute to the long cherished wish of becoming (financially) independent from Denmark. In order to maximally benefit from the creation of an oil and gas sector, the development of a knowledge-based economy and strong educational sector are essential. This is essential because most of the activities take place offshore and require a set of (formal) qualifications, which are not present on a large scale within the Greenlandic workforce at the moment. It is thus of utmost importance for Greenland to work on the development of its human capital. Without having the right set of (formal) skills and qualifications, it is hard to seize the employment opportunities that the offshore oil and gas activities generate.

Chapter 3 shows that local knowledge institutes are essential in creating the necessary base of human capital, which in turn enables small Arctic states such as Iceland, Faroe Islands and Greenland, to maximise local benefits. The Faroe Islands case shows that the income from exploration activities alone can be sufficient to kick-start a knowledgebased economy that can even be exported to other countries. This has made the small Faroese society more resilient to the local boom and bust effects of oil and gas activities. It is also a major opportunity for Greenland and makes human capital development one of the top priorities. Establishing a critical mass of skilled labour takes time and is already one of the biggest challenges. Various initiatives, mainly revolving around the Building School, School of Minerals and Petroleum and Centre for Arctic Technology in Sisimiut, have been taken to increase the level of skilled workers for the extractive industries so that the Greenlandic society will be ready to seize the employment opportunities when they arrive. Lagging behind in capacity-building compared to the pace of industrial development prevents expertise and knowledge from becoming an export product, which can become a serious strain on the process of becoming a self-sustaining economy.

\subsubsection{The contribution of human capital development to a social license to operate in small Arctic societies}

The focus on local benefits in the social license to operate debate logically stems from the reason why the Greenlandic government started looking to develop the oil and gas 
activities in the first place: Namely to diversify the economy and generate sufficient income to fulfil their wish of becoming (financially) independent from Denmark. It is expected that the benefits of the oil and gas development should include more than only taxes and royalties paid to the national government. As Chapter 4 shows, the high level of involvement from local people and businesses in new industrial activities generates clearer benefits for society and thereby contributes to the economic output legitimacy of a social license to operate. To ensure a high level of involvement it is necessary to create a critical mass of skilled workforce, preferably prior to or at the start of the new activities. This can be stimulated by incorporating policy measures on human capital development and knowledge transfer into the regulatory framework, especially when there is little or no experience with the sector that is to be developed. The case of oil and gas development in the Faroe Islands illustrates that policy measures that stimulate knowledge transfer can successfully initiate the creation of local businesses and participation in the industry.

Next to the economic output legitimacy, a focus on human capital development also contributes to the creation of personal trust. Stimulated by knowledge transfer policy measures, stakeholders in the Faroese case started coming together in a hydrocarbon cluster. Oil companies, offshore industry and knowledge institutes established an institutionalised dialogue and structural cooperation on the development of human capital. Even though no commercially viable oil has been found in the Faroe Islands, the dialogue and cooperation between the stakeholders in this cluster has established a Faroese hydrocarbon sector that competes on a global level: Faroese offshore companies work on oil and gas activities worldwide and a growing number of citizens is working in the oil sector abroad. At the same time, working together on human capital development projects and interacting over a number of years, has enabled these stakeholders to show each other that they deliver as promised. Relationships are built, adding to a better mutual understanding and the creation of personal trust. Human capital development thus not only contributes to the economic output legitimacy of an activity, but also contributes to enhancing the level of personal trust. Especially in these small Arctic societies that face the challenge of maximising local benefits, human capital development contributes to several aspects of a social license to operate.

\subsubsection{The international level social license to operate of Arctic oil and gas activities and its} influence on Greenland

Next to the national level debate in Greenland, there is also an international debate about the offshore oil and gas development in Greenland. In contrast to the national level debate, the international debate is not so much focussed on human capital 
development and the maximisation of benefits, but rather on the contribution of these oil and gas activities to global climate change. Furthermore, the international level debate is predominantly shaped by international environmental NGOs and involving international oil companies and nation states. The same activities are thus subject to a national and an international level debate, each of the debates having their own specific focus. Both debates have the potential to influence the social license to operate and thereby the implementation of offshore oil and gas activities in Greenland. The national and international debates briefly came together when Greenpeace scaled a drilling rig that was performing the exploration drills in Greenlandic waters in 2010 and 2011. The social license to operate concept does however not yet include a multilevel component. Chapter 6 develops a set of hypotheses and a typology for the interaction of the social license at multiple levels. Three main categories of social license to operate processes are identified based on the level of overlap:

1. All licenses are separate: Each license occurs both at the national and the international level, but there is no multilevel interaction between the licenses.

2. All licenses are one: Each license fully overlaps with its national/international counterpart.

3. Licenses are partly overlapping. To further operationalise this, three hybrid types can be distinguished based on which licenses partly overlap:

a) There is one social license (national and international fully overlap), but there are separate political and legal licenses on both levels.

b) There is one political license and one legal license (for these two licenses the national and international level fully overlap), but the social license is separate.

c) All licenses partly overlap with their national/international counterpart.

Type 1 and 2 are considered to represent the extremes (fully separated and fully overlapping) and are therefore not likely to occur in practice. The hybrid types are therefore regarded to provide the best reflection of the interactions that could take place between licenses on different levels. Looking at the field of energy development, the case of oil and gas in Russia is an example of Hybrid type 1. The Russian government is consciously limiting the international influence on the national legal and political licenses. Even though these licenses are separate, the national and international social licenses to operate are well connected and can even be regarded as one: They share the same goals, values and beliefs namely to protect the environment from the negative impacts of oil and gas activities and to prevent the degradation of the existing legal framework. 
Hybrid type 2 is illustrated by the development of wind energy on land or near the coast in several European countries. Here the political and legal licenses can be regarded as one, since the national level development of wind energy is driven by formal EU regulations (Directive 2009/28/EC) and international treaties (Paris Agreement). At the same time the social licenses on the national and international level are clearly separate: International environmental NGO's see the development of wind energy as part of the solution to combat global climate change, while local fishermen and residents often protest against the development of these wind farms.

The oil and gas development in Greenland is a good example of hybrid type 3, where none of the licenses fully overlap nor are they fully separated. The licenses interact with their national / international counterparts. With regards to the social license to operate, this interaction mainly takes place via social media and international environmental NGOs being active at the national level. In case of the political license, the interaction takes place via institutionalised inter-state cooperation as well as interaction with state and non-state actors in a range of governance arrangements. Interaction between the legal licenses runs via the ratification of legally binding international agreements. However, Greenland is to a limited extend part of binding international agreements relevant to the development of oil and gas activities. The interaction between the national and international legal licenses is therefore limited.

\subsection{The social license to operate: The case study of Greenland and a multilevel approach}

The previous sections have answered all the sub-questions of this research. Using the multilevel approach that has been developed in Chapter 6, this section concludes on how the social license to operate of Greenlandic oil and gas activities is influenced by legal and political licenses in a multilevel context and on the role of trust, legitimacy and human capital.

\subsubsection{The national level social license to operate needs to be studied in relation to the legal and political licenses using a broader definition of trust and legitimacy}

Until now, scholarly literature and business practices have a rather instrumental understanding of the social license to operate: They predominantly focus on the local project context and the relation between a company and its local stakeholders. This narrow focus of the social license to operate concept misses essential elements of today's increasingly interconnected and complex society. As the case study of oil and gas development in Greenland has shown, governments still has an important role in the development of large industrial activities and a social license to operate does 
not manifests itself in isolation from the political and legal licenses. In Greenland, the steadily increasing societal critique about the oil and gas exploration activities was mainly directed at the Greenlandic government and its role and performance related to the legal and political licenses.

For a thorough understanding of the social license to operate and its relation with the political and legal licenses this research has shown that it is important to not only define output oriented forms of legitimacy, like it is usually done in social license to operate literature, but to use a broader definition and include input and throughput legitimacy as well. The critique of Greenlandic society was fuelled by a perceived lack of throughput legitimacy in the processes of granting a legal license, due to the closed nature of the authority issuing the license and the lack of access to decision making documents. Although the output legitimacy of the oil and gas activities was more obvious, due to the connection between the income of oil and gas activities and independency from Denmark, it became questioned in terms of risks outweighing the benefits. Furthermore, the societal critique was also based on a lack of integrity- and competence-based trust in the government and its authorities issuing the legal and political licenses.

The societal debate and critique, mainly directed at the government, illustrate how the content of the legal framework (legal license) and the behaviour of the government (political license) influence the focus of the social license. The other way around, the social license can also influence the political and the legal licenses. As a result the national level Greenlandic legal license now contains more elements that contribute to the establishment of a social license, although it can never be assumed that the legal license contains all the elements.

\subsubsection{The social license to operate concept needs a multilevel approach}

The environmental and social impacts of oil and gas activities often do not confine themselves to nation state boundaries, nor are these activities operated solely in a national level context: Oil and gas are subject to international commodity prices, transported and used all over the world and subject to high level international politics. Given the link between the combustion of oil and gas and global climate change, the development of oil and gas activities in the Arctic became part of an international societal debate. Both the national and the international level are thus relevant to the social license to operate of oil and gas development in Greenland. The existing definition of the social license to operate concept however lacks a multilevel component and is therefore not suitable to analyse the multilevel context in which these oil and gas 
activities were being developed. Furthermore, to get an in-depth understanding of an international level social license to operate it is also important to take a closer look at the legal and political licenses on the international level. When studying all three licenses at the international level, the focus of the analysis should not only include the relation between society (both national and international) and the private sector company, but also on the role of nation states.

As Rosenau shows, the role of world politics has changed from a state-centric world to a bifurcated system in which state actors engage in different governance arrangements with other state and non-state actors, such as international NGOs and multinational companies. The research presented in this thesis shows that on the international level the political license is shaped by multiple governance arrangements in which the Greenlandic government shares its authority with other actors: Foreign policy is a shared policy domain with Denmark and officially it is Denmark who has a seat at the table on the international level. Furthermore, Greenland participates in several intergovernmental fora, such as the Arctic Council or United Nations. These fora formulate policies and determine the direction for future development, although core decisions regarding where to develop oil and gas (or not) are still the domain of nation states. There are therefore no international binding agreements that determine which oil and gas resources should be left in the ground. This is however essential to determine, given the Paris Agreement (2015) to keep global temperature rise well below two degrees Celsius. One can question whether individual states are able to take this decision alone, as countries are still pursuing their oil and gas ambitions after the Paris Agreement. Moreover, Greenland, in contrast to Denmark, did not sign the Paris Agreement and did not undertook any commitments under the Kyoto Protocol's second commitment period.

The cooperation of (Arctic) states in or in the context of intergovernmental fora such as the Arctic Council has also led to the successful negotiation of legally binding agreements, including the Agreement on Cooperation on Marine Oil Pollution Preparedness and Response (2013) and the Agreement on Cooperation on Aeronautical and Maritime Search and Rescue (2011). However, these binding agreements do not address the question which oil and gas resources should be left in the ground. Furthermore, the development of oil and gas activities in the different Arctic countries is still governed by a patchwork of different legal frameworks instead of one comprehensive legal framework for the entire region. This thus leaves the initiative to each of the Arctic states and results in different legal licenses across the Arctic. 
International environmental NGOs are trying to influence the decision making processes regarding the development of oil and gas development in the Arctic, both at the international as well as at the national level. To influence the decisions of Arctic states and international oil companies, international environmental NGOs did not only use existing national level governmental procedures but also shaped the international societal debate in court cases and by protest actions. These protest actions, such as scaling drilling rigs in Arctic waters, fuelled an international societal debate that was facilitated and held on the internet and social media. The media thus became a space of politics, whereby the internet functioned as a public space where powerful images of scaled drilling rigs accompanied by simple messages (\#SavetheArctic) thrived. In this way the social license to operate of oil and gas activities in Greenlandic waters was shaped on the international level.

Part of the multilevel approach towards the social license to operate concept is not only to include another geographical level in the analysis, but also to create a better understanding of the possible interaction between the two different levels. Based on the analysis of the national and international social license to operate, it can be concluded that in the case of Greenland the political, legal and social licenses do not fully overlap nor are they fully separated: They interact with each other in various ways. With regards to the political licenses this mainly runs via the participation of the Greenlandic state in international governance arrangements and intergovernmental fora. The interaction between the legal licenses primarily runs via formal ratification procedures, but is limited due to the limited amount of international legally binding agreements that Greenland is part of, and. The reason for the social licenses to be regarded as separate albeit with some interaction, is that there is relatively limited participation of Greenlandic actors in the international societal debate. Vice versa the influence of international actors on the Greenlandic societal debate mainly runs via government procedures, mandatory for obtaining the permits for oil and gas activities and thus the national legal license.

\subsubsection{The importance of human capital development in a multilevel social license to operate of oil and gas development in Greenland}

When studying the social license to operate of an activity, human capital development is often associated with the content of an Impact Benefit Agreement This thesis shows that in the context of small Arctic states, human capital development also has a strong link with the creation of trust and legitimacy in relation to a national level social license to operate. Furthermore, human capital development can play a role in the degree of interaction between licenses on multiple geographical levels. 
In Greenland, the economic benefits and employment opportunities that the oil and gas activities were expected to generate, were of great importance in the societal debate. Working on human capital development to increase the level of formal skills and qualifications among the Greenlandic workforce and businesses, enables local stakeholders to better seize the employment opportunities that the oil and gas activities bring. In turn, increased participation of the Greenlandic workforce and local businesses in the oil and gas industry could contribute to the economic output legitimacy of the oil and gas activities. At the same time, human capital development also serves as a vehicle for different stakeholders (government, civil society and companies) to interact and build personal trust.

Within the multilevel social license to operate context, human capital development can also be of importance to the degree in which the national and international level licenses interact and overlap. As human capital development was and still is a top priority for the Greenlandic government, the level of (formal) skills and competencies such as English proficiency is likely to increase over time. These skills and competencies are not only necessary to seize local employment opportunities, but could also contribute to the level of access that Greenlandic people have to international societal debates, which are mainly held in English. Although this is a theoretical exercise, because there are no offshore oil and gas activities in Greenland ongoing at the moment, the national and international social licenses might have moved closer together due to the development of human capital. This shows the importance of including human capital development in the analysis of the social license to operate of Arctic (energy) activities.

\subsubsection{Concluding remarks}

The Greenlandic case study shows that the national social license to operate is inextricably linked to the national legal and political licenses to operate via different, complementary forms of trust and legitimacy. A proactive approach to address societal actors' concerns regarding trust and legitimacy does not necessarily result in a solution that is perceived to be satisfying. It will thus remain a challenge for the Greenlandic government to address societal concerns, which is becoming extra difficult because amending the legal framework cannot continue indefinitely: Either the changes do not have the desired effect and societal actors lose their faith in whether legal amendments will be a solution to their concerns. Or, the changes are so frequent that companies lose their interest to invest in Greenland because it changes the rules of the game so often, which destabilises the investment climate. 
The national social license to operate is also intertwined with the international level social license, which uses the internet and social media to influence national and international level decision making both by governments and by private sector companies. The interconnectedness is a challenge for Greenland when it comes to the social license to operate for oil and gas activities. International actors, such as environmental NGOs and investors, could potentially influence investment decisions of international oil companies regarding projects that are implemented at a local level. Already international environmental NGOs influenced the national societal debate via formal government procedures of the national legal license. What is more, at the international level Greenland is highly dependent on others, such as Denmark, to formally play a role in the international legal and political licenses. The interconnectedness of the national and international social licenses is however also an opportunity for the Greenlandic government. Being organised as a network and not necessarily following formal state structures, the international social license allows Greenland to take part without having to follow traditional, hierarchical structures. Unlike the connections that exist between the political and legal licenses at the international and national level, the connection between both social licenses to operate is vivid, fast and involves individuals directly. For both governments and companies it is important to realise that the implementation of activities locally, is thus subject to direct international level influences, primarily via the social license to operate.

\subsection{Theoretical reflections}

This thesis presents new insights to governance literature that focusses on the social license to operate of industrial activities and more specifically oil and gas projects. Societal debate and scrutiny in relation to large industrial activities has increased since the 1990s and sparked the emergence of the social license to operate concept in corporate practices and scientific literature (e.g. World Bank 2003b; Thomson and Boutilier 2011; Boutilier 2014; Moffat \& Zhang 2014; Morrison 2014; Hall et al. 2015). Thomson and Boutilier defined the concept not as a conventional 'tick-the-boxlicense', but rather as a continuum ranging from the mere acceptance of an activity to psychological identification. They distinguish between various forms of trust and legitimacy, including interactional and institutionalised trust and economic and sociopolitical legitimacy.

The research presented by the existing body of literature is however predominantly concerned with how, when and by whom a private sector company can obtain and maintain its social license to operate. It is therefore very much output oriented and lacks an in depth examination of the relation between the social license and the political 
and legal licenses, which apply to an activity as well (Morrison 2014). In most literature these licenses are only mentioned to determine that the social license is something different, rather a process instead of a tick-the-box license that is granted by a specific authority according to a specific set of procedures. This thesis builds on the research by Morrison (2014), who studied the social license to operate directly in relation to the political and legal licenses. The role of the government and its changing relationship with society is often overlooked. The close connection between society's increasing demand for influence on the development of industrial activities and its perception of the prevailing legal and political system and the failures thereof, makes these political and legal systems important to study in relation to the social license to operate. To study the interactions between the three licenses, a further operationalisation as presented and used in Chapter 5 is essential.

Existing scholarly work on the social license to operate literature usually distinguishes different levels of trust: trust in a person (i.e. personal or interactional trust) and trust in an institution (i.e. institutionalised trust) (Thomson and Boutilier 2011). This thesis builds on this operationalisation of trust and distinguishes the same two forms, as these are considered to be complete. With regards to legitimacy, existing literature on the social license to operate discusses the legitimacy of an activity mainly in terms of its economic and/or socio-political outcomes (Thomson and Boutilier 2011). By doing so, the focus is predominantly on the output legitimacy. While output legitimacy is an important form of legitimacy when it comes to the social license to operate concept, governance, political and public administration literature shows that this is not the only form: This thesis therefore distinguishes between input, throughput and output legitimacy (van Tatenhove 2011), whereby the economic and socio-political legitimacy are both regarded as different forms of output legitimacy (see Chapter 5 for further details). By distinguishing a variety of different forms of legitimacy, the social license to operate concept is better equipped to analyse and establish an in-depth understanding of the (lack of) legitimacy of an activity. Furthermore, this thesis has shown that the different forms of legitimacy do not only play a role in the social license to operate, but also in the political and legal licenses. By analysing the different forms of legitimacy in all three licenses, a more comprehensive view is established about the legitimacy of an activity.

There are also critical voices regarding the social license to operate concept. The concept would be counter-productive to the sustainable development agenda: it is initiated by risks to a company's business case and also aims to reduce these risks, it focusses on reducing overt protest rather than investing in long-term development and 
it implies that society at large can grant the license at the expense of local perspectives (Owen \& Kemp 2013; Harvey 2014; Harvey \& Bice 2014). The implementation of the concept in the practices of businesses is also contested: companies focus too much on outreach, based on the assumption that local stakeholders simply do not understand them (i.e. information delivery), and the implementation of the concept is usually done by professionals with a development background stimulating an outreach approach rather than integrating the concept in the daily practices of projects.

In line with existing literature (Owen \& Kemp 2013; Harvey 2014; Harvey \& Bice 2014), this thesis acknowledges that the social license to operate should not support the notion that approval for an activity can be granted by society at large at the expense of local perspectives. However, in today's globalised world the analysis of a social license to operate should not solely focus on the local level. Focussing on local communities and the national level context excludes important international dynamics that have the potential to influence either the social license to operate locally and/or the investment decision of a private sector company on the implementation of an activity locally. In a world where access to the Internet and social media is increasing (Laniado et al. 2017), from 0,97 billion people in 2010 to 2,28 billion people in 2016 (www.statista. com), the costs of geographical distance in social interaction have been removed (Cairncross 2001). Local and global are now in many cases inevitably connected via internet and social media, but also via global commodity prices, environmental impacts and international (trade) agreements. The international social license to operate and its interconnection with the local social license to operate is however a new field of research. The existing conceptualisation of the social license to operate, which is applied to the national level, is not suitable to apply to the international level and a new operationalisation of the concept is therefore made in this thesis. Using the concept of spheres of authority from post international theory by Rosenau, including multiple centres of decision making and changes in the authority of states, combined with a prominent role for the internet and social media as both a tool and a platform for dialogue has proved to be valuable in studying the international level social license to operate. How this contributes to the new operationalisation of the social license to operate is elaborated upon below.

The social license to operate emerged as a result of the failure of national level legal and political systems to adequately deal with the interests of stakeholders and focussed primarily on local communities (Thomson and Boutilier 2011; Boutilier 2014; Moffat \& Zhang 2014). The failure of the same national level legal and political systems to adequately deal with global environmental and economic problems has resulted 
in an international multi-level governance setting, where both state and non-state actors determine the outcomes of global politics (Ferguson and Mansbach 2007). Post-international theory challenges the division of the world into sovereign, legally dependent states and acknowledges that processes of transformation are empowering citizens and non-state actors as well as driving a de-territorialisation of politics (Rosenau 1997, 2003, 2006). Where the social license to operate concept shows that on a national level the authority of states becomes shared with citizens and non-state actors, postinternational theory shows that also on the international level the authority of states is dispersed over different governance arrangements and actors. The traditional hierarchical power of states, but also other traditional institutions, still exists but is dispersed and shared with other actors in diverse governance arrangements. At the same time, an international movement of empowered citizens and non-state actors, which uses digital horizontal means of communication, is gaining influence on the global level next to the existing hierarchical organisations (Castells 2008).

This thesis studies the role of nation states and traditional private sector companies and their position in this transforming society, both nationally and internationally. The outcomes of this research show that companies, and especially multinational companies, find themselves in the middle of these transformations. As proponents of the debated activities they are not only subject to changes in the three licenses and their mutual interaction; they are also active on multiple levels and the different debates that are held on each of these levels. On the one hand the multinational companies have to relate to more demanding citizens and other non-state actors, both on a national and international level, and on the other hand they also have to relate to the changing position of states. Where they used to rely completely on state authority to get approval for their activities, they now have to take a much greater responsibility themselves next to the state authority where they still rely on. This is not to fill a gap in the legal and political systems, but because roles, expectations and sources of power are changing. Decision making processes are bifurcated: Formally government authorities decide on the legal licenses, but informally it is the (lack) of support in society that puts pressure both on companies and on governments. Companies that do not acknowledge and act upon this greater responsibility get scrutinised by society, both nationally and internationally.

\subsection{Methodological reflections}

A case study approach was used to conduct this research. This approach was appropriate given the research question, studying a real-life phenomenon, its contemporary nature and the lack of influence over the events by the researcher. The 
debate about Arctic oil and gas development was a real-life phenomenon during the majority of the years that this research was conducted. However, in Greenland the oil and gas exploration activities never reached the scale or intensity that was expected. Only Cairn Energy performed exploration drills during the summer seasons of 2010 and 2011. No other exploration drills were performed, only a number of seismic surveys. At the moment there are no offshore oil and gas exploration activities ongoing or planned in Greenland. Given today's circumstances, it can be questioned whether these activities are ever going to take place.

Even though no offshore oil and gas activities take place in Greenland at the moment, the outcomes of this research remain valuable. In today's globalised world, the social license to operate of an activity is an interplay between the local and international level, especially when it concerns energy related activities. The case study of offshore oil and gas development in Greenland clearly illustrates this and has developed a multilevel understanding of the social license to operate concept. During this research, the case of Greenland was continuously placed into a broader perspective: It was compared to the cases of energy development in Iceland and the Faroe Islands, studied in the context of offshore oil and gas development in the wider Arctic and global debate on climate change.

Not being immersed within an Arctic society during the time of research has enabled me to keep an overview and analyse the position of all actors without being part of the phenomenon. On the other hand, a social license to operate is a social phenomenon characterised by dynamics that are not always apparent from written sources. The true local meaning of a social license to operate can therefore be more difficult to grasp when not being part of a society. Conducting a set of interviews on two different moments in time, attending several Arctic conferences and closely following public opinion on Facebook and Twitter, has contributed to a better understanding of the social license to operate. Being able to read and understand Danish has facilitated better access to the discussions and documents on oil and gas development in Greenland. At the same time, not being Danish has prevented me from a bias regarding the relationship with Greenland.

As this research has shown, the social license to operate does not only manifest itself locally but also internationally. The same activity can be debated on various locations, potentially at the same time or in multiple occasions. Although the observations that were part of this research were spread over time and took place in two different Greenlandic locations, on conferences in different Arctic locations and in Dutch Arctic Circle meetings, the social license to operate of Arctic oil and gas development is larger. 
Especially on the international level it is not possible to be aware of each and every debate on every scale. However, having spoken to many different actors over a time period of four years has ensured that the most important aspects of the social license to operate of Arctic oil and gas developments have been captured.

\subsection{Recommendations}

The research of this thesis has contributed to the understanding of the development of a social license to operate of controversial energy projects in a multilevel context. Studying the social license to operate in a multilevel context is however a new approach and requires further research in various theoretical and empirical settings to consolidate and enhance current insights. The final section of this thesis presents recommendations for future research as well as daily practices of companies and governments.

\subsubsection{Recommendations for further research}

As Chapter 6 shows, the influence of the international level on a local social license to operate is present and runs via various mechanisms. In our increasingly interconnected and digital world, it can be expected that the international level influences become more important for the social license to operate of (local) energy projects that are clearly linked with global societal themes such as climate change. The investment decisions of oil and gas projects are often taken by international oil companies, subject to global commodity prices and a worldwide reputation. On the other hand, there is a tendency of increasing nationalism in the Western world, including a growing role of national oil companies. Future research is needed to create a more thorough understanding of the conditions that shape an international social license to operate in this highly dynamic context. Case studies of oil and gas developments in other parts of the world could deepen both the theoretical and empirical understanding of the social license to operate in multilevel context. Our understanding of the international influence on the local level, and vice versa, would benefit from case studies conducted in other parts of the world.

In this context it is also interesting for future research to study the relationship between global civil society and local communities in the context of a social license to operate. Research in this thesis has shown that their views and beliefs do not necessarily have to align and can even contradict each other: Locally, the need for economic development might prevail over environmental and social risks, while globally the economic development is subordinated to climate change. Global civil society and local communities could enhance but also contradict or even counteract each other within a social license to operate context. This is an interesting field for future research, especially when combined with a closer look at the role of social media and the internet 
in shaping this relationship. Furthermore, a closer look at the role and effectiveness of social media in shaping an international digital network, which is driven to change public opinion and steer decision making processes at the global level, would enhance current insights.

Even though the social license to operate concept originated in the extractive industries, it is not bound to activities related to fossil resources. Renewable energy projects also generate a lot of societal debate and require a social license to operate. Even though these activities clearly contribute to a greater goal, namely the transition to a society based on renewable energy, this is not sufficient for society. It would be interesting for future research to study the social license to operate of renewable energy development and examine the local - global nexus: Large renewable energy projects are often a result from international climate change negotiations and sustainability goals. On the other hand, there are often numerous small renewable initiatives that originated at the local level. Implementing renewable energy projects could generate negative environmental impacts as well. The limited space in some parts of the world also creates specific environmental and/or social challenges, for example when an offshore wind farm is planned in an area that will be designated as Natura2000. This could undermine a common point of view among environmental NGOs, which has appeared to be an important driver of the international social license to operate network. These are all interesting avenues for future research into the social license to operate of renewable energy projects in a multilevel context.

This thesis has examined the development of oil and gas activities in the Arctic as one of the most controversial energy projects since the start of the century. It has appeared to be a case on which many people, both local and global, had an opinion. This has proven to be valuable for studying the social license to operate of oil and gas activities in the Arctic from a social science perspective. In this case the need for a social license to operate was apparent. This also raises the question what determines whether a social license to operate is always required and if there are cases in which a social license to operate is not relevant. What are the conditions that determine this? Does it depend on the level of trust and legitimacy of the political and legal licenses? Does it depend on the size of the project and its spatial impact? And can the social license to operate as it has been defined by this research also be applied to less controversial energy projects? These are questions that could be the start of future research, to examine the context of less controversial energy projects and their social license to operate. 


\subsubsection{Recommendations for daily practices}

This section presents a practical approach to the social license to operate, which can be used by companies, governments and others in their daily practices. It is best to start thinking about the social license to operate when commencing a project. If, for whatever reason, a project has already started, it is still valuable to start thinking about the social license of the project to see whether improvements can be made and act proactive instead of reactive. And even though it is rather late to start thinking about the social license to operate when overt protest occurs, it is still worth examining the (lack of a) social license to operate according to the multilevel approach outlined in this section.

Step 1: Make an analysis of the local social license to operate of your project

The first step is to analyse the local social license to operate of your project. It is essential to examine all forms of trust and legitimacy. The following topics and questions can help you to create a comprehensive understanding of the social license to operate:

- The interaction with stakeholders: How have you / are you planning to engage with your stakeholders? Is the way you approach and interact with your stakeholders tailored to their circumstances? Have you selected the right person to represent your project during those interactions?

- How is your project perceived? Have you got all the necessary competencies in your project organisation to successfully implement the activities? How do stakeholders perceive the competencies of your organisation? Based on what values and beliefs have you designed your project execution plan? And do these values and beliefs match the ones of the project's stakeholders?

- Representative engagement: Who are your stakeholders? Which stakeholders will you engage or have you engaged in your project? Is this a representative selection? Do the representatives of stakeholder groups / organisations represent their backing? When are they / have they been engaged in your project? What will be / has been done with their input in the decision making processes of your project? Has this been communicated to them and if yes, how?

- The process: Which information will or has your project disclosed to the various stakeholders? When and how often in the decision making process will this be / was this done? How was the information disclosed? (i.e. digital or hard copy? In documents or face-to-face? In English and/or a country's own language? In jargon or layman's language?) And was this tailored to the needs of these stakeholders? Has your project been transparent on the decisions that have been or will be taken and the reasoning behind it?

- Your project's contribution to society: What does your project contribute to society / local stakeholders? This can be defined in economic terms (i.e. taxes, 
royalties, employment etc.) or in socio-political terms (i.e. sustainability, welfare, health, mobility etc.). And does society / local stakeholders need or want these contributions?

The answers to all these questions will help analysing the different forms of trust and legitimacy, which enables you to get a better understanding of the social license to operate of your project.

Step 2: Determine how the social license to operate connects to the legal and political licenses

As the research of this thesis has shown, the social, legal and political licenses of a project are closely connected. Since they can influence each other, it is important to determine how they are connected in the context of your project.

How is the relationship between your project's local stakeholders and the relevant government authorities involved in the legal and political licenses of your project? Has this relationship been under pressure recently? Is this relationship stable or subject to change?

By analysing the (changing) relationship of society and local stakeholders with the government and its authorities involved in granting the legal and political licenses, one can get a good understanding of the value that these licenses have in society. The analysis can be made by using the same forms of trust and legitimacy. The outcomes of this analysis combined with the outcomes of Step 1, will indicate how the social license to operate is connected with the legal and political licenses to operate.

Step 3: Analyse the social license to operate on other geographical levels

In today's globalised and digital world, other geographical levels can be closer connected to a project than originally thought. Even without a large presence of local stakeholders on social media, a project can become part of an international debate that is held in the digital public space facilitated by social media and the internet. Although it can never be predicted, the likelihood is dependent on a project's link with a larger global theme and whether global actors are pushing it to the fore. Internationally, digital horizontal means of communication play a large role in steering public opinion. This requires a different approach compared to the more traditional ways of communicating project information. To analyse the international social license to operate one has to look at the following aspects: 
- Connection to a global theme: Is there a (negative) connection of the project to an overarching, global theme that has the attention of the world's society? How strong / direct is this connection? Are there any international organisations or is there a public movement already active against any activities that the project is aiming to implement or execute?

- Social media: What has been said about the project or similar projects elsewhere on social media? What is the position of the project proponent's organisation on social media? Are various actors connecting with each other on social media in relation to (the topic of) the project?

- Connection to the 'real' world: Identify any, internationally significant upcoming events that have to do with the global theme that the project is connected to. Such events are opportunities to connect the digital with the 'real' world and are important windows of opportunities to steer the international public opinion.

An analysis of the abovementioned aspects provides a better understanding of the international governance setting in relation to the social license to operate of a project. However, the international domain is extensive and in constant change. It is therefore essential to be immersed in the international digital public space, open up to networks and participate in dialogues.

\section{Step 4: Identify the interfaces}

When having a more profound understanding of the international social license to operate, it is important to identify the interfaces between the local and the international social licenses. The international license can influence the local license via social media, local legal license decision making procedures and pressure on the local political license. The other way around, the local social license to operate can influence the international one mainly via social media or traditional media. The effectiveness of these interfaces depends on a number of things, including local level English proficiency, access to internet/social media, a shared set of values and beliefs and historical relationships between local societal actors and international organisations. The answers on the questions in Step 3 are a good starting point at identifying the interfaces that are relevant for your project.

\section{Step 5: Adapt the project's organisation}

The outcomes of the analyses in Step 1 to 4 provide an integrated and multilevel understanding of the social license to operate of a project. As said, the social license to operate is an ongoing process that runs through the entire lifecycle of a project and is subject to constant change. It is therefore important to integrate the multilevel 
social license to operate approach into a project's organisation. And because it touches upon so many different aspects, this should not be assigned to one specific person or function. It should preferably be integrated into the hearts and minds of all project team members and stimulated by a dedicated person in the same way that Health, Safety and Environment is also integrated into a project. The multilevel approach to a social license to operate is not an additional requirement, but is one of the key factors underlying a project's success. 


\section{REFERENCES}

Aaen, S.B. (2012). Democratic legitimacy in consultation processes associated with largescale projects in Greenland. Mini Report. http://www.ga.gl Accessed August 5, 2016

ACIA (2004). Arctic Climate Impact Assessment. New York: Cambridge University Press

Ackrén, M, Nielsen, S., \& Harms, M. (2011). Greenland's Economy in Perspective for Future Endeavours (Final Draft). http://www.ams.hi.is Accessed November 16, 2014

AD (December 5, 2017). Burgerinitiatief tegen windmolens op land. http://www.ad.nl Accessed December 7, 2018

Agence France-Presse (2011). Greenpeace hijacks oil firms' Greenland talks. The Raw Story. http:// www.rawstory.com/rs/2011/12/01/greenpeace-hijacks-oil-firms-greenland-talks/ Accessed July 14,2013

Alaska History \& Cultural Studies. (n.d.). Modern Alaska. Oil discovery and development in Alaska. http:// www.akhistorycourse.org Accessed February 29, 2012

AMAP (1998). AMAP assessment report. Arctic pollution issues. Oslo: Arctic Monitoring and Assessment Programme (AMAP)

AMAP (2007). Assessment 2007. Oil and gas activities in the Arctic_Effects and potential effects (Vol. 1). Oslo: Arctic Monitoring and Assessment Program. AMAP 2014

AMAP (2014). Geographical coverage. Arctic Monitoring and Assessment Programme. http://www. amap.no Accessed February 14, 2014

Anderson, C.L., \& Bieniaszewska, R.L. (2005). The role of corporate social responsibility in an oil company's expansion into new territories. Corporate Social Responsibility and Environmental Management, 12, 1, 1-9

Arctic Council. (2011, June 22). Search and rescue in the Arctic. The Arctic Council. http://www. arcticcouncil.org Accessed January 11, 2014

Arctic Council (2014) Observers. The Arctic Council. http://www.arctic-council.org Accessed January 13, 2014

Arctic Council (2015). Arctic Peoples. http://www.arctic-council.org Accessed June 30, 2017

Arctic Governance Project (2010, April 14). Arctic governance in an era of transformative change: Critical questions, governance principles, ways forward. The Arctic Governance Project. http:// www.arcticgovernance.org Accessed February 13, 2010

Ármannsson, P.H. (2005). Orkuver og arkitektúr [Power plants and architecture]. In S. Pálsdóttir (Eds.), Fyrirtœekið og umhverfi pess [Landsvirkjun 1965-2005: The company and its environment] (pp. 201-242). Reykjavík: Hið íslenska bókmenntafélag

Arts, B., Van Tatenhove, J., \& Leroy, P. (2000). Policy arrangements. In J. Van Tatenhove, B. Arts, \& P. Leroy (Eds.), Political modernisation and the environment; The renewal of environmental policy arrangements (pp. 53-69). Dordrecht: Kluwer Academic Publishers 
Arts, B., \& Van Tatenhove, J. P. M. (2006). Political modernization. In B. Arts \& P. Leroy (Eds.), Institutional dynamics in environmental governance. Dordrecht: Springer Academic Publishers

Atlantic Supply Base (2011). P/F Atlantic Supply Base_Ársfrásøgn 2011. Tórshavn: SkrásetingFøroya

Austvik, O.G., \& Lembo, C. (2016). International law and EU-Russian gas relations. M-RCBG Associate Working Paper Series, no. 53

Bache, I., \& Flinders, M. (2004). Multi-level governance. Oxford: University Press Oxford

Beck, U. (2005). Power in the global age: A new global political economy (K. Cross, Trans.). Cambridge: Polity Press

Bell, J. (2011, April 4). Greenland's mine school: quality learning, in English. New state high school stresses math, science, technology. Nunatsiaq News. http://www.nunatsiaqonline.ca Accessed November 30, 2013

Berkman, P. A., \& Young, O. R. (2009). Governance and environmental change in the Arctic Ocean. Science, 324, 339-340

Bertelsen, R.G. \& Hansen, K.G. (2015). From Energy to Knowledge? Building Domestic KnowledgeBased Sectors around Hydro Energy in Iceland and Greenland. In S. Ali \& R. Pincus (Eds.), Diplomacy on Ice. Yale: University Press

Bertelsen, R.G., Justinussen, J.C.S. \& Smits, C.C. (2015). Energy as a Developmental Strategy for North Atlantic Microstates in the Search of Independence: Creating Knowledge-Based Energy Sectors in Iceland, Faroe Islands and Greenland. In G. Hønneland \& L. Christian Jensen (Eds.), Handbook of the Politics of the Arctic. United Kingdom: Edward Elgar Publishing

Bertelsen, R.G., Justinussen, J.C.S., \& Smits, C.C.A. (2016). Building international economies. In: Greenland (Eds.), Perspectives on Skills - An Anthology on Informally Acquired Skills in Greenland. Copenhagen: University of Copenhagen

Binderkrantz, A. S. (2011). Diversity and dominance in the Arctic. Ethnic relations in the Greenland bureaucracy. Public Administration, 89, 2, 522-536

BMP. (2009a). Exploration and exploitation of hydrocarbons in Greenland. Strategy for license policy 2009. Nuuk: Bureau of Minerals and Petroleum

BMP. (2009b). Bureau of Minerals and Petroleum annual report. Naalakkersuisut-Bureau of Minerals and Petroleum. http://www.bmp.gl Accessed August 6, 2013

BMP. (2009c). Guidelines for Social Impact Assessments for Mining Projects in Greenland. http:// www.govmin.gl Accessed February 8, 2016

BMP (2011a). Announcement of the opening of the Northeast Greenland Licensing Round 2012. Naalakkersuisut-Bureau of Minerals and Petroleum. http://www.govmin.gl Accessed October 27,2014

BMP (2011b). International reference docs. Naalakkersuisut-Bureau of Minerals and Petroleum. http://www.bmp.gl Accessed April 13, 2012 
BMP. (2012a). Legal foundation. Naalakkersuisut-Bureau of Minerals and Petroleum. http://www. bmp.gl Accessed April 10, 2012

BMP. (2012b). Report to Inatsisartut, the Parliament of Greenland, concerning mineral resources activities in Greenland. Naalakkersuisut-Bureau of Minerals and Petroleum. http://www. bmp.gl Accessed April 27, 2013

BMP. (n.d.). Exploration wells in Greenland. Naalakkersuisut-Bureau of Minerals and Petroleum. http://www.bmp.gl Accessed August 6, 2013

Boedeltje, M., \& Cornips, J. (2004). Input and output legitimacy in interactive governance (No. NIG2-01). Proceedings of the NIG Annual Work Conference 2004 Rotterdam. http://hdl.handle. net/1765/1750 Accessed November 18, 2016

Boutilier, R.G. (2014). Frequently asked questions about the social license to operate. Impact Assessment and Project Appraisal, 32, 4, 263-272

Boutilier, R.G., Black, L., \& Thomson, I. (2012). From metaphor to management tool: how the social license to operate can stabilise the socio-political environment for business. Proceedings of the International Mine Management 2012, 227 - 237

Boyd, A. (2013, May 15). Binding oil spill agreement signed. BarentsObserver. http:// barentsobserver.com Accessed January 11, 2013

Brookings (2014). Offshore oil and gas governance in the Arctic. A leadership role for the U.S. http://www.brookings.edu Accessed October 27, 2014

Butler, J., \& Cantrell, R. (1984). A behavioural decision theory approach to modelling dyadic trust in superiors and subordinates. Psychological Reports, 55, 19-28

Cairncross, F. (2001). The death of distance: How the communications revolution is changing our lives. Cambridge: Harvard Business School Press

Cambridge Econometrics for Greenpeace and WWF-UK (2012). A study into the economics of gas and offshore wind. http://www.wwf.org.uk_Accessed December 7, 2018

Castells, M. (2000). Materials for an exploratory theory of the network society. British Journal of Sociology, 51, 1, 5-24

Castells, M. (2005). Global governance and global politics. Political Science and Politics, 38, 1, 9-16

Castells, M. (2008). The new public sphere: Global civil society, communication networks and global governance. ANNALS, AAPSS, 616, 78-93

Castells, M. (2009). Communication power. Oxford: Oxford University Press

Christensen, H.H. (September 10, 2012). Vil udvikle minedrift. Kalaallit Nunaata Radioa (KNR). http://www.knr.gl Accessed May 14, 2014

CIEP (2015). Russia's oil export strategy: Two markets, two faces. The Hague: Clingendael

Coates, K. (2007). Module 9-Environmental changes and challenges in the circumpolar world. University of the Arctic. http://www.uarctic.org Accessed February 29, 2012 
Committee for Greenlandic Mineral Resources to the Benefit of Society (2014). To the Benefit of Greenland. http://greenlandperspective.ku.dk Accessed September 9, 2016

Compagnon, D., Chan, S., \& Mert, A. (2012). The changing role of the state. In F. Biermann \& P. Pattberg (Eds.), Global environmental governance reconsidered (pp. 237-263). Cambridge: MIT Press

Cullen-Knox, C., Eccleston, R., Haward, M., Lester, E., \& Vince, J. (2017). Contemporary challenges in environmental governance: Technology, governance and the social license. Environmental Policy and Governance, 27, 3-13

Dagg, J., Holroyd, P., Lemphers, N., Lucas, R., Thibault, B., Severson-Baker, C., Kennett, S., Leaton, J., \& Wheeler, B. (2011). Comparing the offshore drilling regulatory regimes in the Canadian Arctic, the U.S., the U.K., Greenland and Norway. Pembina Institute. http://www.jstor.org Accessed October 12, 2018

Dahl-Stamnes, $\varnothing$. (2012). The way forward on the Norwegian Continental Shelf-Into Arctic oceans. Presentation presented at the seminar European Arctic Oil and Gas: Experiences and development, Brussels, Belgium

Debes, H. J. (2000). Hin loerdi skúlin í Havn. Sprotin

Deloitte (2014). License Rounds Alaska. http://www.psg.deloitte.com Accessed October 27, 2014

De Volkskrant (February 19, 2017). Friezen ten strijde tegen modern windreuzen. http://www. volkskrant.nl_Accessed December 7, 2018

De Vos, B.I. (2011). Trust and New Modes of Fisheries Governance. Wageningen: Wageningen University

Duus, S. D. (2012, August 21). Fjord-venner: Det er en farce. Sermitsiaq AG. http://sermitsiaq.ag Accessed January 12, 2014

Duus, S. D. (2013, October 22). Ny demonstration mod uran. Sermitsiaq AG. http://sermitsiaq. ag Accessed January 12, 2014

European Commission (2007). The Programming Document for the Sustainable Development of Greenland-Annex. European Commission from: http://ec.europa.eu Accessed November 30, 2013

European Commission (2013). Study to evaluate the performance of Higher Education in Greenland. http://www.EuropeanCommission.gl Accessed November 30, 2013

Ferguson, Y. H., \& Mansbach, R. W. (2007). Post-internationalism and IR theory. Millennium-Journal of International Studies, 35, 3, 529-549

Filer, C., \& Gabriel, J. (2018). How could Nautilus Minerals get a social license to operate the world's first deep sea mine? Marine Policy, 95, 394-400

Financial Times (2015, February 5). Oil companies put Arctic projects into deep freeze. http:// www.ft.com Accessed May 01, 2016

Franks, D.M., Davis, R., Bebbington, A.J., Ali, S.H., Kemp, D., \& Scurrah, M. (2014). Conflict translates environmental and social risk into business cost. PNAS, 111, 21, 7576-7581 
Friðleifsson, I.B., Svanbjörnsson, A. \& Thorsteinsson, L. (1984). Icelandic experience in transfer of energy technology. Tímarit Verkfrceðingafélags Íslands, 69, 6-10

Fróðskaparsetur Føroya (2014). Fróðskaparsetur Føroya - mál og mið. Tórshavn: Fróðskaparsetur Føroya

GEUS/MIMR (2013, October). Change in mineral resources organisation within the Greenland Government Administration. MINEX Greenland Mineral Exploration Newsletter, 44, 1

Gaini, F. (2002). Føroya Fróðskaparfelag 1952-2002. Tórshavn: Fróðskaparfelag Føroya - Societas Scientarium Færoensis

Giddens, A. (1990). The Consequences of Modernity. Stanford: Stanford University Press

Glomsrød, S., \& Aslaksen, I. (2009). The economy of the North 2008. http://www.ssb.no Accessed September 21, 2014

GOIA (2011). About GOIA. Greenland Oil Industry Association. http://www.goia.gl Accessed April 12,2012

Goldback, I. \& Winther-Jensen, T. (1988). Greenland: Society and Education. Comparative Education, $24,2,257-266$

Greenpeace (2015). Energy [r]evolution. A sustainable world energy outlook 2015. http://www. greenpeace.org Accessed December 7, 2018

Gunningham, N., Kagan, R.A., \& Thornton, D. (2004). Social license and environmental protection: Why businesses go beyond compliance. Law \& Social Inquiry, 29, 2, 307-341

Guðmundsson, V. (1910). Upphitun bæjar með jarðhita [Heating towns withgeothermal heat]. Eimreiðin, 16, 1, 31-32

Hagstova Føroya (2012). Rakstrarviðurskiftið gjaldsjavnans. http://www.hagstova.fo Accessed November 23, 2014

Hagstova Føroya (2015). Arbeiðsfjøld og arbeiðsvirkin skift á kyn og bústað (2005-2014). http:// www.hagstova.fo Accessed February 10, 2016

Hálfdanarson, G. \& Karlsdóttir, U.B. (2005). Náttúrusýn og nýting fallvatna [View of nature and utilization of water falls]. In S. Pálsdóttir (Eds.), Landsvirkjun 1965-2005: Fyrirtcekið og umhverfipess [Landsvirkjun 1965-2005: The company and its environment] (pp. 165 - 199). Reykjavík: Hiðíslenska bókmenntafélag

Hall, N., Lacey, J., Carr-Cornish, S., \& Dowd, A.M. (2015). Social license to operate: understanding how a concept has been translated into practice in energy industries. Journal of Cleaner Production, 86, 301-310

Hansen, A.M. (2014). Community Impacts: Public participation, culture and democracy. Background paper for the Committee for Greenlandic Mineral Resources to the Benefit of Society. http://nyheder.ku.dk/groenlandsnaturressourcer/rapportogbaggrundspapir/ Community_Impacts.pdf Accessed May 5, 2014 
Hansen, R.M. (2015). Mission possible - inside Statoil's Arctic operations. http://www.worldexpro. com Accessed July 27, 2015

Harhoff, F. (1993). Rigsfællesskabet. Disputats, Københavns Universitet (Klim)

Harris, R. (2012). Native Alaskans divided on state's oil drilling debate. NPR. http://www.npr. org/2012/03/20/148754357/native-alaskans-divided-on-states-oil-drilling-debate Accessed August 24, 2013

Harvey, B. (2014). Social development will not deliver social license to operate for the extractive sector. The extractive industries and society, 1, 7-11

Harvey, B., \& Bice, S. (2014). Social impact assessment, social development programmes and social license to operate: tensions and contradictions in intent and practice in the extractive sector. Impact Assessment and Project Appraisal, 32, 4, 327-335

Háskóli Íslands (2014). Aldarafmæli skólans [The Centenary of the School]. http://aldarafmaeli. hi.is/afmaeli Accessed June 10, 2014

Held, D., McGrew, A., Goldblatt, D., \& Perraton, J. (2000). Global transformations. Politics, economics and culture. Cambridge: Polity Press and Blackwell Publishing Ltd

Henry, L. A., \& Mc Intosh Sundstrom, L. (2012). Russia's Climate Policy: International Bargaining and Domestic Modernization. Europe-Asia Studies, 64, 7, 1297-1322

Henry, L. A. \& Mc Intosh Sundstrom, L. (2014). Climate Change Policies in the Postsocialist World. Current History, 113, 765, 278

Hentze, J. M. (2000). Tórshavar skúlasøga. Tórshavn: Tórshavnar Býráð

Holm, M. (1970). Føroya Løeraraskúli 1870-1970. Tórshan: Føroya Læraraskúli

Hooghe, L., \& Marks, G. (2003). Unraveling the central state, but how? Types of multi-level governance. American Political Science Review, 97, 2, 233-243

Houston Chronicle (2012). Types of work done on an oil rig. http://work.chron.com Accessed May 1, 2016

Humrich, C. (2013). Fragmented International Governance of Arctic Offshore Oil: Governance Challenges and Institutional Improvement. Global Environmental Politics, 13, 3, 79-99

Iceland Ministry of Foreign Affairs (2010). Iceland protests a meeting of 5 Arctic Council member states in Canada. Ministry of Foreign Affairs. http://www.mfa.is Accessed July 31, 2013

IFPA. (2012, February). New strategic dynamics in the Arctic region. Implications for national security and international collaboration. Institute for Foreign Policy Analysis. http://www. IFPA.org Accessed March 9, 2012

IIED (2014). Drilling Deeper into Public Opinion. http://pubs.iied.org Accessed October 24, 2014

Ilulissat Declaration (2008).I/ulissat Declaration. Ilulissat: Arctic Ocean Conference 
International Council for Mines and Metals (2010). Good practice guide: Indigenous peoples and mining. http://www.icmm.com Accessed December 7, 2018

Ísleifsson, S.R. (2007). Saga Rafmagnsveitu Reykjavíkur 1921-1998 [The history of Reykjavik Electricity 1921-1998]. Reykjavík: Orkuveita Reykjavíkur

Jacobsen, R. (2014). 10.000 greinar á føroysku Wikipedia, (updated 02.06.2014). http://kvf.fo/ netvarp/uv/2014/06/02/10000-greinar-froysku-wikipedia Accessed June 6, 2014

Jarðfeingi (2016). Guidelines for Grants from License Holders to Competence Development. http:// www.jardfeingi.fo Accessed February 9, 2016

Jarðhitabók (2005). Eðli og nýting auðlindar [The Book on Geothermal Heating: The Nature and Use of Resources], in: G. Pálmason (Eds.), Hið íslenskabókmenntafélag. Reykjavík

Joensen, J. P. (1988). Higher Education in the Faroe Islands. Nordic Journal of International Law, 57, 3, 305-311

Jónsson, G. (1961). Saga Háskóla Íslands: Yfirlit um hálfrar aldar starf [History of the University of Iceland: Overview of Half a Century’s Work]. Reykjavík: Háskóli Íslands

Jónsson, B. 2005, próun tæknipekkingar og fagvinnu við virkjunarframkvæmdir Landsvirkjunar [Technological development by the constructions of Landsvirkjun]. In S. Pálsdóttir (Eds.), Landsvirkjun 1965-2005: Fyrirtcekið og umhverfi pess [Landsvirkjun 1965-2005: The company and its environment] (pp. 243-266). Reykjavík: Hið íslenska bókmenntafélag

Joyce, S., \& Thomson, I. (2000). Earning a social license to operate: Social acceptability and resource development in Latin America. Canadian Mining and Metallurgical Bulletin, 93, 1037, 49-53

Justinussen, J. C. S. (1999). Fanget i Fisken. Rapportserien. Roskilde: Roskilde University Center

Karlsdóttir, U.B. (2010). par sem fossarnir falla: Náttúrusýn og nýting fallvatna á Íslandi 1900-2008 [Where the water falls: Views of nature and use of waterfalls in Iceland 1900-2008]. Reykjavík: Hiðíslenska bókmenntafélag

Keck, M.E., \& Sikkink, K. (1999). Transnational advocacy networks in international and regional politics. International Social Science Journal, 51, 159, 89-101

Keohane, R. O. (1995). 'Hobbes' dilemma and institutional change in world politics: sovereignty in international society. In H. H. Holm \& G. Sorensen (Eds.), Whose world order? (pp. 165-186). Boulder: Westview Press

Kim, P., Ferrin, D., Cooper, C., \& Dirks, K. (2004). Removing the shadow of suspicion: The effects of apology versus denial for repairing competence- versus integrity-based trust violations. Journal of Applied Psychology, 89, 1, 104-118

Koivurova, T. (2010). Limits and possibilities of the Arctic Council in a rapidly changing scene of Arctic governance. Polar Record, 46, 237, 146-156

Koivurova, T. (2013). Gaps in international regulatory frameworks for the Arctic Ocean. In P. A. Berkman \& A. N. Vylegzhanin (Eds.), Environmental security in the Arctic Ocean (pp. 139-155). Dordrecht: Springer 
Koivurova, T., \& Molenaar, E. J. (2009). International governance and regulation of the marine Arctic. Oslo: WWF International Arctic Programme

Kristinsson, G.H. (2005). Raforka, efnishyggja og stjórnmálaátök [Electricity, materialism and political strife]. In S. Pálsdóttir (Eds.), Landsvirkjun 1965-2005: Fyrirtaekið og umhverfi pess [Landsvirkjun 1965-2005: The company and its environment] (pp. 137-163). Reykjavík: Hiðíslenska bókmenntafélag

Kristjánsson, H. (1997). Birta, afl og ylur: Saga Rafmagnsveita Ríkisins i 50 ár 1947-1997 [Light, power and heat: The history of the Iceland State Electricity for 50 years 1947-1997]. Reykjavík: Rafmagnsveitur Ríkisins

Krúnborg Offshore. (2012). Krúnborg Offshore P/F. Tórshavn: Skráseting Føroya

Laniado, D., Volkovich, Y., Scellato, S., Mascolo, C., \& Kaltenbrunner, A. (2017). The impact of geographic distance on online social interactions. Information Systems Frontiers, 1-16

Lloyds (2012). Arctic opening: Opportunity and risk in the high north. Lloyds. http://www.lloyds. com Accessed August 24, 2013

Luhmann, N. (1979). Trust and Power. Chichester: John Wiley and Sons

Macalister, T. (2011, 4 July). Arctic resource wealth poses dilemma for indigenous communities. The Guardian. http://www.theguardian.com Accessed August 24, 2013

Marnersdóttir, M. (2003). Fróðskaparsetur Føroya. In M. Marnersdóttir (Eds.), Universitet i útnorði Tórshavn: Fróðskaparsetur Føroya

Mayer, R., Davis, J., \& Schoorman, D. (1995). An integrative model of organizational trust. Academy of Managament Review, 20, 709-734

Mest. (2013). PAM On \& Offshore. http://www.mest-fo.com Accessed April 13, 2015

Ministry of Industry, Labour and Trade (2015). Guidelines for Social Impact Assessment in Greenland. http://www.Itu.se Accessed January 26, 2016

Moffat, K., \& Zhang, A. (2014). The paths to social license to operate: an integrative model explaining community acceptance of mining. Resources Policy, 39, 61-70

Molenaar, E. J. (2012). Current and prospective roles of the Arctic Council System within the context of the Law of the Sea. The International Journal of Marine and Coastal Law, 27, 553-595

Mølgaard, N. (2013, October 17). Opposition: Så meget spektakel for små ændringer. Sermitsiaq AG. http://sermitsiaq.ag Accessed January 12, 2014

Mørkøre, J. (1991). Class interests and nationalism in Faroese politics. In S. Dybbroe and P.B. Møller (Eds.), Local organisation, cultural identity and national integration in the North Atlantic (pp. 3). Faroe Islands: SNAI-North Atlantic Publications

Morrison, J. (2014). The Social License. How to Keep Your Organization Legitimate. New York: Palgrave Macmillan 
MTI (2005). Vision 2015 - Enterprise Policy. Submitted to the Faroese Parliament for Open Debate. Tórshavn: Ministry of Trade and Industry

Müller, J., \& Djurhuus, T. (2014). Oljan: føroysk vinnu-og samfelagsmenning i 25 ár,Oljan. Tórshavn

Naalakkersuisut. (2012). Redegørelse om Naalakkersuisuts Uddannelsesstrategi. http://nanoq. gl Accessed May 14, 2014

Naalakkersuisut. (2014a). Ét land - ét arbejdsmarked. Beskæftigelsesstrategi 2014-2017. http:// www.naalakkersuisut.gl Accessed November 16, 2014

Naalakkersuisut. (2014b). Grønlands olie- og Mineralstrategi 2014-2018. http://www. naalakkersuisut.gl Accessed November 16, 2014

Naalakkersuisut. (2014c). Impact Benefit Agreement under Mineral Exploration Licence 2014/21 between True North Gems Greenland - Kommuneqarfik Sermersooq - Naalakkersuisut. http:// www.naalakkersuisut.gl Accessed November 16, 2014

Naalakkersuisut (2015). Report to Inatsisartut, the Parliament of Greenland, concerning mineral resources activities in Greenland. http://www.govmin.gl Accessed June 30, 2017

Naalakkersuisut (2016). Social Impact Assessment (SIA). Guidelines on the process and preparation of the SIA report for mineral projects. http://govmin.gl Accessed August 5, 2016

NASA. (2013). Is a Sleeping Climate Giant Stirring in the Arctic? http://www.nasa.gov Accessed October 26, 2014

National Energy Authority Orkustofnun (2016). Oil and Gas Exploration, 2016. http://www.nea. is Accessed February 10, 2016

Newell, J.P., \& Henry, L.A. (2016). The state of environmental protection in the Russian Federation: A review of the post-Soviet era. Eurasian Geography and Economics, 57, 6, 779-801

Nielsen, J.K. (2001). Government, culture and sustainability in Greenland: A microstate with a hinterland. Public Organization Review, 1, 2, 229-243

Nordal, J. (1973). Um nýtingu vatnsafls og stefnuna í orkumálum: Erindi flutt ámiðsvetrarfundi Sambands íslenzkra rafveitna 6. marz 1973 in 14. Miðsvetrarfundur Sambands íslenzkra rafveitna, 29-48

Nordal, J., \& Kristinsson, V. (1996). Iceland, the Republic: Handbook. Reykjavik: Central Bank of Iceland, Reykjavik

Norden (2012). Utvalgsforslag om miljøvern og olje- og gassutvinning i de arktiske områder. Norden. http://www.norden.org Accessed July 31, 2013

NPD (2012). 22nd licensing round - announcement. http://www.npd.no Accessed October 27, 2014

NPD (2014). Nominations for the 23rd licensing round. http://www.npd.no Accessed October 27,2014

NSIDC (2017a). Quick Facts on Ice Sheets. http://nsidc.org Accessed June 30, 2017 
NSIDC (2017b). What is the Arctic? http://nsidc.org Accessed June 30, 2017

Nuttall, M. (2015). Subsurface politics: Greenlandic discourses on extractive industries. In: Jensen, L.C., Hønneland, G. (Eds.), Handbook of the Politics of the Arctic. Edward Elgar

OECD (2011). OECD Territorial Reviews: The Faroe Islands, Greenland, Iceland, and Coastal Norway. NORA region 2011. France: OECD Publishing

Oljumálaráðið. (2003). Leiðreg/ur í samband við stuðul frá loyvishavarum tilvinnuliga førleikamenning. Tórshavn: Føroya Landsstrýrið

Oljuráðleggingarnevndin. (1997). Fyrireikingar til oljuleiting: frágreiðing frá Oljuráðleggingarnevnd landsstýrisins. Tórshavn: Oljuráðleggingarnevndin vegna Føroyalandsstýri

Oljuvinnufelagið (2013). Ársfrágreiðing fyri 2013. http//www.vinnuhusid.fo Accessed February 10,2016

Olsen, K.K. (2013) Education in Greenland. http://www.ankn.uaf.edu Accessed November 25, 2013

Omeje, K. (2005). Oil conflict in Nigeria: contending issues and perspectives of the local Niger Delta people. New Political Economy, 10, 3, 321-334

Ottowa Declaration. (1996). Declaration on the establishment of the Arctic Council. Ottowa: Arctic Council

Owen, J.R., \& Kemp, D. (2013). Social license and mining: a critical perspective. Resources Policy, 38, 29-35

Pálsdóttir, S. (2005). Landsvirkjun: fyrirtækið, framkvæmdir pess og hlutverk [Landsvirkjun: the company, its constructions and its role]. In S. Pálsdóttir (Eds.), Landsvirkjun 1965-2005: Fyrirtaekið og umhverfi pess [Landsvirkjun 1965-2005: The company and its environment] (pp.13-110). Reykjavík: Hið íslenska bókmenntafélag

PAME. (2009, April 29). Arctic offshore oil and gas guidelines. Protection of the Arctic Marine Environment. http://www.pame.is Accessed March 22, 2012

PAME. (n.d.). Greenland-Bureau of Minerals and Petroleum. Protection of the Arctic Marine Environment. http://www.pame.is Accessed August 24, 2013

Parsons, R., \& Moffat, K. (2014). Integrating impact and relational dimensions of social license and social impact assessment. Impact Assessment and Project Appraisal, 32, 4, 273-282

Parsons, R., Lacey, J., \& Moffat, K. (2014). Maintaining legitimacy of a contested practice: how the minerals industry understands its 'social license to operate'. Resources Policy, 41, 83-90

Petersen, L. (1994). Skole pá Føerøerne i 1000 ár - En skolehistorisk håndbog. Tórshavn

Pettersen, T. (2013). Six new observers to the Arctic Council. The Barents Observer. http:// barentsobserver.com Accessed August 24, 2013

PEW (2013). Arctic standards. Recommendations on oil spill prevention, response, and safety in the U.S. Arctic Ocean. The PEW Charitable Trusts. http://www.pewtrusts.org Accessed May 6, 2019 
Pew Research Center (2016). Smartphone ownership and internet usage continues to climb in emerging economies. But advanced economies still have higher rates of technology used. http://pewglobal.org_Accessed October 12, 2018

Pfeifer, S., \& Thompson, C. (2011). The Struggle for Greenland's Oil. http://www.ft.com Accessed October 20, 2014

Pierre, J., \& Peters, B. G. (2000). Governance, politics and the state. London: MacMillan Press Ltd.

Pierre, J., Røiseland A., \& Gustavsen, A. (2011). Legitimacy by performance in democratic systems? Preparing for empirical analysis. http://www.pol.gu.se Accessed September 21, 2015

Prno, J. (2013). An analysis of factors leading to the establishment of a social license to operate in the mining industry. Resources Policy, 38, 577-590

Prno, J., \& Slocombe, D.S. (2012). Exploring the origins of 'social license to operate' in the mining sector: perspectives from governance and sustainability theories. Resources Policy, 37, 346357

Quartz (2015, June 3). Greenpeace crashed the seal-product market, and Inuit livelihood along with it. http://www.qz.com Accessed April 29, 2019

Queen of Denmark. (2009). Act on Greenland Self-Government. Copenhagen: Danish Parliament

Rafaelsen, J. (2013, October 24). Aasiaat: Stille demonstration mod uran. Sermitsiaq AG. http:// sermitsiaq.ag Accessed January 12, 2014

Ragnarsson, S. (1975). Innilokun eða opingátt: Pættir úr sögu fossamálsins [Closure or openness: Elements of the history of the waterfall question]. Saga. 13: 5-105

Ragnarsson, S. (1976). Fossakaup og framkvæmdaáform: pættir úr sögu fossamálsins. Fyrri hluti [Waterfall investments and planning: Elements of the history of the 'waterfall question'. First part], Saga. 14: 125-182

Ragnarsson, S. (1977). Fossakaup og framkvæmdaáform: pættir úr sögu fossamálsins. Siðari hluti [Waterfall investments and planning: Elements of the history of the 'waterfall question'. Second part], Saga. 15: 125-222

Reeves, P. (2011). Greenlanders divided on Arctic oil, gas exploration. NPR. http://www.npr.org/ Accessed March 22, 2012

Rekacewicz, P., \& Ahlenius, H. (2006). Fossil fuels resources and oil and gas production in the Arctic. UNEP/GRID-Arendal. http://www.grida.no Accessed August 6, 2013

Reuters (2014). CORRECTED - Low oil prices threaten Norway's Arctic and UK's mature fields. http://www.reuters.com Accessed July 27, 2015

Revkin, A. C. (2008). 5 Countries agree to talk over the Arctic. The New York Times. http://www. nytimes.com Accessed July 14, 2013

Riabova, L., \& Didyk, V. (2014). Social license to operate for mining companies in the Russian Arctic: Two cases in the Murmansk Region. http://arcticyearbook.com_Accessed August 6, 2016 
Risse, T., \& Kleine, M. (2007). Assessing the legitimacy of the EU's treaty revision methods. JCMS $45,1,69-80$

Roche, P., \& Petit S. (2009). Russia's Withdrawal from the Energy Charter Treaty. Brussels: Norton Rose Fulbright

Rosenau, J. N. (1997). Along the domestic-foreign frontier; Exploring governance in a turbulent world. Cambridge: Cambridge University Press

Rosenau, J. N. (2002). Governance in a new global order. In D. Held \& A. McGrew (Eds.), Governing globalization; Power, authority and global governance (pp. 70-86). Malden: Polity Press and Blackwell Publishing Ltd

Rosenau, J. N. (2003). Distant proximities: Dynamics beyond g/obalization. Princeton/Oxford: Princeton University Press

Rosenau, J. N. (2006). The study of world politics: Globalization and governance (Vol. 2). London/ New York: Routledge

Rottem, S. V. (2013). The Arctic Council and the Search and Rescue Agreement: The case of Norway. Polar Record. http://journals.cambridge.org. Accessed January 12, 2014

Ruggie, J.G. (2004). Reconstituting the Global Public Domain. Issues, Actors, and Practices. European Journal of International Relations, 10, 4, 499-531

Sassen, S. (2006). Territory, authority, rights: From medieval to global assemblages. Princeton, NJ: Princeton University Press

Sermitsiaq (2013, December 2). NGO-koalition kræver længere Tanbreez-høring. Sermitsiaq AG. http://sermitsiaq.ag Accessed January 12, 2014

Sheridan, M. B. (2010). Clinton rebukes Canada at Arctic meeting. The Washington Post. http:// www.washingtonpost.com Accessed August 24, 2013

Short, J., \& Murray, S. (2011). A frozen hell. Nature, 472, 162-163

Sigurðsson, H.M. (2002). Vatnsaflsvirkjanir á Íslandi [Hydro power stations in Iceland]. Reykjavík: Verkfræðistofa Sigurðar Thoroddsen

Skansi (2013). Skansi Offshore Awarded Contract from Statoil. http://www.skansi.fo Accessed April 13, 2015

Slack, K. (2012). Mission impossible? Adopting a CSR-based business model for extractive industries in developing countries. Resources Policy, 37, 179-184

Smits, C.C.A., Bertelsen, R.G., \& Justinussen, J.C.S. (2014a). The challenges \& opportunities for Arctic microstates in developing an energy sector: the role of human capital and knowledge institutes. Arctic Yearbook, 3, 1-17

Smits, C.C.A., van Tatenhove, J.P.M., \& van Leeuwen, J. (2014b). Authority in Arctic governance: changing spheres of authority in Greenlandic offshore oil and gas developments. International Environmental Agreements: Politics, Law and Economics, 14, 4, 329-348 
Smits, C.C.A., Justinussen, J.C.S., \& Bertelsen, R.G. (2015). Oil and gas development in the Faroese islands, Iceland and Greenland: how local competence development contributes to a social license to operate. Offshore Technology Conference, March 2015, 23-25

Smits, C.C.A., Justinussen, J.C.S., \& Bertelsen, R.G. (2016). Human capital development and a social License to operate: examples from Arctic energy development in the Faroe Islands, Iceland and Greenland. Energy Resources and Social Sciences, 16, 122-131

Smits, C.C.A., van Leewen, J., \& van Tatenhove, J.P.M. (2017). Oil and gas development in Greenland: A social license to operate, trust and legitimacy in environmental governance. Resources Policy, 53, 109-116

Solimano, A. (ed.) (2008). The International Mobility of Talent: Types, Causes and Development Impact. Oxford: Oxford University Press

Spaargaren, G., \& Mol, A. P. (2008). Greening global consumption: Redefining politics and authority. Global Environmental Change, 18, 3, 350-359

Statistics Greenland. (2016). Greenland in Figures 2016. http://www.stat.gl Accessed September 9, 2016

Statistics Greenland (2018). Greenland in Figures 2018. http://www.stat.gl Accessed May 6, 2019

Statoil (2013). Johan Castberg project delayed. Statoil. http://www.statoil.com Accessed January 11,2014

The Arctic Journal (2013, October 21). Unions upset over Greenland's revised mining law. The Arctic Journal. http://arcticjournal.com Accessed January 12, 2014

The Arctic Journal (2016). Latest Scandal Comes at Unfortunate Time for Nuuk. http://www. arcticjournal.com Accessed September 9, 2016

The Economist. (2004). Climate Change: A Canary in the Coal Mine. http://www.economist.com Accessed October 26, 2014

The Guardian (June 1, 2018). Dutch fishermen to sail fleet into Amsterdam in wind turbine protest. http://www.theguardian.com_Accessed December 7, 2018

The Local (August 7, 2018). Why do so many people in France hate wind farms? http://www. thelocal.fr Accessed December 7, 2018

Thomson, I., \& Boutilier, R.G. (2011). Modelling and measuring the social license to operate: Fruits of a dialogue between theory and practice. http://sociallicense.com Accessed June 17, 2015

Thor (2011). Thor P/F_Ársfrásøgn við samtaksroknskapi 2011. Tórshavn: Skráseting Føroya

Transparency Greenland (2012). Integrity Study of the Public Sector in Greenland. http://www. ncg.dk Accessed August 5, 2016

Troelsen, P. (2012). Nye uddannelser på Råstofskolen. Kalaallit Nunaata Radioa (KNR). http://www. knr.gl Accessed May 14, 2014 
Underdal, A. (2013). Meeting common environmental challenges: The co-evolution of policies and practices. International Environmental Agreements: Politics, Law and Economics, 13, 1, 15-30

UNDP (2013). Human Development Report 2013: The Rise of the South. Human Progress in a Diverse World. United Nations Development Programme. http://hdr.undp.org Accessed May 14,2014

UNDP (2015). Human Development Report 2015: Work for Human Development. United Nations Development Programme. http://hdr.undp.org Accessed September 20, 2015

USGS. (2008a). 90 barrels of oil and 1,670 trillion cubic feet of natural gas assessed in the Arctic. U.S. Geological Survey. http://www.usgs.gov Accessed February 8, 2012

USGS (2008b). Circum-Arctic Resource Appraisal: Estimates of Undiscovered Oil and Gas North of the Arctic Circle. http://www.usgs.gov Accessed February 8, 2012

Van Leeuwen, J. (2010). Who greens the waves? Changing authority in the environmental governance of shipping and offshore oil and gas production. Wageningen: Wageningen Academic Publishers

Van Leeuwen, J., \& Kern, K. (2013). The external dimension of European Union marine governance: Institutional interplay between the EU and the International Maritime Organisation. Global Environmental Politics, 13, 01, 69-87

Van Tatenhove, J.P.M. (2011). Integrated marine governance: questions of legitimacy. MAST, 10, $1,87-113$

Van Tatenhove, J. (2013). How to turn the tide: Developing legitimate marine governance arrangements at the level of the regional seas. Ocean and Coastal Management, 71, 296-304

Vennix, J. (2006). Theorie en praktijk van empirisch onderzoek. Harlow: Pearson Education Ltd.

Vermont Law School (2011). Arctic Offshore Oil and Gas Guidelines white paper no.5. The Arctic Offshore Oil and Gas Guidelines in Greenland and the Russian Federation. http://www. vermontlaw.edu_Accessed December 7, 2018

Vidal, J. (2011). Cairn Energy threatens to fine Greenpeace for Arctic Drilling Protest. The Guardian. http://www.guardian.co.uk/ Accessed July 14, 2013

Vinnumálaráðið (2013). Heildarcetlan - Fólkaflyting og fólkavøkstur. Tórshavn: Føroya Landsstýrið

Washington Post (2015, April 21). A chill is already in the air ahead of next meeting of Arctic Council. http://www.washingtonpost.com Accessed July 27, 2015

Weihe, P., Rasmussen, M., Jacobsen, E., Hentze, J.P., Harlou, B., Højgaard, E., \& Róin, M. (2005). Frágreiðing og tilmceli i samband við stovnsetan av granskarapark. Tórshavn: Vinnumálaráðið.

Wilburn, K.M., \& Wilburn, R. (2011). Achieving social license to operate using stakeholder theory. Journal of International Business Ethics, 4, 2, 3-16

World Bank. (2003a). Lifelong learning in the global knowledge economy: Challenges for developing countries http://www.worldbank.org Accessed September 21, 2014 
World Bank. (2003b). Striking a better balance: The World Bank and Extractive Industries. http:// web.worldbank.org Accessed September 21, 2015

World Bank. (2009). Education for the knowledge economy. http://web.worldbank.org Accessed September 21, 2014

World Bank (2016). Resource development in an era of cheap commodities. http://pubdocs. worldbank.org Accessed June 30, 2017

WWF \& ICC (2013). Med folkets mandat? Høringsprocesser og borgerinddragelse på råstofområdet. World Wildlife Fund and Inuit Cirmumpolar Council. http://panda.org Accessed January 12, 2014

Yates, B.F., \& Horvath, C.L. (2013). Social License to Operate: how to get it, and how to keep it. Pacific Energy Summit 2013

Yin, R. (2009). Case Study Research: Design \& Methods. Los Angeles: Sage

Young, G.V.C. (1982). Føerøerne - Fra vikingetiden til reformationen. København: Rosenkilde og Bagger

Young, O. R. (2009). Arctic state changes: Implications for governance. The Arctic Governance Project. http://arcticgovernance.custompublish.com/ Accessed August 24, 2013

Zucker, L.G. (1986). Production of trust: institutional sources of economic structure, in: B.M. Staw, L.L. Cummings (Eds.), Research in Organisational Behaviour. Greenwich: JAI Press

Pórðarson, S. (2004). Afl i segulœeðum: Saga rafmagns á Íslandi i 100 ár [Power in magnetic veins: The story of electricity in Iceland in 100 years]. Reykjavík: Verkfræðingafélag Íslands 
APPENDICES

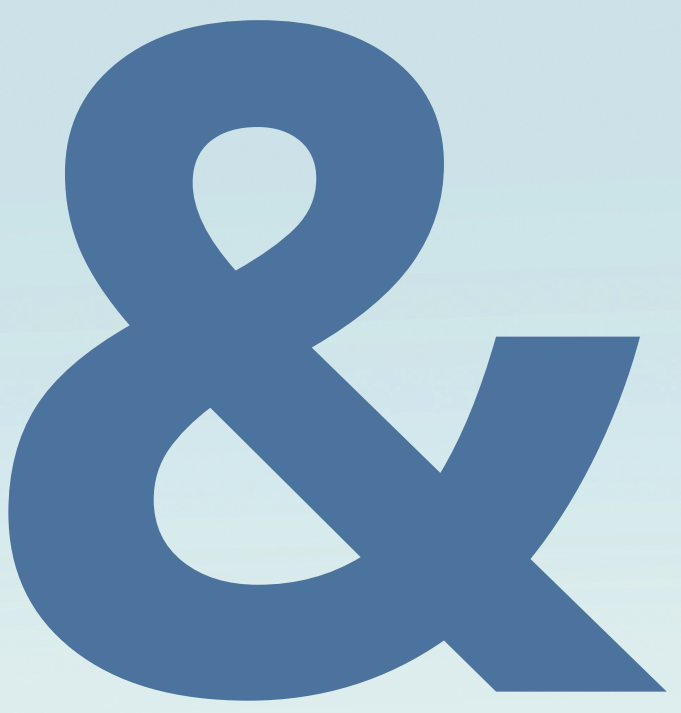




\section{Interview information}

\section{Summary}

About the author

List of publications

Acknowledgements / Dankwoord 


\section{LIST OF INTERVIEWS 2015/2016}

\begin{tabular}{|c|c|c|c|c|}
\hline Sector & Affiliation & Position & Date & $\begin{array}{l}\text { Interview } \\
\text { mode }\end{array}$ \\
\hline $\begin{array}{l}\text { Public } \\
\text { sector }\end{array}$ & $\begin{array}{l}\text { European Commission } \\
- \\
\text { DG MARE }\end{array}$ & Policy officer & $17-12-2015$ & Skype \\
\hline $\begin{array}{l}\text { Public } \\
\text { sector }\end{array}$ & $\begin{array}{l}\text { Ministry of Industry, } \\
\text { Labour \& Trade GL }\end{array}$ & $\begin{array}{l}\text { Special advisor / Socio- } \\
\text { economist }\end{array}$ & $19-01-2016$ & Face-to-face \\
\hline $\begin{array}{l}\text { Public } \\
\text { sector }\end{array}$ & $\begin{array}{l}\text { Mineral License \& } \\
\text { Safety Authority }\end{array}$ & $\begin{array}{l}\text { Head of the license } \\
\text { department }\end{array}$ & $18-02-2016$ & Face-to-face \\
\hline $\begin{array}{l}\text { Public } \\
\text { sector }\end{array}$ & $\begin{array}{l}\text { KANUKOKA - } \\
\text { Municipalities } \\
\text { Association of } \\
\text { Greenland }\end{array}$ & $\begin{array}{l}\text { Special advisor environment } \\
\text { and resources }\end{array}$ & $22-02-2016$ & Face-to-face \\
\hline $\begin{array}{l}\text { Private } \\
\text { sector }\end{array}$ & $\begin{array}{l}\text { Greenland Petroleum } \\
\text { Services }\end{array}$ & CEO & 06-01-2016 & Skype \\
\hline $\begin{array}{l}\text { Private } \\
\text { sector }\end{array}$ & Shell & $\begin{array}{l}\text { Senior advisor Arctic } \\
\text { \& Senior advisor non- } \\
\text { technical risk integration in } \\
\text { external relations }\end{array}$ & 01-03-2016 & Face-to-face \\
\hline $\begin{array}{l}\text { Private } \\
\text { sector }\end{array}$ & NunaOil & Director & $22-02-2016$ & Face-to-face \\
\hline $\begin{array}{l}\text { Civil } \\
\text { society }\end{array}$ & Greenpeace Denmark & Arctic campaigner & $19-01-2016$ & Face-to-face \\
\hline $\begin{array}{l}\text { Civil } \\
\text { society }\end{array}$ & WWF Greenland & Senior advisor Greenland & $19-02-2016$ & Face-to-face \\
\hline $\begin{array}{l}\text { Civil } \\
\text { society }\end{array}$ & $\begin{array}{l}\text { Inuit Circumpolar } \\
\text { Council }\end{array}$ & President of ICC Greenland & $19-02-2016$ & Face-to-face \\
\hline $\begin{array}{l}\text { Civil } \\
\text { society }\end{array}$ & CSR Greenland & $\begin{array}{l}\text { Project leader \& Advisor to } \\
\text { CSR Greenland }\end{array}$ & 23-02-2016 & Face-to-face \\
\hline $\begin{array}{l}\text { Civil } \\
\text { society }\end{array}$ & $\begin{array}{l}\text { Greenland School of } \\
\text { Minerals \& Petroleum }\end{array}$ & Head of school & $25-02-2016$ & Face-to-face \\
\hline
\end{tabular}




\section{LIST OF INTERVIEWS 2012}

\begin{tabular}{lllcc}
\hline Sector & Affiliation & Position & Date & $\begin{array}{c}\text { Interview } \\
\text { mode }\end{array}$ \\
\hline $\begin{array}{l}\text { Public } \\
\text { sector }\end{array}$ & $\begin{array}{l}\text { Ministry of Foreign } \\
\text { Affairs NL }\end{array}$ & Arctic Council Observer NL & 09-05-2012 & Face-to-face \\
$\begin{array}{l}\text { Public } \\
\text { sector }\end{array}$ & $\begin{array}{l}\text { Department of Foreign } \\
\text { Affairs GL }\end{array}$ & Head of office & $16-05-2012$ & Skype \\
$\begin{array}{l}\text { Private } \\
\text { sector }\end{array}$ & London Mining & Communication manager & $01-05-2012$ & Skype \\
$\begin{array}{l}\text { Private } \\
\text { sector }\end{array}$ & Shell & Senior advisor Arctic & $05-06-2012$ & Face-to-face \\
$\begin{array}{l}\text { Civil } \\
\text { society }\end{array}$ & WWF Denmark & Greenland policy officer & $19-04-2012$ & Skype \\
$\begin{array}{l}\text { Civil } \\
\text { society }\end{array}$ & Greenpeace Denmark & Arctic campaigner & $01-05-2012$ & Skype \\
$\begin{array}{l}\text { Civil } \\
\text { society }\end{array}$ & WWF Russia & $\begin{array}{l}\text { Oil and gas officer, WWF } \\
\text { global Arctic programme }\end{array}$ & $01-05-2012$ & Skype \\
\hline
\end{tabular}




\section{LIST OF INTERVIEWS 2011}

\begin{tabular}{|c|c|c|c|c|}
\hline Sector & Affiliation & Position & Date & $\begin{array}{l}\text { Interview } \\
\text { mode }\end{array}$ \\
\hline $\begin{array}{l}\text { Public } \\
\text { sector }\end{array}$ & Premier's Office GL & Executive deputy & $06-12-2011$ & Face-to-face \\
\hline $\begin{array}{l}\text { Public } \\
\text { sector }\end{array}$ & Premier's Office GL & Premier of GL & $06-12-2011$ & Face-to-face \\
\hline $\begin{array}{l}\text { Public } \\
\text { sector }\end{array}$ & $\begin{array}{l}\text { Ministry of Domestic } \\
\text { Affairs, Environment \& } \\
\text { Nature GL }\end{array}$ & $\begin{array}{l}\text { Head of section nature \& } \\
\text { Head of section environment }\end{array}$ & $07-12-2011$ & Face-to-face \\
\hline $\begin{array}{l}\text { Public } \\
\text { sector }\end{array}$ & $\begin{array}{l}\text { Bureau of Minerals and } \\
\text { Petroleum }\end{array}$ & Director & $08-12-2011$ & Face-to-face \\
\hline $\begin{array}{l}\text { Public } \\
\text { sector }\end{array}$ & Nukissiorfiit & CEO & $06-12-2011$ & Face-to-face \\
\hline $\begin{array}{l}\text { Private } \\
\text { sector }\end{array}$ & Inuplan & $\begin{array}{l}\text { CEO \& Senior Engineer \& } \\
\text { Partner }\end{array}$ & $05-12-2011$ & Face-to-face \\
\hline $\begin{array}{l}\text { Private } \\
\text { sector }\end{array}$ & NunaOil & Director & $05-12-2011$ & Face-to-face \\
\hline $\begin{array}{l}\text { Private } \\
\text { sector }\end{array}$ & CairnEnergy & $\begin{array}{l}\text { Greenland country } \\
\text { representative }\end{array}$ & $06-12-2011$ & Face-to-face \\
\hline $\begin{array}{l}\text { Private } \\
\text { sector }\end{array}$ & $\begin{array}{l}\text { Greenland Petroleum } \\
\text { Services }\end{array}$ & CEO \& Logistical officer & $08-12-2011$ & Face-to-face \\
\hline $\begin{array}{l}\text { Private } \\
\text { sector }\end{array}$ & Royal Arctic Line & $\mathrm{COO}$ & $06-12-2011$ & Face-to-face \\
\hline $\begin{array}{l}\text { Private } \\
\text { sector }\end{array}$ & NunaMinerals & CFO & $07-12-2011$ & Face-to-face \\
\hline $\begin{array}{l}\text { Private } \\
\text { sector }\end{array}$ & $\begin{array}{l}\text { Greenland Minerals } \\
\text { and Energy }\end{array}$ & CEO & $08-12-2011$ & Face-to-face \\
\hline $\begin{array}{l}\text { Private } \\
\text { sector }\end{array}$ & London Mining & Communication manager & $13-12-2011$ & Face-to-face \\
\hline $\begin{array}{l}\text { Civil } \\
\text { society }\end{array}$ & $\begin{array}{l}\text { Greenland Institute of } \\
\text { Natural Resources }\end{array}$ & $\begin{array}{l}\text { Director \& Head of } \\
\text { department of birds and } \\
\text { mammals }\end{array}$ & $07-12-2011$ & Face-to-face \\
\hline
\end{tabular}




\section{INTERVIEW QUESTIONNAIRE 2015/2016}

\begin{tabular}{|c|c|c|}
\hline Topic & Question & Asked to \\
\hline Understanding SLO & $\begin{array}{l}\text { What is your understanding of a Social License } \\
\text { to Operate for oil and gas activities in the Arctic/ } \\
\text { Greenland? }\end{array}$ & Everyone \\
\hline Understanding SLO & $\begin{array}{l}\text { What elements do you consider essential in } \\
\text { obtaining and maintaining a social license to } \\
\text { operate? }\end{array}$ & Everyone \\
\hline Understanding SLO & $\begin{array}{l}\text { How does your company act on obtaining and } \\
\text { maintaining its social license to operate? And how } \\
\text { is this concept embedded in your organisation? }\end{array}$ & Private Sector \\
\hline Understanding SLO & $\begin{array}{l}\text { Does your organisation collaborate with other } \\
\text { parties to obtain and maintain a social license } \\
\text { to operate for oil and gas activities in the Arctic/ } \\
\text { Greenland? }\end{array}$ & Private Sector \\
\hline Understanding SLO & $\begin{array}{l}\text { If yes, what kind of parties do you collaborate with? } \\
\text { (If possible mention the names of organisations/ } \\
\text { government departments etc.) }\end{array}$ & Private Sector \\
\hline Understanding SLO & $\begin{array}{l}\text { If yes, in which phase of an activity do you a) } \\
\text { approach which party to be or b) are you involved } \\
\text { in obtaining and maintaining a SLO for Arctic/ } \\
\text { Greenlandic oil and gas activities? }\end{array}$ & Private Sector \\
\hline Understanding SLO & $\begin{array}{l}\text { How does your government act when an actor } \\
\text { wants to obtain and maintain its social license to } \\
\text { operate? And how is this concept embedded in the } \\
\text { relevant government authorities? }\end{array}$ & Public Sector \\
\hline Understanding SLO & $\begin{array}{l}\text { Does your organisation collaborate with parties } \\
\text { who seek to obtain or maintain a social license } \\
\text { to operate for oil and gas activities in the Arctic / } \\
\text { Greenland? }\end{array}$ & Research Institutes \\
\hline Understanding SLO & $\begin{array}{l}\text { If yes, with what kind of parties do you collaborate? } \\
\text { (If possible mention the names of organisations/ } \\
\text { government departments etc.) }\end{array}$ & Research Institutes \\
\hline Understanding SLO & $\begin{array}{l}\text { If yes, has this ever led to criticism on your } \\
\text { research institute and how has your organisation } \\
\text { responded to this? }\end{array}$ & Research Institutes \\
\hline Understanding SLO & $\begin{array}{l}\text { Do you think the social license to operate for oil } \\
\text { and gas activities in the Arctic / Greenland will } \\
\text { significantly change in the future? And why? }\end{array}$ & Everyone \\
\hline
\end{tabular}




\begin{tabular}{|c|c|c|}
\hline Topic & Question & Asked to \\
\hline Understanding SLO & $\begin{array}{l}\text { Does a social license to operate in the Arctic differ } \\
\text { from a SLO for non-Arctic activities? And why? }\end{array}$ & Everyone \\
\hline $\begin{array}{l}\text { Legal vs. Political } \\
\text { vs. Social }\end{array}$ & $\begin{array}{l}\text { Is there a relation for you between the Social } \\
\text { License and the Legal and Political licenses that } \\
\text { are needed to develop Arctic/Greenlandic oil and } \\
\text { gas activities? }\end{array}$ & Everyone \\
\hline $\begin{array}{l}\text { Legal vs. Political } \\
\text { vs. Social }\end{array}$ & $\begin{array}{l}\text { If yes, can you describe the relation between these } \\
\text { three types of licenses? }\end{array}$ & Everyone \\
\hline $\begin{array}{l}\text { Legal vs. Political } \\
\text { vs. Social }\end{array}$ & $\begin{array}{l}\text { If no, why is there no relation between those } \\
\text { licenses according to you? }\end{array}$ & Everyone \\
\hline $\begin{array}{l}\text { Legal vs. Political } \\
\text { vs. Social }\end{array}$ & $\begin{array}{l}\text { What are the important differences and similarities } \\
\text { between these three types of licenses? }\end{array}$ & Everyone \\
\hline $\begin{array}{l}\text { Legal vs. Political } \\
\text { vs. Social }\end{array}$ & $\begin{array}{l}\text { How do you see the future for each of these three } \\
\text { licenses and the relation between them? }\end{array}$ & Everyone \\
\hline $\begin{array}{l}\text { Legal vs. Political } \\
\text { vs. Social }\end{array}$ & $\begin{array}{l}\text { What is your position and role with regards to } \\
\text { these three types of licenses for oil and gas } \\
\text { activities in the Arctic/Greenland? }\end{array}$ & Everyone \\
\hline $\begin{array}{l}\text { Legal vs. Political } \\
\text { vs. Social }\end{array}$ & $\begin{array}{l}\text { How is your company organised to deal with these } \\
\text { three types of licenses? i.e. are there different } \\
\text { departments taking care of it? }\end{array}$ & Private Sector \\
\hline $\begin{array}{l}\text { Legal vs. Political } \\
\text { vs. Social }\end{array}$ & $\begin{array}{l}\text { In what stages of a development are these three } \\
\text { licenses of relevance to your company? And why? }\end{array}$ & Private Sector \\
\hline $\begin{array}{l}\text { Legal vs. Political } \\
\text { vs. Social }\end{array}$ & $\begin{array}{l}\text { How is your organisation organised to deal with } \\
\text { these three types of licenses? }\end{array}$ & Civil Society \\
\hline $\begin{array}{l}\text { Legal vs. Political } \\
\text { vs. Social }\end{array}$ & $\begin{array}{l}\text { Do you have a different strategy towards each of } \\
\text { these licenses in your campaigns? }\end{array}$ & Civil Society \\
\hline $\begin{array}{l}\text { National vs. } \\
\text { International }\end{array}$ & $\begin{array}{l}\text { How do you view the national, regional and } \\
\text { international dimension for each of the three } \\
\text { licenses (Legal, Political and Social) related to oil } \\
\text { and gas development in the Arctic/Greenland? }\end{array}$ & Everyone \\
\hline $\begin{array}{l}\text { National vs. } \\
\text { International }\end{array}$ & $\begin{array}{l}\text { Is the development of oil and gas activities in the } \\
\text { Arctic/Greenland exclusively a matter of national } \\
\text { decision making? And why? }\end{array}$ & Everyone \\
\hline $\begin{array}{l}\text { National vs. } \\
\text { International }\end{array}$ & $\begin{array}{l}\text { How do you experience the international attention } \\
\text { for oil and gas activities in the Arctic/Greenland? }\end{array}$ & Everyone \\
\hline $\begin{array}{l}\text { National vs. } \\
\text { International }\end{array}$ & $\begin{array}{l}\text { What are the challenges and opportunities } \\
\text { related to the national, regional and international } \\
\text { attention in the development of Arctic/Greenlandic } \\
\text { oil and gas activities? }\end{array}$ & Everyone \\
\hline
\end{tabular}




\section{Topic}

Question

One project can affect an entire company, and one

Company SLO vs. Industry SLO

Company SLO vs. Industry SLO

Company SLO vs. Industry SLO

Company SLO vs. Industry SLO

Company SLO vs. Industry SLO

Company SLO vs. Industry SLO

General Arctic Energy

Trust

Trust

Trust

Trust

Trust

Legitimacy

Legitimacy

Legitimacy

company can affect the entire industry. Based on this reasoning, what is your understanding of a SLO for project, company and industry?

Which of these levels (project, company or industry) is of your concern? And if more than one level is of your concern, how are you organised to deal with these different levels?

What is your position and role concerning these three different levels and their SLO? obtaining and maintaining an industry-wide SLO?

If yes, are all companies active in the Arctic involved? And how does this collaboration look like? And will this be different in the future?

How do you view the future of oil and gas development in the Arctic and in particular in Greenland?

How do you work on building trust with various stakeholders?

And does your trust building approach differ per type of stakeholder?

Are you involved in trust building with and between various stakeholders? For example between private sector companies and the local communities?

Is the development of oil and gas activities considered legitimate among Greenlandic society?

If yes, what are the most important aspects supporting this legitimacy?

If no, why not?
Asked to

Everyone

Everyone

Everyone

Private Sector

Private Sector

Private Sector

Private Sector

Public Sector

Private Sector /

Public Sector

Everyone

Everyone

Everyone 


\section{SUMMARY}

The Arctic is changing. The effects of climate change are most profound in this part of the world: Sea ice extend is decreasing and temperatures are rising faster than anywhere else. The melting Greenlandic ice sheet is expected to contribute 6 meters to global sea level rise and is a threat for many densely populated coastal communities around the world. At the same time, the decreasing sea ice extend and rising temperatures also create new opportunities. The region is opening up to activities including fisheries, tourism, shipping, mining and oil and gas. Over the past decade an increase in economic activities was experienced throughout the Arctic and it was estimated that the region could potentially attract over $\$ 100$ billion of investments. Shipping, mining and oil and gas were considered to be the main drivers of economic development and between 2010 and 2015 offshore oil and gas exploration activities took place in many parts of the Arctic Ocean. Even though the development of Arctic offshore oil and gas activities has largely come to a halt now, it has sparked a lot of debate and controversy over the past years.

In 2009, right at the start of the boom in Arctic offshore oil and gas activities, Greenland obtained Self-Rule within the Kingdom of Denmark, thereby obtaining authority over the underground and thus the development of oil, gas and minerals. Greenland expressed the wish to develop these extractive resources to generate additional income and employment opportunities to support the long term wish of becoming (financially) independent from Denmark. In Greenland everything comes together: The melting ice sheet illustrating global climate change and at the same time a government expressing the ambition to develop oil and gas resources. Opening up to oil and gas development attracted the attention from some of the largest international oil companies and the world's largest states, while Greenland has a population of only 56.000 people living on the world's largest island. Furthermore, the oil and gas exploration activities that took place in Greenlandic waters were subject to critique from individual citizens and NGOs, both in Greenland and far beyond.

Critique, societal debate and resistance against large industrial activities, including oil and gas, is increasingly studied from a social science perspective by using the concept of a 'Social License to Operate'. The social license to operate concept addresses the emergence of increasingly critical civil society organisations and citizens at a local level that seeks to have influence on the development of large industrial activities. However, the case of Greenland shows that the development of oil and gas activities is not solely an affair of state authorities and companies, nor is it solely a national affair: National level stakeholders want to become more involved in the decision making process and 
at the same time oil and gas activities are closely linked to the globally debated theme of climate change and the transition towards renewable energy.

The traditional, rather instrumental focus of the social license to operate concept on a local project context and the relation between a company and its local stakeholders, therefore misses essential elements of today's increasingly interconnected and complex society. Trust and legitimacy are in general considered key components of a social license to operate, but are also difficult to measure and therefore less examined. The role of human capital development is hardly studied, even though human capital development is one of the main challenge in small Arctic societies. Influences from political and legal arenas or other operational levels that could influence the implementation of an activity are not necessarily integrated in the current social license to operate approach.

The aim of this thesis is therefore to understand the development of a social license to operate of controversial energy projects by analysing the role of trust, legitimacy and human capital development in an Arctic context and by developing a multilevel approach of a social license to operate that includes legal and political licenses both in theory and in practice.

The central research question is: How is the social license to operate of Greenlandic oil and gas activities influenced by legal and political licenses in a multilevel context, what is the role of trust, legitimacy and human capital development and how does this contribute to a multilevel approach of a social license to operate?

1. What is the multilevel governance setting in which Arctic oil and gas activities take place and what is the authority of a state such as Greenland?

2. What is a social license to operate and how does it relate to the legal and political licenses of oil and gas activities in the Greenland?

3. In what way do trust and legitimacy play a role in the different licenses to operate for oil and gas activities in Greenland?

4. What are the challenges and opportunities for Greenland to maximise local benefits in the development of an oil and gas sector?

5. In what way does human capital development contribute to a social license to operate for oil and gas development in Greenland and other small Arctic states?

6. How has the social license to operate of Arctic oil and gas activities developed at the international level and how does it interact with the local level?

To answer these research questions, a case-study approach was selected. The selection of the Greenlandic case is based on a controversial energy development, evoking debate in society both at a national and international level, and the accessibility of information 
regarding the activities at hand. Primary data to study this case was collected in two sets of semi-structured interviews (December 2011 and February 2016) and observations, and supplemented by secondary data from literature, project and policy documents, social media and newspapers.

Chapter 2 explores the multilevel governance setting of Arctic oil and gas activities and studies the changing spheres of authority in Greenland (sub-question 1). The Arctic sphere of authority on oil and gas consists of many different governance arrangements. Crucial in this respect is the expanding role of the Arctic Council with regards to facilitating the development of binding regulation related to offshore oil and gas activities, as well as the increasing role of non-Arctic states in this governance arrangement. Another important element is the changing Danish-Greenlandic relationship. It is expected that other (Arctic) states will try to influence the Greenlandic oil and gas arrangements when Greenland becomes more independent from Denmark. It is therefore considered important that the capacity of the Greenlandic government and civil society should be the primary guideline for the pace in which oil and gas activities are being developed. If not, Greenland would run the risk of formally being the most important actor, while de facto other actors would take over. This would hamper the maximisation of benefits from the offshore oil and gas activities for Greenland and its society.

Chapter 3 therefore takes a closer look at the challenges and opportunities of maximising the local benefits of energy development for small Arctic states (subquestion 4). In this respect it is interesting to compare Greenland to the Faroe Islands and Iceland: Like many Arctic states, Iceland and the Faroe Islands used to be the resource-based economies, which Greenland is today. Remotely located in relation to the world economy, Iceland and the Faroe Islands have succeeded in maximising local benefits and developing a knowledge-based economy related to their energy sector. The cases of the Faroe Islands and Iceland show that it is possible for small societies to create a critical mass of human capital, by developing strong knowledge institutes and stimulating the exchange of knowledge.

Chapter 4 examines the role of human capital development in relation to obtaining and maintaining a local social license to operate for the development of energy activities in small Arctic states, including Iceland, the Faroe Islands and Greenland (sub-question 5). When looking at the social license to operate of Arctic energy activities, human capital development plays an important role in the maximisation of local benefits via increasing the level of (formal) skills and capacities among a local workforce. This enables the local workforce to seize (higher skilled) job opportunities and develop a knowledge-based 
economy that could eventually be exported to other countries. In this way human capital development contributes to one of the elements of a social license to operate, namely the economic legitimacy of an activity. Furthermore, human capital development requires the input of multiple stakeholders (i.e. state authorities, private sector companies, schools and universities). Since human capital takes time to be developed, it offers a platform for cooperation between different stakeholders. In this way, human capital development can create a basis of interactional trust between the various stakeholders involved in the development of energy activities such as offshore oil and gas.

Chapter 5 analyses the role of trust and legitimacy, as two fundamental elements of not only the social license but also the political and legal licenses to operate. Two forms of trust (personal and institutionalised trust) and three forms of legitimacy (input, throughput and output legitimacy) are being distinguished. The close connection between society's increasing demand for influence on the development of industrial activities and its perception of the prevailing legal and political system and the failures there of, makes these political and legal systems important to study in relation to the social license to operate. This chapter develops a broader perspective on the social license to operate concept by studying the role of various forms of trust and legitimacy as well as their role in the interaction between the social, legal and political licenses to operate (sub-questions 2 and 3). The case of offshore oil and gas development in Greenland shows that the three licenses to operate are complementary to each other, as each of the licenses has a different emphasis with regards to trust and legitimacy.

Subsequently, chapter 6 develops a set of hypotheses and a typology for the interaction of the social license to operate at multiple levels, including interaction with the political and legal licenses (sub-question 6). The case of offshore oil and gas development in Greenland, where the exploration activities were debated at a national and international level at the same time, shows that there is a need for the social license to operate concept to include international dynamics as well. Three types of a broad, multilevel social license to operate have been defined based on the level of overlap between the licenses (political, legal, social) on each level (fully overlapping, party overlapping, not overlapping).

The first type concerns a situation in which all licenses are separate, meaning that each license occurs both at the national and the international level, but there is no multilevel interaction between the licenses. A second type can be identified in which all licenses are one, meaning that each license fully overlaps with its national/international counterpart. Type 1, where there is no interaction between licenses at all, is in the current globalised world not likely to occur. Type 2, where all licenses fully overlap with 
their national/international counterpart, is also not likely to occur as it would assume that national boundaries have completely evaporated.

The third type identified in chapter 6 concerns situations where the licenses are partly overlapping. This type has been further operationalised into three hybrid types: a) There is one social license (national and international fully overlap), but there are separate political and legal licenses on both levels; b) There is one political license and one legal license (for these two licenses the national and international level fully overlap), but the social license is separate; c) All licenses partly overlap with their national/international counterpart. The hybrid types are regarded to provide the best reflection of the interactions that could take place between licenses on different levels

Hybrid situations such as in Greenland, where licenses do not fully overlap and are not completely separate, are indeed becoming more likely in our globalising society. The nation states system still exist, but is increasingly becoming networked through involvement in multiple governance arrangements across different scales. This bifurcated system, where the national state system evolves through its co-existence and interaction with the network (civil) society and global markets, influences the way in which the different licenses manifest themselves at different levels.

Chapter 7 concludes that based on the research presented in this thesis, the national level social license to operate concept needs to be studied in relation to the legal and political licenses using a broader definition of trust and legitimacy. Furthermore, the environmental and social impacts of oil and gas activities often do not confine themselves to nation state boundaries, nor are these activities operated solely in a national level context. Incorporating multilevel dynamics into the social license to operate concept is thus essential in analysing the multilevel context in which Arctic oil and gas activities were being developed. With regards to the Arctic context, it is important to consider the role of human capital development as it has a strong link with trust building and legitimacy at a national level and can play a role in the degree of interaction between licenses on multiple geographical levels within a multilevel social license to operate concept. This thesis shows that it is thus important for both governments and companies to realise that the implementation of energy activities locally, is thus subject to direct international level influences, which run primarily via the social license to operate. Future research, based on case studies conducted in other parts of the world, could enhance the multilevel social license to operate concept as developed in this thesis. Furthermore, the multilevel social license to operate concept would benefit from further research into the role and effectiveness of social media in shaping an international digital network, which is driven to change public opinion and steer decision making processes. 


\section{ABOUT THE AUTHOR}

Coco C.A. Smits was born on the $29^{\text {th }}$ April 1988 in Cuijk, the Netherlands. In 2006 she completed grammar school at 'het Stedelijk Gymnasium Nijmegen' and started studying International and European Law at the Radboud University in Nijmegen. After realising that a career in Law would not make her happy, she started studying Social and Political Sciences of the Environment at the Radboud University in Nijmegen. In the third year of her Bachelor she went on an Erasmus exchange programme to the University of Bergen, Norway. This is where her fascination for the Arctic began: the vivid debate on oil and gas development in the ecologically sensitive Lofoten area, the beauty of the raw and unpolished nature and the adventure of watching the northern lights from a tent on a mountain in Tromsø. For her Master, Coco decided to study Environmental Sciences with a specialisation in Environmental Policy at the Wageningen University. During her internship at Royal HaskoningDHV she prepared a business trip to Greenland, following up the visit of CEO Erik Oostwegel and (then) crown-prince of the Netherlands Willem-Alexander that was organised by WWF. In December 2011 Coco visited Greenland for the first time and conducted interviews with a number of stakeholders on the development of oil and gas in Greenlandic waters.

After finalising her Master thesis on the governance of oil and gas development in Greenland, she started working for Royal HaskoningDHV in London, UK, per October 2012. Early 2013 she moved to Athens, Greece, to work on the Trans Adriatic Pipeline project. For her professionalism and exemplary work at Royal HaskoningDHV Coco received the Graduate Award of the Institute of Environmental Management and Assessment (IEMA) at the Sustainability Leaders Awards in London in 2013. While living in Athens she also published a number of scientific articles and contributed to a book chapter in the Arctic Policy Handbook. When returning to the Netherlands in 2014, she continued her work on the Arctic: In 2015 she co-organised the MARE Policy Day on the social license to operate of oil and gas in the Arctic, she represented Royal HaskoningDHV in the Dutch Arctic Circle and decided to formalise her scientific work into a PhD at the Wageningen University. Following this decision she went to Greenland again to conduct a follow up series of interviews in February 2016. Based on this data she wrote the final chapters of her PhD thesis.

Mid 2018 Coco started working for TenneT TSO as project lead spatial planning and licensing for one of the grid connections of the offshore wind farm IJmuiden Ver. IJmuiden Ver is one of the offshore wind farms that the Dutch government aims to develop in order to facilitate the transition towards renewable energy supply in the Netherlands. With a total capacity of about four gigawatt, IJmuiden Ver is the largest wind farm to be connected to the Dutch national grid before 2030. 


\section{LIST OF PUBLICATIONS}

Smits, C.C.A., Van Leeuwen, J., \& Van Tatenhove, J.P.M. (2017). Oil and gas development in Greenland: A social license to operate Trust and Legitimacy in Environmental Governance. Resources Policy, 53, 109-116. (Chapter 5 in this thesis)

Smits, C.C.A., Bertelsen, R.G., Justinussen, J.C.S. (2016). Human capital development and a Social License to Operate: Examples from Arctic energy in the Faroe Islands, Iceland and Greenland. Energy Research and Social Science, Special Issue: Arctic Energy: Views from the social sciences, 16, 122-131. (Chapter 4 in this thesis)

Smits, C.C.A. \& Huber, T.F. (2016). A Social License to Operate in the Arctic: Exploring the Challenges and Opportunities for Offshore Oil and Gas Activities in Greenland. Conference Proceedings SPE International Conference and Exhibition on Health, Safety, Security, Environment and Social Responsibility, 2016.

Bertelsen, R.G., Justinussen, J.C.S., \& Smits, C.C.A. (2016). Informal Skills for Building International Economies in Iceland, the Faroe Islands and Greenland. In Greenland Perspectives (eds.), Everybody on Board. Copenhagen.

Smits, C.C.A., Bertelsen, R.G., \& Justinussen, J.C.S. (2015). Oil and gas development in the Faroese Islands, Iceland and Greenland: How local competence development contributes to a Social License to Operate. Arctic Technology Conference Proceedings, 2015.

Smits, C.C.A., Bertelsen, R.G., \& Justinussen, J.C.S. (2014). The challenges \& opportunities for Arctic microstates in developing an energy sector: The role of human capital and knowledge institutes. Arctic Yearbook, 2014, 324-341. (Chapter 3 in this thesis)

Bertelsen, R.G., Justinussen, J.C.S. \& Smits, C.C.A. (2014). Energy as a Developmental Strategy for North Atlantic Microstates in the Search of Independence: Creating Knowledge-Based Energy Sectors in Iceland, Faroe Islands and Greenland. In G. Hønneland \& L. Christian Jensen (eds.), Handbook of the Politics of the Arctic. United Kingdom: Edward Elgar Publishing.

Smits, C.C.A., Van Tatenhove, J., \& Van Leeuwen, J. (2014). Marine governance in the Arctic: Changing authority of Greenland in offshore oil and gas developments. International Environmental Agreements: Politics, Law and Economics, 14, 4, 329-348. (Chapter 2 in this thesis)

Smits, C.C.A. (2013). Arctic oil and gas. Reason for conflict or cooperation? Centenary Publication of the Association for Consultancy and Engineering (ACE) UK, 32-34 


\section{ACKNOWLEDGEMENTS / DANKWOORD}

First of all I would like to thank all the interviewees that participated in this research and have answered all of the questions I had about the development of oil and gas activities in Greenland and the wider Arctic. I am grateful for the new perspectives and deeper understanding they gave me. In particular I would like to thank Mininnguaq Kleist, who has shared his network with me and brought me into contact with many Greenlandic stakeholders.

Beste Jan, vanaf het allerleerste begin ben je betrokken bij dit Groenland-avontuur! Wat begon als een afspraak om op basis van mijn Master stage en thesis samen een wetenschappelijk artikel te schrijven, heeft geresulteerd in dit proefschrift. Ik waardeer jouw open visie, rust en focus op kansen en mogelijkheden. Het heeft me geleerd dat sommige dingen tijd nodig hebben, soms meer dan ik vooraf had kunnen/willen bedenken. Ik ben je dankbaar voor alle begeleiding in de afgelopen jaren en het mooie resultaat dat nu voor ons ligt.

Beste Judith, samen met Jan ben jij al vanaf het begin betrokken en heb jij mij tijdens al die jaren begeleid. Jouw kritische blik en focus op een gedegen theoretische inbedding hebben me veel geleerd. Die theorie was en is nog steeds niet mijn favoriete onderdeel van onderzoek doen, maar ik heb het mede dankzij jou leren waarderen. Ik heb oprecht plezier beleefd aan de discussies die we in de laatste fase van mijn onderzoek hebben gehad over het theoretisch kader en de reflectie daarop. Ook jou wil ik graag bedanken voor alle begeleiding in de afgelopen jaren en het mooie resultaat waar dat toe heeft geleid.

Stefan, bij jou is het allemaal begonnen! Ergens op een zeilboot op de zandmeren bij Kerkdriel. Jaren later, toen ik je benaderde voor een stageplek bij Royal Haskoning, reageerde je meteen. Een leuk gesprek op het terras van het Vlaams Arsenaal in Nijmegen volgde, waarin je me vroeg wat ik graag zou willen doen. Ik vertelde je over mijn interesse in het Arctisch gebied en alles wat daar stond te gebeuren. Toeval wilde dat Erik Oostwegel, de CEO, net met WNF naar Groenland was geweest om daar te praten over de balans tussen klimaatverandering en economische ontwikkeling. Een followup visit aan Groenland stond voor later dat jaar op de agenda en ik mocht die gaan voorbereiden. Ik heb een grote bewondering voor jouw aanstekelijke enthousiasme, grote netwerk en oog voor kansen en samenwerking. Je hebt niet alleen voor een geweldige stageplek gezorgd, maar als kers op de taart heb je het ook voor elkaar gekregen dat ik in december 2011 mee mocht naar Groenland. Ik ben je hier voor altijd dankbaar voor! 
Erik, ik kan me onze eerste ontmoeting op het kantoor van Royal Haskoning in Nijmegen nog goed herinneren! Ik kwam jou als business developer ondersteunen bij de voorbereidingen van de follow-up visit naar Groenland. En dat moest wel goed en gedegen gebeuren. Gelukkig kwamen onze standaarden overeen en was dit het begin van een jarenlange samenwerking. Tijdens mijn stage en in de jaren die volgden heb ik ontzettend veel van jou geleerd! Ik bewonder je om jouw strategische blik, oog voor detail en feilloze inschatting van sfeer en situaties. Het absolute hoogtepunt was onze gezamenlijke reis naar Groenland, mijn eerste business trip. Maar ook het proposal voor Yamal LNG in Londen, de laatste fases van het TAP project en onze bijdragen aan de Dutch Arctic Circle zullen me altijd bijblijven. Ontzettend bedankt voor deze geweldige start van mijn carrière en alle enerverende gedachtewisselingen die we hebben gehad!

Taco, een stagiair kan zich geen betere begeleider wensen! Niet alleen tijdens mijn stage maar ook daarna kon ik altijd bij je binnenlopen. Je hebt me wegwijs gemaakt binnen Royal Haskoning en me het bedrijf leren kennen. Je maakt altijd tijd voor een praatje, bent een echt mensen-mens en vaak betrokken bij de meest interessante initiatieven, ik bewonder dat enorm! Controversiële onderwerpen ga je niet uit de weg en probeer je met feiten te de-escaleren. Bedankt voor alles wat ik de afgelopen jaren van je geleerd heb!

Dear Rasmus and Jens Christian, I would like to thank you for the articles we wrote together on energy development in Iceland, the Faroe Islands and Greenland. Our book chapter for the Arctic Policy Handbook was the start of a fruitful cooperation, resulting in a number of scientific articles and conference presentations. It has been a pleasure working with you and I greatly value the insights I gained from your research on Iceland and the Faroe Islands!

Lieve Renée, ik vind het fantastisch dat je me overal bent komen opzoeken en op alle plekken bent geweest waar ik in het buitenland heb gewoond: Bergen (Noorwegen), Londen en Athene. Je helpt me relatieveren en soms iets meer aan mezelf te denken. Bedankt dat je er altijd voor me bent! Om samen te lachen, lekker thee te drinken en te freubelen, ook als het even wat minder gaat!

Lieve Sanne, we kennen elkaar al sinds de kleuterklas en hebben vanalles samen meegemaakt. Ik ben blij dat we altijd in contact zijn gebleven en met elkaar gedeeld hebben wat ons bezig hield! Nog steeds kan ik alles met je bespreken en blijven we elkaar zien, in Cuijk, Harderwijk of alles daar tussenin. Ik hoop dat dit nooit veranderd! 
Lieve Marjolein, met veel plezier kijk ik terug op mooie en hilarische momenten uit onze middelbareschooltijd! De cultuurreis naar Griekenland als absoluut hoogtepunt! Ik vind het fijn dat we elkaar sindsdien steeds zijn blijven opzoeken, want wanneer we afspreken is het altijd reuze gezellig!

My dear Efi, I am so grateful that we met! That we shared an amazing apartment in Athens and experienced the adventurous TAP rollercoaster project together! We share a passion for good food and together we explored all the great places to eat in Athens and around. Thank you for calling me crazy when I was working on scientific articles

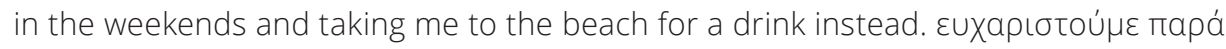
по入ú for showing me the real Greece and making me fall in love with it!

Dear Daisy and Svenja, wat was het geweldig om met jullie samen te werken bij Royal HaskoningDHV! Daisy, samen met jou in Griekenland was fantastisch! Ik heb veel van jouw kordate en doelgerichte manier van werken geleerd en kijk met veel plezier terug op alle uitstapjes die we samen hebben gemaakt! Svenja, toen ik na mijn buitenlandse projecten terugkwam op kantoor in Nijmegen was jij daar! Jouw gezelligheid en ambitie hebben me enorm geholpen om me weer thuis te voelen in Nederland. Ik heb bewondering voor de stappen die je hebt gezet en voor de energie waarmee jij jouw dromen najaagt!

Lieve Laila en Isabel, bedankt dat jullie me altijd scherp houden! Met grapjes, gevatte opmerkingen en goede gesprekken. Lai, ik bewonder jouw ondernemendheid en creativiteit, en vind het fantastisch om te zien hoe jij en Edo samen een geweldig (t) huis voor jullie aanstaande gezinnetje maken in Weurt. let, ik bewonder jouw krachtige eigen wil en prachtige Engelse uitspraak, en vind het geweldig hoe jij als 'mevrouw Smits' al die pubers op het Stedelijk Gym in toom houdt. Ik vind het fijn dat ik jullie zo regelmatig zie en we onze levens met elkaar delen.

Lieve papa en mama, zonder jullie had ik dit nooit kunnen doen. Jullie hebben me altijd gestimuleerd, ondersteund en de ruimte gegeven om het beste in mezelf naar boven te halen. Mam, de gedrevenheid om iets goed te doen en het doorzettingsvermogen om je eigen droom waar te maken heb ik zeker weten van jou. Bedankt dat je me daarin altijd op allerlei manieren hebt ondersteund! Pap, mijn gevoel voor taal en schrijfvaardigheid heb ik aan jou te danken. Een prachtige gave die me veel heeft gebracht. Daarnaast was ik nooit geweest waar ik nu ben zonder jouw onvoorwaardelijke support. Zo heb je me elke zaterdag naar Nautilus in Kerkdriel gebracht en gehaald. Hierdoor heb ik Stefan leren 
kennen die me bij Royal Haskoning heeft geintroduceerd, wat uiteindelijk geleid heeft tot dit proefschrift, en heb ik Thijs ontmoet als mijn vriend en vader van onze twee zoons.

Liefste Thijs, jij bent mijn alles! De afgelopen 14 jaar hebben we alles met elkaar gedeeld, waaronder dit promotie-avontuur. Het heeft soms best wel veel van me gevraagd, maar jij bleef altijd positief en op zoek naar pragmatische oplossingen. Zonder jou had ik dit nooit gekund! Nu gaan we samen genieten van onze twee zoons, Floris en Guus, ons prachtige plekje in Cuijk en al het andere moois in ons leven! Bedankt lieve schat! 
The research described in this thesis was financially supported by Royal HaskoningDHV.

Financial support from Wageningen University for printing this thesis is gratefully acknowledged.

Design by Elisa Calamita, persoonlijkproefschrift.nl.

Printed by Ipskamp Printing, proefschriften.net 